2016

\title{
Chemical Additives and Foam to Enhance SAGD Performance
}

\author{
$\mathrm{Li}$, Ran
}

Li, R. (2016). Chemical Additives and Foam to Enhance SAGD Performance (Unpublished master's thesis). University of Calgary, Calgary, AB. doi:10.11575/PRISM/25312

http://hdl.handle.net/11023/2874

Downloaded from PRISM Repository, University of Calgary 


\title{
UNIVERSITY OF CALGARY
}

Chemical Additives and Foam to Enhance SAGD Performance

by

Ran Li

\begin{abstract}
A THESIS
SUBMITTED TO THE FACULTY OF GRADUATE STUDIES

IN PARTIAL FULFILMENT OF THE REQUIREMENTS FOR THE DEGREE OF MASTER OF SCIENCE
\end{abstract}

GRADUATE PROGRAM IN CHEMICAL AND PETROLEUM ENGINEERING

CALGARY, ALBERTA

MARCH, 2016

(C) Ran Li 2016 


\begin{abstract}
Adding chemical additives with in-situ generation of foam is an approach to enhance SAGD (steam assisted gravity drainage) performance both in terms of oil production and SOR (steam oil ratio). Simulation study tells that, owing to gas mobility control, interfacial tension reduction and emulsification, the steam chamber profile is substantially controlled with a reduced heat loss, and the residual oil saturation drops dramatically. A heterogeneous model based on a Suncor Firebag project is further employed to testify that bubbles are conducive to improve volumetric sweep efficiency by diverting steam into low-permeable area. Simultaneously, foam favors to reduce the influences of top water zone and maintain a bowl-shaped and uniformly-developed steam chamber growth. Afterwards, an analytical method is introduced to further explain the physical mechanisms with a modified finger rising model, which shows that CAFA-SAGD (chemical additives and foam assisted SAGD) owns a lower finger rising velocity with less steam consumption.
\end{abstract}




\section{Acknowledgements}

I hope to deliver my gratitude to my supervisor Dr. Zhangxing (John) Chen, who keeps providing support and suggestions to guide my research and study.

I would also like to thank Dr. Shauheen Etminan for his patient and careful guidance to help me with my research and professional skills.

My gratitude also goes to the members of the examination members, Dr. Matthew Alexander Clarke and Dr. Hua Song. Thanks for their valuable suggestions.

I also appreciate all the members in the Reservoir Simulation Group and all the sponsors of the Group. 


\section{Table of Contents}

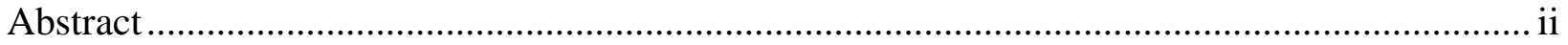

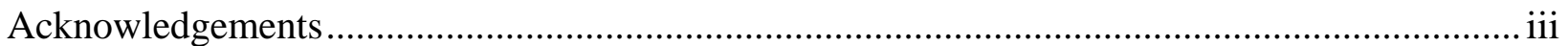

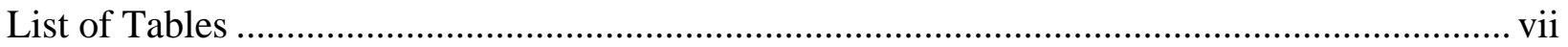

List of Figures and Illustrations ...............................................................................................viii

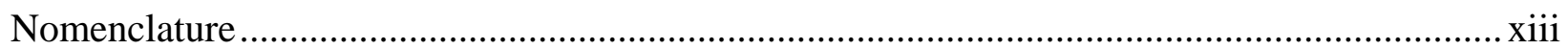

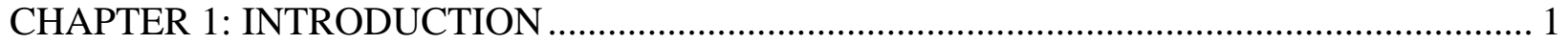

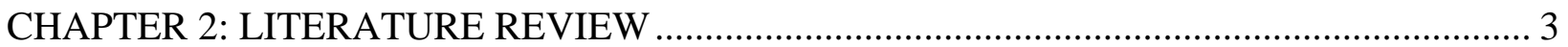

2.1 Literature Review of SAGD ........................................................................................ 3

2.1.1 Basic SAGD Concept .................................................................................................... 3

2.1.2 SAGD Startup Process .................................................................................................. 4

2.1.3 SAGD Operation Process and Mechanisms ................................................................... 5

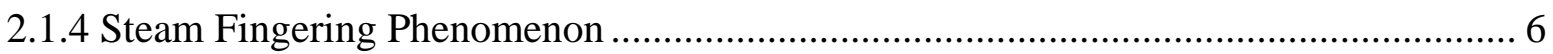

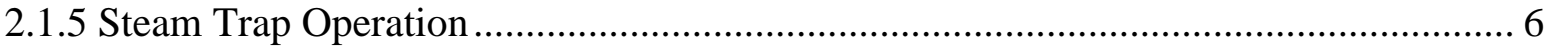

2.1.6 Steam Properties ............................................................................................. 6

2.1.7 Heat Conduction and Convection during SAGD ........................................................... 7

2.1.8 Emulsification during SAGD Production ........................................................................... 8

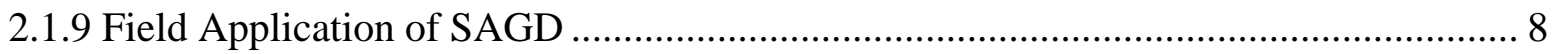

2.1.10 SAGD Analytical Model and Theory …………............................................................ 8

2.1.11 Influencing Factors during SAGD Process.................................................................. 11

2.1.12 The Influences of Reservoir Heterogeneity ……….................................................... 12

2.1.13 Problems and Disadvantages of SAGD ...................................................................... 13

2.1.14 Improvements and Potential Solutions ........................................................... 14

2.2 Literature Review of Foam ........................................................................................ 16

2.2.1 Basic Foam Concept ................................................................................................... 16

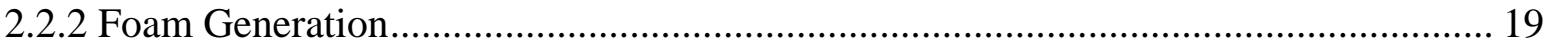

2.2.3 Foam Collapse ………………………………………………………………… 21

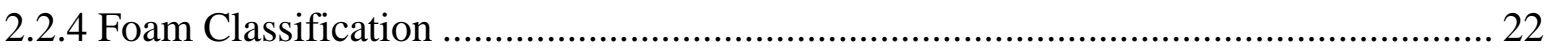

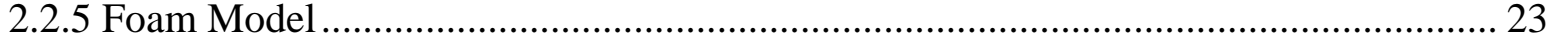

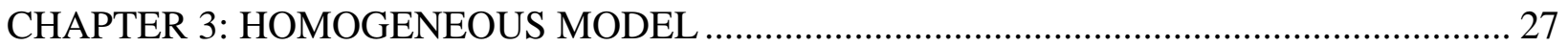


3.1 Basic Homogeneous Simulation Model................................................................... 27

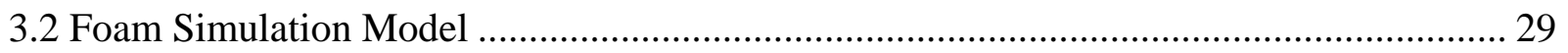

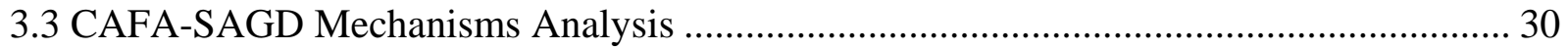

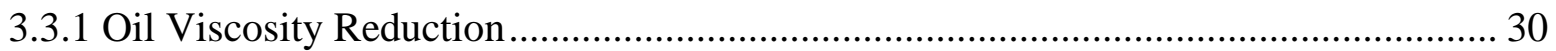

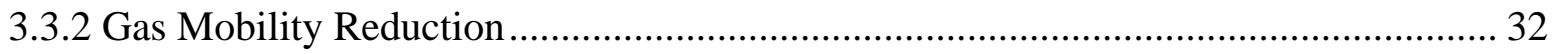

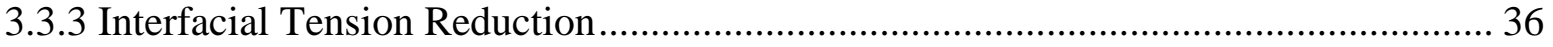

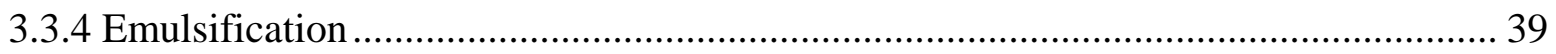

3.4 Results Comparison between SAGD and CAFA-SAGD and Interpretation.................... 43

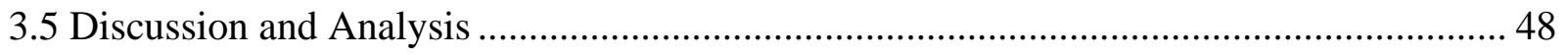

3.5.1 Discussion of Injection Scheme.................................................................... 48

3.5.2 CAFA-SAGD Application for Multiple Well Pairs................................................. 52

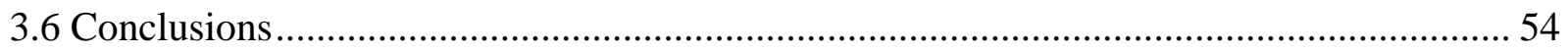

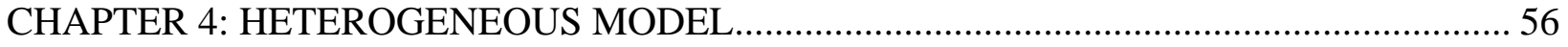

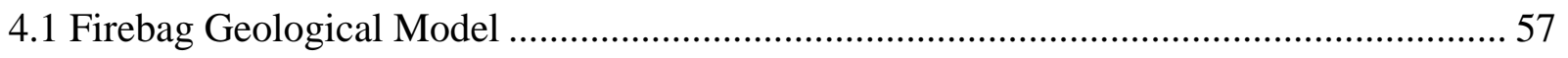

4.1.1 Suncor's Firebag Project Introduction............................................................. 57

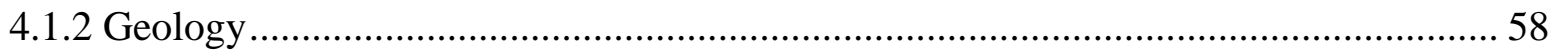

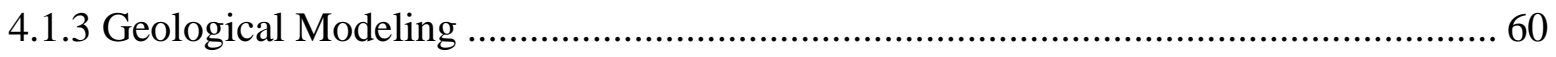

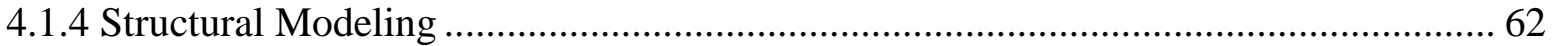

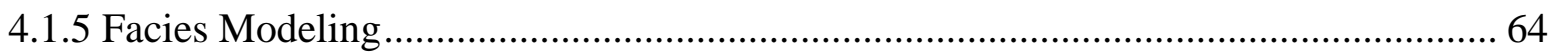

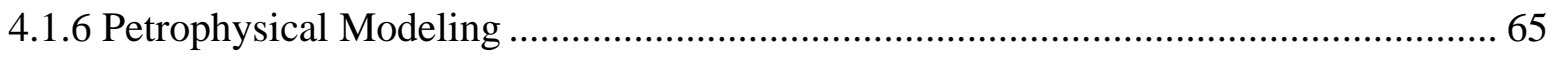

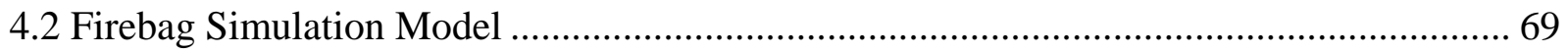

4.2.1 Basic Heterogeneous Simulation Model............................................................ 69

4.2.2 Results Comparison between SAGD and CAFA-SAGD and Interpretation.............. 73

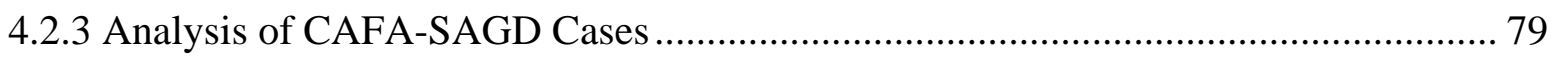

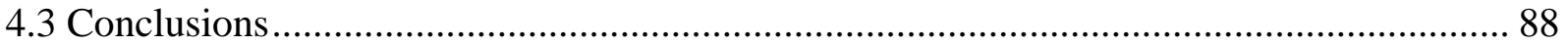

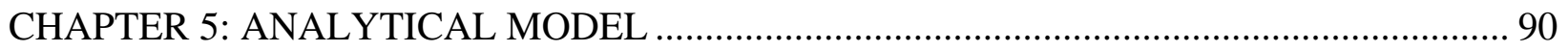

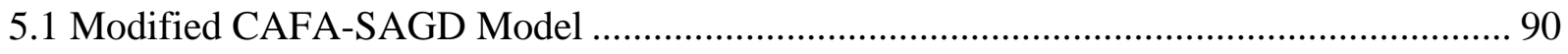

5.1.1 CMG Empirical Foam Model ............................................................................. 91

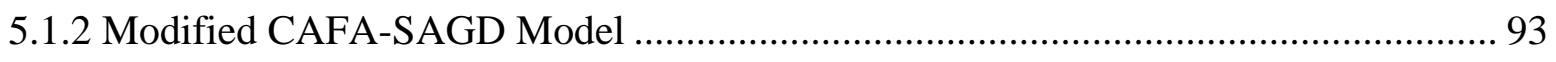

5.1.3 Discussion of Oil Saturation and Relative Permeability....................................... 98 
5.2 Numerical Example …………………............................................................................. 99

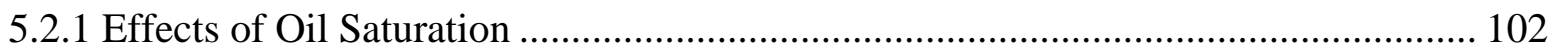

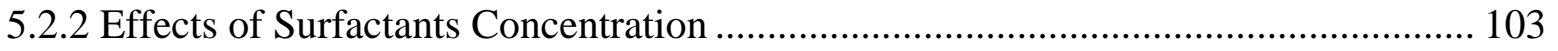

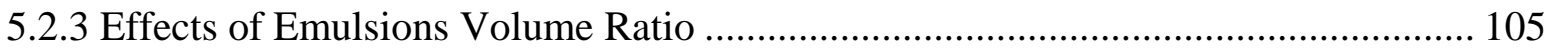

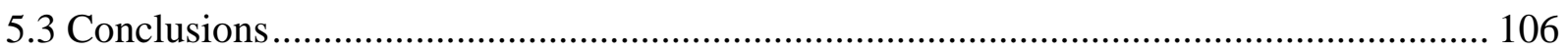

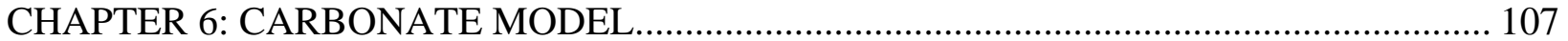

6.1 Carbonate Single Porosity Model ..................................................................................... 107

6.2 Carbonate Dual Porosity Model........................................................................................... 109

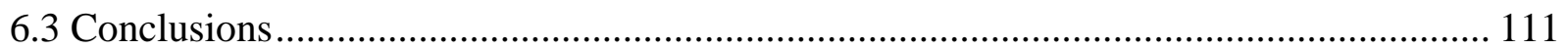

CHAPTER 7: CONCLUSIONS AND FUTURE WORK................................................... 112

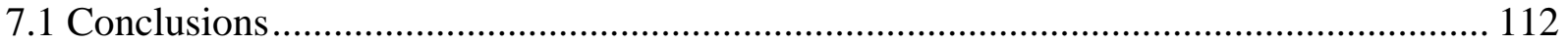

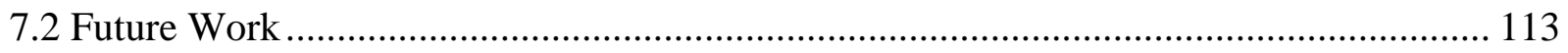

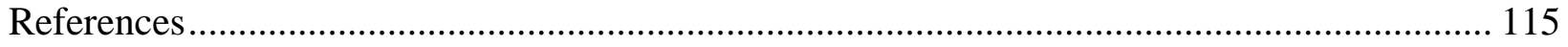

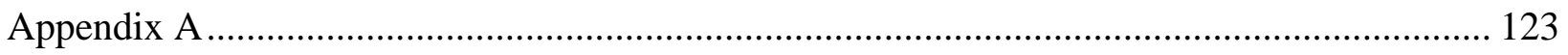

Derivation for Butler’s Finger Rising Model.............................................................................. 123 


\section{List of Tables}

Table 3-1 Basic reservoir parameters of homogeneous model ............................29

Table 3-2 Performance comparison for injection start time study of homogeneous model (A: 09Year11Month; B: 10Year08Month; C: 12Year10Month; D:13Year07Month) .................50

Table 3-3 Performance comparison for surfactants injection period study of homogeneous model

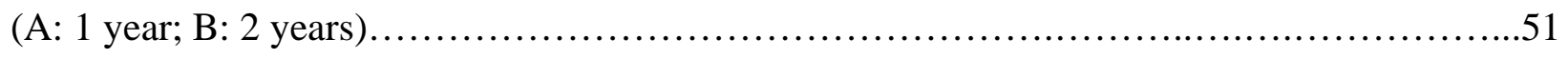

Table 3-4 Performance comparison for surfactants injection method study of homogeneous model........................................................................52

Table 4-1 Preheating periods and operation periods......................................72

Table 4-2 Performance comparison for heterogeneous SAGD and CAFA-SAGD cases..........78

Table 4-3 Performance comparison for heterogeneous CAFA-SAGD cases with different

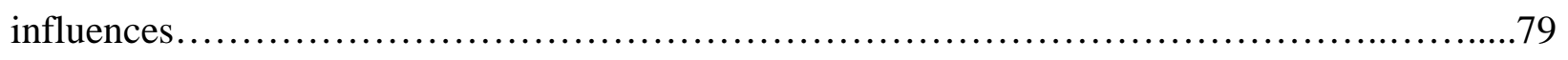

Table 5-1 Data used for comparison (Gotawala and Gates, 2008)...........................99

Table 5-2 Fluid data used for comparison (Athabasca Oil, m=4) (Murtaza et al, 2014)..........100

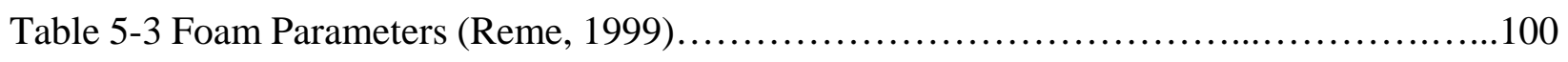

Table 6-1 Basic reservoir parameters of single porosity carbonate model.......................108

Table 6-2 Basic reservoir parameters of dual porosity carbonate model.......................110 


\section{List of Figures and Illustrations}

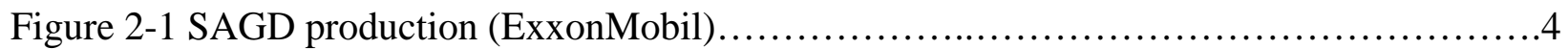

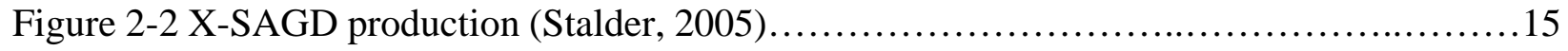

Figure 2-3 Foam structure (Schramm, 1994) ........................................17

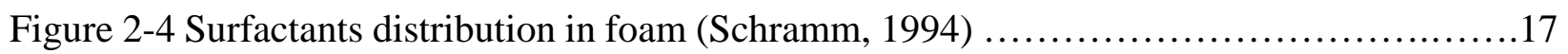

Figure 2-5 Disjoining pressure and capillary pressure (Schramm, 1994) ....................18

Figure 2-6 Foam generation mechanisms (A: Snap off; B: Division; C: Leave-behind) (Ransohoff and Radke, 1988) ....................................................20

Figure 3-1 2D homogeneous model (A: IK cross section; B: JK cross section) ................28

Figure 3-2 Oil viscosity and temperature relationship (A: Oil viscosity and temperature plot; B:

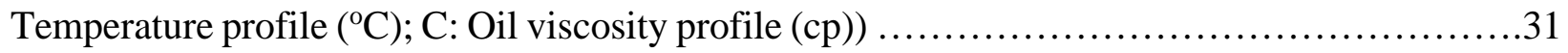

Figure 3-3 Gas relative mobility distribution comparison of homogeneous model (1 year after surfactants injection) (1/cp) (A: SAGD; B: CAFA-SAGD) ..............................34

Figure 3-4 Lamella mole fraction distribution of homogeneous model (A: 1 year after surfactants injection; B: 2 years after surfactants injection) .......................................

Figure 3-5 Nitrogen mole fraction distribution of homogeneous model (A: year after surfactnats injection; B: 2 years after surfactants injection) ........................................

Figure 3-6 Oil flux distribution comparison of homogeneous model (1 year after surfactants

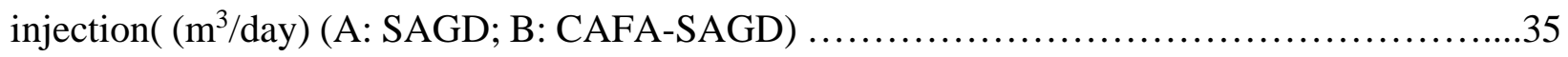

Figure 3-7 Surfactants molecules distribution with different concentration ....................37

Figure 3-8 Surfactants mole fraction distribution of homogeneous model (A:1 year after

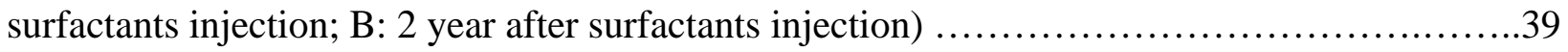

Figure 3-9 Interfacial tension distribution of homogeneous model (dyne/cm) (A: 1 year after

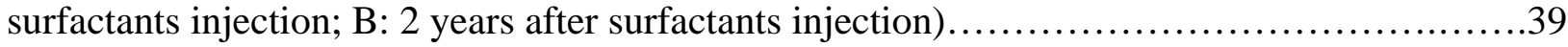

Figure 3-10 O/W emulsions mole fraction distribution of homogeneous model (A: 1 year after surfactants injection; B: 2 years after surfactants injection) ...........................43

Figure 3-11 Interfacial tension distribution of homogeneous model (dyne/cm) (A: 1 year after

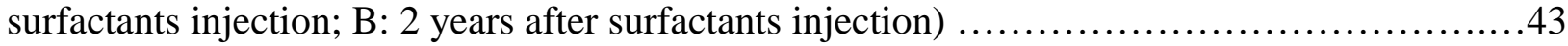

Figure 3-12 Oil saturation distribution comparison of homogeneous model (2 years after surfactants injection) (A: SAGD; B: CAFA-SAGD with gas mobility reduction; C: CAFA-SAGD with gas mobility reduction and interfacial tension reduction; D: CAFA-SAGD with gas mobility

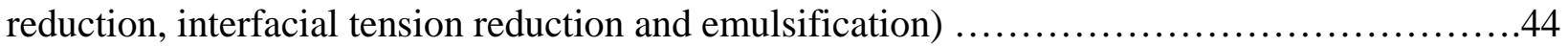

Figure 3-13 Cumulative oil production and oil rate comparison of homogeneous model (A: SAGD; 
B: CAFA-SAGD with gas mobility reduction; C: CAFA-SAGD with gas mobility reduction and interfacial tension reduction; D: CAFA-SAGD with gas mobility reduction, interfacial tension

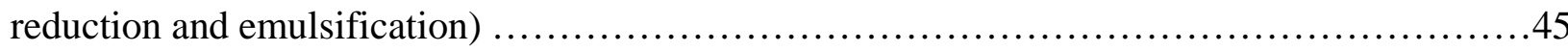

Figure 3-14 Temperature distribution comparison of homogeneous model (1 year after surfactants injection) $\left({ }^{\circ} \mathrm{C}\right)$ (A: SAGD; B: CAFA-SAGD with gas mobility reduction; C: CAFA-SAGD with gas mobility reduction and interfacial tension reduction; D: CAFA-SAGD with gas mobility reduction, interfacial tension reduction and emulsification) .46

Figure 3-15 SOR comparison of homogeneous model (A: SAGD; B: CAFA-SAGD with gas mobility reduction; C: CAFA-SAGD with gas mobility reduction and interfacial tension reduction; D: CAFA-SAGD with gas mobility reduction, interfacial tension reduction and emulsification) . .48

Figure 3-16 Injection start time study of homogeneous model $\left({ }^{\circ} \mathrm{C}\right)$ (A: 09Year11Month; B: 10Year08Month; C: 12Year10Month; D: 13Year07Month) ....

Figure 3-17 Temperature comparison for injection start time study of homogeneous model (14Year01Month) $\left({ }^{\circ} \mathrm{C}\right)$ (A: 09Year11Month; B: 10Year08Month; C: 12Year10Month; D: 13Year07Month).

Figure 3-18 Lamella mole fraction distribution model for multiple well pairs study of homogeneous (A: 1 year after surfactants injection; B: 2 years after surfactants injection) ........53 Figure 3-19 Temperature distribution comparison model for multiple well pairs study of homogeneous (1 year after surfactants injection) $\left({ }^{\circ} \mathrm{C}\right)$ (A: SAGD; B: CAFA-SAGD)..............53

Figure 3-20 Oil saturation comparison model for multiple well pairs study of homogeneous model (1 year after surfactants injection) (A: SAGD; B: CAFA-SAGD) ..........................54

Figure 3-21 Oil flux distribution model for multiple well pairs study of homogeneous model ( $\mathrm{m}^{3}$ /day) (A: 1 year after surfactants injection; B: 2 years after surfactants injection)...............54

Figure 3-22 O/W emulsions mole fraction distribution model for multiple well pairs study of homogeneous model (A: 1 year after surfactants injection; B: 2 years after surfactants injection) .54

Figure 4-1 Suncor's Firebag project location (Suncor Firebag SAGD Report, 2006)................57

Figure 4-2 Suncor's Firebag well pads distribution map (Suncor Firebag SAGD Report, 2006)....58 Figure 4-3 Suncor’s Firebag stratigraphic chart (Suncor Firebag SAGD Report, 2006)...........59

Figure 4-4 Suncor's Firebag structural cross section (Pad 101 Pair 7) (Suncor Firebag SAGD

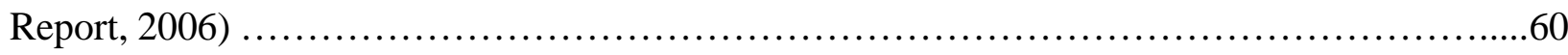

Figure 4-5 Well pairs and observation wells in the study area (A: Overall view; B: In the vicinity of well pairs) .61

Figure 4-6 Lithology interpretation of several wells in the study area (MM: McMurray; BL: 
Beaverhill Lake)

Figure 4-7 Structural maps of McMurray and Beaverhill Lake (A: McMurray surface; B:

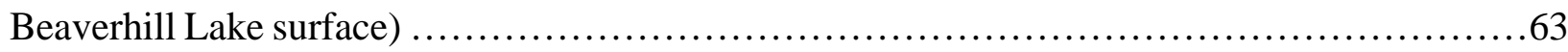

Figure 4-8 Facies model cross profile ............................................64

Figure 4-9 Petrophysical models (A.1: 2D lithology model; A.2: 3D lithology model; B.1: 2D water saturation model; B.2: 3D water saturation model; C.1: 2D permeability model; C.2: 3D permeability model; D.1: 2D porosity model; D.2: 3D porosity model) .....................69

Figure 4-10 Properties distribution of 3D heterogeneous model (A: permeability; B: porosity; C:

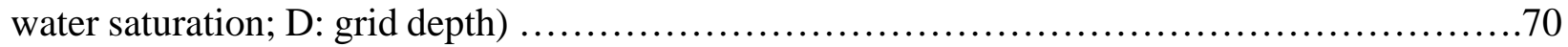

Figure $4-11$ Oil viscosity and temperature plot .....................................

Figure 4-12 Wells location of 3D heterogeneous model (IK cross section, $\mathrm{J}=7$ ) ...............71

Figure 4-13 Properties distribution of 2D heterogeneous model (A: permeability; B: porosity; C:

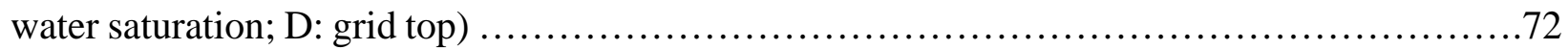

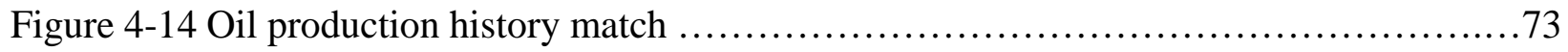

Figure 4-15 Properties distribution of 2D heterogeneous model (Well Pair 7) (A: vertical permeability; B: porosity; C: water saturation; D: oil saturation) ........................74

Figure 4-16 Temperature distribution comparison of 2D heterogeneous model $\left({ }^{\circ} \mathrm{C}\right)$ (A.1: SAGD, May $1^{\text {st }}, 2007$; A.2: SAGD, May $1^{\text {st }}, 2008 ;$ A.3: SAGD, May $1^{\text {st }}, 2009 ;$ B.1: CAFA-SAGD, May $1^{\text {st }}, 2007$; B.2: CAFA-SAGD, May $1^{\text {st }}, 2008$; B.3: CAFA-SAGD, May $\left.1^{\text {st }}, 2009\right) \ldots . . . . . . . . .75$

Figure 4-17 Oil Saturation distribution comparison of 2D heterogeneous model (May $1^{\text {st }}, 2009$ )

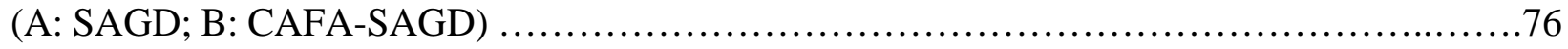

Figure 4-18 Lamella mole fraction distribution of 2D heterogeneous model (A: May 1 $1^{\text {st }}$ 2007; B:

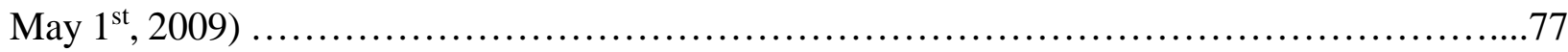

Figure 4-19 O/W emulsions mole fraction distribution of 2D heterogeneous model (A: May $1^{\text {st }}$,

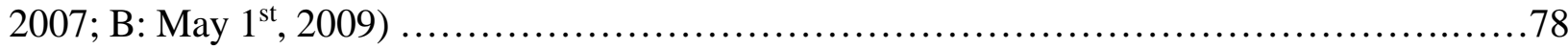

Figure 4-20 Temperature distribution comparison of 2D heterogeneous model $\left({ }^{\circ} \mathrm{C}\right)$ without

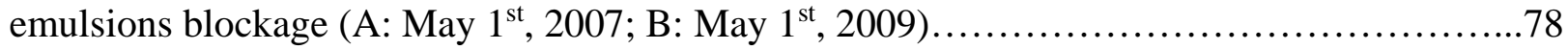

Figure 4-21 Lamella mole fraction distribution for oil influence study of 2D heterogeneous model

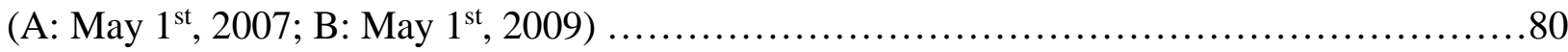

Figure 4-22 Temperature distribution for oil influence study of 2D heterogeneous model $\left({ }^{\circ} \mathrm{C}\right)(\mathrm{A}$ :

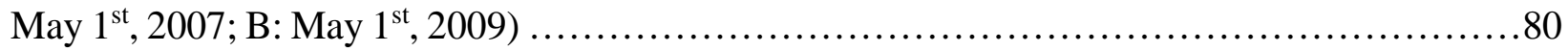

Figure 4-23 Sensitivity analysis for oil influence study of 2D heterogeneous model.................81

Figure 4-24 Surfactants adsorption distribution for chemical additives adsorption study of 2D heterogeneous model $\left(\right.$ gmole $\left./ \mathrm{m}^{3}\right)\left(\right.$ A: May $1^{\text {st }}, 2007$; B: May $\left.1^{\text {st }}, 2009\right) \ldots \ldots \ldots \ldots \ldots \ldots \ldots \ldots . . . .2$ 
Figure 4-25 Surfactants mole fraction distribution for chemical additives adsorption study of 2D heterogeneous model (A: May $1^{\text {st }}, 2007$; B: May $\left.1^{\text {st }}, 2009\right)$

Figure 4-26 Lamella mole fraction distribution for chemical additives adsorption study of 2D

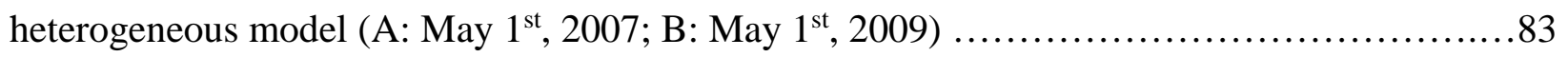

Figure 4-27 O/W emulsions mole fraction for chemical additives adsorption study of 2D

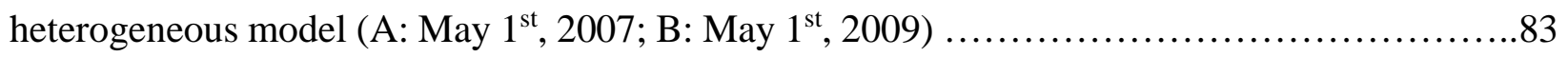

Figure 4-28 Sensitivity analysis for chemical additives adsorption study of 2D heterogeneous

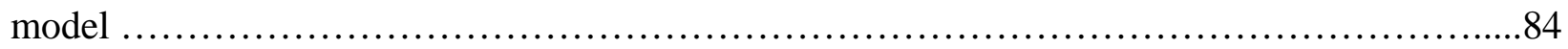

Figure 4-29 Surfactants mole fraction distribution for chemical additives degradation study of 2D

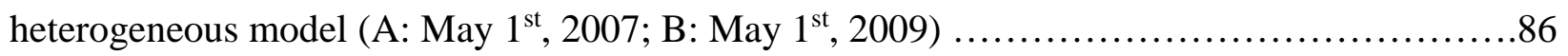

Figure 4-30 Sensitivity analysis for chemical additives degradation study of 2D heterogeneous model .86

Figure 4-31 Surfactants mole fraction distribution in water phase for chemical additives partition study of 2D heterogeneous model (A: May $1^{\text {st }}, 2007$; B: May $\left.1^{\text {st }}, 2009\right)$ .87

Figure 4-32 Surfactants mole fraction distribution in oil phase for chemical additives partition study of 2D heterogeneous model (A: May $1^{\text {st }}, 2007$; B: May $\left.1^{\text {st }}, 2009\right) \ldots \ldots \ldots \ldots \ldots \ldots \ldots \ldots . . . .28$

Figure 4-33 Sensitivity analysis for chemical additives partition study of 2D heterogeneous model

Figure 5-1 Steam finger rising velocity comparison between Butler's model and CAFA-SAGD model .101

Figure 5-2 SOR comparison between Butler's model and CAFA-SAGD model.................101

Figure 5-3 Steam finger rising velocity sensitivity analysis for oil saturation study...............102

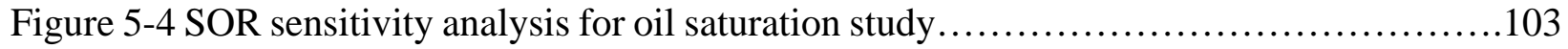

Figure 5-5 Steam finger rising velocity sensitivity analysis for surfactants concentration study .104

Figure 5-6 SOR sensitivity analysis for surfactants concentration study ......................104

Figure 5-7 Steam finger rising velocity sensitivity analysis for volume ratio study..................105

Figure 5-8 SOR sensitivity analysis for volume ratio study ............................106

Figure 6-1 Gas relative permeability comparison (1 year after surfactants injection) (single porosity model) (A: SAGD; B: CAFA-SAGD) .....................................108

Figure 6-2 Cumulative oil production comparison (single porosity model) ....................109

Figure 6-3 Temperature comparison of dual porosity model (1 year after surfactants injection) $\left({ }^{\circ} \mathrm{C}\right.$ ) (A: SAGD; B: CAFA-SAGD) ..............................................110 
Figure 6-4 Gas relative permeability comparison of dual porosity model (1 year after surfactants

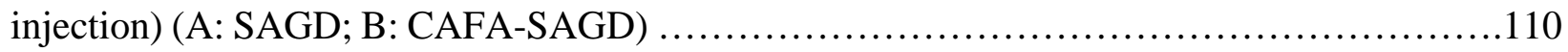

Figure 6-5 Cumulative oil production comparison of dual porosity model .....................111

Figure A-1 Rising finger plot (Butler, 1987) ......................................... 128

Figure A-2 Interfering steam chambers plot (Butler, 1987).................................128 


\section{Nomenclature}

\begin{tabular}{|c|c|}
\hline$a$ & constant \\
\hline$b$ & constant \\
\hline$c$ & constant \\
\hline$C_{S}$ & surfactants concertation \\
\hline$c_{w}$ & water specific heat, $\mathrm{kJ} /\left(\mathrm{kg} \cdot{ }^{\circ} \mathrm{C}\right)$ \\
\hline$c_{e m}$ & emulsions specific heat, $\mathrm{kJ} /\left(\mathrm{kg} \cdot{ }^{\circ} \mathrm{C}\right)$ \\
\hline$D$ & constant \\
\hline$E$ & constant \\
\hline$E P C A P$ & exponent controls the effect of capillary number \\
\hline$E P G C P$ & exponent which controls the critical capillary number's effect \\
\hline EPOIL & parameter that controls the oil saturation contribution \\
\hline EPOMF & exponent for the oil mole fraction contribution to do the interpolation \\
\hline EPSALT & parameter that controls the salt mole fraction contribution \\
\hline EPSURF & $\begin{array}{l}\text { parameter controlling the mobility's dependence on surfactants } \\
\text { concentration }\end{array}$ \\
\hline$f_{g}$ & gas fraction \\
\hline$f_{s t}$ & steam quality \\
\hline$F 1$ & surfactants concentration dependent function \\
\hline$F 2$ & oil saturation dependent function \\
\hline$F 3$ & capillary number dependent function \\
\hline$F 4$ & critical capillary number dependent function \\
\hline$F 5$ & oil mole fraction dependent function \\
\hline F6 & salt mole fraction dependent function \\
\hline FLOIL & lower critical oil saturation used in foam interpolation \\
\hline FLSALT & lower critical salt mole fraction used in foam interpolation \\
\hline$F M$ & gas relative permeability modifier \\
\hline$F M C A P$ & reference rheology capillary number \\
\hline$F M G C P$ & critical capillary number for foam generation \\
\hline$F M M O B$ & maximum reduction of gas relative permeability \\
\hline FMOIL & higher critical oil saturation used in foam interpolation \\
\hline$F M O M F$ & critical oil mole fraction for component numx \\
\hline FMSALT & higher critical salt mole fraction used in foam interpolation \\
\hline FMSURF & critical surfactants mole fraction \\
\hline$g$ & gravity acceleration, $\mathrm{m} / \mathrm{s}^{2}$ \\
\hline$h_{w}$ & water enthalpy, $\mathrm{kJ} / \mathrm{kg}$ \\
\hline$H_{c}$ & heat inside the steam chamber, $\mathrm{kJ} / \mathrm{s}$ \\
\hline$H_{o}$ & heat in oil flow leaving the between the steam chambers, $\mathrm{kJ} / \mathrm{s}$ \\
\hline
\end{tabular}


$H_{R} \quad$ heat in the reservoir, $\mathrm{kJ} / \mathrm{s}$ 


$\begin{array}{ll}H_{T} & \text { total heat released by the steam, } \mathrm{kJ} / \mathrm{s} \\ k_{1} & \text { number of foam generation sites. } \\ k_{2} & \text { constant } \\ k_{3} & \text { constant } \\ k_{4} & \text { constant } \\ k_{-1}\left(S_{w}\right) & \text { foam coalescence constant } \\ k_{r g}^{f} & \text { gas relative permeability after foam generation } \\ k_{r w} & \text { water relative permeability } \\ K & \text { reservoir permeability, } \mathrm{m}^{2} \\ K_{r g} & \text { gas relative permeability } \\ K_{r o} & \text { oil relative permeability } \\ K_{r o} & \text { oil relative permeability after the surfactants injection } \\ K_{r o}^{l} & \text { original oil relative permeability without surfactants } \\ K_{r o}^{M} & \text { oil relative permeability when oil and water are miscible } \\ L_{v} & \text { vaporization enthalpy, } \mathrm{kJ} / \mathrm{kg} \\ m & \text { constant depends on oil properties } \\ m_{S} & \text { amount of steam, kg } \\ n_{f} & \text { flowing foam density } \\ n_{l} & \text { constant which controls the effect of surfactants towards interfacial tension } \\ n_{t} & \text { trapped foam density } \\ \nabla p & \text { pressure gradient } \\ P_{b} & \text { pressure of the bulk liquid in foam, } \mathrm{kPa} \\ P_{c} & \text { capillary pressure, } \mathrm{kPa} \\ P_{c}^{*} & \text { critical capillary pressure, } \mathrm{kPa} \\ P_{f} & \text { pressure of liquid film in foam, } \mathrm{kPa} \\ P_{g} & \text { pressure of gas phase in foam, } \mathrm{kPa} \\ q & \text { oil rate, } \mathrm{m}^{3} / \mathrm{s} \\ Q_{b} & \text { sink-source term for foam } \\ Q_{g} & \text { gas volumetric flow across the normal plane, } \mathrm{m}^{3} /(\mathrm{m} \cdot \mathrm{s}) \\ Q_{i o} & \text { oil flow at the point of interference, } \mathrm{m}^{3} /(\mathrm{m} \cdot \mathrm{s}) \\ Q_{o} & \text { oil volumetric flow across the normal plane, } \mathrm{m}^{3} /(\mathrm{m} \cdot \mathrm{s}) \\ Q_{s} & \text { sink-source term for surfactants } \\ r_{c} & \text { foam collapse rate } \\ r_{g} & \text { foam generation rate } \\ R & \text { ratio of gas flow rate to oil flow rate } \\ R^{\prime} & \text { volumetric steam oil ratio } \\ S_{f} & \text { flowing foam saturation } \\ S_{t} & \text { trapping foam saturation } \\ S_{g} & \text { alteration of oil saturation during production } \\ S_{o} & \end{array}$




\begin{tabular}{|c|c|}
\hline$\Delta S_{o}{ }^{\prime}$ & change of oil saturation after the surfactants injection \\
\hline$S_{t}$ & trapped foam saturation \\
\hline$S_{w}$ & water saturation \\
\hline$S_{w}^{*}$ & critical water saturation \\
\hline$S_{w c}$ & critical water saturation \\
\hline$t$ & time, $\mathrm{s}$ \\
\hline$T_{m}$ & mixing temperature of oil, ${ }^{\circ} \mathrm{C}$ \\
\hline$T_{R}$ & reservoir temperature, ${ }^{\circ} \mathrm{C}$ \\
\hline$T_{S}$ & steam temperature, ${ }^{\circ} \mathrm{C}$ \\
\hline$u$ & finger rise velocity, m/s \\
\hline$u_{f}$ & flowing foam velocity, m/s \\
\hline$u_{g}$ & gas velocity, m/s \\
\hline$u_{w}$ & water velocity, m/s \\
\hline$v_{f}$ & interstitial gas velocity, m/s \\
\hline$v_{w}$ & interstitial water velocity, m/s \\
\hline $\mathrm{V}$ & volume fraction of water in the emulsions \\
\hline$x_{1}$ & half distance between the two fingers, $\mathrm{m}$ \\
\hline$x_{i}$ & interface position, m \\
\hline$\Pi(h)$ & disjoining pressure in foam, $\mathrm{kPa}$ \\
\hline$\Pi_{\max }$ & maximum disjoining pressure in foam, $\mathrm{kPa}$ \\
\hline$\rho_{e m}$ & emulsions density, $\mathrm{kg} / \mathrm{m}^{3}$. \\
\hline$\rho_{c} C_{c}$ & $\begin{array}{l}\text { volumetric heat capacity of steam chamber together with the residual } \\
\text { oil and connate water, } \mathrm{kJ} /\left(\mathrm{m}^{3} \cdot{ }^{\circ} \mathrm{C}\right)\end{array}$ \\
\hline$\rho_{o} C_{o}$ & heat capacity of oil, $\mathrm{kJ} /\left(\mathrm{m}^{3} \cdot{ }^{\circ} \mathrm{C}\right)$ \\
\hline$\rho_{g}$ & mass density of gas, $\mathrm{kg} / \mathrm{m}^{3}$ \\
\hline$\rho_{o}$ & mass density of oil, $\mathrm{kg} / \mathrm{m}^{3}$ \\
\hline$\rho_{R} C_{R}$ & heat capacity of reservoir, $\mathrm{kJ} /\left(\mathrm{m}^{3} \cdot{ }^{\circ} \mathrm{C}\right)$ \\
\hline$\Gamma_{s}$ & surfactants adsorption on the rock, gmole $/ \mathrm{m}^{3}$ \\
\hline$\frac{\partial P}{\partial y}$ & pressure gradient, $\mathrm{Pa} / \mathrm{m}$ \\
\hline$\varepsilon$ & distance between point $\mathrm{P}$ and the symmetry plane, $\mathrm{m}$ \\
\hline$\vartheta_{\text {em }}$ & emulsions kinematic viscosity, $\mathrm{m}^{2} / \mathrm{s}$ \\
\hline$\vartheta_{o}$ & oil kinematic viscosity, $\mathrm{m}^{2} / \mathrm{s}$ \\
\hline$\vartheta_{O S}$ & oil kinematic viscosity at $T_{S}, \mathrm{~m}^{2} / \mathrm{s}$ \\
\hline$\mu_{\mathrm{em}}$ & emulsions viscosity, $\mathrm{Pa} \cdot \mathrm{s}$ \\
\hline$\mu_{g}$ & gas viscosity, $\mathrm{Pa} \cdot \mathrm{s}$ \\
\hline$\mu_{g}^{f}$ & foam viscosity, $\mathrm{Pa} \cdot \mathrm{s}$ \\
\hline$\mu_{\mathrm{o}}$ & oil viscosity, Pa·s \\
\hline$\mu_{\mathrm{w}}$ & water viscosity, $\mathrm{Pa} \cdot \mathrm{s}$ \\
\hline$\alpha$ & thermal diffusivity, $\mathrm{m}^{2} / \mathrm{s}$ \\
\hline
\end{tabular}




$\begin{array}{ll}\varnothing & \text { porosity } \\ \varphi & \text { water to oil viscosity ratio } \\ \sigma & \text { interfacial tension, dyne/cm } \\ \eta & \text { emulsions viscosity, } \mathrm{Pa} \cdot \mathrm{s} \\ \eta_{o} & \text { external phase viscosity, } \mathrm{Pa} \cdot \mathrm{s} \\ \eta_{i} & \text { internal phase viscosity, } \mathrm{Pa} \cdot \mathrm{s} \\ \theta & \text { angle between boundary to the horizontal direction } \\ \lambda & \text { latent heat of condensation, } \mathrm{kJ} / \mathrm{kg}\end{array}$




\section{CHAPTER 1: INTRODUCTION}

Heavy oil and bitumen distinguish themselves from the conventional oil by their high viscosity and high density. This is highly related to a high content of heavy hydrocarbon, resins and asphaltenes (Meyer et al., 2007). It is estimated that the oil deposits are more than two trillion barrels around the world, and bitumen is said to occupy 100 billion barrels (Oil and Energy Trends, 2006). Canada and Venezuela are the major deposits of heavy oil and bitumen. Most of the Canadian bitumen lies in the northern part of Alberta (Athabasca deposits, Cold Lake deposits and Peace River deposits).

It is known that heavy oil and bitumen have a viscosity greater than $100 \mathrm{cp}$. The viscosity of bitumen in Alberta even shows to be around $10^{6} \mathrm{cp}$ at the initial reservoir temperature. The extraordinary high viscosity prevents oil from moving through porous media easily and predicts the difficulties of oil extraction. On this occasion, thermal recovery methods are put forward to mobilize the oil in formations through supplementing energy to heat up reservoirs. SAGD (steamassisted gravity drainage) is one of the most commonly-used and commercial thermal methods, which favors a stable oil displacement as it relies primarily on gravity to drain oil.

However, rapid vertical steam movement is likely to form an early contact with overburden and lead to substantial heat loss during SAGD operation. A large amount of energy provided to 
mobilize bitumen bypasses a target area and escapes when thief zones exist. In addition, a partiallydeveloped steam chamber due to reservoir heterogeneity tends to generate low sweep efficiency and unsatisfied oil production. Steam tends to enter high-permeable channels and ignore the oil in low-permeable regions. This study aims to investigate the feasibility to improve SAGD performance with an addition of chemical additives and the generation of foam by a comparison between SAGD and CAFA-SAGD (chemical additives and foam assisted SAGD).

A homogeneous model with Athabasca oil properties and geological features is first built. Both SAGD and CAFA-SAGD are applied to this model to investigate the mechanisms involved in detail and analyze their differences through comparisons. Then a heterogeneous model is established based on a Suncor Firebag project to further check the CAFA-SAGD performance in the field application. In this case, a geological model representing the geological characteristics and petrophysical properties of the McMurray formation is built and history match is conducted. Afterwards, one well pair is selected to carry out CAFA-SAGD to observe the behaviors of chemical additives and bubbles. Also, a modified finger rising model incorporating the effects of surfactants and foam is built and compared with Butler's SAGD finger rising model using the typical Athabasca reservoir data. Finally, we investigate the CAFA-SAGD operation in a carbonate reservoir to evaluate its efficiency. 


\section{CHAPTER 2: LITERATURE REVIEW}

\subsection{Literature Review of SAGD}

\subsubsection{Basic SAGD Concept}

SAGD is a thermal recovery method relies on the gravity force, in which, steam is injected into a reservoir through a horizontal injector perforated near its bottom (Figure 2-1). Then due to the density difference, the steam rises and forms an expanding steam chamber. The cold oil is heated by the provided enthalpy and further mobilized after the oil viscosity drops several orders of magnitude. With the help of gravity, oil is drained along the steam chamber border into the producer, which locates several meters below the injector. The production of oil further leaves more space for a steam chamber to grow both vertically and laterally. According to Al-Bahlani et al. (2009), there are two reasons why oil drains along the steam chamber border rather than inside the steam chamber. First, the residual oil saturation is too low for the oil to flow. Also, water imbibition and interfacial tension enforce the oil to flow laterally. The residual oil saturation is higher when the steam injection pressure is larger (Walls et al, 2003). 


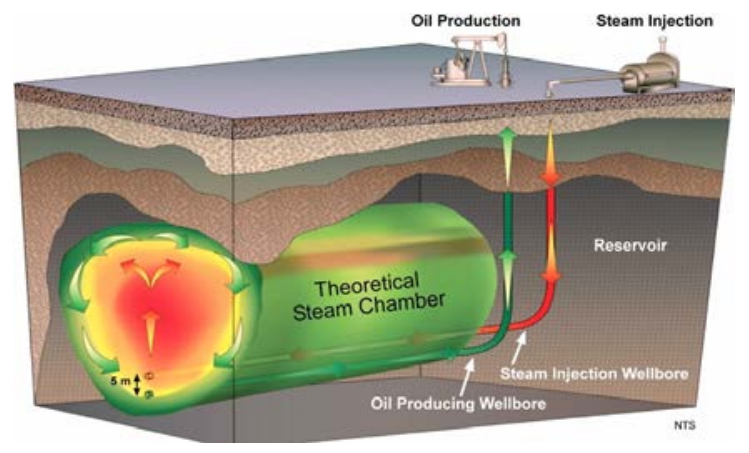

Figure 2-1 SAGD production (ExxonMobil)

\subsubsection{SAGD Startup Process}

Before production, both wells need to be heated by steam circulation to mobilize the oil between the two wells and establish certain heat communication. This is the startup stage aiming to maintain the steam quality and temperature, which usually lasts for a few months. According to Anderson and Kennedy (2012), a traditional startup is a process where the steam is injected into the well through a tubing string at the toe and produced at the heel. Heat carried by steam is transferred by conduction towards the reservoir along the horizontal wells to activate drainage for the entire wells. The heat efficiency of the startup process is directly measured by the length of circulation time. Also, decreasing the distance between a well pair, distributing wells evenly and introducing a small pressure difference between the two wells lead to a shorter circulation time. A too large circulation rate is not able to guarantee enough residency time for the steam to heat the reservoir completely. There is also an optimum circulation rate which maximize the conductive heat transfer to the formation (Prada et al. 2005). Shin and Polikar (2007) found out that a startup period increased as 
the permeability decreased and well spacing increased. Doan et al. (1999) also suggested to introduce a blow down period before switching to SAGD operation after startup, which enabled the reservoir to be depressurized and the steam to be injected with higher latent heat.

\subsubsection{SAGD Operation Process and Mechanisms}

After the achievement of heat communication, the steam circulation is transformed into the SAGD production mode. Gotawala and Gates (2008) divided the SAGD process into two stages. The first stage is before a steam chamber contact the overburden, during which all the latent heat is used up to heat the oil, in which, the heat efficiency is high as the heat loss is minimal. Then, when the steam chamber is expanded to the overburden, a significant amount of heat is absorbed by the surrounding rock. SOR (steam oil ratio) begins to increase rapidly as the heat allocated to the cool bitumen is reduced. There are two types of flow during the steam chamber growth. One is slope drainage (co-current flow) and the other one is ceiling drainage (counter-current flow). The slope drainage mainly occurs parallel to the steam chamber towards a producer. Both condensate and mobilized oil drain under the force of gravity. For the ceiling drainage, it happens when the steam rises and oil falls inside the steam chamber (Mohammadzadeh and Chatzis, 2009). The prorogation rate of counter-current flow is much lower as it is impeded by the condensate and oil, which is a function of steam temperature and vertical permeability (Good et al., 1994). 


\subsubsection{Steam Fingering Phenomenon}

The development of a steam chamber is related to steam fingering according to Butler and Dargie (1994). They declared that the steam chamber was dome-shaped in general, but the steam fingers protruded at the top of the steam chamber instead of a flat front. The oil then flowed downward along the perimeter of the fingers. Afterwards, oil left the fingers and entered into the steam chamber as the counter-current flow against the steam movement. Ito and Ipek (2005) found that steam fingers were extremely significant in the steam chamber expansion and a high pressure accounted a lot in promoting the steam fingering phenomenon.

\subsubsection{Steam Trap Operation}

During the operation of SAGD, steam trap control is the key to achieve economic efficiency. It demands the control of the liquid level above the producer to avoid the steam being produced directly from the injector. Generally, $10^{\circ} \mathrm{C} / \mathrm{m}$ is an accepted value, which is enough to maintain a steady and successful SAGD operation. Yuan and Nugent (2013) carried numerous studies and drew several conclusions. They found that there was a minimum subcool for the sake of flow stability. Moreover, for certain productivity, the liquid level increased when the bottom pressure of a producer dropped or the subcool was set higher.

\subsubsection{Steam Properties}

An enormous latent heat is an advantage of steam over water. A large amount of energy is released 
when steam is condensed on cold oil. According to Ali (2006), the enthalpy available is calculated by Equation (2-1).

$$
h=h_{w}+f_{s t} L_{v}-c_{w} T_{R}
$$

where $h_{w}$ is the water enthalpy, $\mathrm{kJ} / \mathrm{kg} ; f_{s t}$ is the steam quality, which is mass of the steam by the mass of the total mixture; $L_{v}$ is the vaporization enthalpy $\mathrm{kJ} / \mathrm{kg} ; c_{w}$ is the water specific heat, which varies with temperature, $\mathrm{kJ} /\left(\mathrm{kg} \cdot{ }^{\circ} \mathrm{C}\right) ; T_{R}$ is the reservoir temperature, ${ }^{\circ} \mathrm{C}$.

\subsubsection{Heat Conduction and Convection during SAGD}

The heat transfer process is controversial. Butler considered conduction while ignoring convection at first. He assumed that the latent heat carried by steam was transferred only by conduction to the cold oil, and there was no steam flow beyond the steam chamber edge. However, Ali (1997) mentioned that convection also dominated due to a large amount of condensate flowing along the edge of the steam chamber. Edmunds (1999) considered that convection only accounted for less than 5\% in the overall heat transfer during SAGD. But Ito (1999) challenged his conclusion and argued that it should fall in the range of $50 \%$. He calculated that convection took up for around $50 \%$ by assuming three areas, a pure conduction area, a pure convection area and a coexistence area. Sharma and Gates (2011) derived an analytical model and validated it with field data to study the convection at the edge of a steam chamber. They discovered that convection dominated above about $225^{\circ} \mathrm{C}$, while conduction contributed below $225^{\circ} \mathrm{C}$. When the temperature was lower than $125^{\circ} \mathrm{C}$, convection almost had no effect. 


\subsubsection{Emulsification during SAGD Production}

The production of W/O (water in oil emulsions) happens a lot when steam condenses on the cooler oil. Then the oil tends to spread on the water surface and causes some water droplets to be surrounded by the oil. The production of $\mathrm{W} / \mathrm{O}$ is higher when steam is injected near the bottom compared to top injection. Also, connate water saturation, steam quality and pressure are studied to measure their effects towards the amount of produced emulsions (Chung and Butler, 1988). It shows that emulsions are less likely to be formed when the initial connate water saturation is higher, while steam quality and pressure do not bring large influence.

\subsubsection{Field Application of SAGD}

Good et al. (1994) described the application of SAGD in western Canada reservoirs such as Athabasca, Peace River and Cold Lake. AOSTRA UTF initiated the Phase A pilot test to test the SAGD theory in 1987, which turned out to be successful. Then it designed Phase B to check if it was technically and economically successful. Early oil production was quite encouraging. Shell Canada adopted SAGD in Peace River and obtained $160 \mathrm{~m}^{3} /$ day production. Imperial Oil also tested SAGD performance after CSS application in Cold Lake Clearwater Oil Sands deposit. They estimated that 300 to 400 billion barrels of bitumen could be recovered by SAGD from Athabasca.

\subsubsection{SAGD Analytical Model and Theory}

Butler (1991) first derived a classical SAGD analytical model (Equation (2-2)) based on several 
assumptions. It was assumed that a reservoir was homogeneous, and a steam chamber was symmetric and two-dimensional. Also, the pressure inside the steam chamber was regarded as constant and the temperature equaled that of the injected steam. Furthermore, the oil flow along the steam chamber border was a single phase flow and heat exchange was carried out only by heat conduction. Then the oil drainage rate is

$$
q=2 \sqrt{\frac{2 \varnothing \Delta S_{o} k g \alpha h}{m \vartheta_{o}}}
$$

where $q$ is an oil rate, $\mathrm{m}^{3} / \mathrm{s} ; \emptyset$ is the porosity; $\Delta S_{o}$ is the change of oil saturation; $k$ is the permeability, $\mathrm{m}^{2} ; g$ is the gravity acceleration, $\mathrm{m} / \mathrm{s}^{2} ; \alpha$ is the thermal diffusivity of the rock, $\mathrm{m}^{2} / \mathrm{s}$; $h$ is the drainage height, $\mathrm{m} ; \vartheta_{o}$ is the kinetic oil viscosity, $\mathrm{m}^{2} / \mathrm{s} ; \mathrm{m}$ is a parameter to reflect the effect of temperature on viscosity. The oil rate is a function of the drainage height instead of the steam chamber shape. Also it is related to the permeability, the oil viscosity, the oil saturation and the parameter $m$.

Butler modified his original model with the TANDRAIN model (Equation (2-3)) which adjusted the interface curves at a producer, and then the steam chamber slope was the tangent lines from the producer. He also put forward a LINDRAIN model. This model was a derivation of the TANDRAIN model by assuming that the border was a straight line to the top of a reservoir. Reis (1992) modified the interface velocity to equal the maximum velocity and considered the change of velocity at different interface locations (Equation (4)). Akin (2005) also took the asphaltene deposition into account as the asphaltene content influenced the oil viscosity. He thought that 
steam distillation and asphaltene deposition accounted a lot in the SAGD process. Both the models of Reis and Akin assumed the steam chamber to be an inverted triangle.

$$
\begin{gathered}
q=2 \sqrt{\frac{1.5 \varnothing \Delta S_{o} k g \alpha h}{m \vartheta_{o}}} \\
q=2 \sqrt{\frac{\varnothing \Delta S_{o} k g \alpha h}{2 a m \vartheta_{o}}}
\end{gathered}
$$

where $a$ is a constant.

SAGD relies on heat transfer through the steam chamber fingers to a cold reservoir as mentioned above. Under the assumptions that the fingers rose at a constant velocity and heat transfer was carried out by conduction, Butler (1987) also developed an analytical model to predict the steam finger rising velocity considering multiphase flow. This model will be explained in detail in the following chapter.

Sharma and Gates (2010) considered the impacts of oil saturation and relative permeability at the edge of a steam chamber. They first assumed that oil saturation was linear to temperature. It started at residual oil saturation at the steam chamber edge and ended to be initial oil saturation in the reservoir. With the help of both Corey's equation and Butler's temperature-distance relationship, they obtained a higher oil rate than what Butler's classical model did. Gotawala and Gates (2008) modified Butler's finger rising model and revealed that the finger rising rate was related to the gas phase mobility and the density difference between the oil and gas phases. They also criticized the theory that steam fingers penetrated several meters outside a steam chamber. Murtaza et al. (2014) 
included the coupling between oil and water based on Butler's and Gotawala and Gates’ models. The finger rising velocity increased and oil production was, therefore, higher.

\subsubsection{Influencing Factors during SAGD Process}

According to Nguyen et al. (2012), porosity ranked first among all other factors. Kiasari (2010) maintained that SOR was reduced significantly when the porosity was higher. Llauno et al. (2002) agreed that reservoir properties such as thickness, porosity and oil saturation influenced more than flow properties did. Also, enlarging the pay thickness leads to a higher oil production. If a reservoir is too thin, a steam chamber contacts the cap rock rapidly, and most of the enthalpy is released to overburden. Thus SAGD is not suitable for thin reservoirs when the thickness is less than $15 \mathrm{~m}$ (Edmunds and Chhina, 2001). In terms of oil saturation, Nguyen et al. (2012) asserted that lower oil saturation cut down the oil production heavily. To guarantee successful SAGD, the horizontal permeability (higher than $5 \mathrm{D}$ ) and vertical permeability-horizontal permeability ratio (higher than 0.6) should be large enough. A low permeability may block the water drainage and reserve the water between well pairs. It also impedes the oil flow and the growth of a steam chamber (Mukherjee et al., 1994). Nasr et al. (1997) observed an increase in SOR with the reducing permeability by numerical simulation. In addition, Butler (1991) suggested to inject steam in an area with a higher permeability. Oil viscosity is also a determining element for SAGD. Das (2007) discovered that both injectivity and production increased when the viscosity decreased for a carbonate reservoir. Singhal et al. (1998) showed that horizontal wells and subcool were essential 
when the oil viscosity exceeded 65,000 mPa·s. Furthermore, Al-Bahlani and Babadagli (2009) explained the influence of well length and well spacing. It was declared that $500 \mathrm{~m}$ long wells with $100 \mathrm{~m}$ well spacing were the best choice by Singhal et al. (1998). Sasaki et al. (2001) investigated a 2D laboratory model and noticed that a larger distance between an injector and a producer did favor to the steam chamber rising rate and oil production rate. But Canbolat et al. (2002) considered that this might lead to low recovery efficiency. Also, Shin and Polikar (2007) discovered that this resulted in a decreased SOR, while reducing the distance enabled the oil production first to roar to the highest point and then fall. Nguyen et al. (2012) explained that raising a steam injection rate generated a higher oil rate as well as a higher SOR as the heat could not be employed efficiently.

\subsubsection{The Influences of Reservoir Heterogeneity}

Munoz (2013) built a 2D simulation model for the McMurray Formation in Alberta and carried out a study towards bottom water and gas pool. He concluded that a producer was suggested to place at the bottom of a reservoir when there was no bottom water, which achieved the highest oil recovery. Similarly, the existence of bottom water behaved like an enthalpy sink, posing a threat to the SAGD performance, especially when the water-bitumen thickness ratio exceeded 0.4. Also, depleted gas pools connected with a reservoir might undermine the SAGD operation. Yang and Butler (1992) studied the effects of a barrier length on top steam injection. A short horizontal barrier possessed little risk on the overall process, while a long horizontal barrier cut down the oil production to some extent but not severely. Chen et al. (2007) divided the reservoir into a NWR 
(near well region) and an AWR (above well region), and further studied the influence of shale distribution. NWR was sensitive to the spread of shale and AWR was sensitive to long and continuous shale. In addition, hydraulic fracturing enhanced the steam chamber growth by intensifying the vertical communication. Fractures around the two wells was able to increase both oil production and OSR (oil steam ratio). According to Kumar et al. (2014), shale correlation length and proportion influenced the vertical and lateral expansion of a steam chamber. Baker et al. (2008) gained an insight into water zones. High water saturation at bottom initiated enormous heat absorption from steam, and water thief zones determined the drainage height of a steam chamber as well as heat loss. Shin and Choi (2009) conducted a simulation study, in which shale barriers with the size of $10 \mathrm{~m}$ between an injector and a producer did harm to the SAGD performance to the largest extent. A shale layer located above an injector with a size between 5 to $25 \mathrm{~m}$ had a minimal effect on wherever it was distributed.

\subsubsection{Problems and Disadvantages of SAGD}

Ali (1997) pointed out that there were some limitations in Butler's theory. He believed that flow was multiphase flow, the steam pressure was not constant in a whole steam chamber, and the heat transfer was carried out by both conduction and convection. He also concerned that the geology and heterogeneity of a reservoir influenced the formation of a steam chamber a lot. And furthermore, geomechanical activities, flow in wells and the effect of wellbore were not clarified. Butler and Yee (2002) also pointed out that SAGD consumed a large amount of steam as it heated 
a whole reservoir, which led to a heat exchange with overburden in the end. There are also some obstacles such as sand control, a low drainage rate, and a difficulty in removing fluid when SAGD is employed in the field (McCormack, 2001).

\subsubsection{Improvements and Potential Solutions}

Equation (2-2) illustrates the influencing factors towards an oil production rate. According to Azom (2013), we can improve oil production by adjusting those parameters. $\Delta S_{o}$ can be increased by injecting surfactants and reducing interfacial tension, which enables oil to be removed more easily and results in a small residual oil saturation. Oil is also probably be carried away in the form

of oil in water emulsions. $k$ is able to be increased by geo-mechanical activities and inducing hydraulic fractures. $\vartheta_{o}$ will then be reduced by increasing steam temperature and adding light hydrocarbons.

According to Al-Bahlani and Babadagli (2009), SAGD performance can be enhanced in two aspects. One is chemical methods and the other one is geometrical approaches.

In terms of the geometrical method, XSAGD (Cross SAGD) is put forward to maintain the steam trap without undermining the oil rate (Figure 2-2). It is designed that injectors are drilled above and perpendicular to producers. Several wells near the cross points are plugged and the points of injection and production are moved apart laterally. This enables an increase in the oil production 
rate while preventing the steam from escaping through the injectors. XSAGD behaves better than SAGD at lower pressure and it has a flexible injector-producer ratio. However, XSAGD can only promote the formation of successful steam chambers near the cross points. Also, it raises economic and operational problems when carrying out plugging (Staler, 2005). F-SAGD (Fast-SAGD) is another geometrical method, which is a combination of SAGD and CSS. It calls for another horizontal well drilled beside a SAGD well pair. When a steam chamber is well developed for SAGD, the new well starts steam injection cyclically to accelerate the steam chamber growth. A steam chamber of F-SAGD is larger with higher oil production while the SOR remains the same as that of SAGD (Gong et al. 2002).

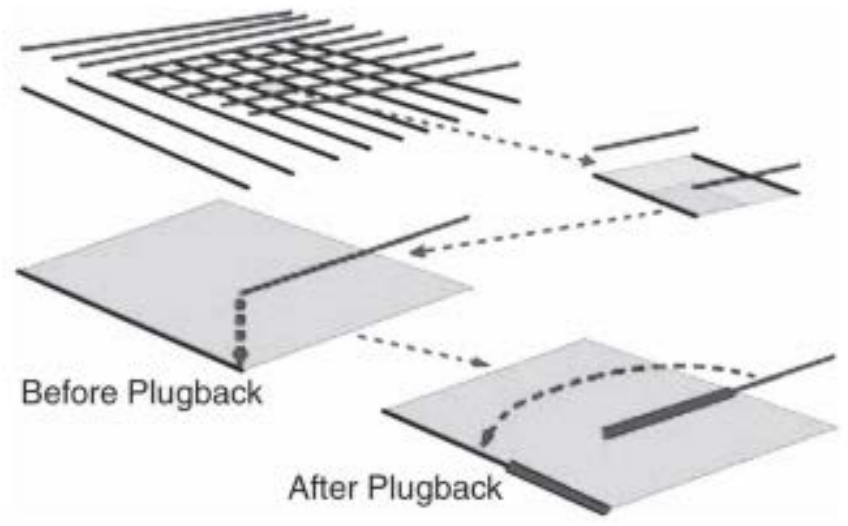

Figure 2-2 X-SAGD production (Stalder, 2005)

For the chemical method, ES-SAGD (Expanding-Solvent SAGD) is co-injection of solvent with steam. Solvent is congealed at a steam chamber border and further diffuses into bitumen, reducing 
the oil viscosity together with the steam, which is proposed by Nasr et al. (2003). After a study through a field scale 3D heterogeneous simulation model, Govind et al. (2008) concluded that the SOR was reduced and more oil was recovered. Higher solvent concentration was preferred but the cost needed to be considered. Butler put forward the theory of SAGP (Steam and Gas Push), adding non-condensable gas to the steam to increase the pressure and push oil downward. Also, it accumulates at the top of a reservoir, acting as an insulation to prevent heat loss to overburden. It can obtain higher oil production at a lower SOR (Butler, 1999). Wang et al. (2012) thought that sufficient non-condensable gas reduced the steam consumption as well as the oil rate after a simulation study.

This thesis will investigate whether the addition of chemicals and generation of foam improve the SAGD performance and overcome the problems and disadvantages illustrated above.

\subsection{Literature Review of Foam}

\subsubsection{Basic Foam Concept}

Foam is known as dispersion of gas in the continuous water phase with thin films (lamellae) acting as a separation. Schramm (1994) described the foam structure as in Figure 2-3. Normally, due to a density difference, liquid exists at bottom, gas accumulates at the top, and foam occupies the space in between. It can be seen that a lamella separates the gas phase and the liquid phase. Besides,

there is an area named Plateau border where three lamellae connect. The pressure at the Plateau 
border is lower than that at thin film, and, therefore, the Plateau border acts as a reserve during the liquid drainage process. Foam can be generated continuously as long as the gas injection rate is higher than the liquid drainage rate. However, foam collapses easily as the surface area is extremely large. It is essential to inject surfactants to extend foam's lifetime and strengthen its stability. The surfactants molecules can be absorbed at the interface between liquid and gas to reduce the IFT (interfacial tension) (Figure 2-4).

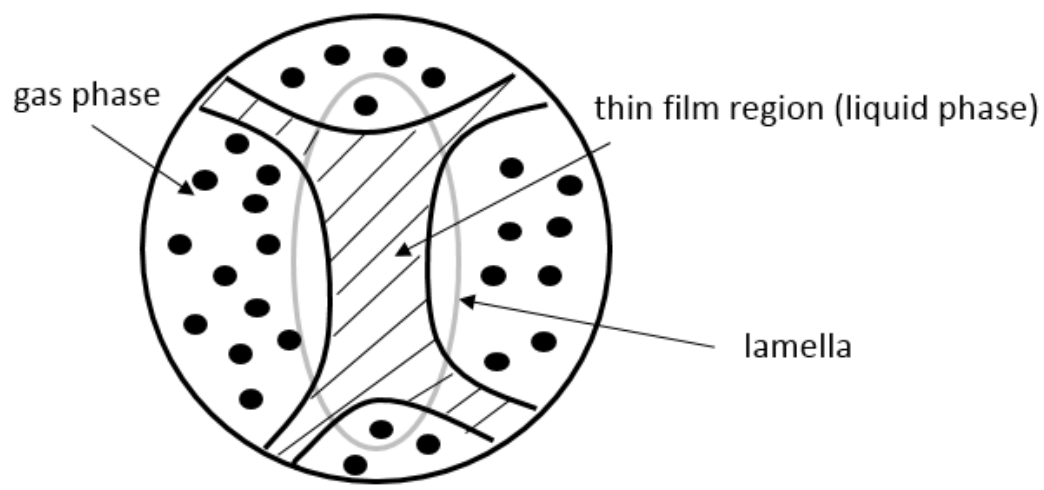

Figure 2-3 Foam structure (Schramm, 1994)

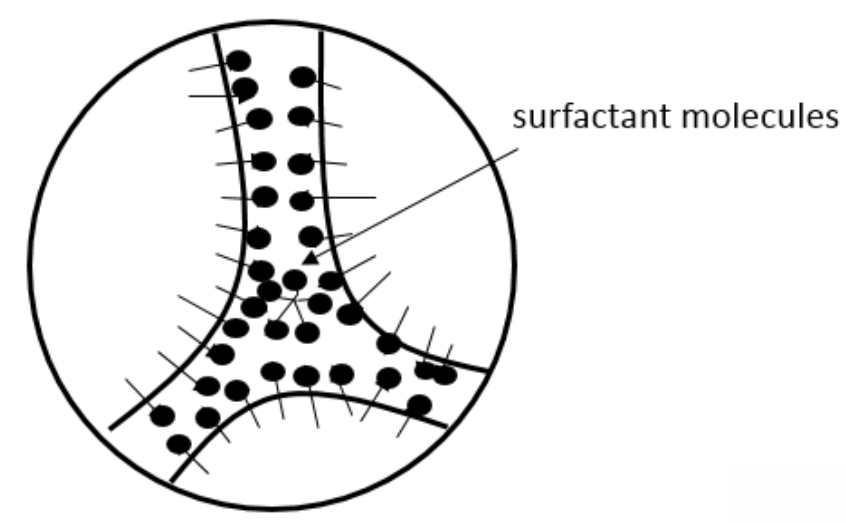

Figure 2-4 Surfactants distribution in foam (Schramm, 1994) 
In Figure 2-3, water can take the form of a bulk liquid or liquid film, and thus it can change its status to maintain the balance of foam bubbles (Reme, 1999). The pressure of the gas phase is $P_{g}$, the pressure of the bulk liquid is $P_{b}$, and then the capillary pressure $P_{c}$ is calculated in Equation (2-5). The pressure of a liquid film is $P_{f}$, thus the disjoining pressure $\Pi(h)$ is calculated as in Equation (2-6). $\Pi(h)$ is a function of the film thickness $h$, and is determined by both attraction and repulsion between the interfaces. When the bubbles are stable, $\Pi(h)$ is equal to $P_{c}$. From Figure 2-5, it can be seen that there is a critical water saturation $S_{w}^{*}$. When the water saturation is lower than $S_{w}^{*}$, critical pressure $P_{c}^{*}$ will exceed the maximum disjoining pressure $\Pi_{\max }$, the film thickness will be thinner than the critical value $h_{c r}$, and then foam collapses.

$$
\begin{gathered}
P_{c}=P_{g}-P_{b} \\
\Pi(h)=P_{g}-P_{f}
\end{gathered}
$$
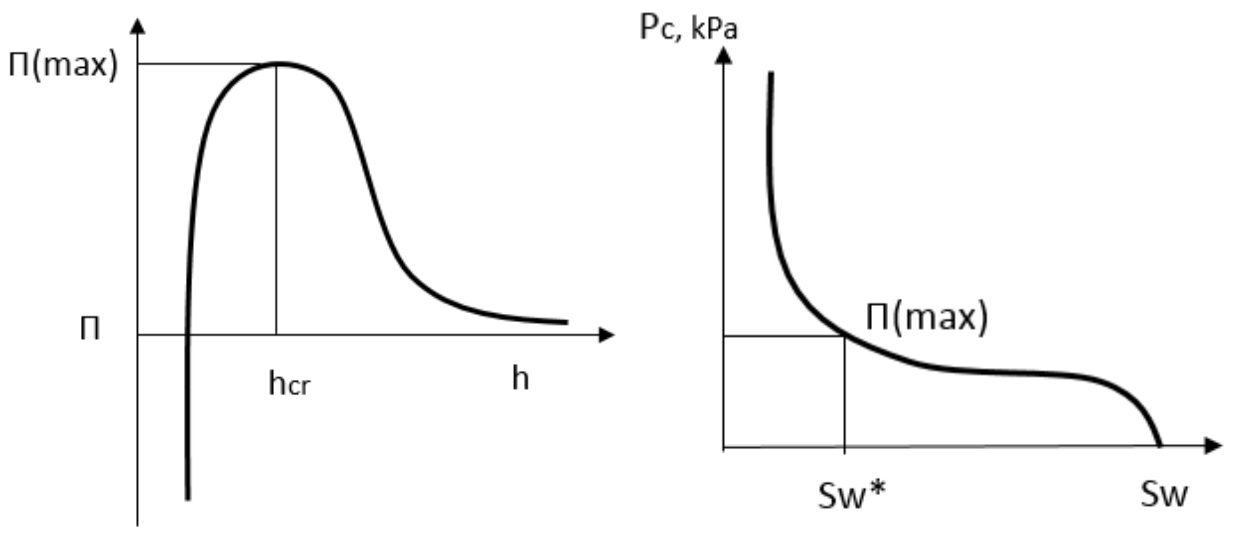

Figure 2-5 Disjoining pressure and capillary pressure (Schramm, 1994)

The stability of foam is influenced by surface elasticity and surface charge. The adsorption of 
surfactants can increase the elasticity of films to withstand squeezing, deformation and rupturing. If there is a sudden disturbance, part of a film is extended, and the surfactants molecules density of that part is lower. Therefore, local interfacial tension is increased to contract the film. The liquid will then flow towards the extended area to repair the thinner film (Schramm, 1994). Higher surface elasticity decreases the liquid drainage rate and adds stability. In addition, the existence of electrolyte compresses an electric double layer and thin a liquid film, even rupture it.

\subsubsection{Foam Generation}

It is known that there are mainly three foam generation mechanisms, they are snap-off, division and leave-behind (Figure 2-6).

Snap-off is discovered by Roof (1970), which is distinguished as the dominant foam generation scheme. It happens when gas flows into a pore constriction where water occupies originally. The required entry pressure is $P_{c}^{c}$. After entering the constriction, if the capillary pressure drops to a value that is low enough $\left(P_{c}^{s n}\right)$, there will be a water collar swelling and bridging the constriction, forming a lamella. Snap-off depends on the pore geometry, fluid properties and capillary and viscous forces (Ransohoff and Radke, 1988).

According to Schramm (1994), if there are mobile foam bubbles which are larger than a pore size, they will be divided when reaching a branch point. At this time, a bubble will be separated into 
two bubbles, which flow in two branches. Then the interface is stretched and split into two lamellae for different directions.

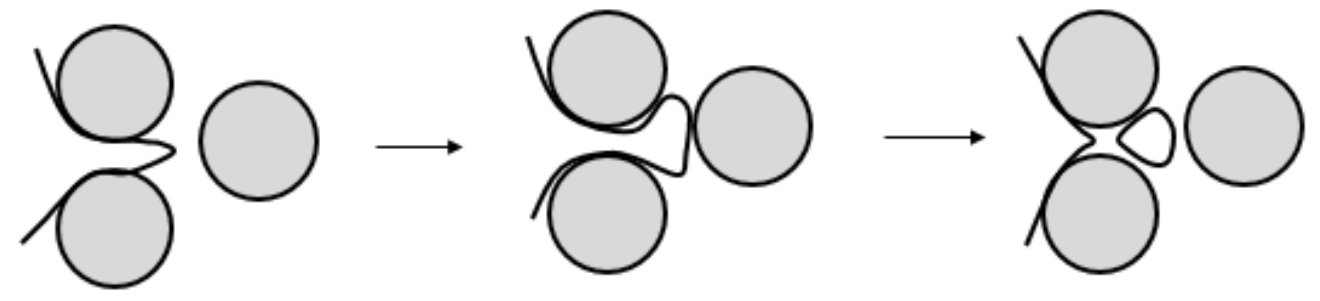

A

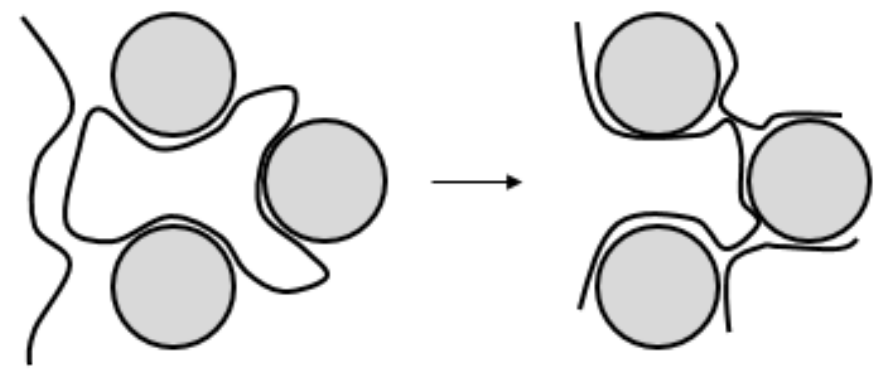

B
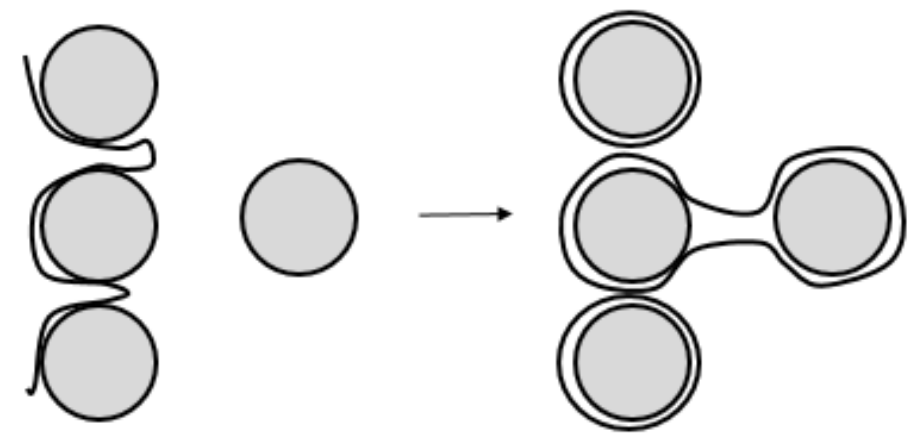

C

Figure 2-6 Foam generation mechanisms (A: Snap off; B: Division; C: Leave-behind) (Ransohoff and Radke, 1988) 
Leave-behind happens when two gas menisci approach pores which are filled with a liquid. Afterwards, the two menisci combine and form a lens, which can be drained into a film. Leavebehind is said to be generated only during drainage and deliver continuous foam as the film created is arranged along the flow direction (Schramm, 1994).

Ransohoff and Radke (1988) conducted several experiments in glass bead packs to ascertain the relative importance of the three mechanisms by changing bead sizes, gas velocity, gas fractional flow and surfactants types. It was discovered that there existed a critical capillary number in their homogeneous model. Snap-off and division dominated and strong foam was generated when the capillary number exceeded the critical value. Otherwise, leave-behind leaded and produced weak foam.

\subsubsection{Foam Collapse}

Capillary suction and gas diffusion are two main mechanisms accounting for foam coalescence. In addition, capillary suction is dominant. As illustrated above, when the water saturation drops below the critical water saturation, the critical pressure exceeds the maximum disjoining pressure and a film is thinner than the critical value, foam collapses. Also, it is known that the pressure at the convex side is higher than the concave side. Thus the pressure in small bubbles is higher than that in large bubbles. Driven by a pressure difference, gas diffuses through the film from small bubbles to large bubbles. Small bubbles tend to be smaller and smaller, and even disappear finally 
(Schramm, 1994).

\subsubsection{Foam Classification}

Foam is classified as continuous foam and discontinuous foam (Reme, 1999). For continuous foam, gas has at least one channel that is not blocked by lamella and flows as s Newtonian fluid. In terms of discontinuous foam, all the channels are disconnected and closed by lamella.

Also, there are strong foam and weak foam differing in the foam texture. Generally speaking, strong foam is finely-textured with small bubbles, which reduce the gas mobility to a very large extent. Usually, strong foam behaves better in mobility control. In contrast, weak foam is usually coarsely-textured with large bubbles, and its ability to lower the gas mobility is restricted (Zhang et al. 2009). Strong foam tends to transform into weak foam suddenly around the critical pressure $P_{c}^{*}$.

Osterloh and Jante (1992) found that there were two foam flow regimes distinguished by foam quality. The pressure gradient of a high quality regime is dependent on a liquid flow rate but independent on a gas flow rate. The flow in this regime can be Newtonian, shear thinning or shear thickening (Martinez, 1998). A high quality regime is dominated by bubble coalescence at $P_{c}^{*}$. In terms of the low quality regime, the pressure gradient depends on a gas flow rate instead of a liquid flow rate. The flow is controlled by bubble trapping and bubble mobilization (Zhang et al., 2009). 


\subsubsection{Foam Model}

\subsubsection{Population Balance Model}

Foam is a complicated component involving constantly changing properties and a variety of activities during flow. There are a lot of models to predict foam flow, among which the population balance model is a relatively rounded model reflecting the foam generation and foam coalescence at the pore level to account for the evolution of the foam texture. It incorporates the equations of mass, momentum and energy conservation, which also describes the gas trapping and mobilization (Patzek, 1987).

From Figure 2-3, there are a pure liquid phase, a pure gas phase and foam flow in a porous medium. The mass balance equation for the gas phase is shown in Equation (2-7).

$$
\frac{\partial\left(\varnothing \rho_{g} S_{g}\right)}{\partial t}+\frac{\partial\left(\rho_{g} u_{g}\right)}{\partial x}=Q_{g}
$$

where $t$ is the time, $x$ is the location, $\emptyset$ is the porosity, $\rho_{g}$ is the mass density of gas, $S_{g}$ is the gas saturation, $u_{g}$ is the gas velocity, and $Q_{g}$ is a sink-source term for gas.

Surfactants are necessity as mentioned above. Thus there is an equation for surfactants mass balance (Equation (2-8)).

$$
\frac{\partial\left[\varnothing\left(C_{S} S_{w}+\Gamma_{S}\right)\right]}{\partial t}+\frac{\partial\left(u_{w} C_{S}\right)}{\partial x}=Q_{S}
$$

where $C_{s}$ is the surfactants concertation, $S_{w}$ is water saturation, $\Gamma_{s}$ is the surfactants adsorption on the rock, $u_{w}$ is water velocity and $Q_{s}$ is a sink-source term for surfactants. 
Then it simulates the foam flow depending on the foam texture (Equation (2-9)).

$$
\frac{\partial\left(\varnothing\left(S_{f} n_{f}+S_{t} n_{t}\right)\right.}{\partial t}+\frac{\partial\left(u_{f} n_{f}\right)}{\partial x}=\varnothing S_{g}\left(r_{g}-r_{c}\right)+Q_{b}
$$

where $n_{f}$ and $n_{t}$ represent the flowing foam and trapped foam density separately, $S_{f}$ and $S_{t}$ are the flowing foam and trapped foam saturation correspondingly, $u_{f}$ is the flowing foam velocity, $S_{g}$ is gas saturation, $r_{g}$ and $r_{c}$ are the foam generation rate and collapse rate, and $Q_{b}$ is a sink-source term for foam. The first term on the left-hand side describes the change of foam texture, and the second term on the left-hand side reflects the rate of foam trapping. When foam is in a stable state, $r_{g}$ and $r_{c}$ can be assumed equal.

It is assumed that foam generation merely comes from snap off and foam collapses only due to capillary suction. Kovscek (1995) suggested that snap off was proportional to the liquid rate and the gas rate (Equation (2-10)).

$$
r_{g}=k_{1} v_{f}^{a} v_{w}^{b}
$$

where $v_{w}$ and $v_{f}$ are the interstitial water and gas velocities, respectively. $a$ and $b$ are constants, and $k_{1}$ stands for the number of foam generation sites.

The foam collapse rate is proportional to the flowing foam velocity. The foam bubbles moving at a higher velocity tend to collapse more easily (Equation (2-11)).

$$
\begin{gathered}
r_{c}=k_{-1}\left(S_{w}\right) v_{f} n_{f} \\
k_{-1}\left(S_{w}\right)=k_{-1}^{o}\left(\frac{1-S_{w}}{S_{w}-S_{w}^{*}}\right)
\end{gathered}
$$


where $k_{-1}\left(S_{w}\right)$ is a foam coalescence constant which depends on the water saturation significantly and corresponds to the critical pressure theory (Equation (2-12), $k_{-1}^{o}$ is a constant. When the water saturation is close to $S_{w}^{*}$, foam collapses to an infinite large extent.

\subsubsection{Local Equilibrium Model}

The population balance model uses conservation equations to calculate the foam texture, while local equilibrium models calculate it with simpler algebraic equations to represent the change of gas mobility. Local equilibrium models assume that foam lies in a local steady state. Ma et al. (2015) concluded several local equilibrium models.

Marfoe et al. (1987) put forward a model which realized gas mobility reduction through gas viscosity alteration (Equation (2-13)). Their model incorporates the influence of water saturation, surfactants saturation and gas velocity towards the gas viscosity.

$$
\mu_{g}^{f}=\mu_{g}\left[1+R C_{s}\left(S_{w}-S_{w c}\right) f\left(u_{g}\right)\right]
$$

where $\mu_{g}$ is the gas viscosity, $R$ is a constant, $S_{w c}$ is the critical water saturation, $\mu_{g}^{f}$ is the foam viscosity.

Islam and Ali (1990) adopted the change of the gas viscosity similarly (Equation (2-14)). This model involves the effects of oil, water saturation, surfactants concentration, permeability and pressure gradient. Oil should be contained as it is extremely detrimental to foam stability. The 
other constants are matched by experiments.

$$
\mu_{g}^{f}=\frac{\mu_{g}\left[1+D f_{c}\left(C_{s}\right)\left(S_{w}-S_{w c}\right) f_{k}(k)+f_{p}(\nabla p)\right]}{1+E S_{o}^{2}}
$$

where $D$ and $E$ are constants, $k$ is the permeability, $\nabla p$ is the pressure gradient, $S_{o}$ is the oil saturation.

Chang et al. (1990) used the reduction of gas permeability to simulate foam. Equation (2-15) reflects the influence of the gas fractional flow, the gas velocity, the water saturation and the oil saturation.

$$
\frac{k k_{r g}^{f}}{\mu_{g}^{f}}=\left(k_{1} f_{g}+k_{2} v_{g}^{n}\right)\left[1+k_{3} C_{s}\left(S_{w}-S_{w c}\right)\right]\left[1+k_{4}\left(S_{o}-S_{o r}\right)\right]
$$

where $k_{r g}^{f}$ is the gas relative permeability after foam generation, $f_{g}$ is gas fraction, $k_{1}, k_{2}, k_{3}$, $k_{4}$ are constants.

Rossen and Zhou (1995) designed a model according to the critical capillary pressure theory:

$$
\nabla p=u_{w} \frac{\mu_{w}}{k k_{r w}\left(S_{w}^{*}\right)}
$$

where $P_{c}^{*}$ is the critical pressure, which depends on rock properties and surfactants, $u_{w}$ is the water velocity, $\mu_{w}$ is the water viscosity, $k_{r w}$ is the water saturation. At $P_{c}^{*}$, foam collapses dramatically. 


\section{CHAPTER 3: HOMOGENEOUS MODEL}

As already stated in the previous section, SAGD is recognized as a profitable and stable approach to tackle the exploitation of heavy oil and oil sand resources on account of a high recovery factor and the utilization of gravity as the primary driving force. The efficiency of SAGD, which is a close relative of a sufficiently-expanded and uniformly-developed steam chamber, tends to catch the industry's attention as it is tied to economic and environmental measures. There are numerous issues reducing its efficiency potentially during its operation, in some cases, steam rising rapidly as a result of density difference is prone to induce low volumetric sweep efficiency and unsatisfied oil output. It also happens that a substantial amount of heat is released when steam contacts overburden, whose thermal conductivity is much higher, and more steam is thus required for a given amount of oil production. For those reasons, people are committing themselves to presenting methods to settle those problems. Injection of chemical additives and generation of foam are proposed to restrain heat loss and control a steam chamber conformance to improve thermal efficiency and oil production. In this chapter, we use a 2D homogeneous simulation model to discuss the potential mechanisms and evaluate the differences between SAGD and CAFA-SAGD.

\subsection{Basic Homogeneous Simulation Model}

A 2D homogeneous model with a grid size of $1 \mathrm{~m} \times 50 \mathrm{~m} \times 1 \mathrm{~m}$ is built to carry out an evaluation.

In total, there are $101 \times 1 \times 40$ grids, covering an area of $101 \mathrm{~m} \times 50 \mathrm{~m}$ with the net pay to be 40 
m (Figure 3-1). Heterogeneity along the horizontal wells is ignored and the injection and production rates are thus measured with the unit of $\mathrm{m}^{3}$ per $50 \mathrm{~m}$. The porosity is 0.307 and the permeabilities are 6,292 $\mathrm{mD}$ and 4,892 $\mathrm{mD}$ for the horizontal and vertical directions, respectively. Oil viscosity is around $10^{7} \mathrm{cp}$ at the initial reservoir temperature $\left(12{ }^{\circ} \mathrm{C}\right)$. The basic reservoir parameters are summarized in Table 3-1, which are typical properties for the Athabasca reservoirs. The steam is injected into the injector at the maximum pressure of 2,000 $\mathrm{kPa}$ and the producer is produced at the minimum pressure of $1500 \mathrm{kPa}$, and the steam trap for the producer is set to be 10 ${ }^{\circ} \mathrm{C}$ to prevent the steam escape. The distance between the injector and producer is $5 \mathrm{~m}$. In terms of SAGD, pure steam is injected at the quality of 0.8 continuously from January, 2009. With regard to CAFA-SAGD, $0.015 \%$ (mole fraction) surfactants are injected after 3 years' SAGD production. After injecting chemicals and steam mixture for 3 years, the CAFA-SAGD case switches back to the SAGD production mode.

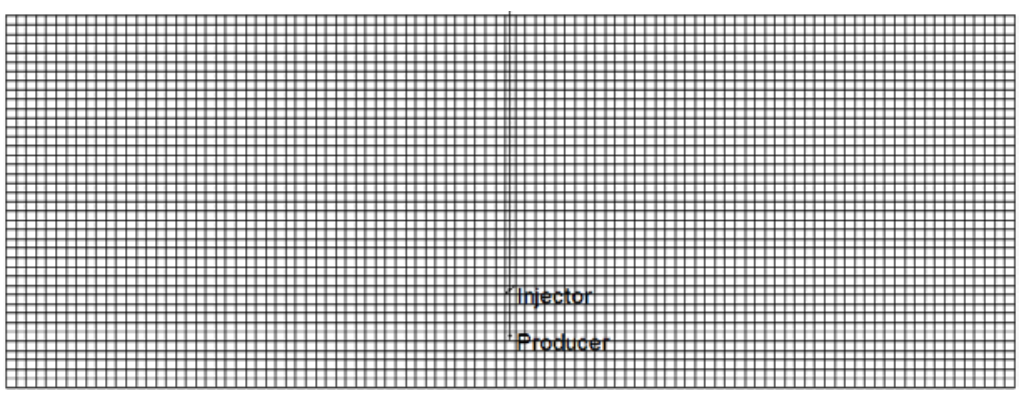

A

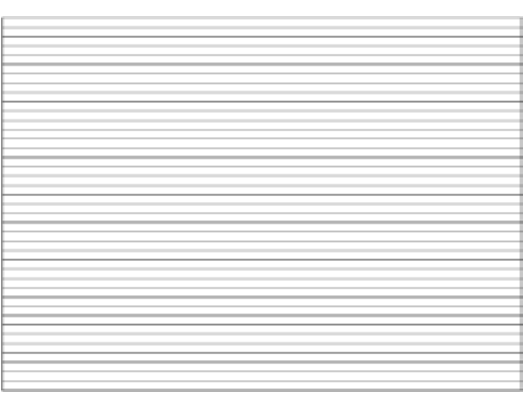

B

Figure 3-1 2D homogeneous model (A: IK cross section; B: JK cross section) 
Table 3-1 Basic reservoir parameters of homogeneous model

\begin{tabular}{|c|c|c|c|}
\hline Parameter & Value & Parameter & Value \\
\hline Porosity & 0.307 & $\begin{array}{l}\text { Rock Thermal Conductivity, } \\
\qquad \mathrm{J} /\left(\mathrm{m}^{*} \mathrm{day}^{* 0} \mathrm{C}\right)\end{array}$ & $2.7 \mathrm{e} 5$ \\
\hline Horizontal Permeability, mD & 6,292 & Rock Heat Capacity, $\mathrm{J} /\left(\mathrm{m}^{3 * 0} \mathrm{C}\right)$ & $2.3 \mathrm{e} 6$ \\
\hline Vertical Permeability, mD & 4,892 & $\begin{array}{l}\text { Water Thermal Conductivity, } \\
\qquad \mathrm{J} /\left(\mathrm{m}^{*} \mathrm{day}^{* \circ} \mathrm{C}\right)\end{array}$ & $5.4 \mathrm{e} 4$ \\
\hline \multirow[t]{2}{*}{ Reservoir Temperature, ${ }^{\circ} \mathrm{C}$} & 12 & Oil Thermal Conductivity, J/(m*day*o C) & $1.2 \mathrm{e} 4$ \\
\hline & & Gas Thermal Conductivity, $\mathrm{J} /\left(\mathrm{m} * \mathrm{day}^{* \mathrm{o}} \mathrm{C}\right)$ & 4,000 \\
\hline
\end{tabular}

\subsection{Foam Simulation Model}

In general, there are two methods to simulate and explain foam behaviors in $\mathrm{CMG}^{\circledR}$ STARS. One is a foam percolation mechanism model, in which the strength of foam is reflected through the lamella density (number of lamella per unit volume/mass). A new component named lamella is defined in the gas phase, rather than a mixture of liquid phase, gas phase and surfactants. On this occasion, the existence of lamella influences local gas viscosity and a gas resistance factor. As the foam generation, foam coalescence and bubbles trap affect the local lamella density, the change of lamella density can be used to estimate the alteration of foam properties and foam propagation. A lamella is the product of water and surfactants in the simulator (Equation (3-1)).

$$
\text { Water }+ \text { aSurfactants }=\text { Lamella }
$$

where $a$ is a reaction coefficient, which depends on the surfactants and brine properties. The order of magnitude is usually $10^{-5}$. 
The other model is an empirical model that will be introduced later (Equation (5-1)). This model assumes that foam exists as long as gas and surfactants contact, and foam generation and foam collapse are initiated and completed immediately. It introduces a gas relative permeability modifier to simulate the mobility control ability of foam. The modifier measures the effects of surfactants concentration, oil saturation, capillary number and salinity towards the gas mobility. The lower the modifier, the larger the foam mobility control ability.

\subsection{CAFA-SAGD Mechanisms Analysis}

Coupled with the foam percolation mechanism model, the homogeneous model illustrated above is adapted to evaluate the mechanisms involved in CAFA-SAGD, figure out the chemicals behaviors in the porous medium and assess the feasibility of CAFA-SAGD through comparisons. Here we consider lamella generation, lamella decay and lamella adsorption. With the purpose of quantifying the contribution of each mechanism, here we add each mechanism of CAFA-SAGD into SAGD one by one to discuss their effects.

\subsubsection{Oil Viscosity Reduction}

There is no room for any doubt that the dominant mechanism in all thermal recovery methods is providing enthalpy for heavy oil and bitumen to reduce their viscosity and achieve their mobility. Water is frequently selected as heat supplier as it owns the highest specific heat. Further, steam enjoys even more advantages due to its extra substantial latent heat besides its high specific heat. 
During SAGD, the steam carrying latent heat spreads and releases heat. Ultimately, the viscosity drops significantly, enabling oil to be driven at considerable rates together with the condensate along a steam chamber border (Butler, 1991). Figure 3-2 shows the oil viscosity and temperature profiles at a certain stage of SAGD operation.

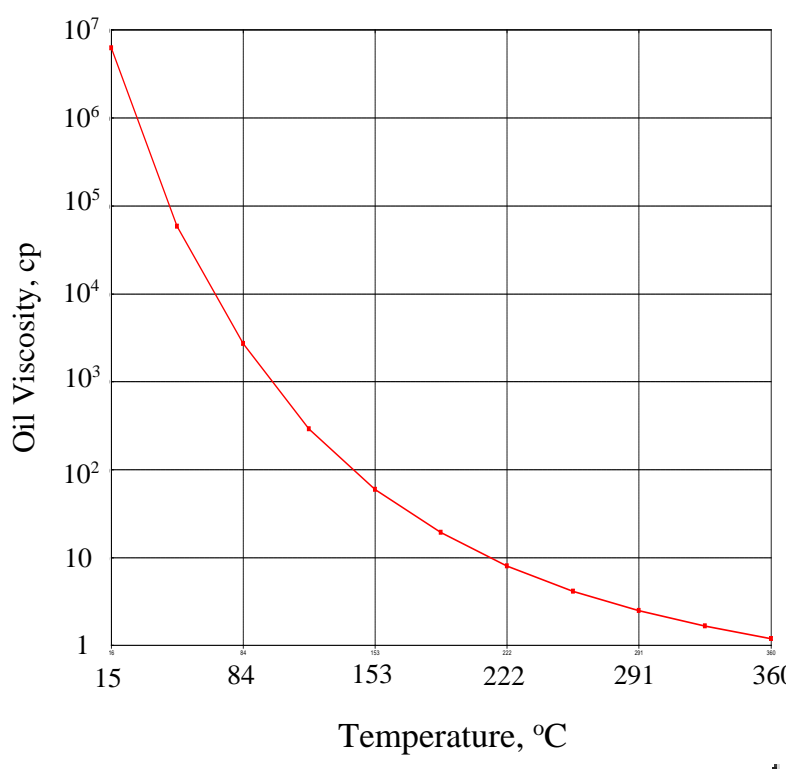

A
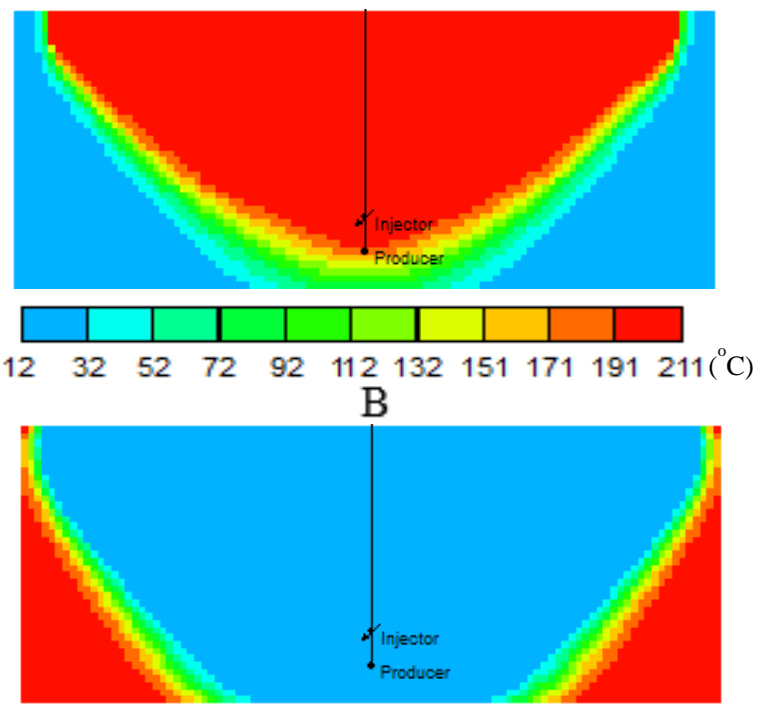

1.1e11.2e6 2.3e6 3.5e6 4.6e65.8e67.0e6 8.1e69.3e61.0e71.2e7 (ср)

$\mathrm{C}$

Figure 3-2 Oil viscosity and temperature relationship (A: Oil viscosity and temperature plot; B: Temperature profile $\left({ }^{\circ} \mathrm{C}\right)$; C: Oil viscosity profile (cp))

It is known that multiphase flow exists both inside the steam chamber and along the chamber border. Sharma and Gates (2010) derived analytical models to show that the oil drainage velocity changes when multiphase flow at the steam chamber edge was included. Besides, Gotawala and Gates (2008) discovered that a finger rising rate was determined by the gas phase mobility and a density difference between the oil and gas phases. Murtaza et al. (2014) also put forward that the 
steam fingering depended on multiphase flow regimes and the finger rising velocity changed when oil flow and water flow were coupled. Therefore, the properties alteration of each phase and the interfaces calls for great importance to be attached as it tends to exert extensive influences towards phase behaviors and oil production. The injection of chemical additives and in-situ generation of foam initiate intricate physical and chemical reactions both at the interfaces and bulk phases, and there are bound to be lots of changes in the CAFA-SAGD production process. Next is the specific analysis of the differences through side-by-side comparisons with SAGD. The underlying driven mechanisms to be discussed are gas mobility control, interfacial tension reduction and emulsification.

\subsubsection{Gas Mobility Reduction}

Given its distinct texture, i.e., the dispersion of gas in a continuous water phase with lamella as a separator, foam is a potential chemical agent proposed to control gas mobility and further improve volumetric sweep efficiency. Kovscek et al. (1993) carried out foam displacement experiments with Boise sandstone at backpressure of $5 \mathrm{MPa}$. They noticed that when gas and liquid were injected simultaneously into the surfactants-saturated core, the resistance for gas flow built up rapidly. By contrast, gas flow seemed almost unchanged without surfactants' participation. Similarly, Bernard et al. (1964) testified that gas permeability was reduced to $10^{-3} \mu \mathrm{m}^{2}$ after being co-injected with surfactants solution into a porous medium. In addition, the trapped gas saturation was around $10-70 \%$, which depended on the surfactants types and the oil properties. Hirasaki and 
Lawson (1985) considered that the foam bubbles transported like a bubble train. During flow, the front bubble interfaces stretched towards the capillary wall while the back interfaces contracted towards the centerline, leading to a surface tension gradient, impeding the gas movement and increasing the gas effective viscosity.

According to Sepehrnoori et al. (2003), foam modifies gas mobility with two approaches. On one hand, it undermines effective gas relative permeability by gas trapping. Numerous gas flow channels are blocked by the slow-moving or even stagnant bubbles and the cross-sectional area for gas to flow is limited by lamella as a result. Therefore, along with the rise of trapped gas saturation, mobile gas saturation declines and gas relative permeability drops thereupon. On the other hand, the existence of lamella adds additional resistance for bubbles advance, resulting in a larger apparent gas viscosity. Sepehrnoori et al. (2003) maintained that there was a minimal yield stress, only when the pressure gradient exceeded the yield stress, foam could be mobilized. Moreover, Rossen and Zhou (1995) declared that this yield stress governed both gas trapping and viscosity control, to separate the effects on gas relative permeability and viscosity became unrealistic in consequence. Accordingly, people usually choose either the alteration of gas relative permeability or gas viscosity to stand for the change of gas mobility in the model.

Figure 3-3 is a snapshot of the gas relative mobility (gas relative permeability divided by gas viscosity) comparison between SAGD and CAFA-SAGD. Gas relative mobility drop inside the 
steam chamber, by 10 times as likely, is much in evidence after surfactants injection and foam generation. The gas flow of CAFA-SAGD seems further resisted as it gets closer to the steam front. Figure 3-4 describes how bubbles are accommodated together with the other components, which reflects the foam generation and spread pattern clearly. It has been stated that a higher lamella density signifies foam with higher strength. Consequently, consistent with gas mobility figures, strong foam accumulates along the inner boundary of the steam chamber, developing a low gas rate circle surrounding the steam chamber, while a certain amount of weak foam fills inside the chamber.
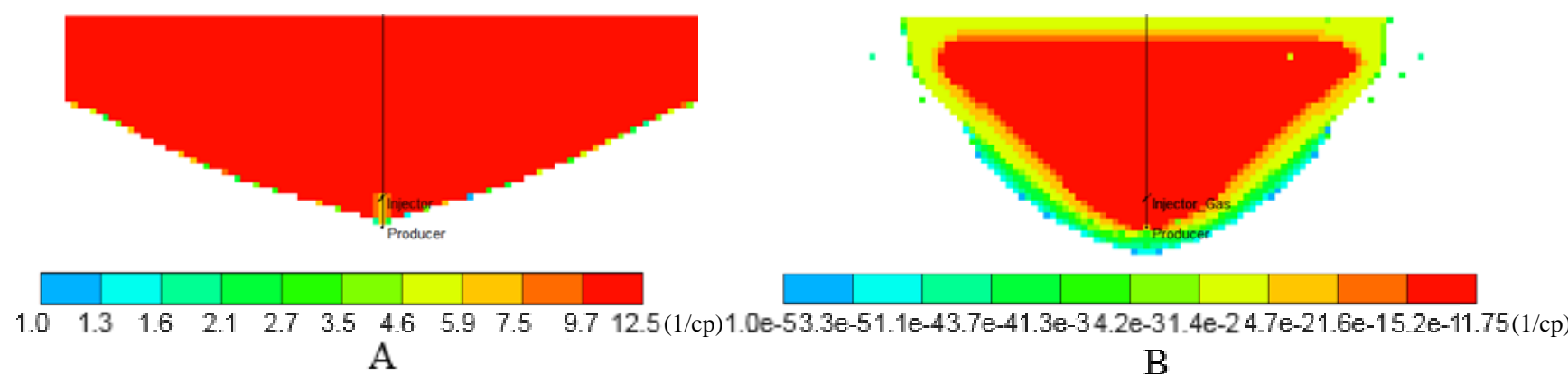

Figure 3-3 Gas relative mobility distribution comparison of homogeneous model (1 year after surfactants injection) (1/cp) (A: SAGD; B: CAFA-SAGD)
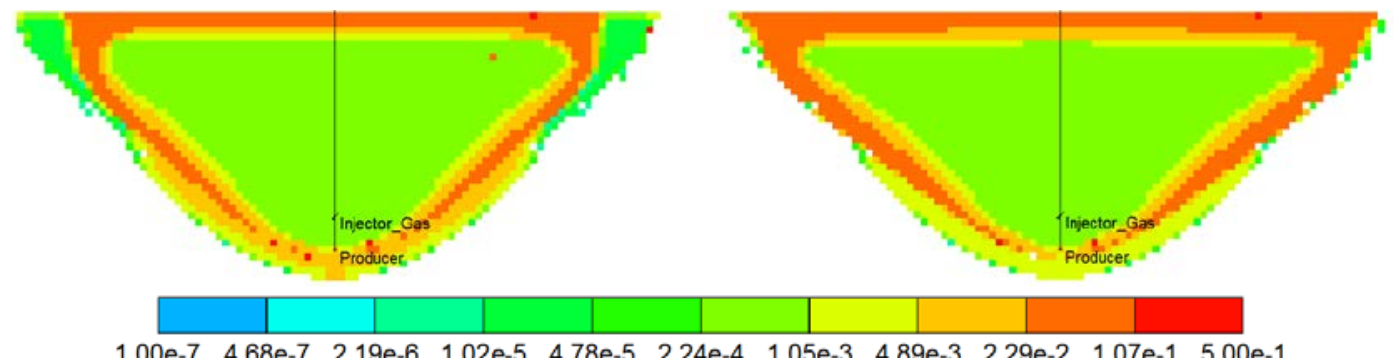

A

B

Figure 3-4 Lamella mole fraction distribution of homogeneous model (A: 1 year after surfactants injection; B: 2 years after surfactants injection) 


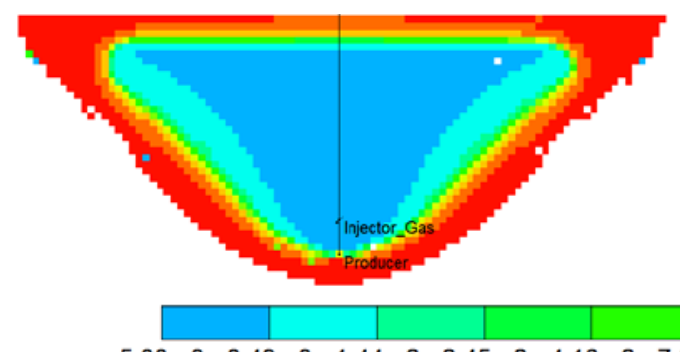

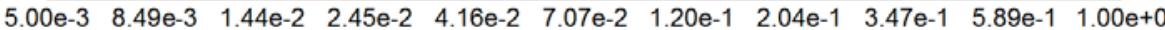

A

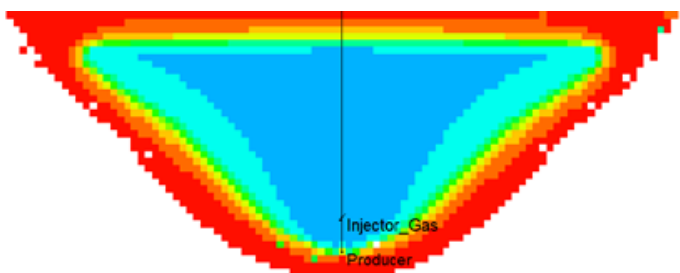

$\mathrm{B}$

Figure 3-5 Nitrogen mole fraction distribution of homogeneous model (A: 1 year after surfactants injection; B: 2 years after surfactants injection)

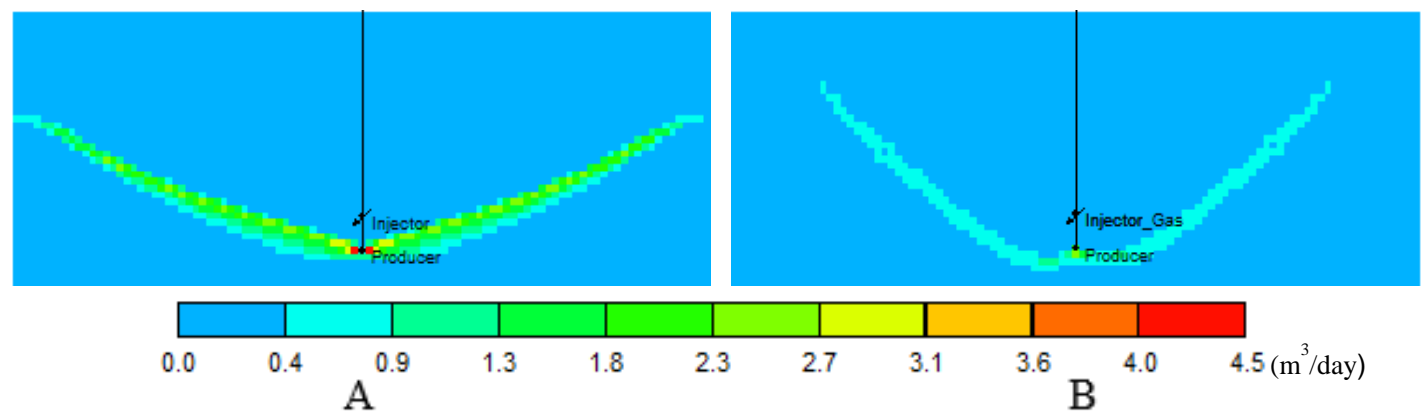

Figure 3-6 Oil flux distribution comparison of homogeneous model (1 year after surfactants injection) (m³/day) (A: SAGD; B: CAFA-SAGD)

Part of the reason is estimated to go to the specific water distribution. Higher condensate saturation at the steam front leads to a lower capillary pressure while lower water saturation inside the steam chamber produces a higher capillary pressure. According to Figure 2-3, strong foam tends to maintain its stability where water saturation is higher. As soon as the local capillary pressure exceeds the critical capillary pressure, strong foam collapses and turns into weak foam. Besides, the nitrogen distribution at the border intensifies the situation as the non-condensable gas favors foam stability compared to steam (Figure 3-5). Also, given the sensitivity to oil in the oil drainage path, strong foam only scatters around the inner border rather than the outer boundary. High oil displacement rate is liable to accelerate lamella rupture and bubbles collapse. 
The oil rate profiles in Figure 3-6 indicate that oil production is likely to be dramatically impeded as a result of foam generation even though a higher injection pressure is already introduced. Demanding a higher injection pressure is a necessity but a disadvantage for CAFA-SAGD.

\subsubsection{Interfacial Tension Reduction}

The molecules in the bulk liquid phase are exposed to an equal attraction force in different directions, thereby net force is summed to be zero. However, the molecules at the interface between the liquid phase and the gas phase (or solid phase or another liquid phase) suffer an attraction force from the molecules towards the liquid phase and another smaller attraction from the molecules towards the gas phase. The two forces exert towards the opposite directions. Therefore, the net force is directed towards the liquid phase. IFT (interfacial tension) is the force that holds the phase together and measured as the tension force per unit length. Normally, IFT decreases with the increasing temperature as the kinetic energy of molecules is higher. When the surfactants molecules are moved from the bulk liquid to the interface, additional energy is needed as the molecules at the interface has higher energy. It is also a function of pressure and the composition of each phase.

By definition, surfactants are the chemical additives which are able to lower IFT to a significant extent with an extremely low concentration (less than $1 \%$ ), changing the composition and structure of the interface. Generally, surfactants work as the molecules contain two types of groups, one is 
hydrophobic and the other one is hydrophilic. Based on the differences of group constitution, surfactants are classified into anionic surfactants (carboxylate surfactant, sulfonate surfactant, sulfate surfactant, etc.), cationic surfactants (quaternary ammonium surfactant, pyridinium surfactant, etc.), nonionic surfactants (AEO, etc.) and amphiphilic surfactants (betaine surfactant, taurine surfactants, etc.). Owing to the particular structures of surfactants molecules, they are easily absorbed at the interface. The hydrophobic tails give the molecules the tendency to escape the bulk liquid, while the hydrophilic heads resist. At first, the surfactants molecules distribute themselves at the interface at random. Then with the increase of surfactants concentration, they are arranged upright and organized (Figure 3-7). It is said that when the hydrophilic chains are similar, if there are more carbon atoms in the linear hydrocarbon chain of the hydrophobic groups, the surfactants are more easily absorbed at the interface. Also, nonionic surfactants have a larger absorption capacity compared to ionic surfactants under the same condition. For the ionic surfactants, reducing temperature and adding salt prompt the adsorption.
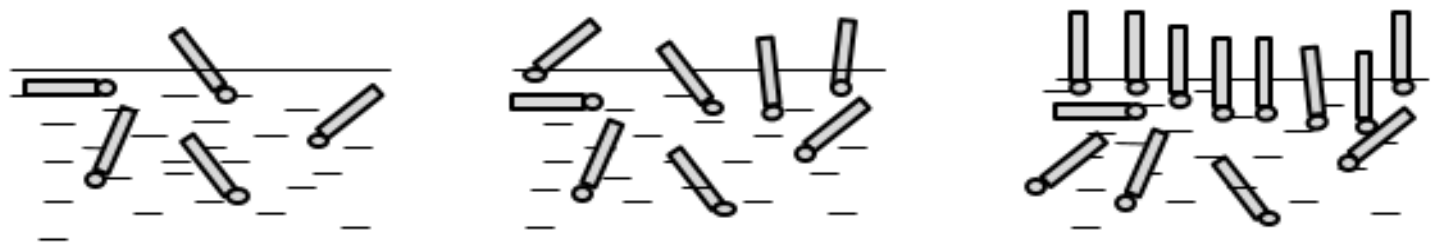

Figure 3-7 Surfactants molecules distribution with different concentration

Once the surfactants concentration exceeds a certain value, surfactants molecules associate 
themselves into colloidal aggregation to reduce the system energy and preserve stability. The value is defined as CMC (critical micelle concentration). According to Schramm (1994), CMC is a property of surfactants, which is reduced by increasing the molecular weight of hydrophobic groups, decreasing temperature and adding electrolyte or polar organic. Adding electrolyte works better for the ionic surfactants as the counter ions contained incorporate with the micelle to weaken the repulsion. The formation of micelle is conducive to solubilization, and the chemicals can be solubilized inside or at the surface of the micelle depending on its polarity.

The injection of surfactants is a prerequisite for foam generation and foam stability in particular. Bubbles are still able to be generated without surfactants. However, bubbles of this type are likely to be destroyed within a few seconds. The surfactant molecules are dedicated to maintain the lifetime of foam through combating the surface tension, retarding lamella thinning and impeding gas diffusion through lamella. This water-gas interface problem is already included in the previous section. Here we only discuss the water-oil interfacial tension reduction. The amphiphilic structure enables surfactants to be adsorbed at the interface and reduce the oil adhesion force at the rock surface. Oil is more likely to be taken away, the oil displacement efficiency is thus improved consequently. 

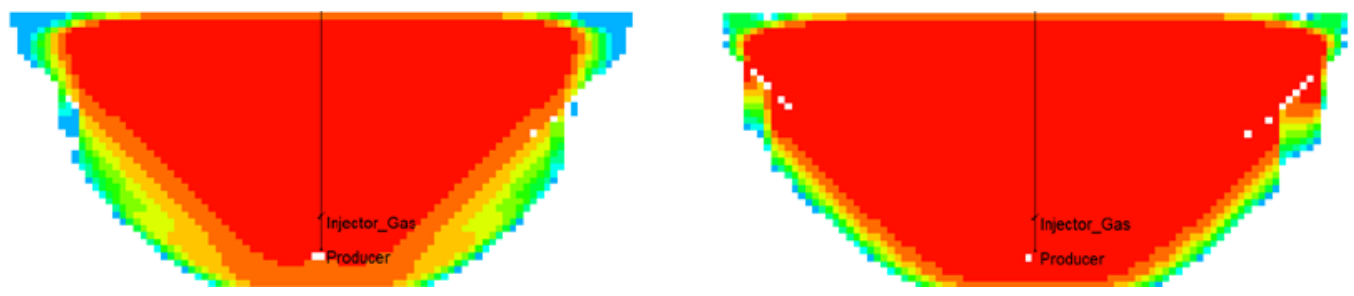

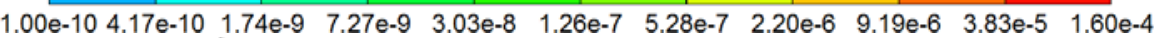
A Figure 3-8 Surfactants mole fraction distribution of homogeneous model (A: 1 year after surfactants injection; B: 2 years after surfactants injection)

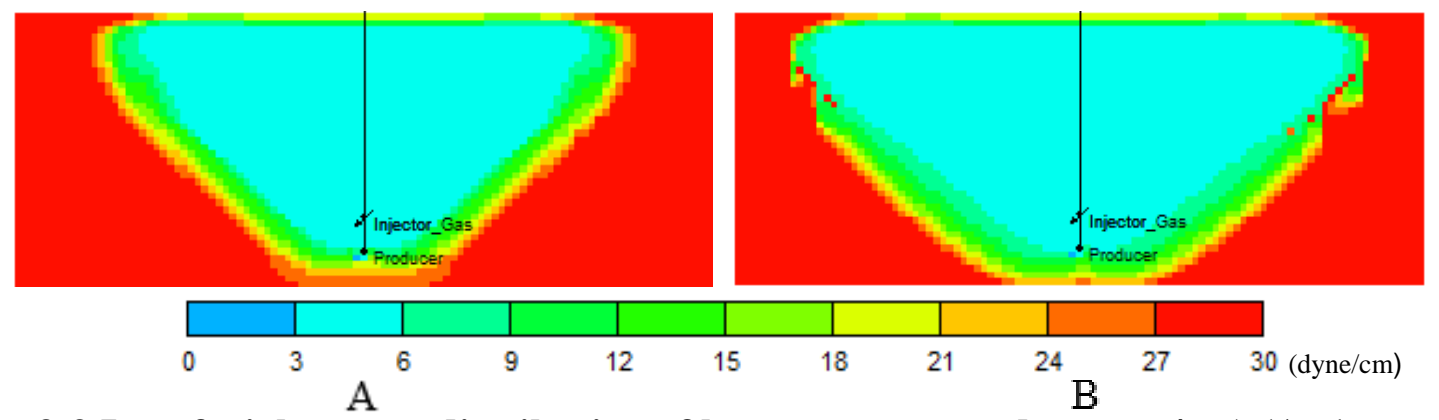

Figure 3-9 Interfacial tension distribution of homogeneous model (ayne/cm) (A: 1 year after surfactants injection; B: 2 years after surfactants injection)

Figure 3-8 shows how the surfactants distribute in the steam chamber. The farther from the injector, the smaller the concentration. Corresponding to Figure 3-8, Figure 3-9 shows that the surfactants injection modifies interfacial tension, which slides by approximately tenfold.

\subsubsection{Emulsification}

Emulsions belong to colloidal dispersion, in which at least one liquid phase is dispersed in another continuous liquid phase, and the two phases are immiscible. The dispersed phase is the internal phase and the continuous phase is the external phase. For the petroleum emulsions, the two phases are water and oil in most cases. The emulsions types are diverse and varies with different liquid 
properties and environment, for instance, $\mathrm{O} / \mathrm{W}$ (oil in water emulsions), W/O (water in oil emulsions), $\mathrm{W} / \mathrm{O} / \mathrm{W}$ (water in oil in water emulsions) and $\mathrm{O} / \mathrm{W} / \mathrm{O}$ (oil in water in oil emulsions). Normally, when the volume ratio is extremely large or small, the phase occupies a small volume is more likely to be the internal phase. Bancroft (1913) considered that the liquid which solubilized more emulsifier was the external phase. He also added that there were two interfacial tensions (water-film IFT and oil-film IFT) and the film tended to bend towards the higher IFT. Griffin (1946) adopted HLB (hydrophilic-lipophilic balance) to measure the surfactants' properties. A lower HLB signifies higher lipophilicity, whereas a higher HLB implies higher hydrophilicity. Experience indicates that W/O emulsions can be generated when HLB lies from 3 to 6 , and O/W emulsions can be formed when HLB ranges between 8 and 18. There are numerous discussions about which kind of emulsions exist during SAGD production, which is rather complicated and highly related to steam quality, water saturation and emulsifiers. Some people maintain that the high temperature and small density difference promote $\mathrm{O} / \mathrm{W}$ emulsification. There are also those who say $\mathrm{W} / \mathrm{O}$ is more generated.

Emulsions viscosity is an important property, which is influenced by the internal phase, external phase and emulsifier. For dilute emulsions, the Einstein equation can be used (Equation (3-2)).

$$
\eta_{r}=\frac{\eta}{\eta_{o}}=1+2.5 \varnothing
$$

where $\eta$ is the emulsions viscosity, $\eta_{o}$ is the external phase viscosity, and $\varnothing$ is the volume ratio of the internal phase. 
Considering the influence of the internal phase, Equation (3-2) is corrected into Equation (3-3).

$$
\eta_{r}=\frac{\eta}{\eta_{o}}=1+2.5\left(\frac{\eta_{i}+\frac{2}{5 \eta_{o}}}{\eta_{i}+\eta_{o}}\right) \emptyset
$$

where $\eta_{i}$ is the internal phase viscosity, $\eta_{r}$ falls between 1 and 6 , and $\varnothing$ is less than 0.16 .

The viscosity and rheology always change with the internal phase volume. Therefore a more complicated equation is needed (Equation (3-4)).

$$
\eta_{r}=1+a \emptyset+b \emptyset^{2}+c \emptyset^{3}+\cdots
$$

where $a, b$, and $c$ are empirical constants.

The properties of an interfacial film determines the emulsions stability. If the absorbed molecules at the interface are arranged closely and tightly, and the film has enough strength and elasticity to prevent coalescence, the emulsions can be stable. Also, if the repulsive force between droplets exceeds the van der Waals force, the stability is more easily to be preserved. Therefore, it is advantageous to enlarge the surface potential (Schramm, 1992). We only consider emulsions generation and emulsion trapping in this study.

With regard to heavy oil reservoirs, an adverse mobility ratio instead of capillary pressure accounts more for the immobilization of the residual oil (Bryan and Kantzas, 2007). They claim that interfacial tension reduction is not a primary mechanism consequently, while emulsification dominates instead. The reduction of interfacial tension and shear induced instability at the water- 
oil interface promotes the in-situ emulsification of oil in water and the solubilization of residual oil. Oil displacement by water entrainment contributes to a higher displacement efficiency. Simultaneously, the emulsions droplets accumulation forms the Jamin effect, which develops flow resistance and improves the sweep efficiency. Wang and Dong (2010) concluded that the formation of $\mathrm{O} / \mathrm{W}$ emulsions was able to impede water flow by entrapment in a porous medium and diverted water into the region not being swept yet, which corresponding to the filtration theory provided by Soo and Radke (1984). In this model, we regard the O/W emulsions as a product of water, oil and surfactants. The generation of $\mathrm{O} / \mathrm{W}$ emulsions poses flow resistance for water flow by straining and interception in the porous medium, which is represented by introducing a resistance factor towards the water relative permeability.

$\mathrm{O} / \mathrm{W}$ emulsions mostly distribute around the steam chamber border, which is attributable to the small density difference and instantaneous hydrodynamic instability there (Figure 3-10). However, the blockage effect by emulsions is not discussed due to a high permeability for the homogeneous model. Compared to Figure 3-9, Figure 3-11 shows that the interfacial tension reduction area shrinks. The speculated reason is that a certain amount of surfactants is employed to produce emulsions when the total surfactants amount is given. 


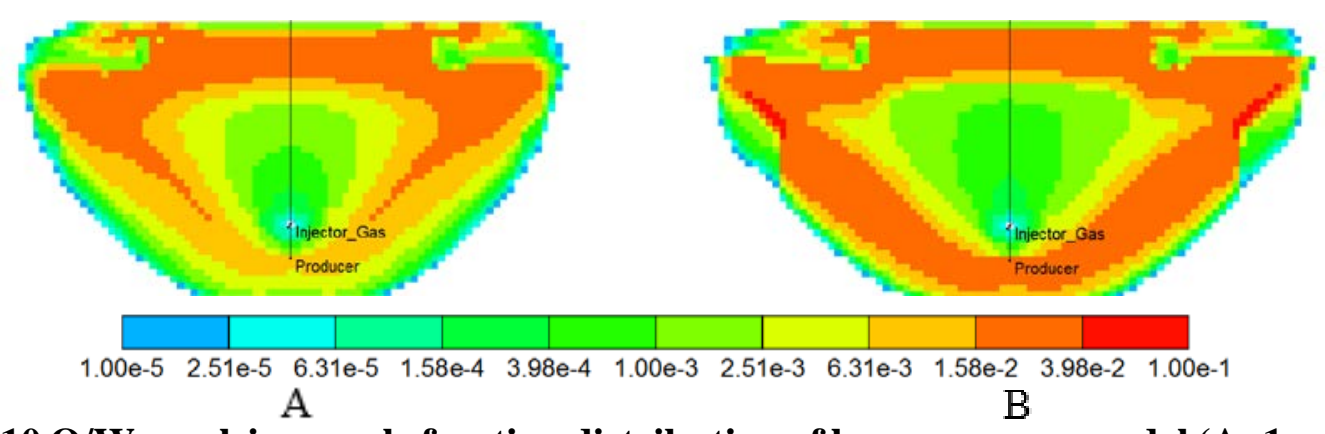

Figure 3-10 O/W emulsions mole fraction distribution of homogeneous model (A: 1 year after surfactants injection; B: 2 years after surfactants injection)

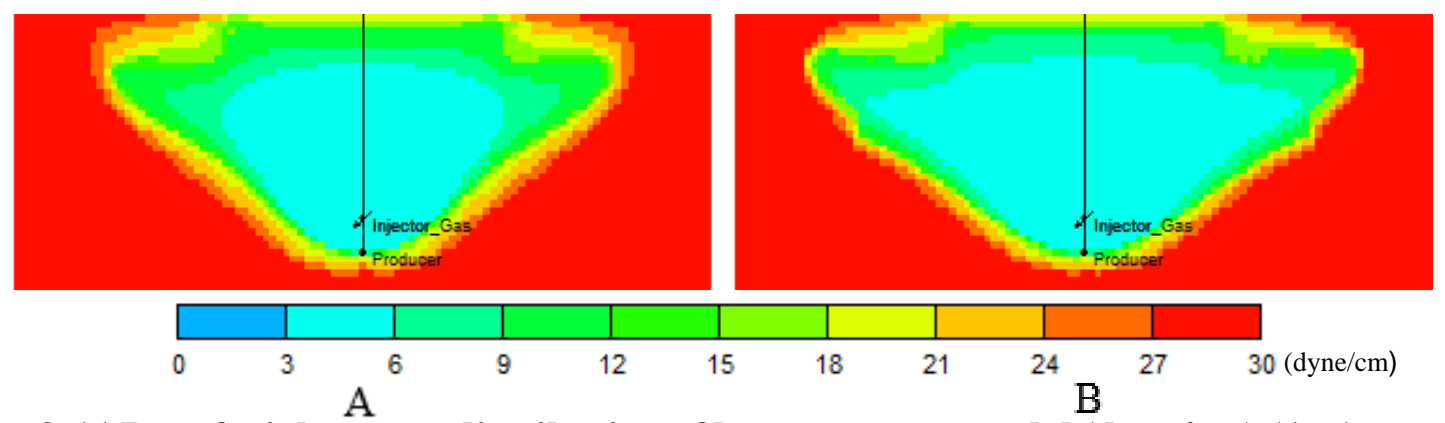

Figure 3-11 Interfacial tensıon distribution of homogeneous model (dyne/cm) (A: 1 year after surfactants injection; B: 2 years after surfactants injection)

\subsection{Results Comparison between SAGD and CAFA-SAGD and Interpretation}

Figure 3-12 shows that oil is more depleted in the steam chamber of CAFA-SAGD. According to Figure 3-13, it is noticed that the oil rate of SAGD roars sharply to an all-time record after the preheating period before initiating a slightly fluctuated collapse in the later stage. On this account, the oil rate of SAGD outnumbers that of CAFA-SAGD right after surfactants injection. This gap is closely involved with the mobility reduction of steam, the decrease of the heat front velocity and the drop of the driving forces. Moreover, the nitrogen injected to generate foam carries lower temperature compared to that of steam, disturbing the temperature field and aggravating the situation. But later on after SAGD exhausts the formation energy and enters the depletion 
production mode, and the oil rate of CAFA-SAGD overtakes that of SAGD due to higher displacement efficiency and volumetric sweep efficiency introduced by gas mobility control, IFT reduction and emulsification. Unlike SAGD, whose oil yields almost reach a plateau after a dramatic rise, CAFA-SAGD preserves a rather constant oil rate for more than 10 years after 2017. It shows that CAFA-SAGD is liable to promote the oil production efficiently and maintain a steady production mode rather than adopting a quickly attenuate pattern.

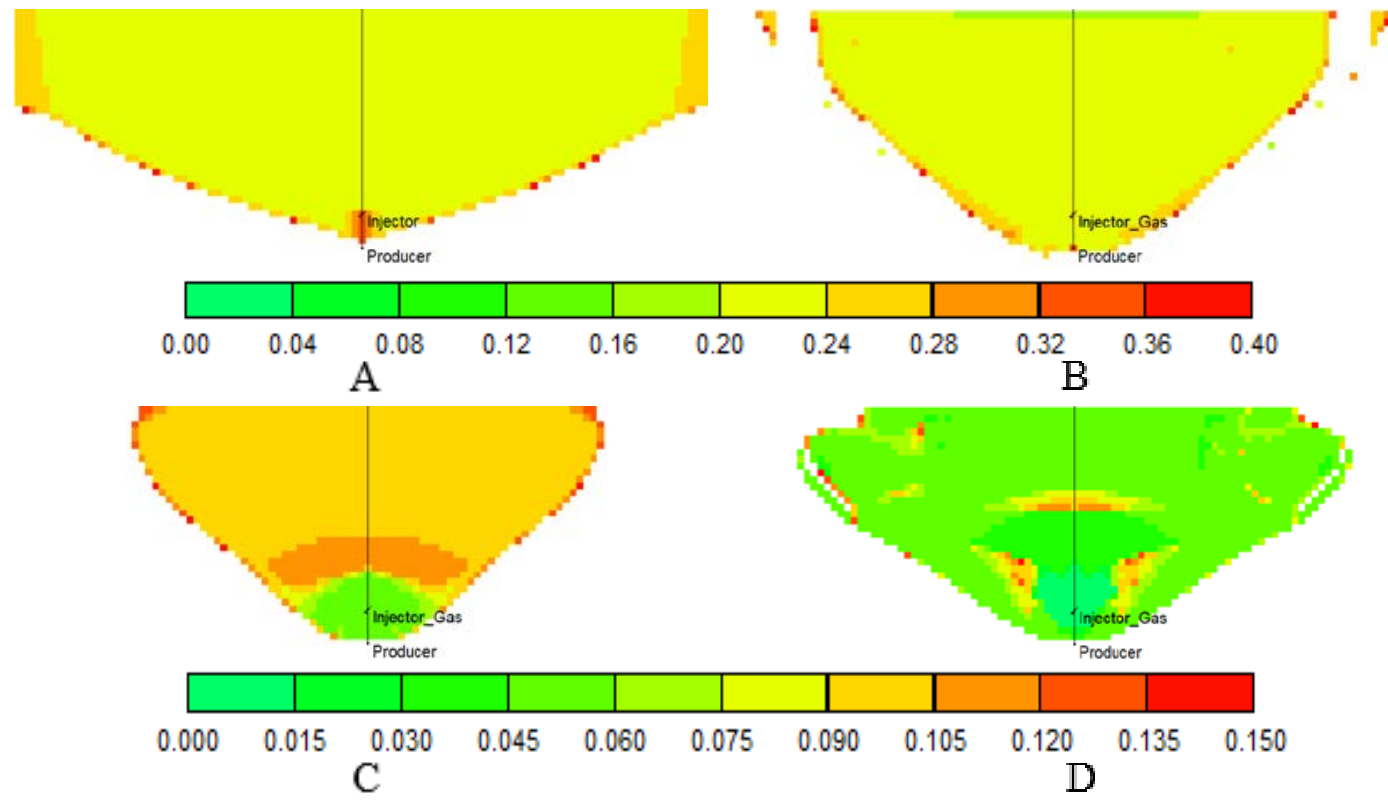

Figure 3-12 Oil saturation distribution comparison of homogeneous model (2 years after surfactants injection) (A: SAGD; B: CAFA-SAGD with gas mobility reduction; C: CAFASAGD with gas mobility reduction and interfacial tension reduction; D: CAFA-SAGD with gas mobility reduction, interfacial tension reduction and emulsification)

However, it is unreasonable to carry out CAFA-SAGD operation for several decades. The time for the oil rate to recover, which is controlled by surfactant properties, foam strength, temperature, 
pressure and reservoir characteristics, is required to be shortened. A higher injection pressure is able to push steam forward, accelerate early expansion of its steam chamber and maintain a reasonable oil rate. In addition, adjusting properly the strength of bubbles is another way out.

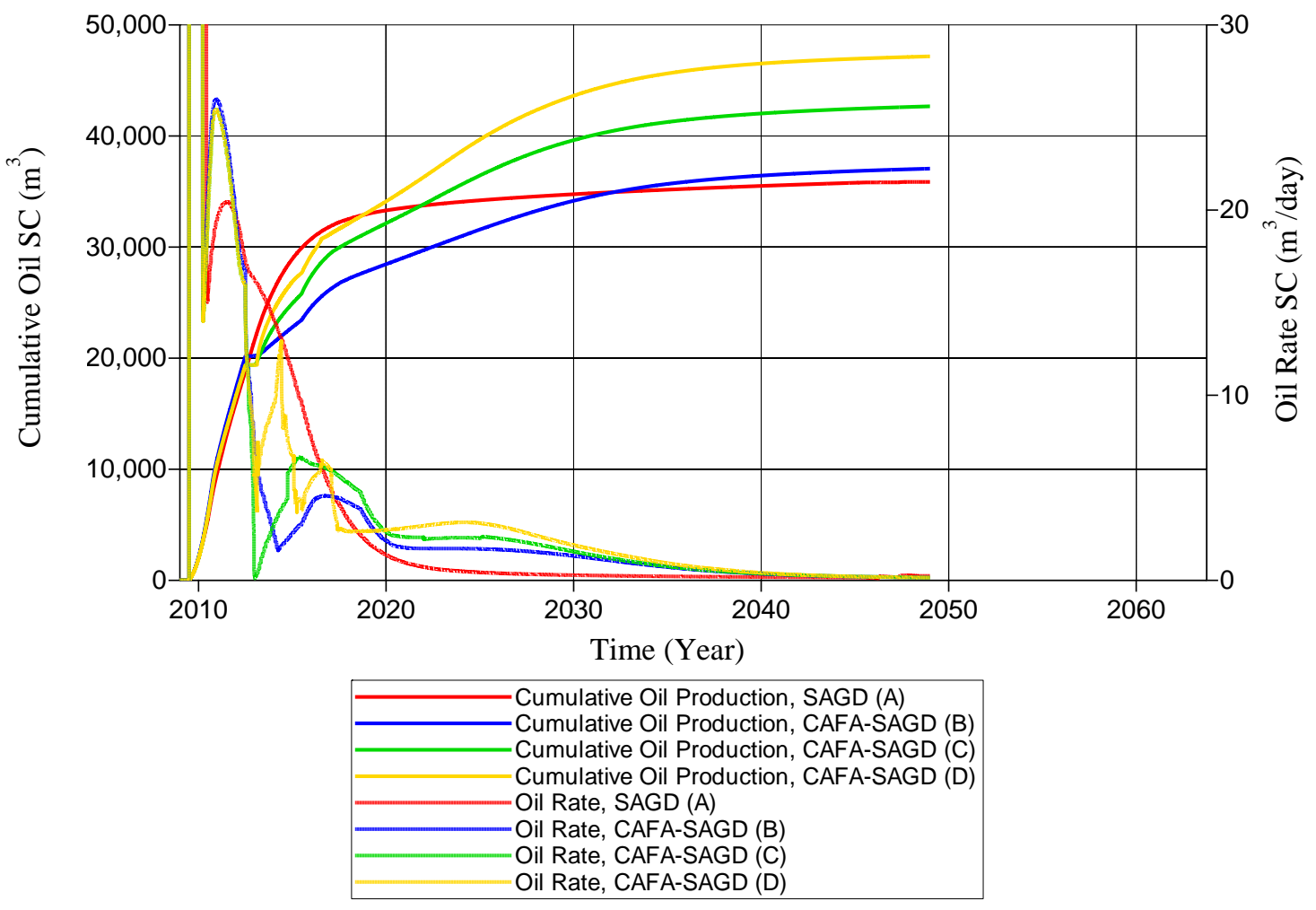

Figure 3-13 Cumulative oil production and oil rate comparison of homogeneous model (A: SAGD; B: CAFA-SAGD with gas mobility reduction; C: CAFA-SAGD with gas mobility reduction and interfacial tension reduction; D: CAFA-SAGD with gas mobility reduction, interfacial tension reduction and emulsification)

By comparison, all the mechanisms contribute to oil recovery enhancement (Figures 3-12, 3-13).

Gas mobility control and a higher injection pressure brings about more thorough oil drainage, a

3.34\% increase in oil production is obtained finally. There are some $1200 \mathrm{~m}^{3}$ more oil displaced. 
Interfacial tension reduction adds $15.13 \%$ more by mobilizing residual oil on this basis, which raises oil output from $37,063 \mathrm{~m}^{3}$ to $42,670 \mathrm{~m}^{3}$. In addition, emulsification makes further efforts to produce $10.54 \%$ more oil through water entrainment. For this homogeneous model, emulsification mainly contributes to the oil production through mobilizing residual oil by entrainment. To sum up, there are about $47170 \mathrm{~m}^{3}$ oil produced in CAFA-SAGD.

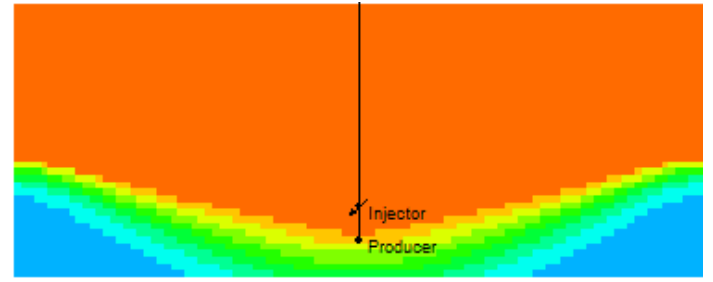

A

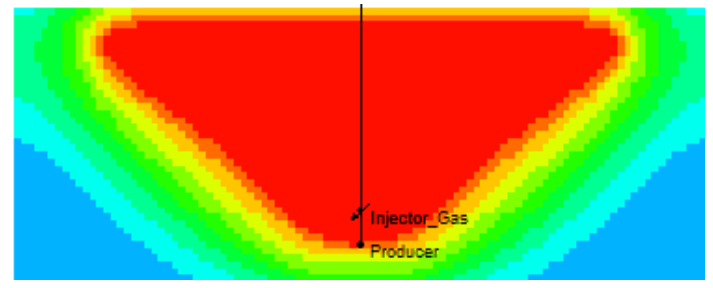

$\mathrm{C}$

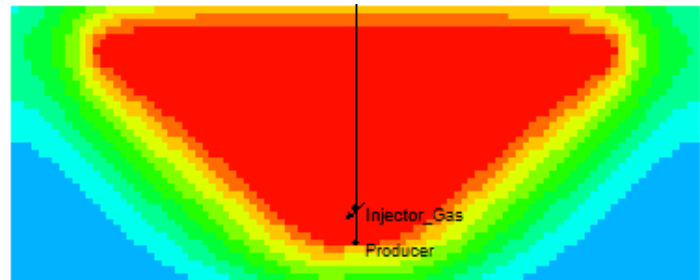

B

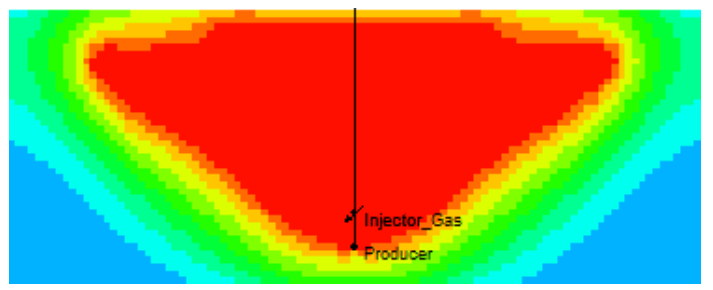

$\mathrm{D}$

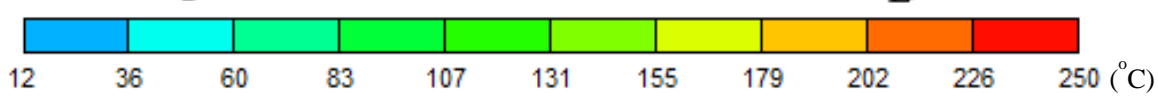

Figure 3-14 Temperature distribution comparison of homogeneous model (1 year after surfactants injection) $\left({ }^{\circ} \mathrm{C}\right)$ (A: SAGD; B: CAFA-SAGD with gas mobility reduction; C: CAFA-SAGD with gas mobility reduction and interfacial tension reduction; D: CAFASAGD with gas mobility reduction, interfacial tension reduction and emulsification)

From Figure 3-14, the steam chamber of CAFA-SAGD has a smaller expansion rate as the existence of strong foam restricts the lateral extension of the steam chamber wings at the overburden efficiently. The contact area with the overburden formation is reduced, and thus less 
heat escapes and more energy is diverted into oil displacement. In contrast, the steam chamber of SAGD spreads quickly and achieves an enormous heat exchange with overburden, which exposes the steam chamber to experience more heat loss and achieve lower efficiency. It resembles the comparison between a quickly developed fingering advancement and a slow piston-like displacement. Meanwhile, Figure 3-4 demonstrates that weak foam exists between the injector and producer. Foam not only blocks the steam front movement but also prevents steam from entering into the producer. This does favor to a steam trap control to some extent.

It can be seen that SOR drops sharply by $25.06 \%$ owing to gas mobility control. Both interfacial tension reduction and emulsification reduce SOR by around 10\% further according to Figure 315. Consequently, gas mobility reduction exerts more in increasing steam heating efficiency and reducing heat loss to lower SOR. It merely helps a little to oil production due to higher injection pressure. However, in the case of heterogeneous reservoirs, it is estimated that gas mobility reduction work better to improve oil production through diverting steam into a low-permeable area and protecting a uniformly growing steam chamber. In contrast, interfacial tension reduction and emulsification act more in an oil production increase. The water redistribution effect will be discussed with a heterogeneous model later on. The reduction of SOR relies more on additional oil output instead of steam conservation. 


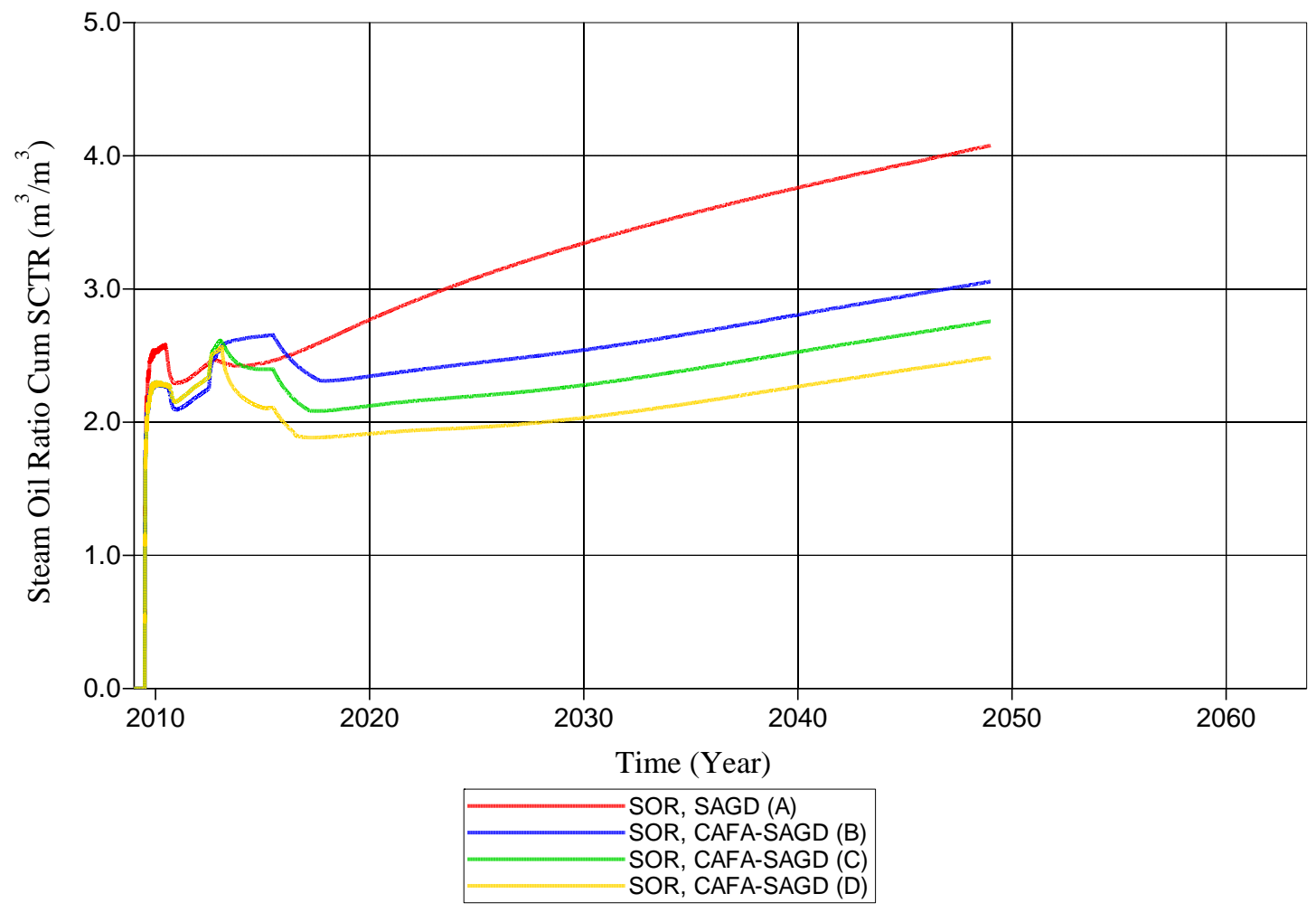

Figure 3-15 SOR comparison of homogeneous model (A: SAGD; B: CAFA-SAGD with gas mobility reduction; C: CAFA-SAGD with gas mobility reduction and interfacial tension reduction; D: CAFA-SAGD with gas mobility reduction, interfacial tension reduction and emulsification)

\subsection{Discussion and Analysis}

\subsubsection{Discussion of Injection Scheme}

Due to the high cost of chemical additives, it is not affordable to inject surfactants constantly from beginning to end. It is more economically efficient to inject a surfactants slug and resume pure steam injection afterwards. But how to design the start time of the chemical additives slug injection, the length of the injection period and the injection interval remain a challenge. 


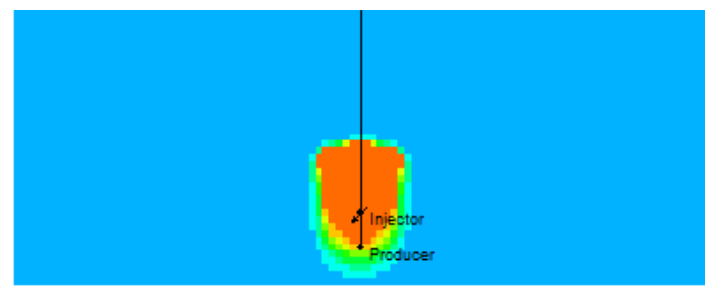

A
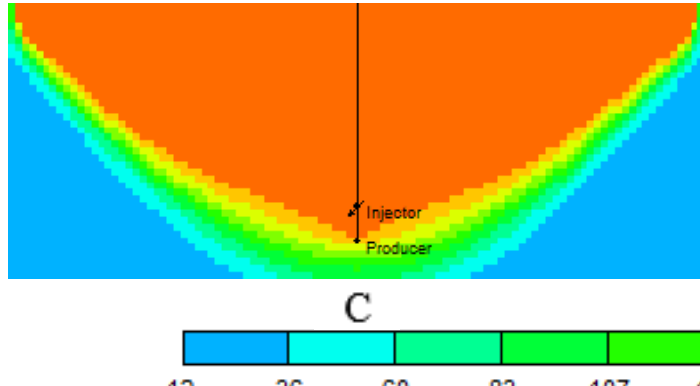

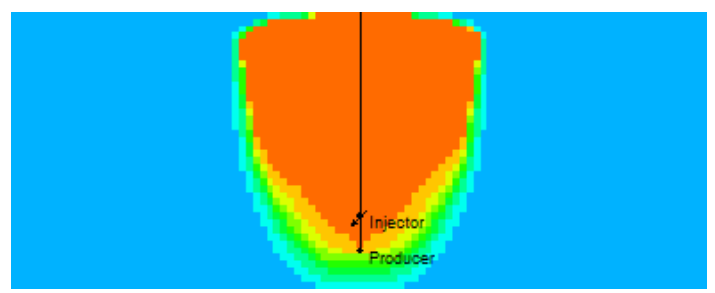

B

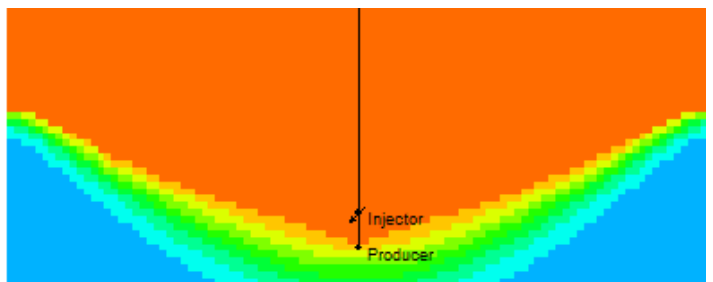

$\mathrm{D}$

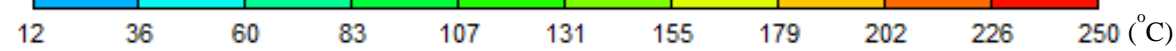

Figure 3-16 Injection start time study of homogeneous model $\left({ }^{\circ} \mathrm{C}\right)$ (A: 09Year11Month; B: 10Year08Month; C: 12Year10Month; D: 13Year07Month)

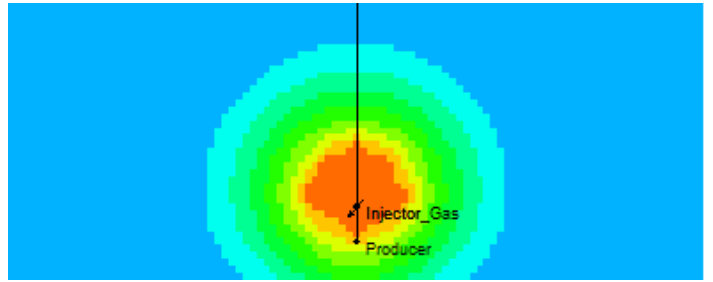

A

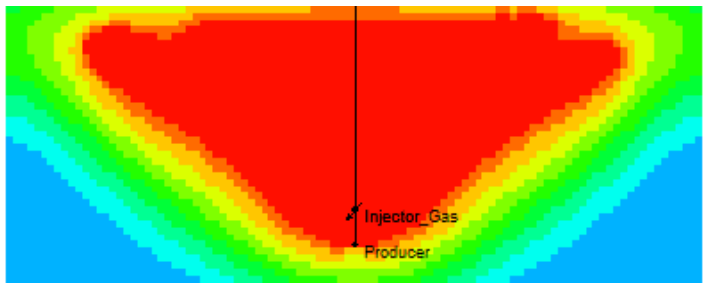

$\mathrm{C}$

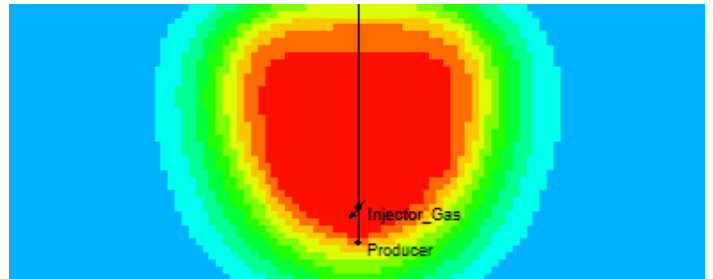

B

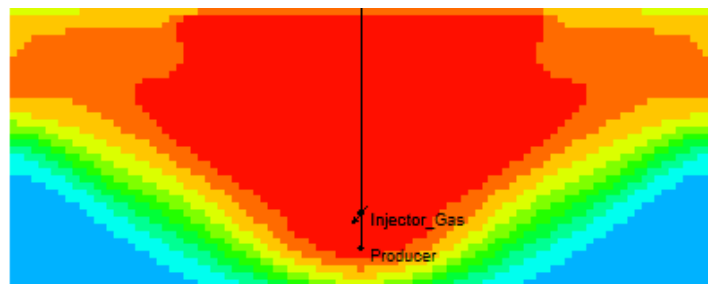

D

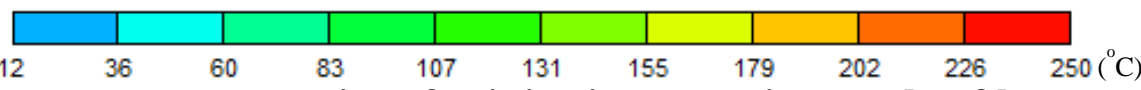

Figure 3-17 Temperature comparison for injection start time study of homogeneous model (14Year01Month) $\left({ }^{\circ} \mathrm{C}\right)$ (A: 09Year11Month; B: 10Year08Month; C: 12Year10Month; D: 13Year07Month)

Firstly, we change the start time to be before the steam chamber contacts the overburden (November, 2009), when the rising chamber just reaches the overburden (August, 2010), when the 
growing chamber wings just reach the ends (October, 2012), when the chamber height is reducing (July, 2013), while maintaining the surfactants injection period to be 3 years like the original CAFA-SAGD case (July, 2012) (Figure 3-16). As seen in Table 3-2, the original case obtains the highest oil production while injecting surfactants when the rising chamber just reaches the overburden receives the lowest SOR. The root cause lies in the severe suppression of steam chamber vertical growth and lateral expansion in the early stage when injecting surfactants too early, which calls for an extremely long time for the oil output to be resumed. But injecting surfactants too late fails to control the steam chamber growth timely and efficiently and a considerable amount of heat may have lost already, which is quite difficult to be remedied (Figure 3-17). It is recommended to inject chemical additives after the rising chamber just reaches the overburden and before the growing chamber wings just reach the ends for this model.

Table 3-2 Performance comparison for injection start time study of homogeneous model (A: 09Year11Month; B: 10Year08Month; C: 12Year10Month; D: 13Year07Month)

\begin{tabular}{|c|c|c|c|c|}
\hline Case & $\begin{array}{c}\text { Cumulative Oil } \\
\text { Production (1/3 } \\
\text { stage) } \mathrm{m}^{3}\end{array}$ & $\begin{array}{c}\text { Cumulative Oil } \\
\text { Production (2/3 } \\
\text { stage), } \mathrm{m}^{3}\end{array}$ & $\begin{array}{c}\text { Cumulative Oil } \\
\text { Production (total), } \\
\mathrm{m}^{3}\end{array}$ & SOR, $\mathrm{m}^{3} / \mathrm{m}^{3}$ \\
\hline $\begin{array}{c}\text { Original } \\
\text { Case }\end{array}$ & $3.63 \mathrm{e} 4$ & $4.56 \mathrm{e} 4$ & $4.72 \mathrm{e} 4$ & 2.49 \\
\hline A & $1.16 \mathrm{e} 4$ & $3.95 \mathrm{e} 4$ & $4.52 \mathrm{e} 4$ & 2.57 \\
\hline B & $2.04 \mathrm{e} 4$ & $4.01 \mathrm{e} 4$ & $4.49 \mathrm{e} 4$ & 2.44 \\
\hline C & $3.79 \mathrm{e} 4$ & $4.42 \mathrm{e} 4$ & $4.52 \mathrm{e} 4$ & 2.57 \\
\hline D & $4.03 \mathrm{e} 4$ & $4.46 \mathrm{e} 4$ & $4.55 \mathrm{e} 4$ & 2.62 \\
\hline
\end{tabular}

Another major issue is to measure the influence of a surfactants injection period ( 1 year, 2 years 
and 3 years) while ensuring the same injection start time (July, 2012). From Table 3-3, it is obvious that injecting surfactants after 3 years pure steam injection and sustaining it for 3 years can provide the best outcome in terms of oil production and SOR. If the chemical additives are not enough, foam and emulsions cannot be sufficiently generated and the steam efficiency cannot be guaranteed. But the economic efficiency calls for a further discussion.

Table 3-3 Performance comparison for surfactants injection period study of homogeneous model (A: 1 year; B: 2 years)

\begin{tabular}{|c|c|c|c|c|}
\hline Case & $\begin{array}{c}\text { Cumulative Oil } \\
\text { Production (1/3 } \\
\text { stage), } \mathrm{m}^{3}\end{array}$ & $\begin{array}{c}\text { Cumulative Oil } \\
\text { Production (2/3 } \\
\text { stage) } \mathrm{m}^{3}\end{array}$ & $\begin{array}{c}\text { Cumulative Oil } \\
\text { Production (total), } \\
\mathrm{m}^{3}\end{array}$ & SOR, $\mathrm{m}^{3} / \mathrm{m}^{3}$ \\
\hline $\begin{array}{c}\text { Original } \\
\text { Case }\end{array}$ & $3.63 \mathrm{e} 4$ & $4.56 \mathrm{e} 4$ & $4.72 \mathrm{e} 4$ & 2.49 \\
\hline A & $3.85 \mathrm{e} 4$ & $4.51 \mathrm{e} 4$ & $4.59 \mathrm{e} 4$ & 2.71 \\
\hline B & $3.53 \mathrm{e} 4$ & $4.42 \mathrm{e} 4$ & $4.56 \mathrm{e} 4$ & 2.60 \\
\hline
\end{tabular}

Also, our intention is to understand whether the surfactants should be injected continuously or in a slug format. There are 4 cases in which surfactants injection intervals are different (Case A: injecting surfactants every 1 year, Case B: injecting surfactants every 3 months, Case C: injecting surfactants with the interval to be 1, 3, 5, 7, 9 and 11 months separately, Case D: injecting surfactants with the interval to be 11, 9, 7, 5, 3 and 1 months in turn). From Table 3-4, constant surfactants injection achieves the highest oil production which consumes more chemical additives, while injecting surfactants every 3 months has the lowest SOR. It is estimated that alternative injection poses threat to bubbles stability as the both liquid flow and gas flux changes from time 
to time. On one hand, it guarantees the oil flow rate recovery when strong bubbles rupture. On the other hand, it restricts the steam chamber growth rate to some degrees. Thus it can strike a balance to gain the best outcome after being properly designed.

Table 3-4 Performance comparison for surfactants injection method study of homogeneous model

\begin{tabular}{|c|c|c|c|c|}
\hline Case & $\begin{array}{c}\text { Cumulative Oil } \\
\text { Production (1/3 } \\
\text { stage) } \mathrm{m}^{3}\end{array}$ & $\begin{array}{c}\text { Cumulative Oil } \\
\text { Production (2/3 } \\
\text { stage) } \mathrm{m}^{3}\end{array}$ & $\begin{array}{c}\text { Cumulative Oil } \\
\text { Production (total), } \\
\mathrm{m}^{3}\end{array}$ & $\mathrm{SOR}, \mathrm{m}^{3} / \mathrm{m}^{3}$ \\
\hline $\begin{array}{c}\text { Original } \\
\text { Case }\end{array}$ & $3.63 \mathrm{e} 4$ & $4.56 \mathrm{e} 4$ & $4.72 \mathrm{e} 4$ & 2.49 \\
\hline A & $3.61 \mathrm{e} 4$ & $4.34 \mathrm{e} 4$ & $4.53 \mathrm{e} 4$ & 2.46 \\
\hline B & $3.71 \mathrm{e} 4$ & $4.44 \mathrm{e} 4$ & $4.63 \mathrm{e} 4$ & 2.37 \\
\hline C & $3.64 \mathrm{e} 4$ & $4.34 \mathrm{e} 4$ & $4.53 \mathrm{e} 4$ & 2.40 \\
\hline D & $3.90 \mathrm{e} 4$ & $4.56 \mathrm{e} 4$ & $4.72 \mathrm{e} 4$ & 2.62 \\
\hline
\end{tabular}

\subsubsection{CAFA-SAGD Application for Multiple Well Pairs}

Usually, several well pairs are drilled to corporate as the drainage area of one well pair is limited.

We want to discover how chemical additives, generated foam and emulsions distribute between the well pairs.

Figure 3-18 tells that strong foam is mainly accumulated at the top to decrease the heat exchange with overburden, which is consistent with the situation of single well pair. Also, it gathers at the bottom of the contact area between two steam chambers, helping to slow down a chamber height reducing rate. Those areas mostly have low oil saturation and low temperature, beneficial to the 
stability of bubbles (Figures 3-19, 3-20 and 3-21). In addition, a certain amount of foam with certain strength spreads at the top of the contact area between the two chambers, probable to upset enthalpy communication between chambers and affect the overall oil production. Figure 3-22 tells that emulsions droplets still gather around the inner border of the steam chamber and they are able to be generated around the contact region between the steam chambers.

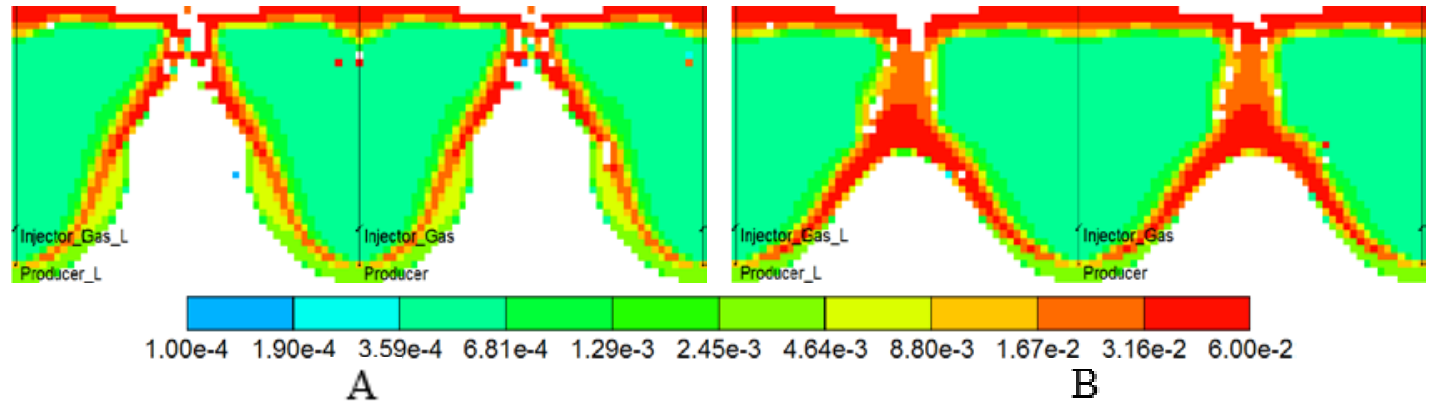

Figure 3-18 Lamella mole fraction distribution model for multiple well pairs study of homogeneous (A: 1 year after surfactants injection; B: 2 years after surfactants injection)

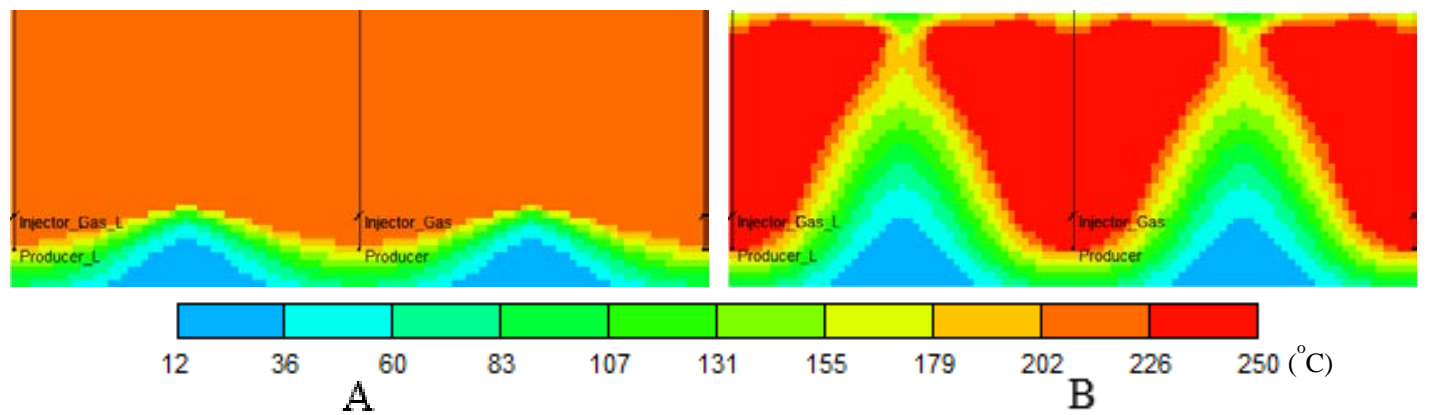

Figure 3-19 Temperature distribution comparison model for multiple well pairs study of homogeneous (1 year after surfactants injection) $\left({ }^{\circ} \mathrm{C}\right)$ (A: SAGD; B: CAFA-SAGD) 


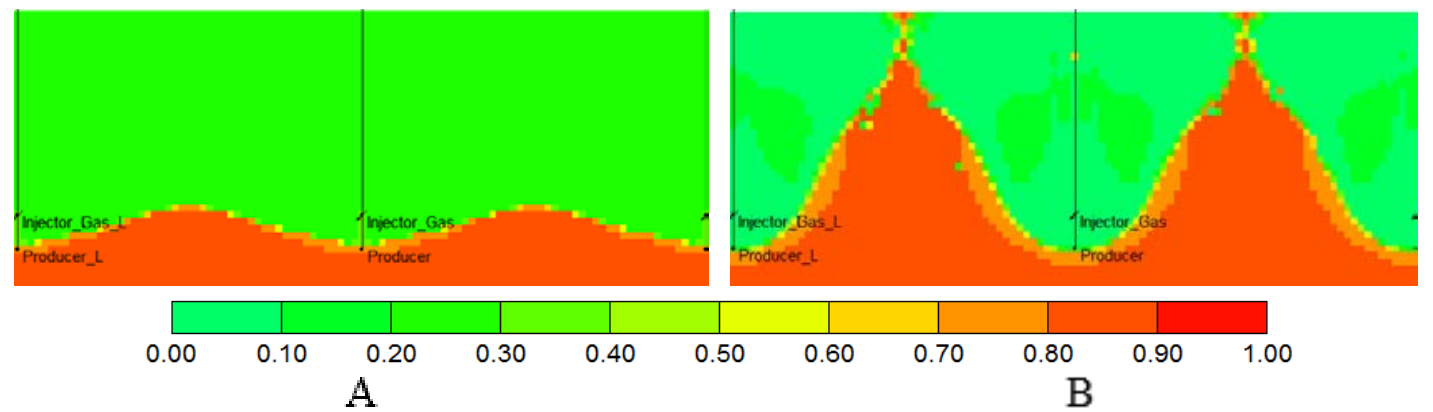

Figure 3-20 Oil saturation comparison model for multiple well pairs study of homogeneous model (1 year after surfactants injection) (A: SAGD; B: CAFA-SAGD)

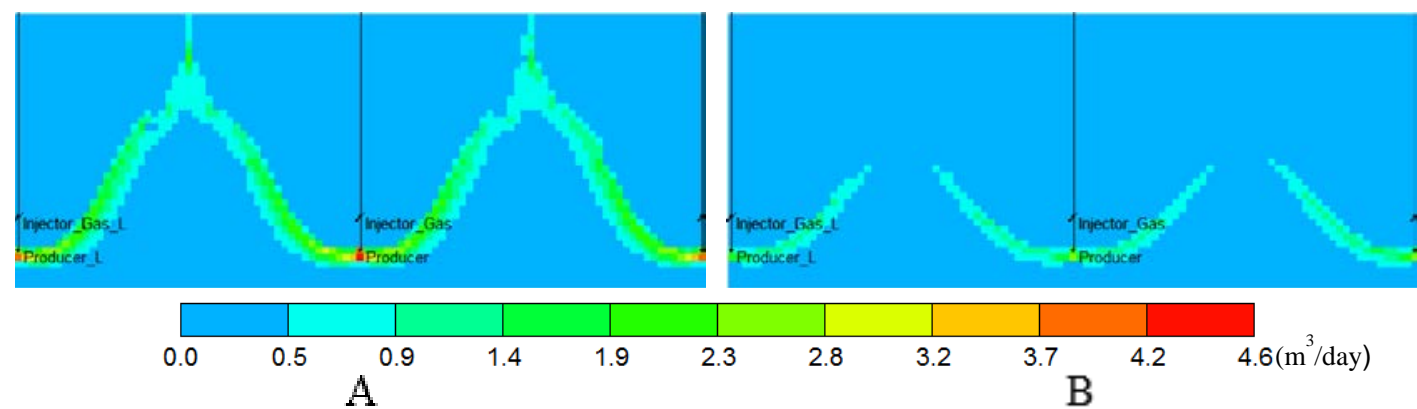

Figure 3-21 Oil flux distribution model for multiple well pairs study of homogeneous model ( $\mathrm{m}^{3} /$ day) (A: 1 year after surfactants injection; B: 2 years after surfactants injection)

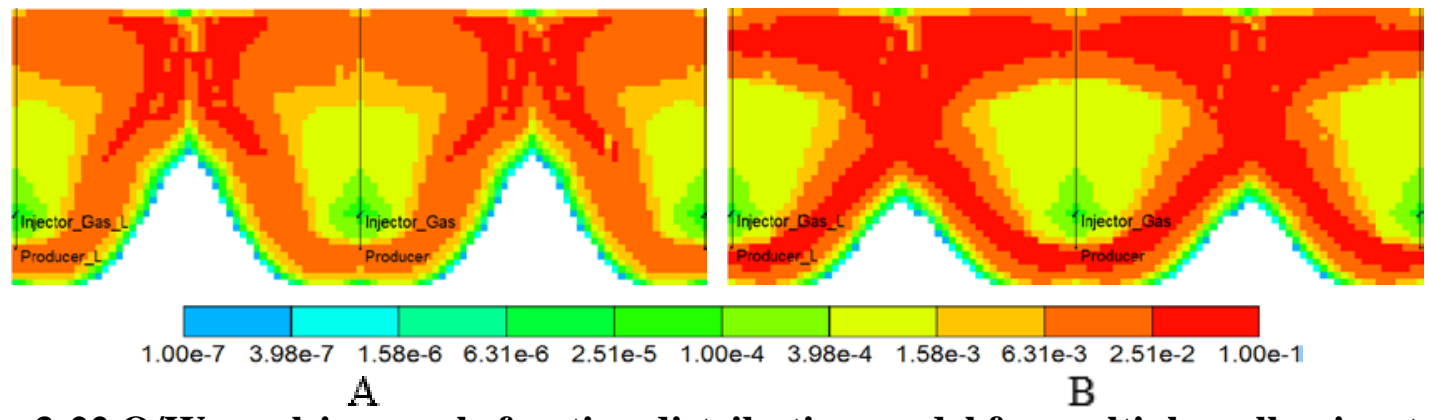

Figure 3-22 O/W emulsions mole fraction distribution model for multiple well pairs study of homogeneous model (A: 1 year after surfactants injection; B: 2 years after surfactants injection)

\subsection{Conclusions}

We have analyzed the main mechanisms involved in CAFA-SAGD with a homogeneous model.

It shows that the injection of chemical additives and generation of foam cut down steam 
consumption and preserve heat efficiency through controlling the steam chamber profile. Also, extra considerable oil output is claimed as a result of interfacial tension reduction and emulsification. In addition, it is suggested that chemical additives should be injected after the steam chamber achieves an enough expansion area. The choice of an injection scheme should be based on the analysis of the reservoir properties. Lastly, CAFA-SAGD is analyzed and testified to be beneficial to multiple well pairs. 


\section{CHAPTER 4: HETEROGENEOUS MODEL}

Last chapter elaborates on the distribution of surfactants, bubbles and emulsions with a homogeneous model, by which, it further elucidates the dominant mechanisms involved with CAFA-SAGD. CAFA-SAGD is verified to be more efficient over SAGD by means of controlling steam movement and improving oil production. However, it never come down to how CAFASAGD behaves in a heterogeneous situation and it is thus far away from a real field application.

Ali et al. (1997) considered the geology and heterogeneity of a reservoir as a threat towards the uniform formation of a steam chamber and the final performance would be modified with certainty. It is obvious that the low-permeable formations have little chance to be exposed to steam, and most of steam may escape though a high-permeable area with less resistance. Likewise, the intercepted water layers and surrounding water zones may further disturb the temperature field and transform the steam chamber. It is speculated that heterogeneity is also likely to convert distribution pattern of chemical additives and impact CAFA-SAGD's final yields. In this chapter, a heterogeneous geological model is built with Petrel Software and matched according to the recorded data of a Suncor's Firebag project in AccuMap Software to test the possible influences of heterogeneity towards CAFA-SAGD and verify whether CAFA-SAGD can be employed to help to combat the influences and maintain a uniformly-developed steam chamber. 


\subsection{Firebag Geological Model}

\subsubsection{Suncor's Firebag Project Introduction}

Suncor's Firebag project locates 40 km northeast of the original oil sands plant, which lies between

Fort McMurray and Fort MacKay (Figure 4-1). Surface mining was applied to exploit the reserved resources at the very beginning. After a few decades, SAGD was put forward to target the bitumen in 2003, which was not able to be exploited by at early stage (Gaviria et al., 2007). Currently, there are 11 SAGD pads (Pads 101-108, 108N and Pads 115-116) in operation (Figure 4-2). The oil production is averaged to be $28,201 \mathrm{~m}^{3} /$ day in total with SOR at approximately 2.71 (Suncor Firebag SAGD Report, 2015).

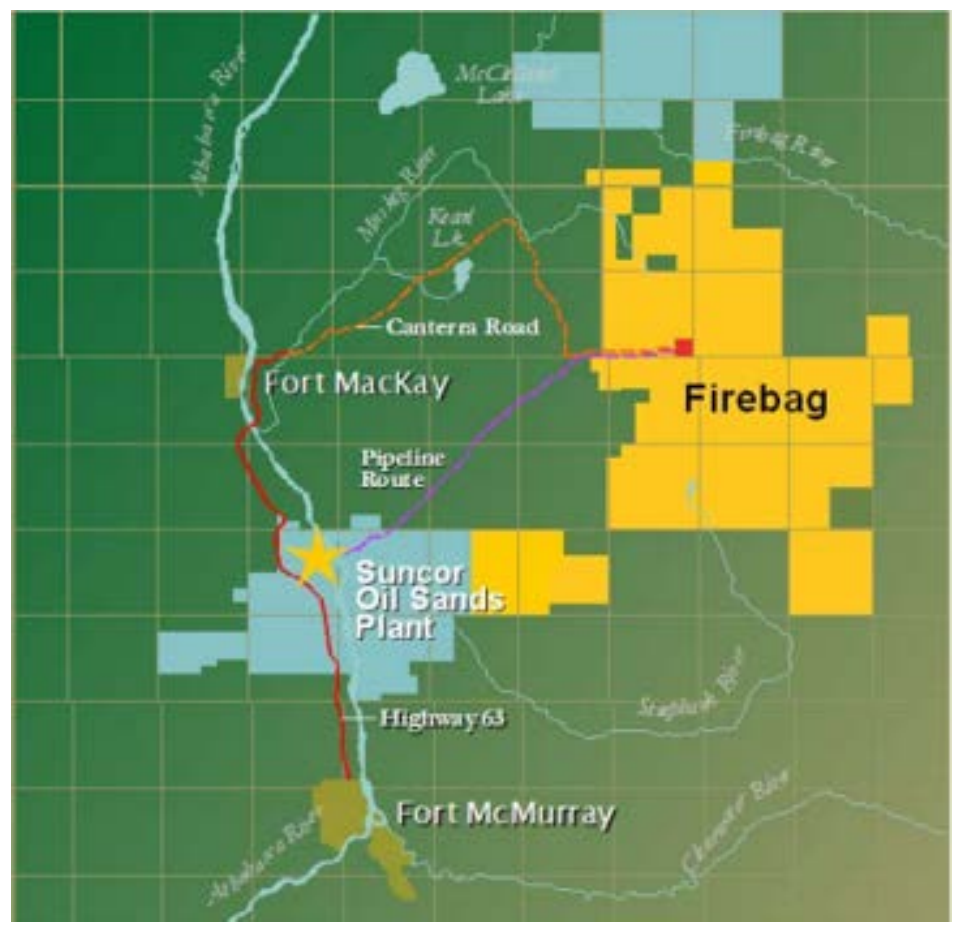

Figure 4-1 Suncor’s Firebag project location (Suncor Firebag SAGD Report, 2006) 


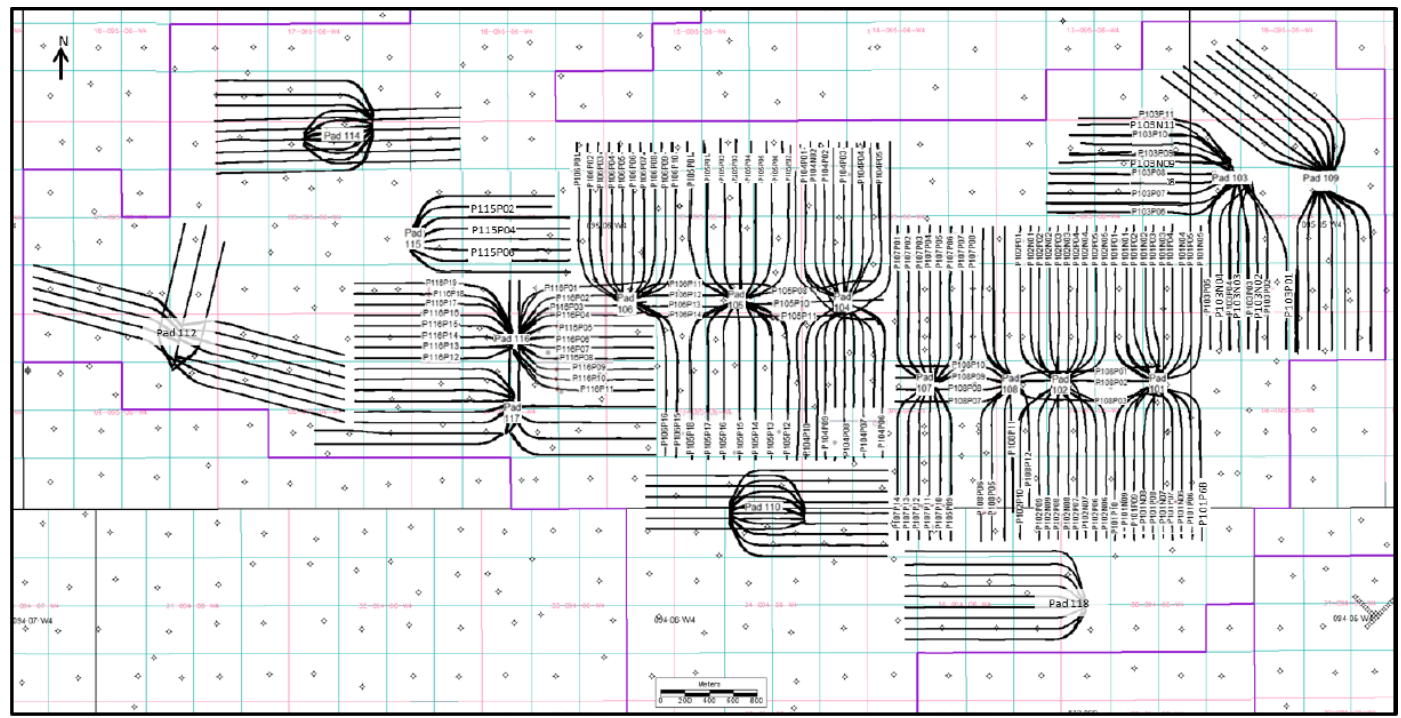

Figure 4-2 Suncor's Firebag well pads distribution map (Suncor Firebag SAGD Report, 2006)

\subsubsection{Geology}

The Firebag stratigraphic chart is shown below (Figure 4-3). The Grand Rapids formation, which contains a large portion of mudstone, acts primarily as the cap rock. Below is the Clearwater formation, mainly consisting of black and green shale, imbedded with certain mudstone, sandstone and siltstone. Depending on lithology, it is divided into two members, Upper Clearwater and Wabiskaw. Wabiskaw is further divided into the upper and lower parts. Among those, the Upper Clearwater member and the Upper Wabiskaw sub-member work as the cap rock due to their high content of shale and mudstone. Oil sands are mainly reserved in the McMurray formation, containing a majority of fine to coarse grained quartz sand and sandstone, interbedded with a small amount of silt, mud, and clay. The three constituted members of McMurray formation are Upper 
McMurray, Middle McMurray and Lower McMurray. The middle and lower parts are the main pay with bitumen deposited in the fluvial channel and estuarine channel environment with finegrained sands, while the upper part contains more tidal flat sands (Glass, D.J. 1990). Figure 4-4 shows the structure cross section of one well pair, which demonstrates the strata sequence more clearly.

\begin{tabular}{|c|c|c|c|c|c|}
\hline Erathem & Group & Formation & Member & $\begin{array}{c}\text { Sub- } \\
\text { Member }\end{array}$ & Content \\
\hline Cenozoic & \multicolumn{3}{|c|}{$\begin{array}{l}\text { Quaternary glacial, fluvial and modern } \\
\text { deposits }\end{array}$} & & $\begin{array}{l}\text { till, clay sand gravel, peat } \\
\text { and muskeg }\end{array}$ \\
\hline \multirow[t]{9}{*}{ Mesozoic } & \multirow[t]{9}{*}{ Mannville } & $\begin{array}{l}\text { Grand } \\
\text { Rapids }\end{array}$ & & & mudstone \\
\hline & & \multirow[t]{3}{*}{ Clearwater } & $\begin{array}{c}\text { Upper } \\
\text { Clearwater }\end{array}$ & & shale, mudstone \\
\hline & & & \multirow[t]{2}{*}{ Wabiskaw } & $\begin{array}{c}\text { Upper } \\
\text { Wabiskaw }\end{array}$ & \multirow[t]{2}{*}{ shale, mudstone, sand } \\
\hline & & & & $\begin{array}{c}\text { Lower } \\
\text { Wabiskaw }\end{array}$ & \\
\hline & & \multirow[t]{5}{*}{ McMurray } & $\begin{array}{c}\text { Upper } \\
\text { McMurray }\end{array}$ & & \multirow{5}{*}{$\begin{array}{l}\text { Sand, mudstone, HIS, } \\
\text { intraclast breccias, lignite } \\
\text { and karast breccia }\end{array}$} \\
\hline & & & $\begin{array}{l}\text { Middle } \\
\text { McMurray }\end{array}$ & & \\
\hline & & & \multirow[t]{3}{*}{$\begin{array}{c}\text { Lower } \\
\text { McMurray }\end{array}$} & $\begin{array}{c}\text { Lower } \\
\text { McMurray } 3\end{array}$ & \\
\hline & & & & $\begin{array}{c}\text { Lower } \\
\text { McMurray } 2\end{array}$ & \\
\hline & & & & $\begin{array}{c}\text { Lower } \\
\text { McMurray } 1\end{array}$ & \\
\hline Paleozoic & $\begin{array}{l}\text { Beaverhill } \\
\text { Lake }\end{array}$ & Waterways & & & $\begin{array}{c}\text { Fossiliferous, caleareous } \\
\text { mudstone }\end{array}$ \\
\hline
\end{tabular}

Figure 4-3 Suncor's Firebag stratigraphic chart ( $\square$ caprock reservoir) (Suncor Firebag SAGD Report, 2006) 


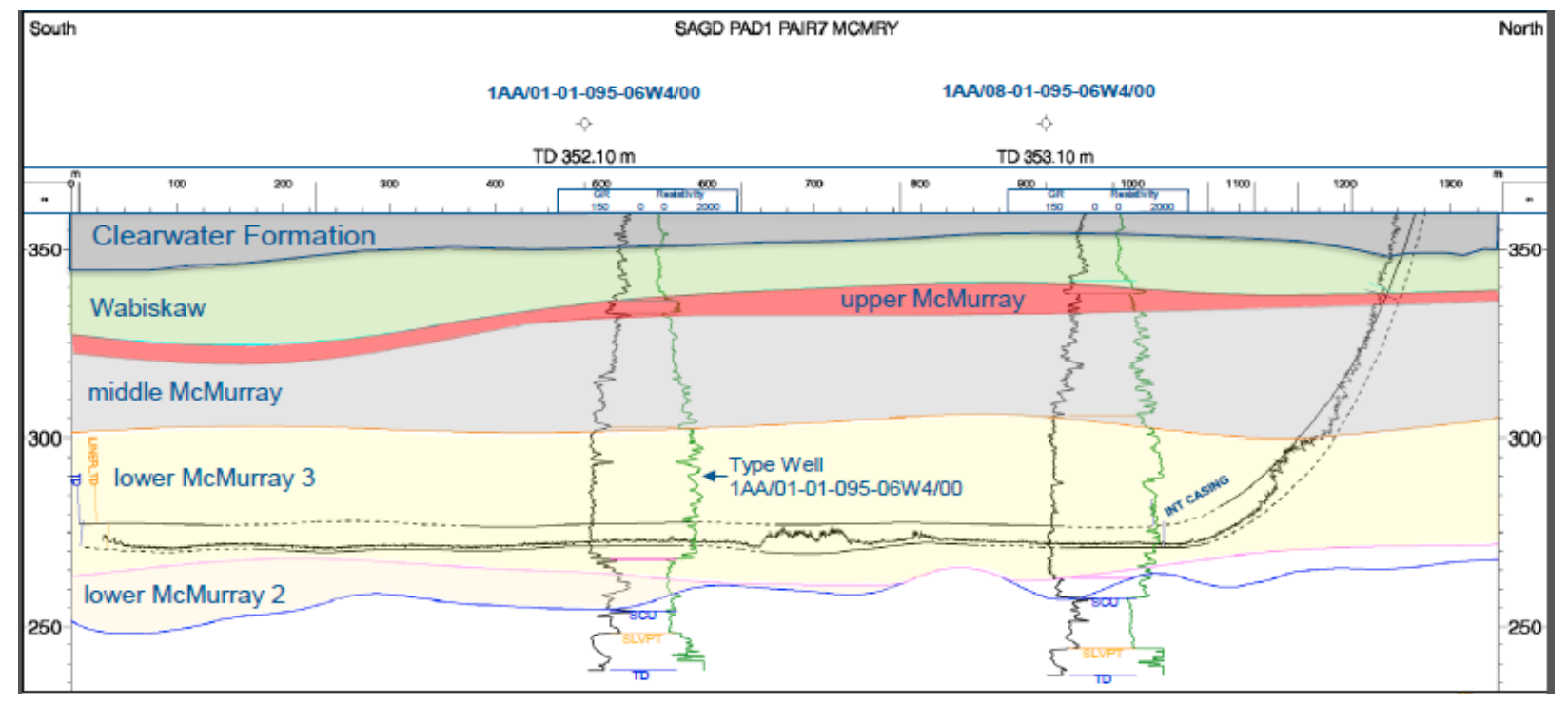

Figure 4-4 Suncor's Firebag structural cross section (Pad 101 Pair 7) (Suncor Firebag SAGD Report, 2006)

\subsubsection{Geological Modeling}

The well pairs of interest are Pair 6 to 10 of Pad 102. Totally, for accuracy, data of 5 well pairs and 51 observation wells are collected from AccuMap Software and employed to carry out geological modeling with Petrel Software (Figure 4-5). Cores and well logs analyses are combined to derive porosity, permeability, water saturation and lithology distribution, in which, the porosity and permeability relationship is also evaluated through correlation. Lithological interpretation of several observation wells is presented (Figure 4-6). 

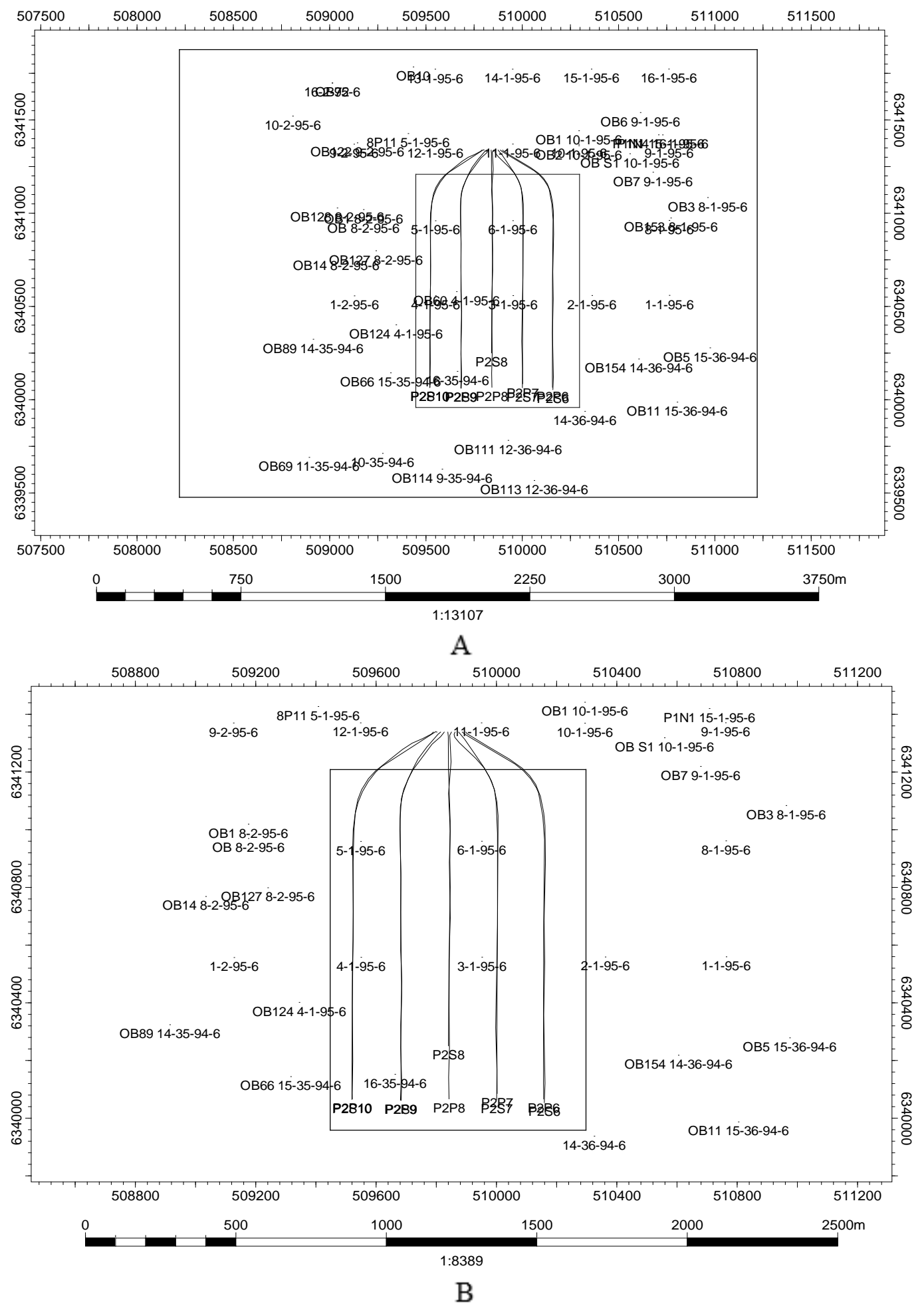

Figure 4-5 Well pairs and observation wells in the study area (A: Overall view; B: In the vicinity of well pairs) 


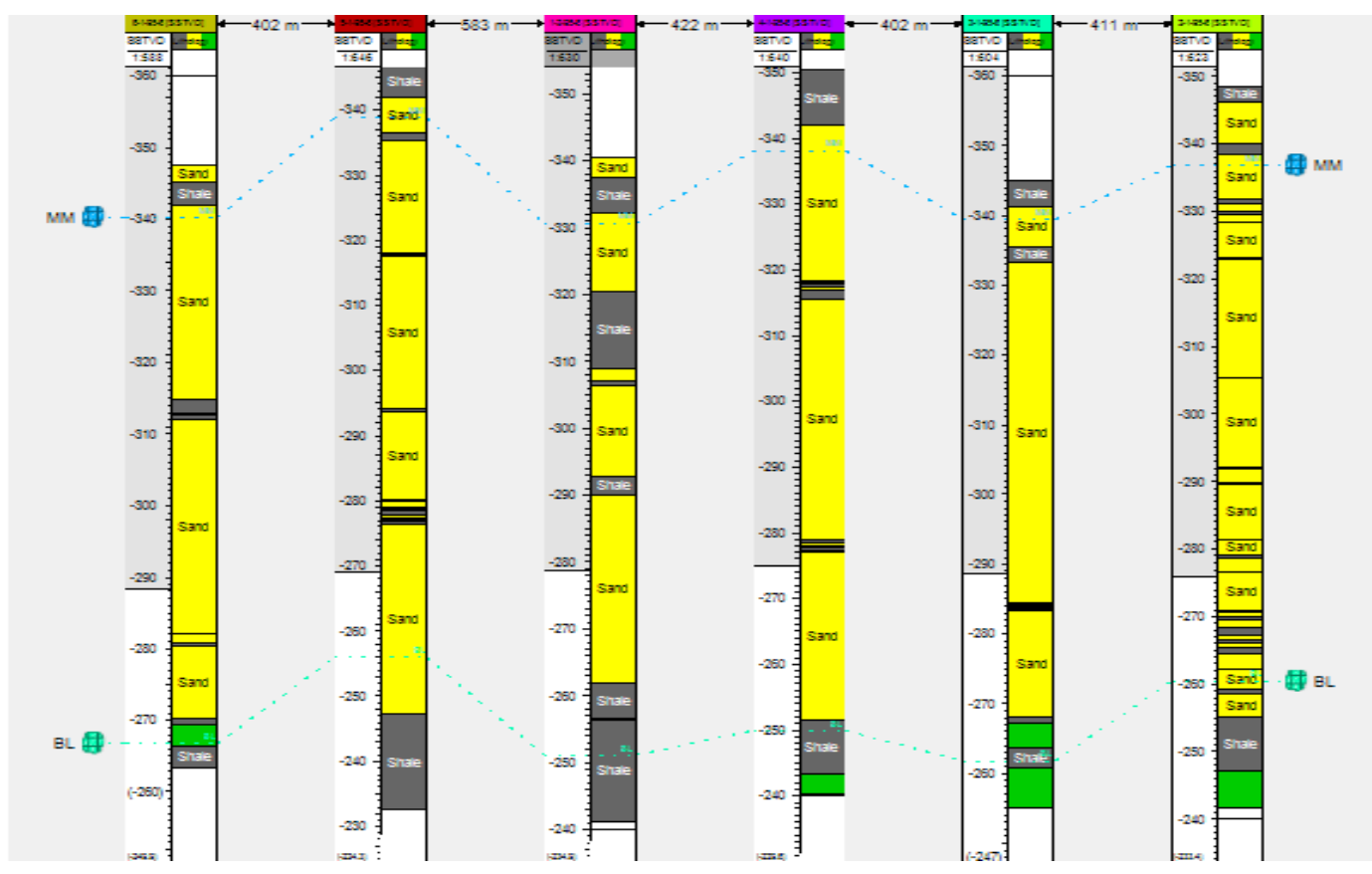

Figure 4-6 Lithology interpretation of several wells in the study area (MM: McMurray; BL: Beaverhill Lake)

\subsubsection{Structural Modeling}

Two horizons, McMurray and Beaverhill Lake formations, serving as the constraints for a structural model to define the boundary and carry out interpolation (Figure 4-7). The constructed geological model contains $600 \times 480 \times 117$ blocks with the size of $5 \mathrm{~m} \times 5 \mathrm{~m} \times 1 \mathrm{~m}$, covering the area of $3000 \mathrm{~m} \times 2400 \mathrm{~m}$. 


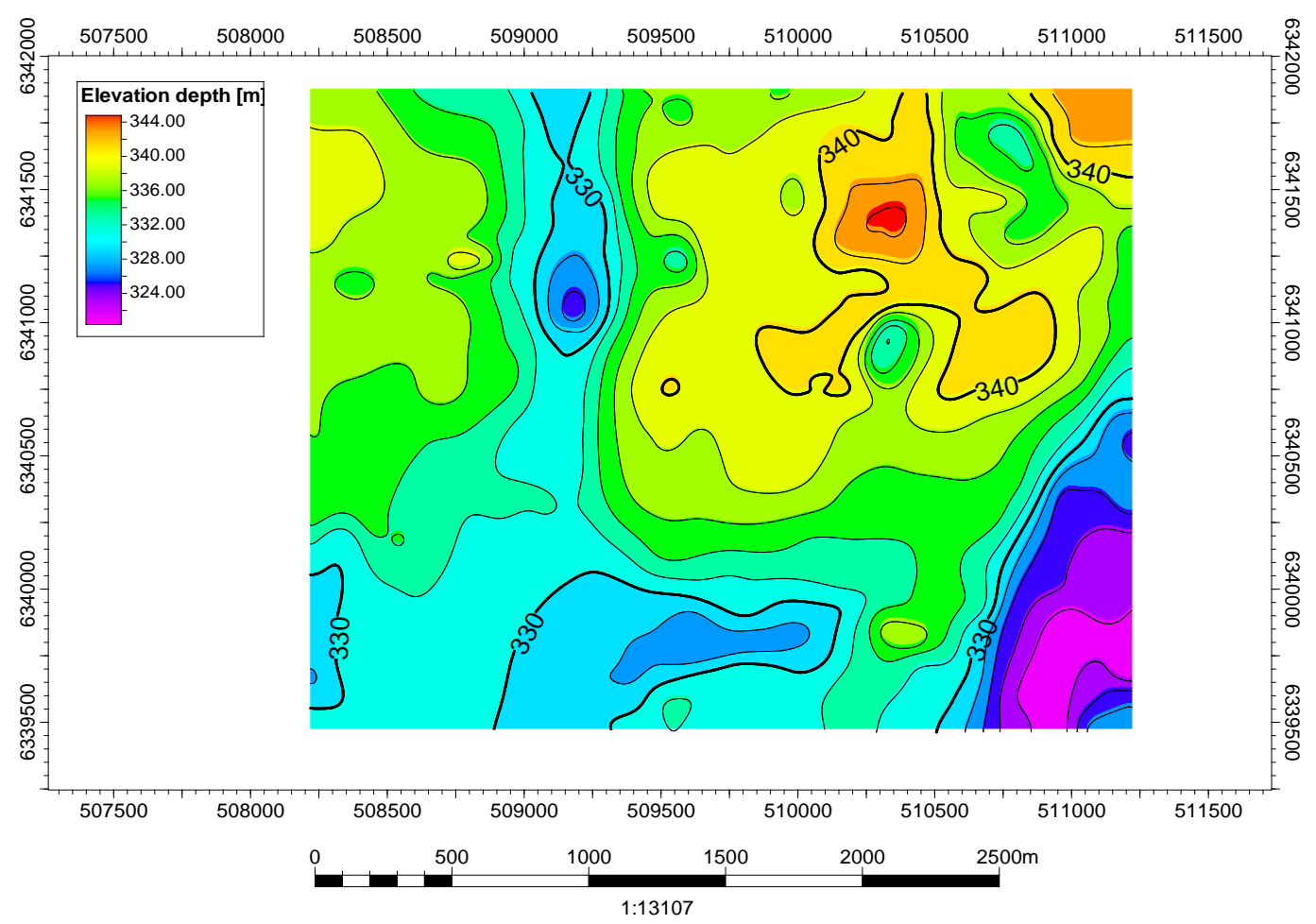

A

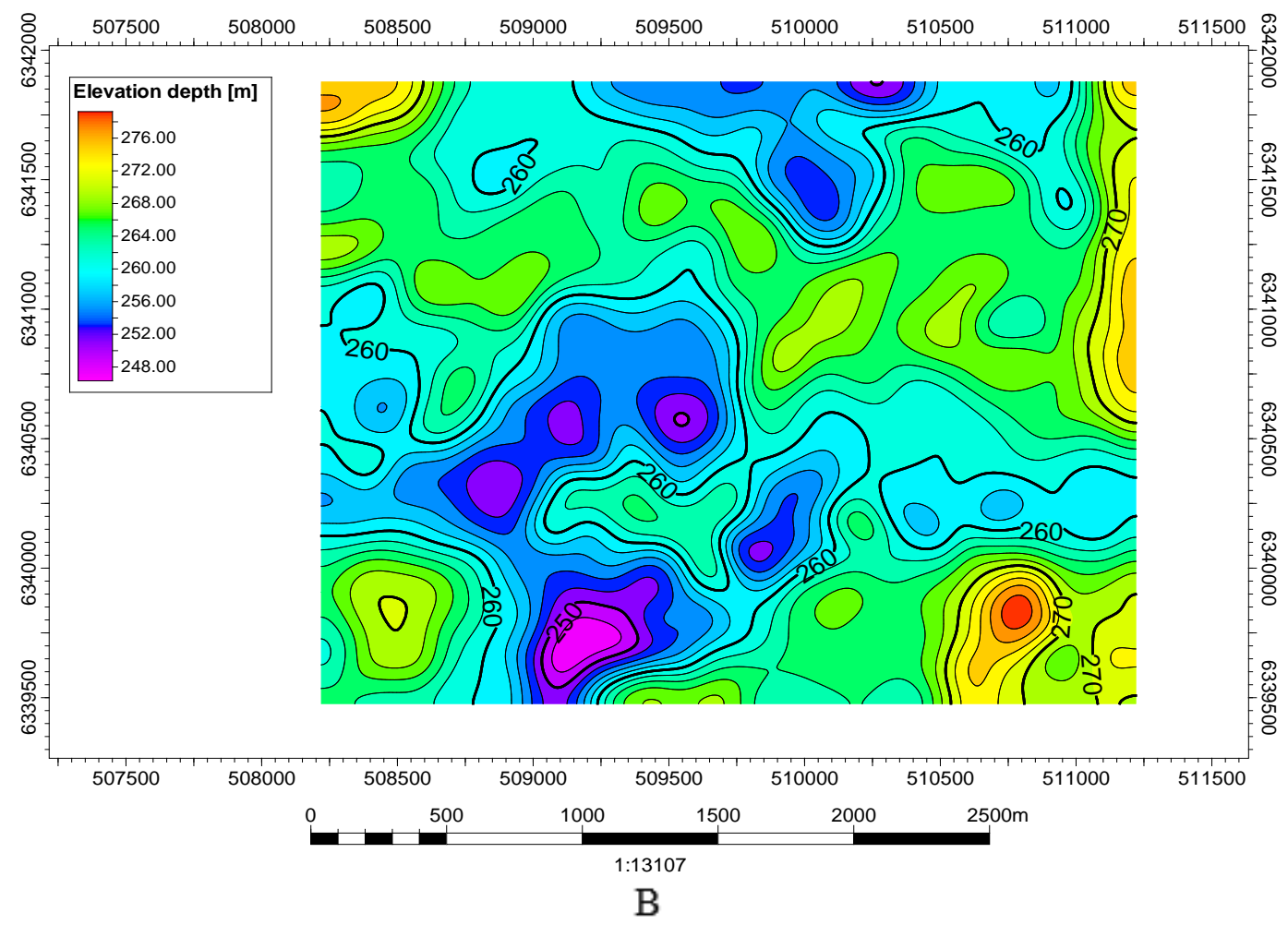

Figure 4-7 Structural maps of McMurray and Beaverhill Lake (A: McMurray surface; B: Beaverhill Lake surface) 


\subsubsection{Facies Modeling}

Facies modeling is a means to distribute discrete data to the whole structural model with two different methods, namely, deterministic and stochastic modeling methods. The deterministic method produces the same result as long as the initial input is given. In contrast, the stochastic method is able to deliver different equiprobable results for different seed numbers. Different states can be reflected by probability distributions. This in turn helps to estimate the uncertainty and reduce errors. SIS (Sequential Indicator Simulation) is one of the stochastic modeling methods using a pixel based technique. This study adopts a variogram model, which quantifies spatial continuality of the data, to carry out data analysis. Multiple realizations are run and averaged to evaluate the uncertainty. The derived facies model of the research area is listed below (Figure 48). Accordingly, it is seen that the majority of the model is occupied by sandstone, interbedded with a small amount of shale.

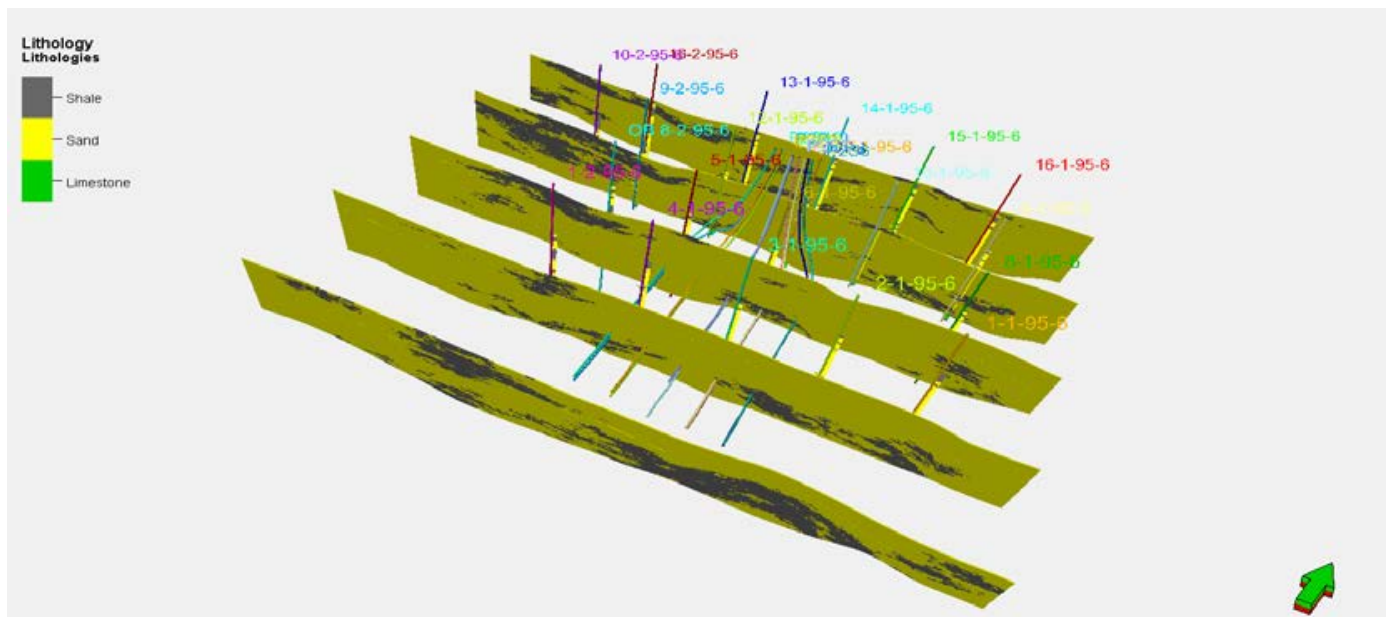

Figure 4-8 Facies model cross profile 


\subsubsection{Petrophysical Modeling}

Petrophysical modeling is the interpretation of continuous data throughout a model grid. Similarly, it has the deterministic method and the stochastic method. The SGS (Sequential Gaussian Simulation) method is one of the stochastic methods, which helps to guarantee the variability of the data. Figure 4-9 displays the petrophysical models and its 2D cross sections (intersecting Well Pair 10). The water saturation is averaged to be approximately 0.351 . The average permeability and average porosity are around $4,382 \mathrm{mD}$ and 0.3061 , respectively.

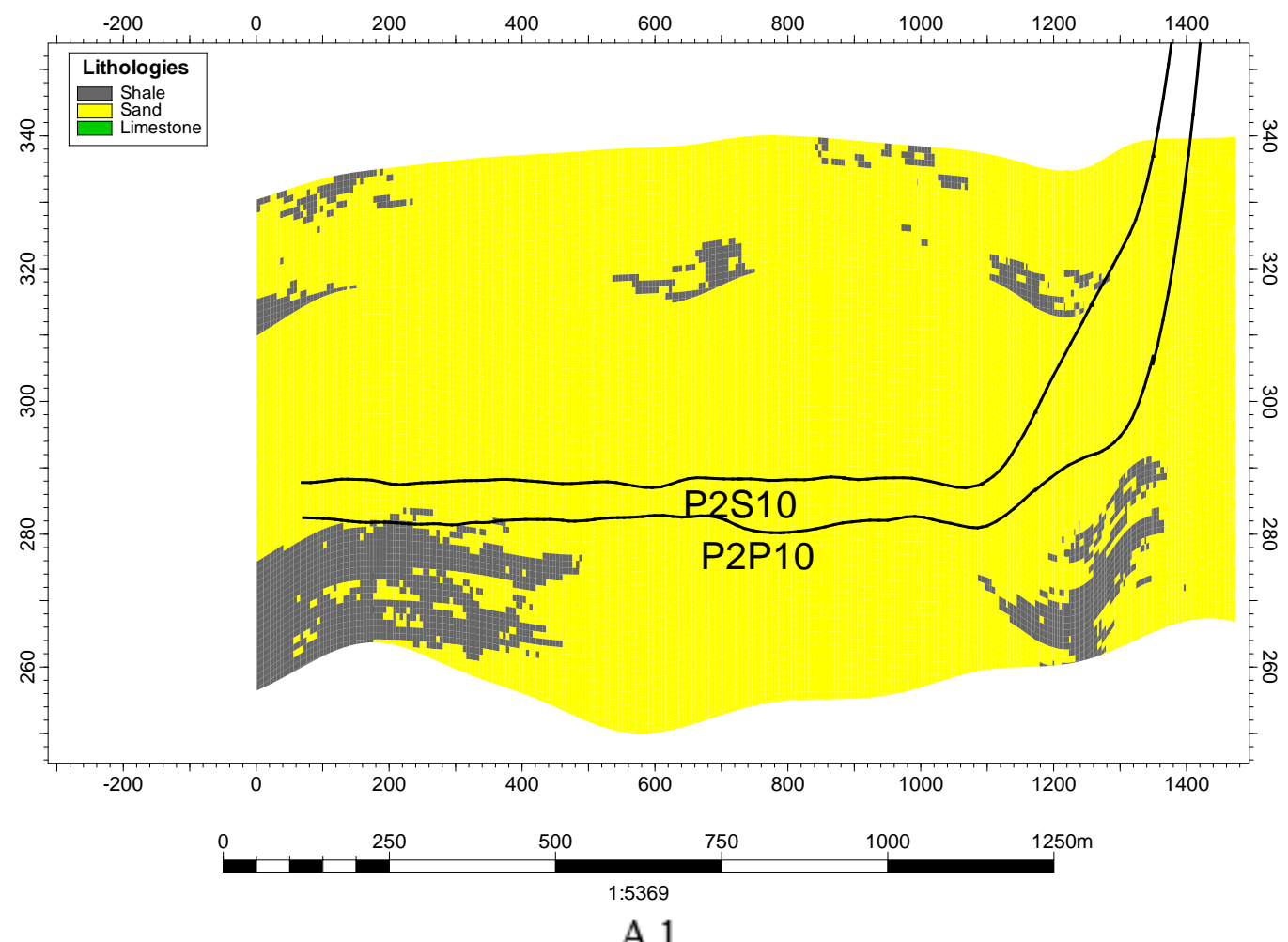




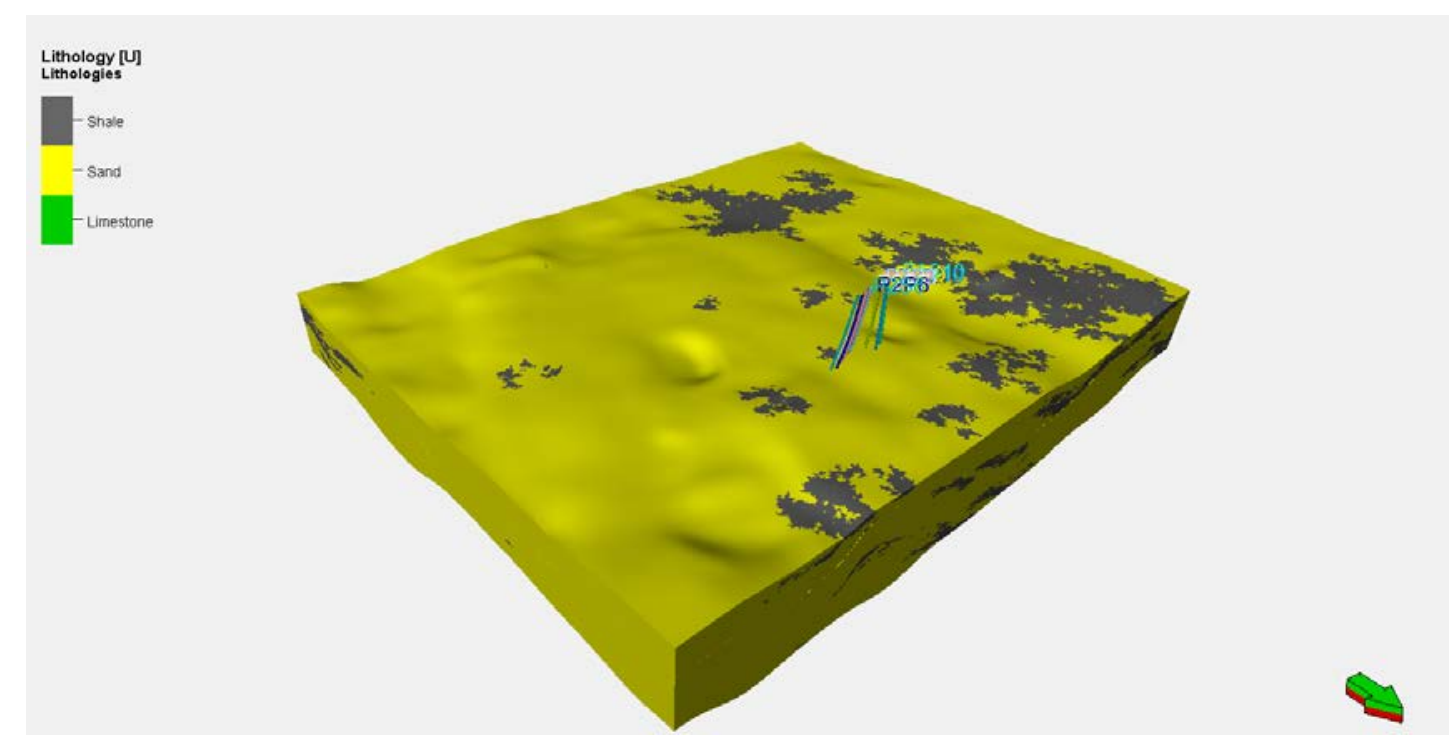

A. 2

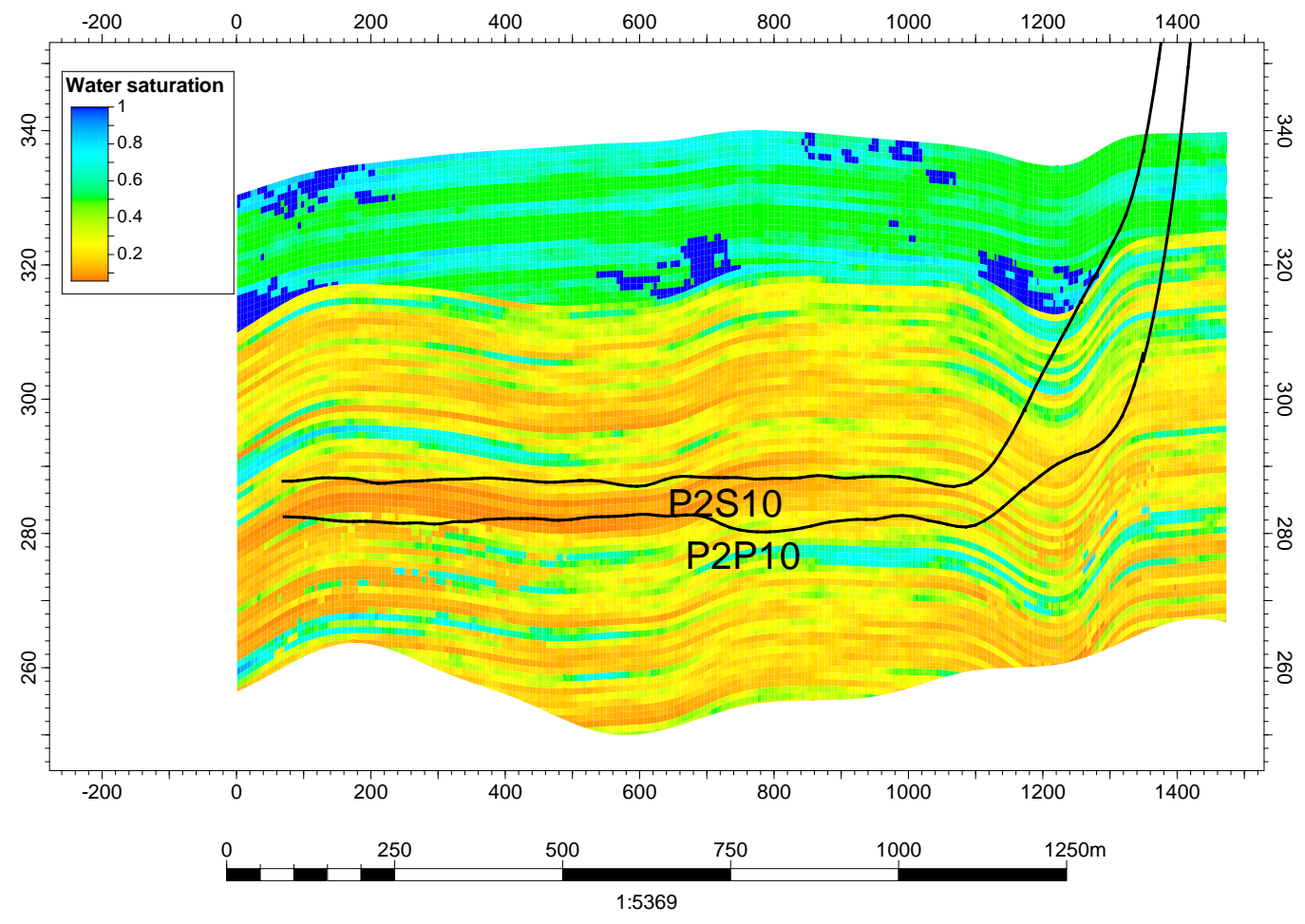

B. 1 


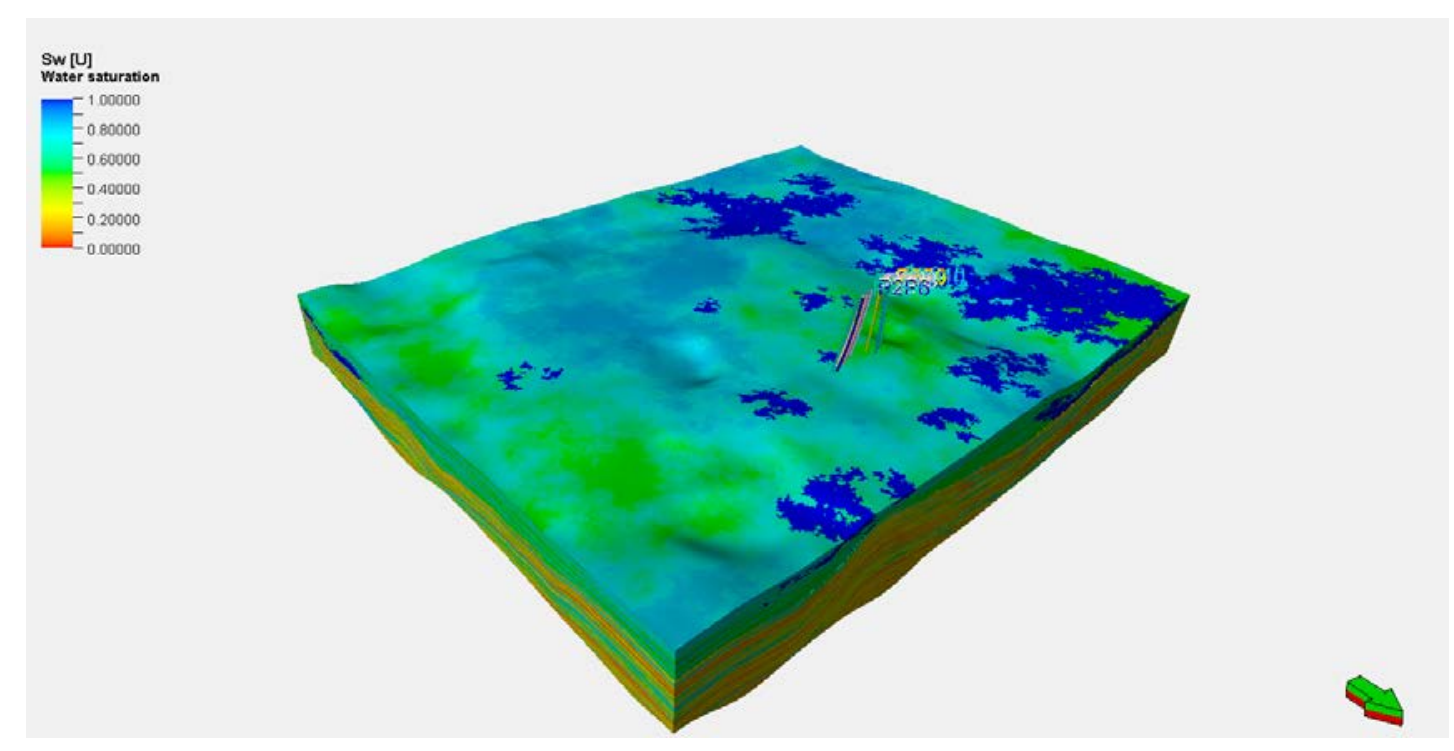

B. 2

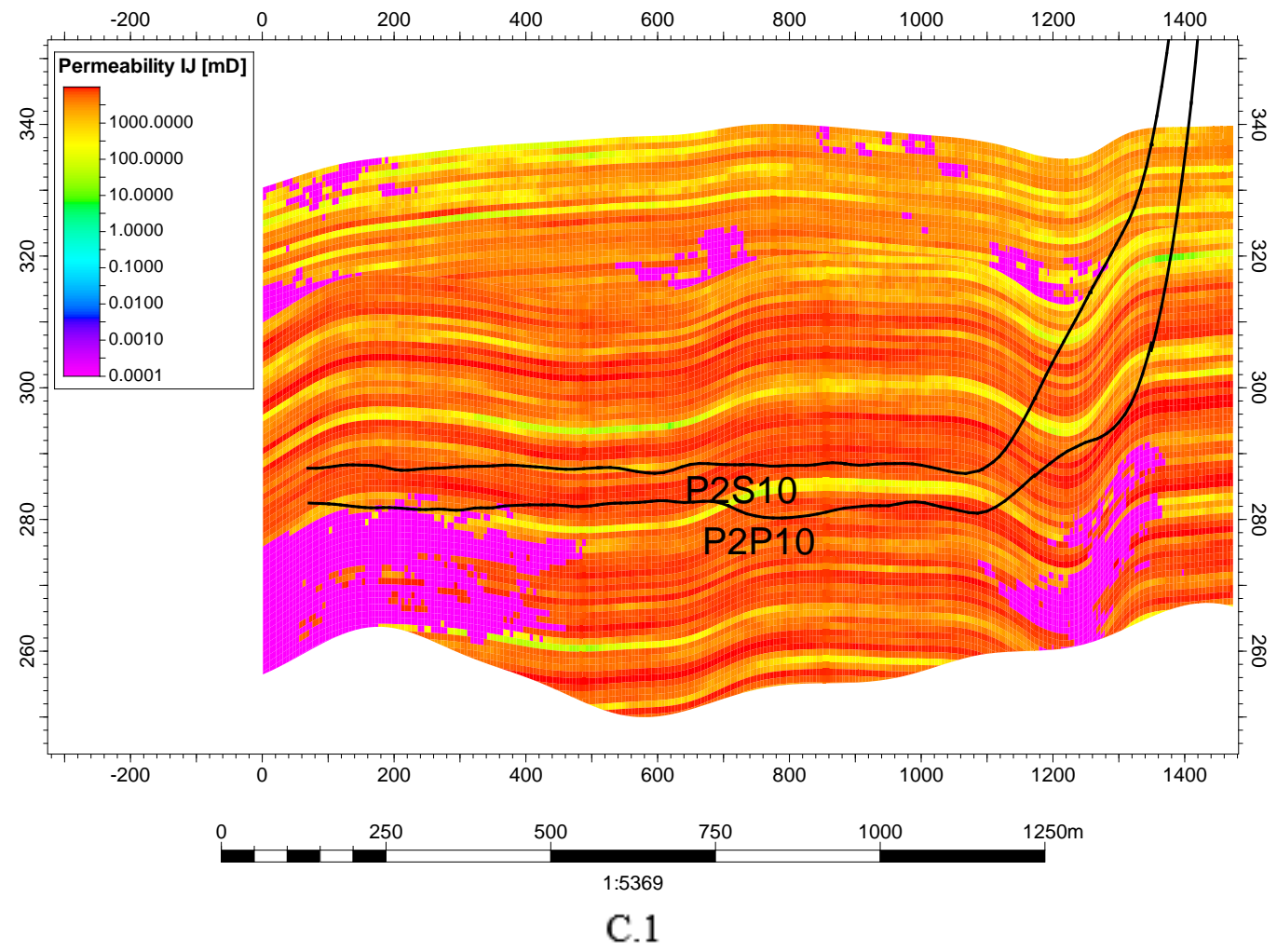




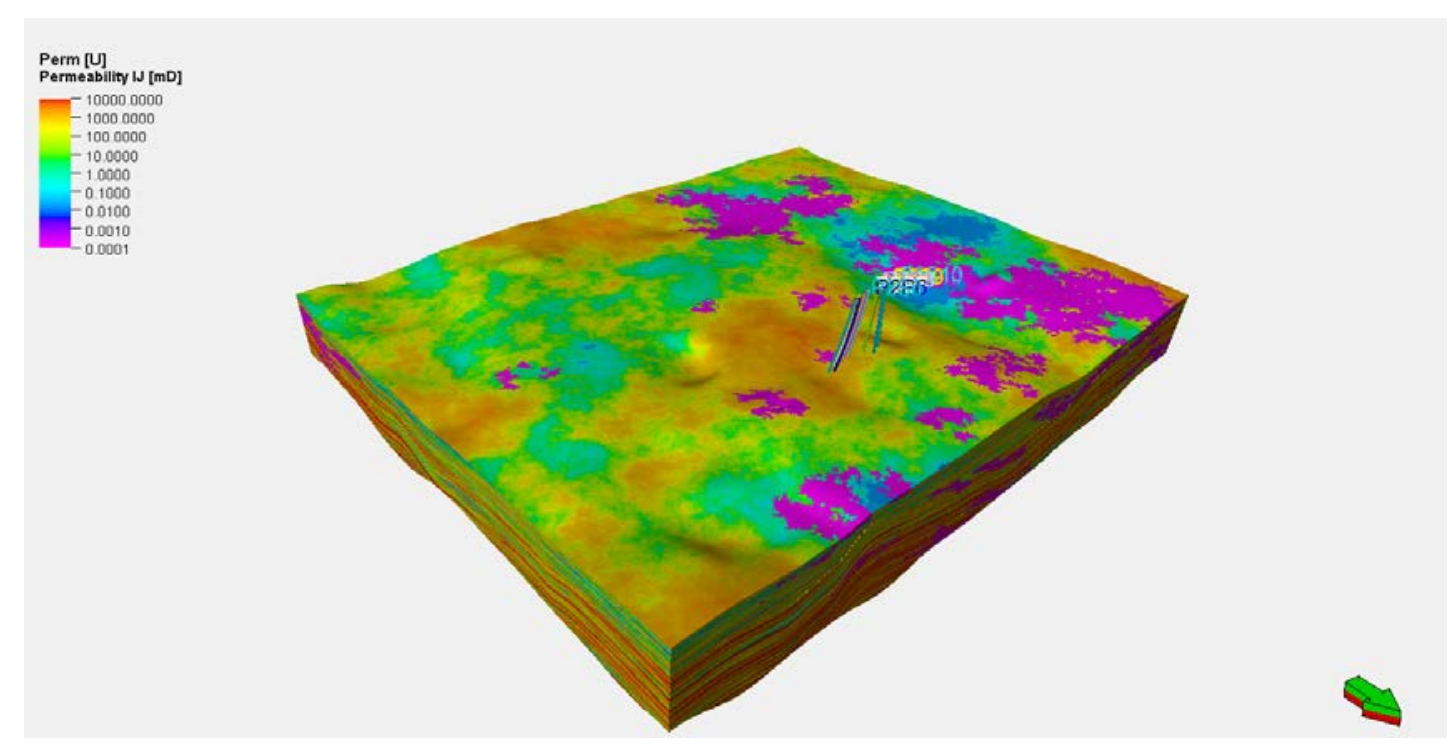

C. 2

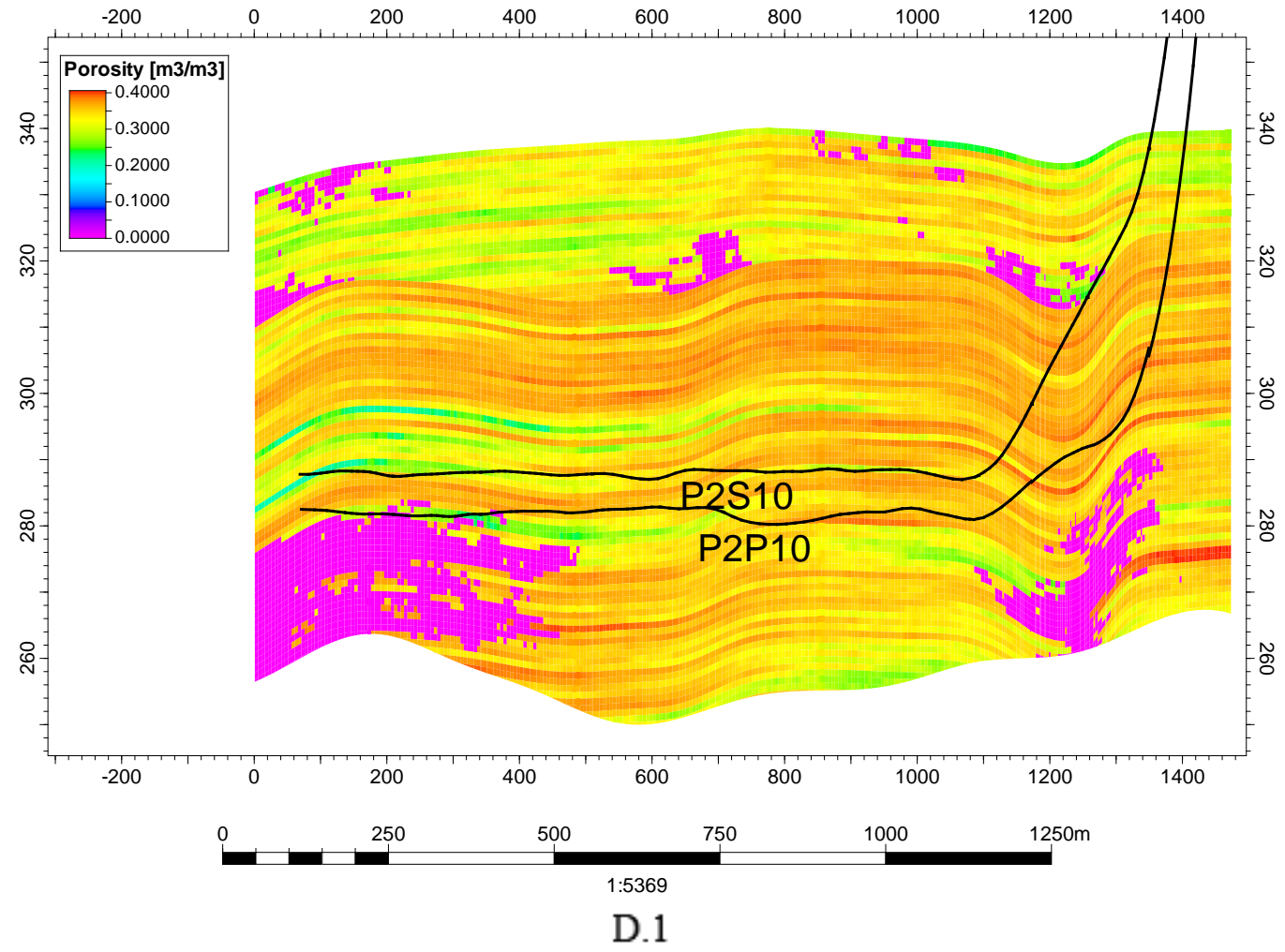




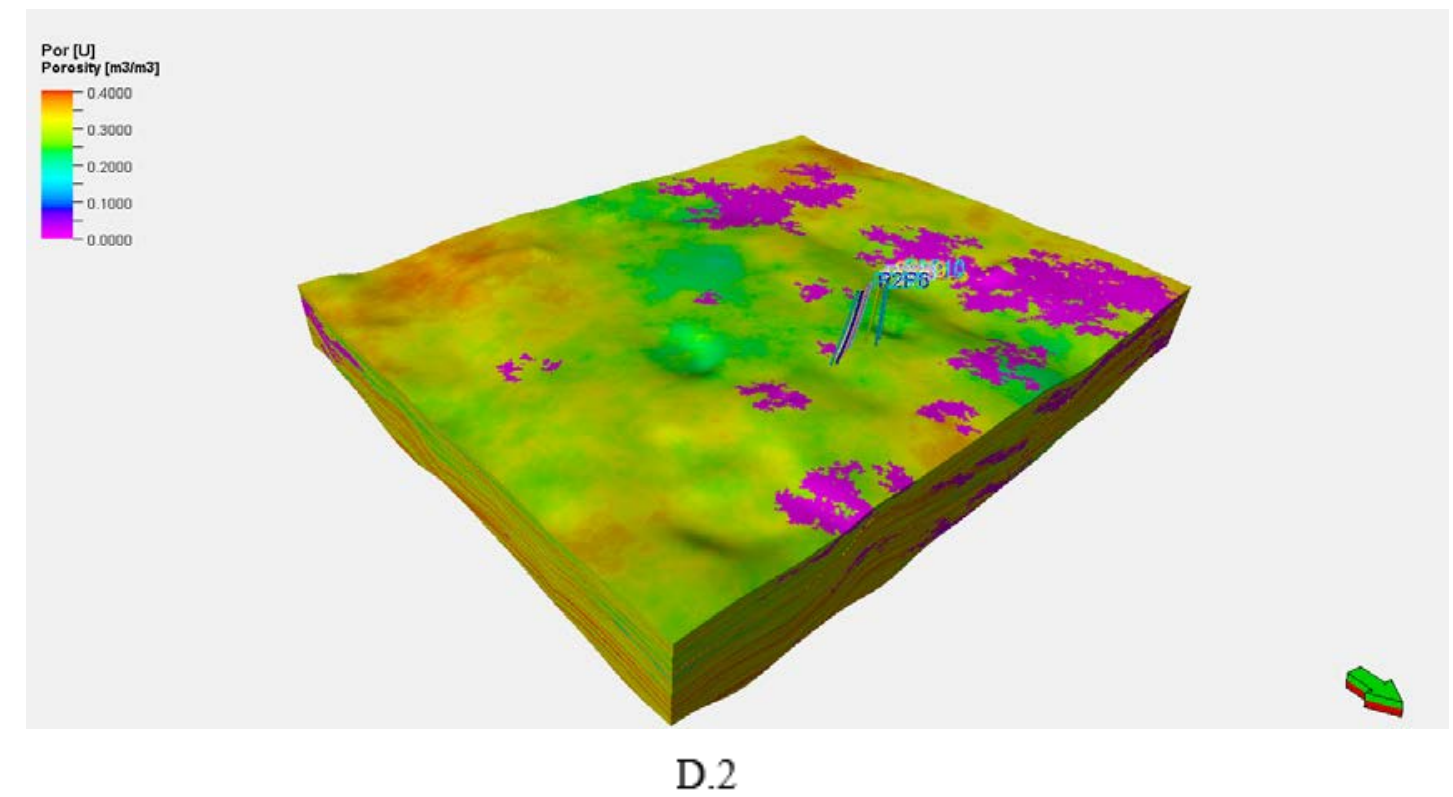

Figure 4-9 Petrophysical models (A.1: 2D lithology model; A.2: 3D lithology model; B.1: 2D water saturation model; B.2: 3D water saturation model; C.1: 2D permeability model; C.2: 3D permeability model; D.1: 2D porosity model; D.2: 3D porosity model)

\subsection{Firebag Simulation Model}

\subsubsection{Basic Heterogeneous Simulation Model}

A 3D model covering the area $(850 \mathrm{~m} \times 1,280 \mathrm{~m} \times 81 \mathrm{~m})$ in the vicinity of the five well pairs is intercepted from the original geological model. Afterwards, the intercepted model is imported into $\mathrm{CMG}^{\circledR}$ STARS from Petrel, the grid size of which is scaled up to be $5 \mathrm{~m} \times 100 \mathrm{~m} \times 1 \mathrm{~m}$.

The water saturation distribution plot predicts a higher storage of oil in the middle and lower parts, where water saturation is relatively low, but intersected with several high water-bearing layers. By contrast, abundant water reservation at the top resembles a top water zone, which may act as a 
potential thief zone for the SAGD production. Thus all the well pairs are drilled in the middle and lower parts to fully utilize gravity and stay away from the high potential enthalpy sink. The model has relatively good porosity and permeability favoring the SAGD production. However, it is still obvious that the research area is of high heterogeneity, and steam chamber development is bound to be severely affected (Figure 4-10).

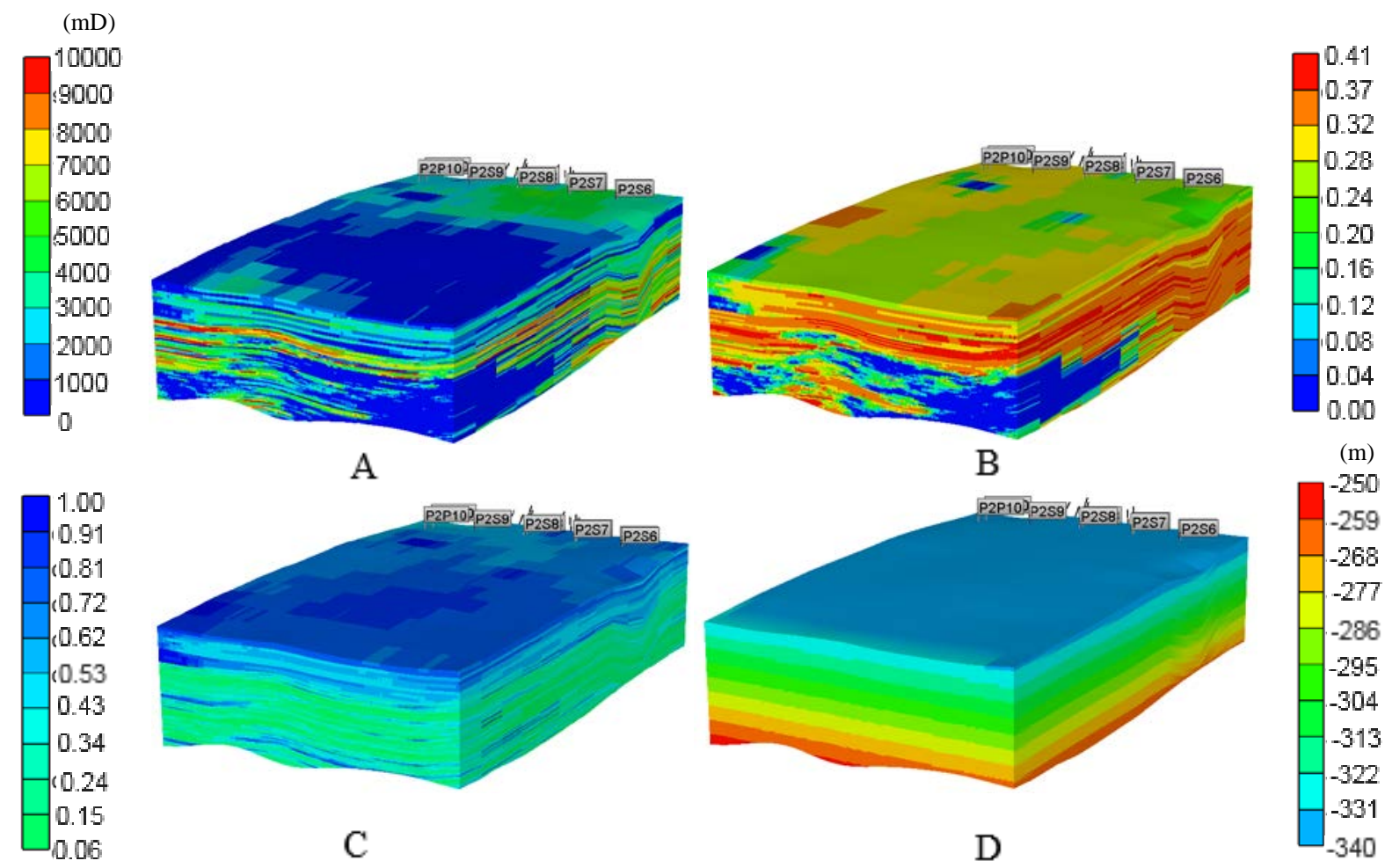

Figure 4-10 Properties distribution of 3D heterogeneous model (A: permeability; B: porosity; C: water saturation; D: grid depth)

The model contains three components, which are water, oil and methane, separately. The oil viscosity declines along with the increasing temperature (Figure 4-11). 


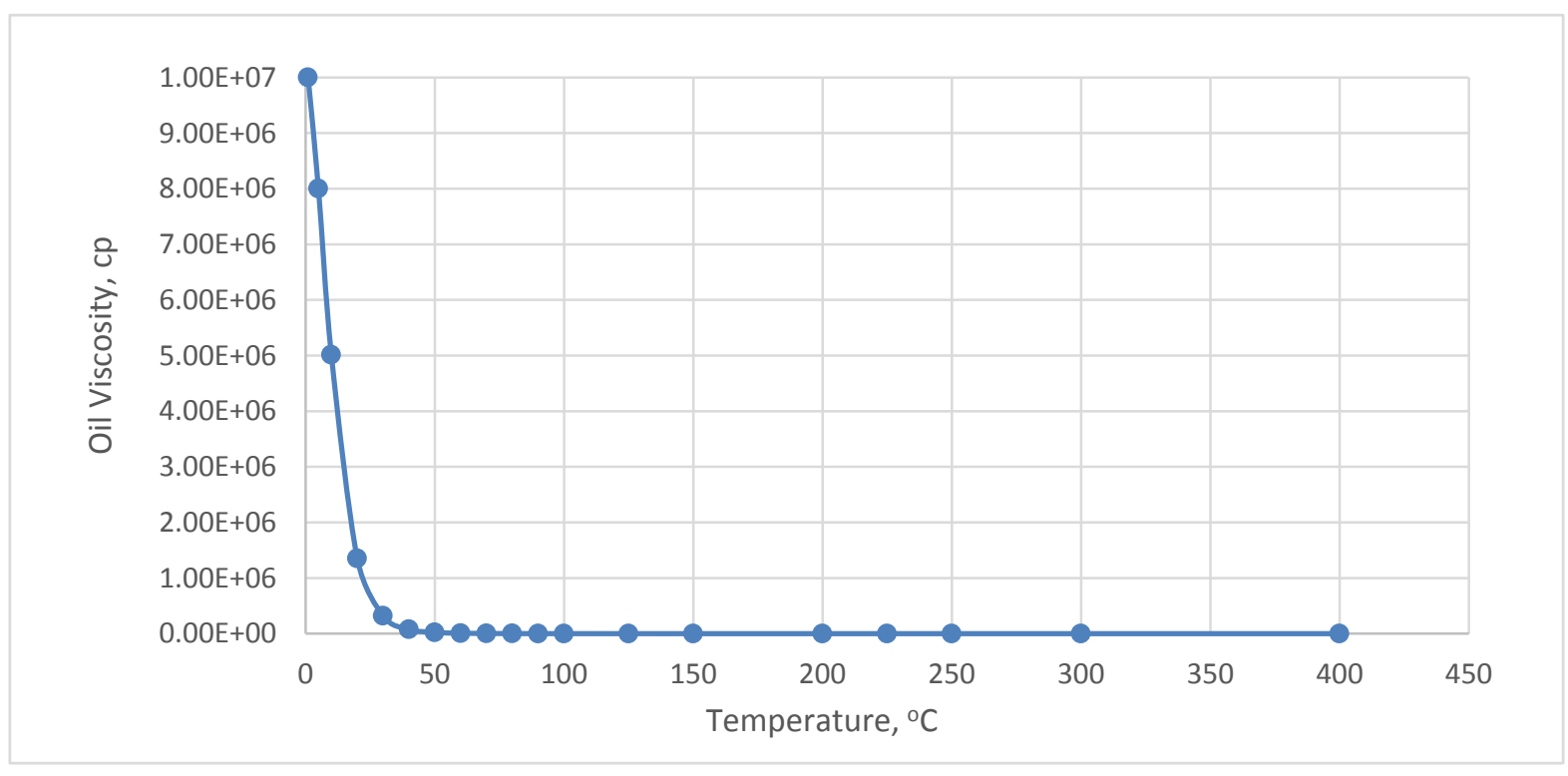

Figure 4-11 Oil viscosity and temperature plot

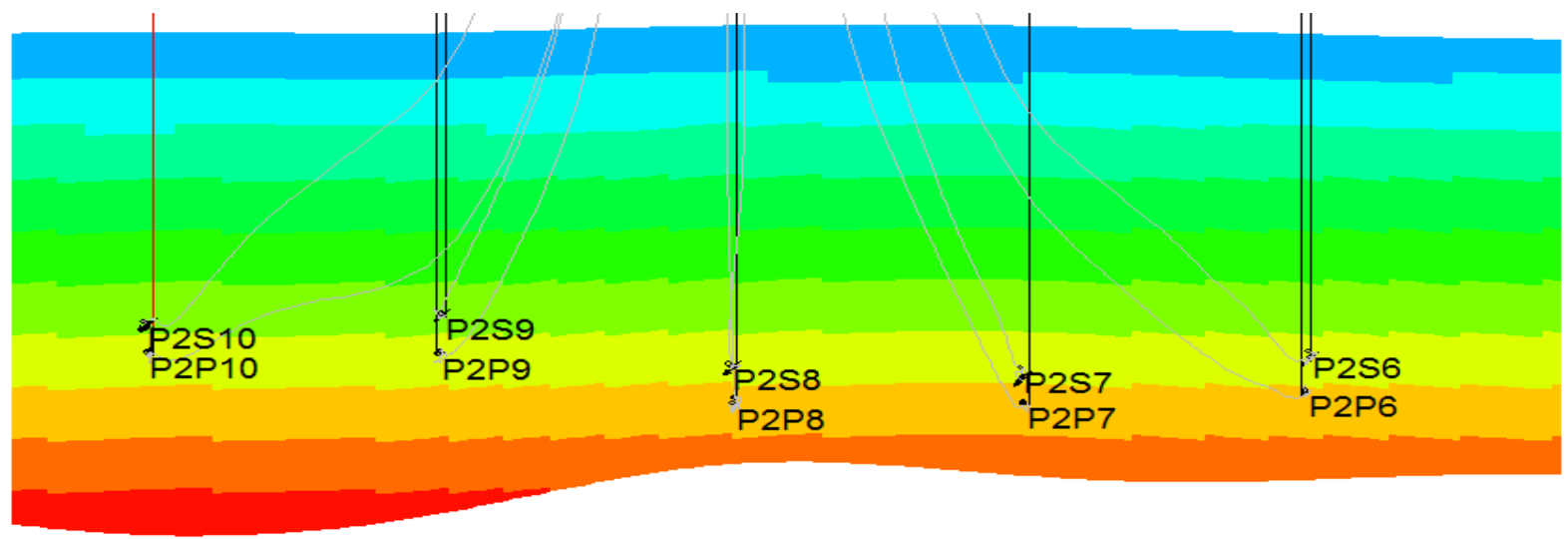

Figure 4-12 Wells location of 3D heterogeneous model (IK cross section, $J=7$ )

All producers locate near the bottom of the reservoir and the injectors stay around $5 \mathrm{~m}$ above the producers (Figure 4-12). Five well pairs have different preheating periods and operation periods, the start times of which differ but the end times are the same (Table 4-1). The simulation period lasts for eight years after being initiated in September, 2003. 
Table 4-1 Preheating periods and operation periods

\begin{tabular}{|c|c|c|c|}
\hline Well & Preheating Start & Preheating End & Operation End \\
\hline P2S6,P2P6 & $2003-09-01$ & $2004-10-01$ & $2011-01-01$ \\
\hline P2S7, P2P7 & $2003-09-01$ & $2004-11-01$ & $2011-01-01$ \\
\hline P2S8, P2P8 & $2005-02-01$ & $2005-11-01$ & $2011-01-01$ \\
\hline P2S9, P2P9 & $2008-07-01$ & $2009-02-01$ & $2011-01-01$ \\
\hline P2S10, P2P10 & $2008-07-01$ & $2009-01-01$ & $2011-01-01$ \\
\hline
\end{tabular}

A 2D cross-sectional model (Figure 4-13) is further cut out to carry out history match as the simulation time for the whole model consumes long time and the history match process requires thousands of runs. Finally, history match is achieved through tuning relative permeability curves

(Figure 4-14).
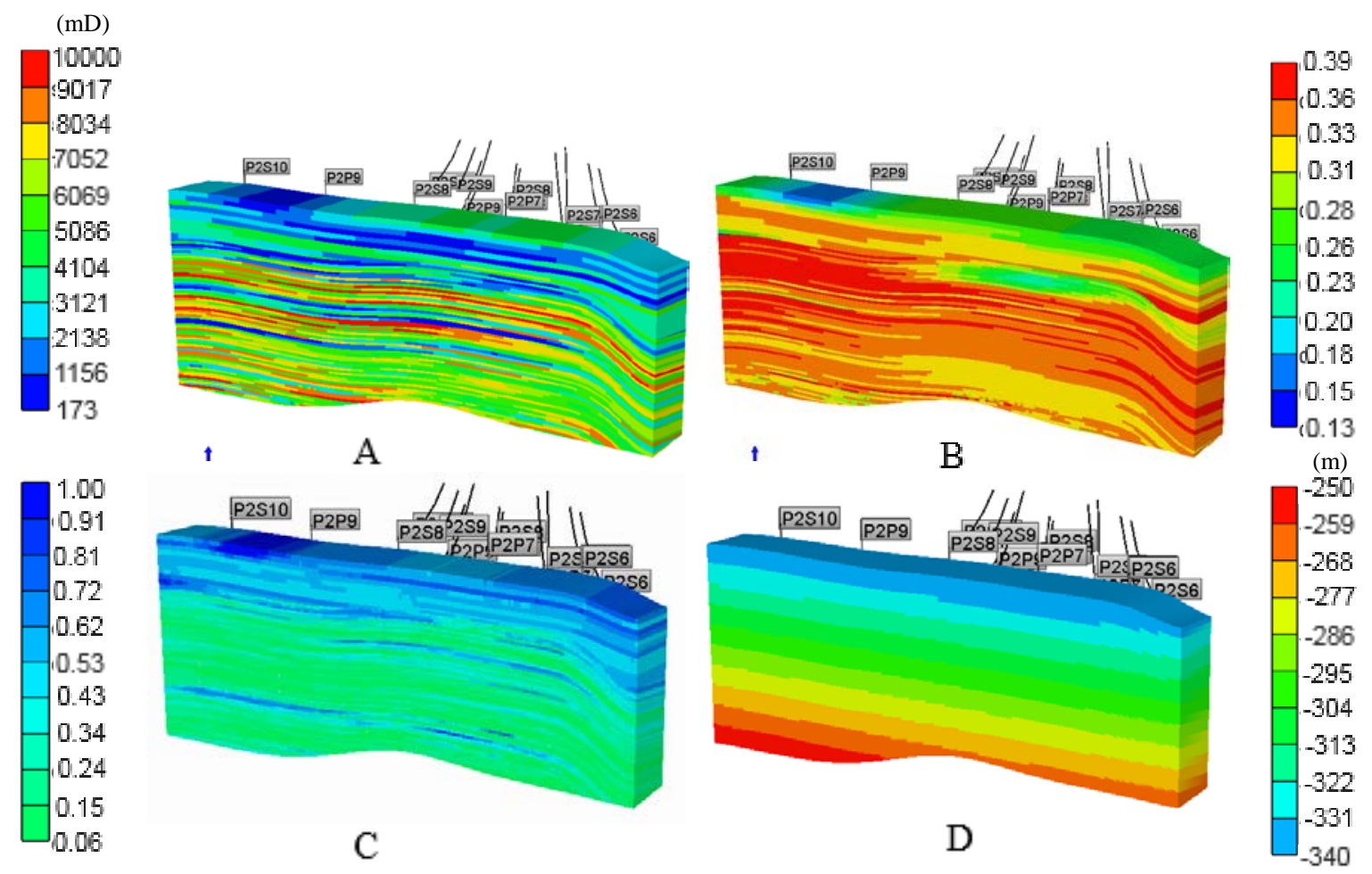

Figure 4-13 Properties distribution of 2D heterogeneous model (A: permeability; B: porosity; C: water saturation; D: grid top) 


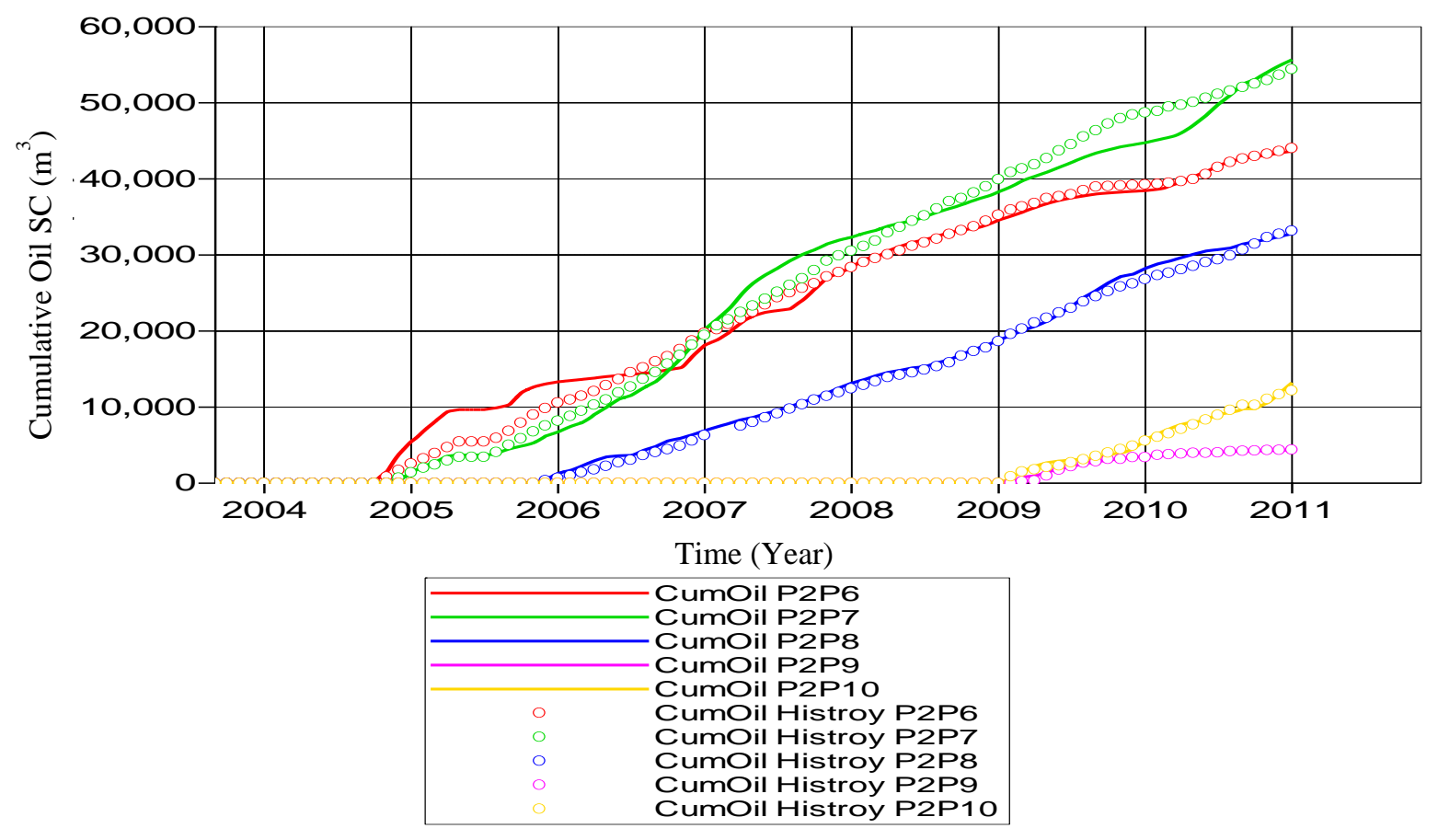

Figure 4-14 Oil production history match

\subsubsection{Results Comparison between SAGD and CAFA-SAGD and Interpretation}

Well Pair 7, by reason of a longer production history and a better performance, is chosen to inject chemical additives to investigate how CAFA-SAGD performs under heterogeneous conditions. According to the previous study, it is highly recommended to inject chemical additives after the steam chamber touches the overburden in the case of the aforementioned homogeneous model. However, there are several low-permeable layers in the upper part and a top water zone which works as a potential thief zone (Figure 4-15). We choose to inject chemical additives once the steam chamber is relatively expanded and the steam front approaches a low-permeable area to prevent the steam from bypassing the oil in the upper part and losing heat in time (around May 1st, 
2005).

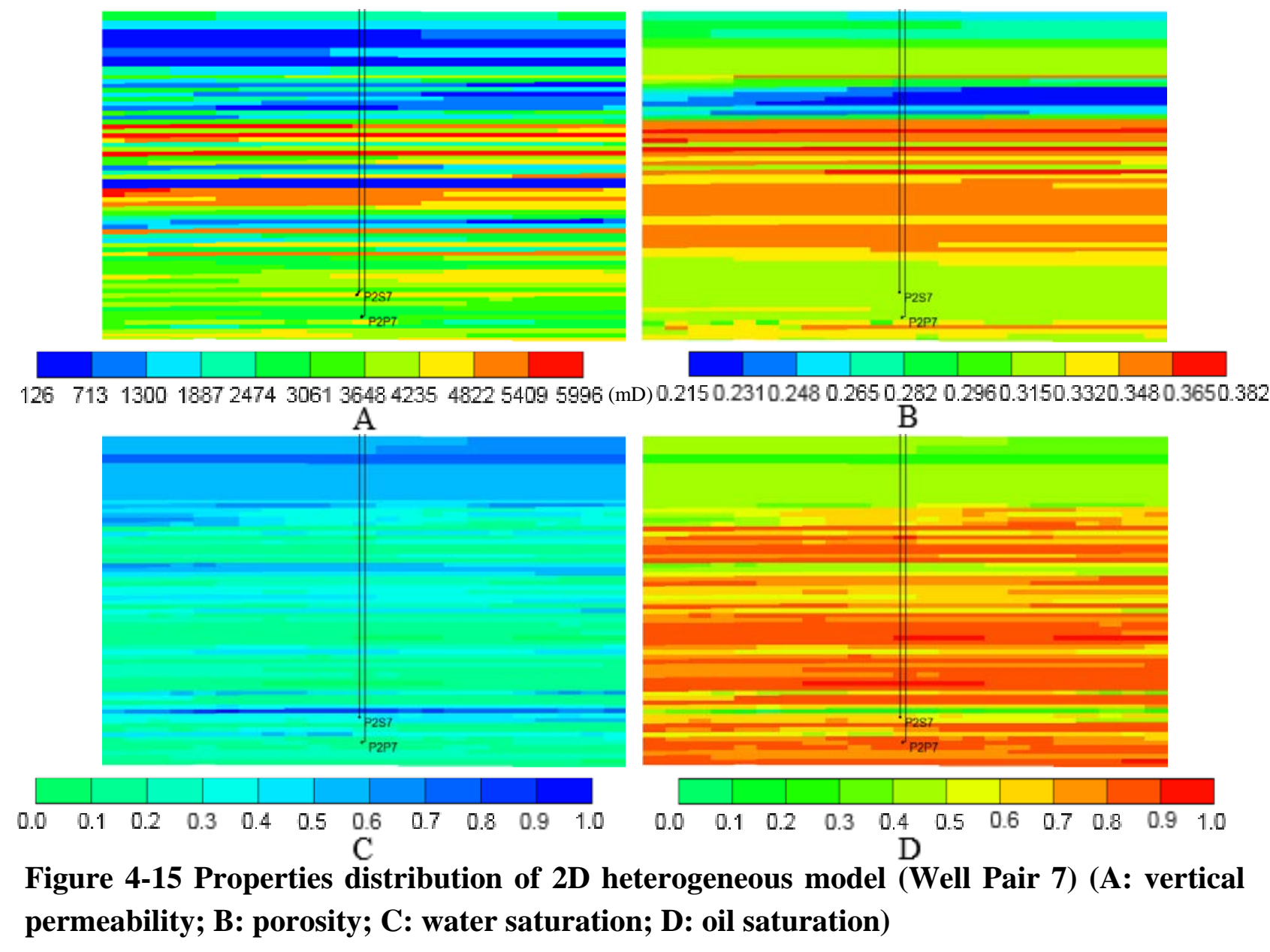

Water has higher thermal conductivity and heat capacity. The existence of top water acts as a thief zone, which adsorbs heat and deteriorates heat efficiency when the steam chamber runs into it.

Due to the existence of top water, the steam chamber of SAGD grows quickly towards the enthalpy sink vertically and ignores a large area in the horizontal direction at the lower part of the reservoir. 


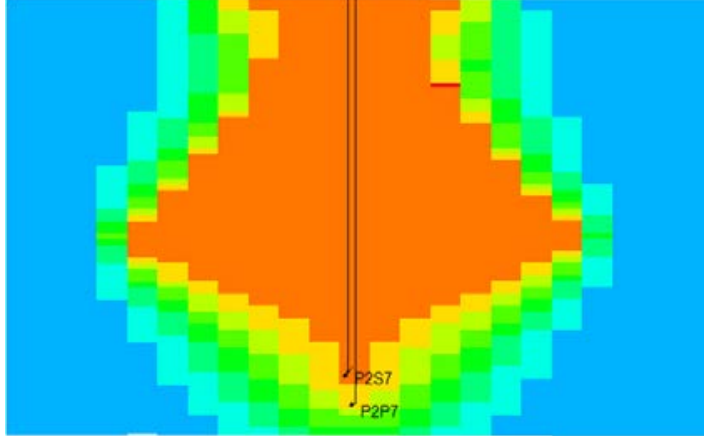

A.1

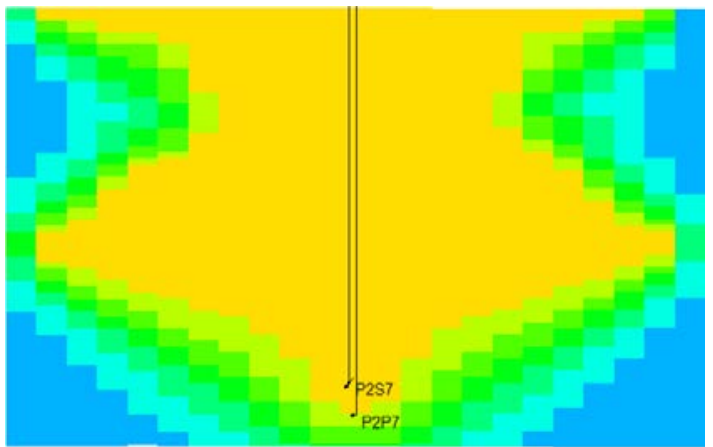

A. 2

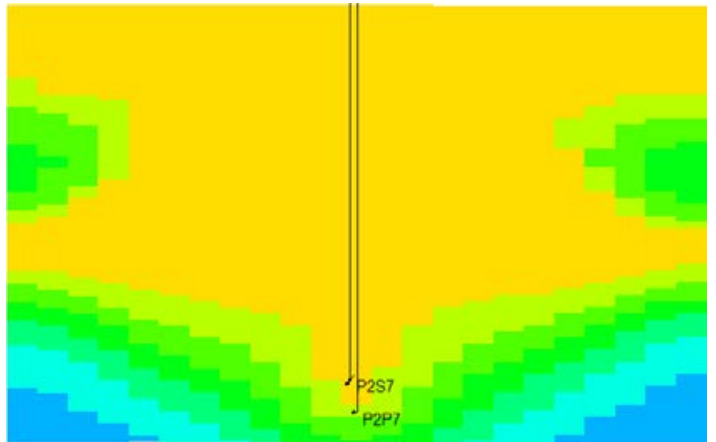

A.3

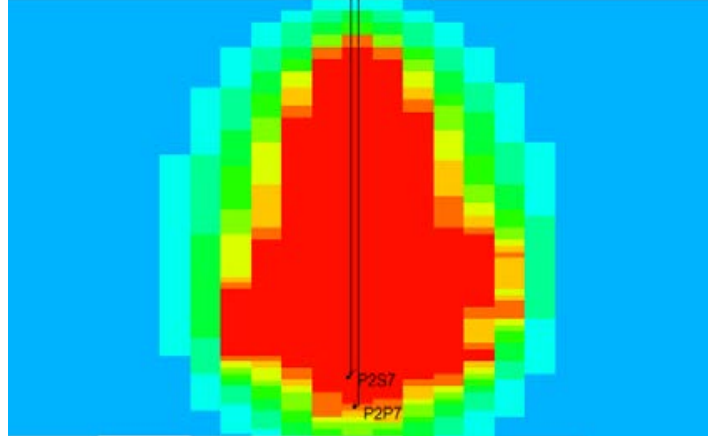

B.1

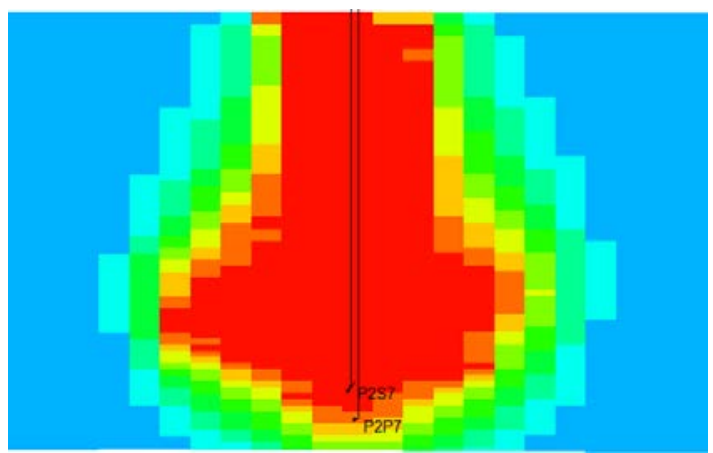

B. 2

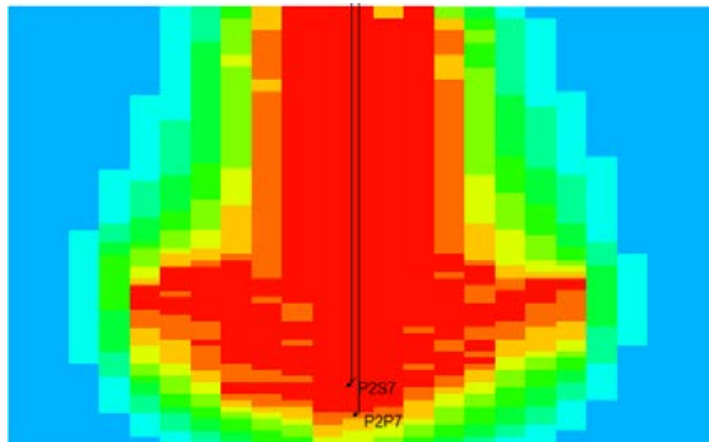

B.3

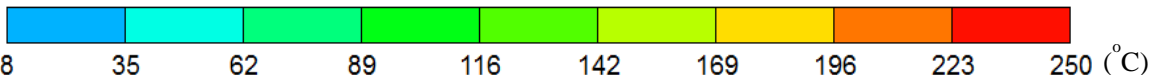

Figure 4-16 Temperature distribution comparison of $2 \mathrm{D}$ heterogeneous model $\left({ }^{\circ} \mathrm{C}\right)(\mathrm{A} .1$ : SAGD, May $1^{\text {st }}$, 2007; A.2: SAGD, May $1^{\text {st }}$, 2008; A.3: SAGD, May $1^{\text {st }}, 2009$; B.1: CAFASAGD, May $1^{\text {st }}, 2007$; B.2: CAFA-SAGD, May $1^{\text {st }}, 2008$; B.3: CAFA-SAGD, May $\left.1^{\text {st }}, 2009\right)$

After contacting the overburden, the chamber stretches and extends at a substantial lateral rate along the overburden immediately, achieving an enormous heat exchange surface and forming a plate-shape steam chamber. At the same time, the low-permeable layers make things worse. They 
are less likely to be swept by steam as most of the steam tends to escape though the high- permeable area with less flow resistance. A direct result is the chamber's excessive lateral growth along the high conductive area and contraction at the area with poor pore structures. Thus there are two recessions at the contour (Figure 4-16). Consequently, the residual oil saturation is high in the corresponding area as it is not fully heated. Also, owing to the rapid vertical movement of steam, the oil reserved in the lower reservoir is neglected in a way (Figure 4-17).

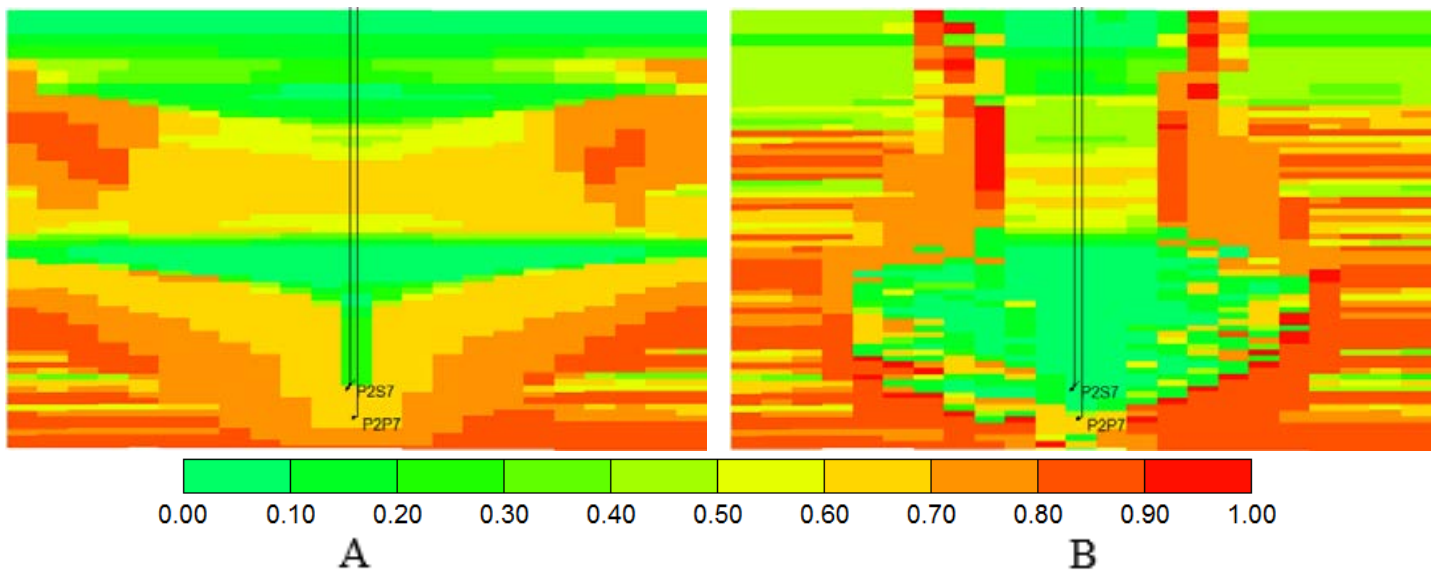

Figure 4-17 Oil Saturation distribution comparison of 2D heterogeneous model (May $1^{\text {st }}$, 2009) (A: SAGD; B: CAFA-SAGD)

The generation of foam, especially the strong bubbles concentrating around the margin of the steam chamber helps to slow down the steam rising velocity in terms of CAFA-SAGD, agreeing with the foam distribution pattern of the homogeneous model. This delays the vertical steam movement, counters the trend of steam chamber lateral extension in the early days, reduces the heat consumption towards the top water, and saves more energy to mobilize oil in the lower part. 
Also, it is speculated that the strong bubbles generated in the high-permeable area force the steam to penetrate into the low-permeable regions under a higher pressure. A certain number of weak bubbles accommodate in the low-permeable layers. In this way, bubbles manage to push the steam front uniformly and control the steam chamber circumference into a bowl-shape without severe fingering phenomenon (Figures 4-16 to 4-18). Also, the emulsions droplets are more accommodated around the inner border of the steam chamber (Figure 4-19). Wang and Dong (2010) hold that the entrapment of emulsion droplets posed resistance to water flow and diverted it into the un-swept area, which further combated the impacts of heterogeneity. Figure 4-20 shows the steam chamber profiles of CAFA-SAGD without emulsions blockage effect, which is less restricted compared to Figure 4-16. Finally, the performance of SAGD and CAFA-SAGD is listed in Table 4-2. The oil recovery factor has more than doubled with a 30\% lower SOR. A smaller steam chamber volume signifies a lower expansion rate.

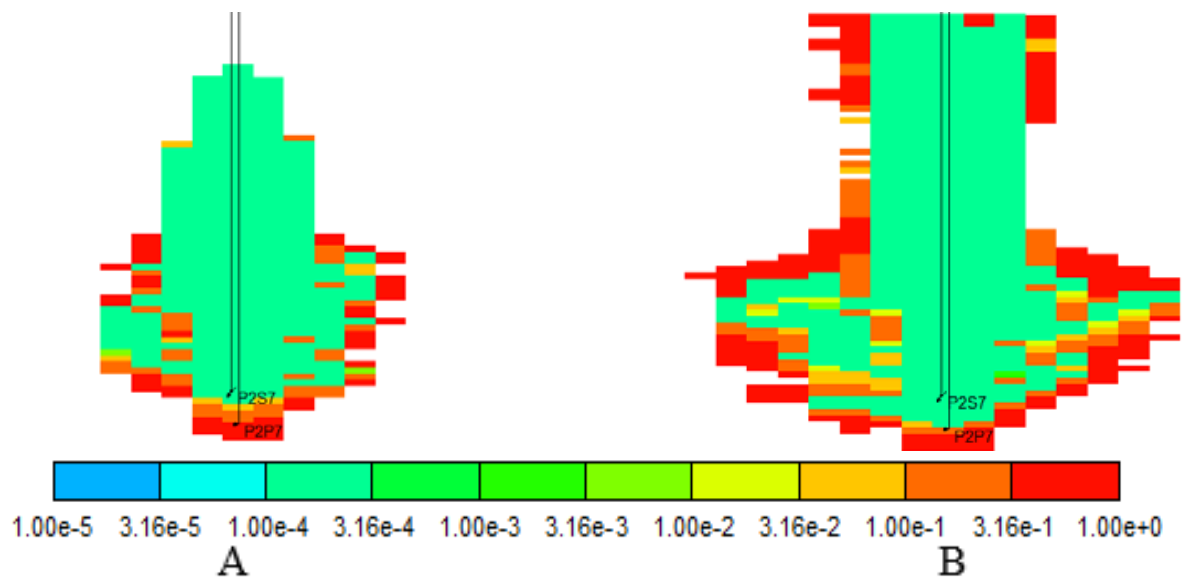

Figure 4-18 Lamella mole fraction distribution of 2D heterogeneous model (A: May $1^{\text {st }}, 2007$; B: May $1^{\text {st }}$ 2009) 


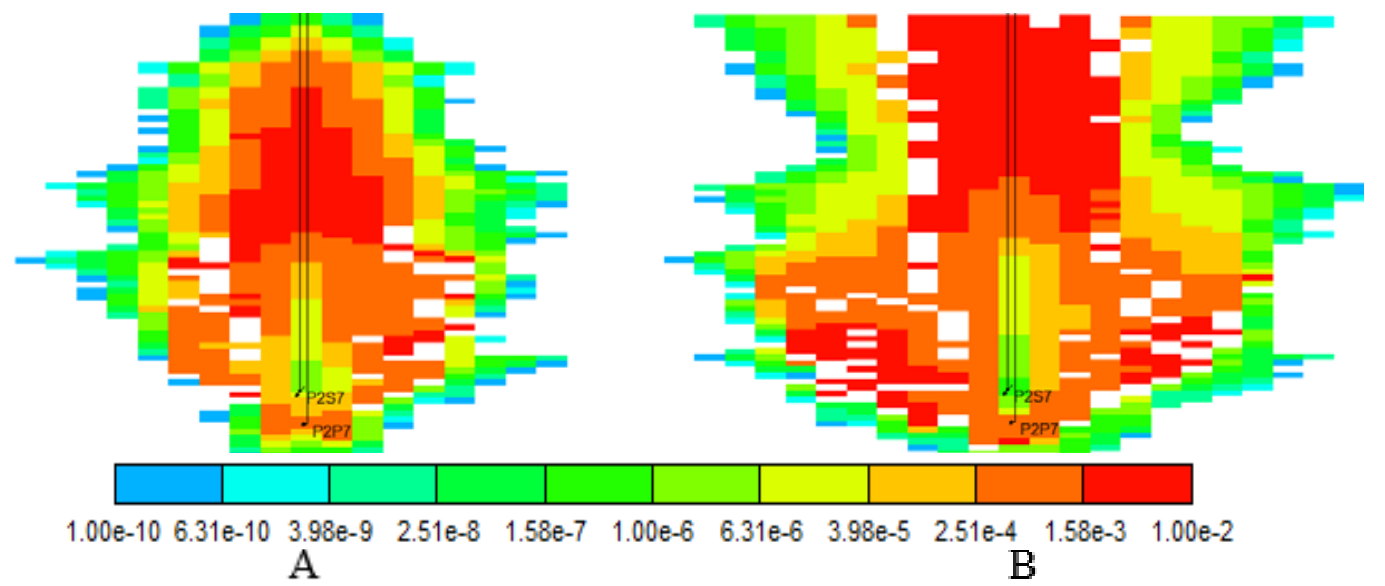

Figure 4-19 O/W emulsions mole fraction distribution of 2D heterogeneous model (A: May $1^{\text {st }}, 2007$; B: May $\left.1^{\text {st }}, 2009\right)$

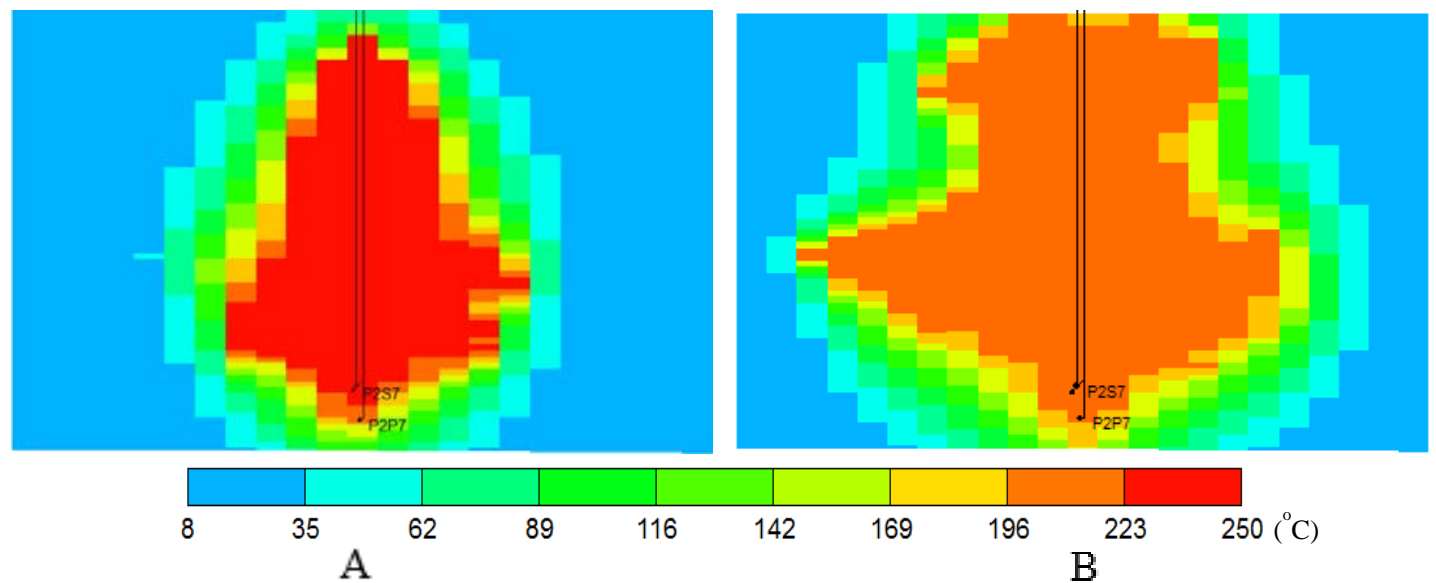

Figure 4-20 Temperature distribution comparison of $2 \mathrm{D}$ heterogeneous model $\left({ }^{\circ} \mathrm{C}\right)$ without emulsions blockage (A: May $1^{\text {st }}, 2007$; B: May $\left.1^{\text {st }}, 2009\right)$

Table 4-2 Performance comparison for heterogeneous SAGD and CAFA-SAGD cases

\begin{tabular}{|c|c|c|c|c|}
\hline Case & $\begin{array}{c}\text { Cumulative Oil } \\
\text { Production, } \mathrm{m}^{3}\end{array}$ & $\begin{array}{c}\text { Oil Recovery } \\
\text { Factor, } \%\end{array}$ & SOR, $\mathrm{m}^{3} / \mathrm{m}^{3}$ & $\begin{array}{c}\text { Steam Chamber } \\
\text { Volume, } \mathrm{m}^{3}\end{array}$ \\
\hline SAGD & $5.57 \mathrm{e} 4$ & 31.41 & 3.48 & $8.66 \mathrm{e} 4$ \\
\hline $\begin{array}{c}\text { CAFA- } \\
\text { SAGD }\end{array}$ & $1.27 \mathrm{e} 5$ & 71.38 & 2.47 & $5.62 \mathrm{e} 4$ \\
\hline
\end{tabular}




\subsubsection{Analysis of CAFA-SAGD Cases}

In the last section, we only consider the collapse of foam due to lamella instability during its movement. It is also assumed that chemical additives are fully employed to alter the interfacial properties without any loss. However, massive foam collapse occurs when co-existing with oil droplets. Furthermore, chemical additives are easily lost during the transport through pores and channels. Table 4-3 concludes the influences of the following elements (each influencing factor is added on the basis of the former one).

Table 4-3 Performance comparison for heterogeneous CAFA-SAGD cases with different influences

\begin{tabular}{|c|c|c|c|}
\hline Case & $\begin{array}{c}\text { Cumulative Oil } \\
\text { Production, } \mathrm{m}^{3}\end{array}$ & $\begin{array}{c}\text { Oil Recovery } \\
\text { Factor, } \%\end{array}$ & $\mathrm{SOR}, \mathrm{m}^{3} / \mathrm{m}^{3}$ \\
\hline + Oil Influence & $1.15 \mathrm{e} 5$ & 64.87 & 2.74 \\
\hline + Chemical Additives Adsorption & $1.05 \mathrm{e} 5$ & 59.35 & 2.80 \\
\hline + Chemical Additives Degradation & $9.34 \mathrm{e} 4$ & 52.68 & 2.91 \\
\hline +Chemical Additives Partition & $9.28 \mathrm{e} 4$ & 52.37 & 2.92 \\
\hline
\end{tabular}

\subsubsection{Oil Influence}

According to Schramm (1994), foam may have little interaction with oil sometimes when there is a well-defined border in-between. It happens that the border is stable enough and oil does not play any part at all. But more generally, there is one case that oil can be emulsified into small droplets. After a certain time, the oil drops can be released and carried away by the following lamella in a small proportion of cases. However, in most situations, those emulsified oil drops enter and spread 
at the gas-liquid interface, disturbing the stability of lamella and resulting in foam collapse. Schramm and Novosad (1990) observed the foam-oil interaction in a glass micro-visual cell and concluded that the oil destroyed foam mainly by emulsification of its droplets into foam structure and rupturing the liquid-gas interface. They maintained that the most oil-resistant foam always had high interfacial tension against oil but low surface tension, which was a research direction for the injected surfactants.

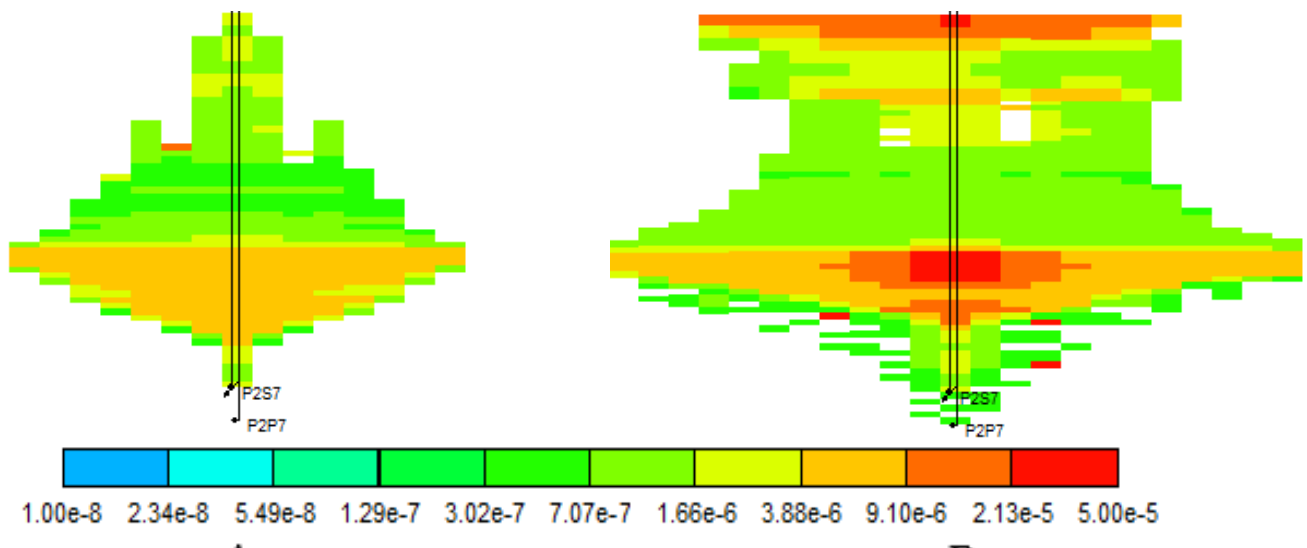

A

B

Figure 4-21 Lamella mole fraction distribution for oil influence study of 2D heterogeneous model (A: May $1^{\text {st }}$, 2007; B: May $1^{\text {st }}, 2009$ )

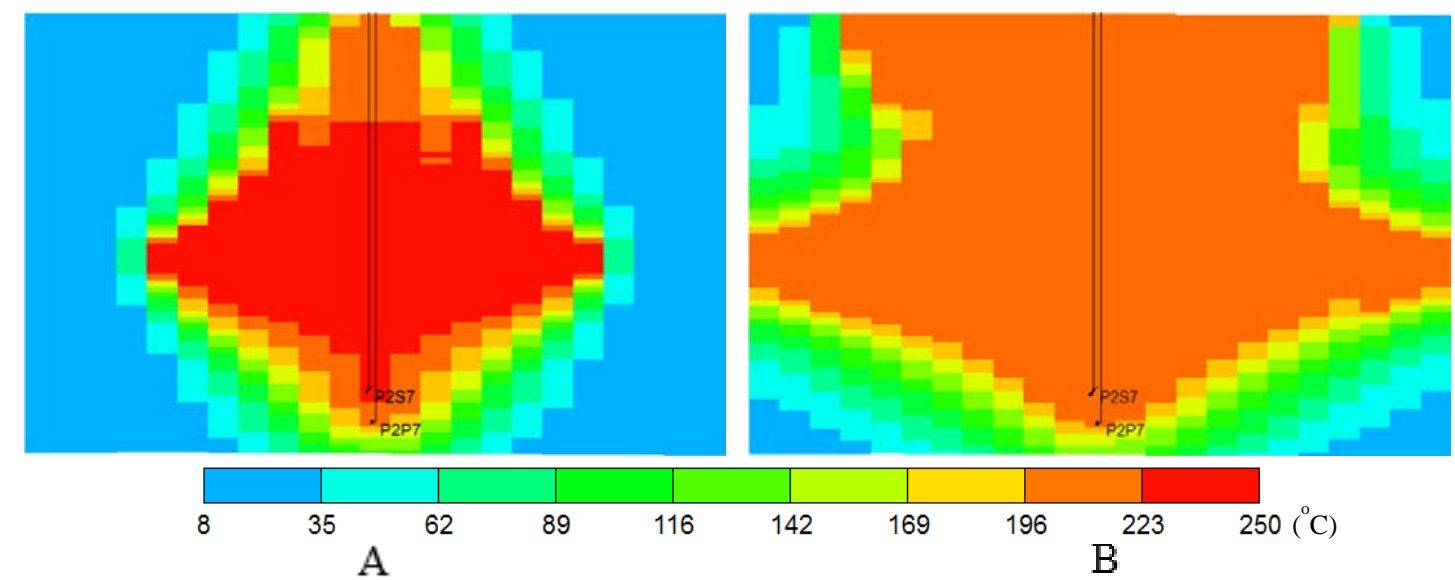

Figure 4-22 Temperature distribution for oil influence study of $2 \mathrm{D}$ heterogeneous model $\left({ }^{\circ} \mathrm{C}\right)$ (A: May $1^{\text {st }}, 2007$; B: May $1^{\text {st }}, 2009$ ) 


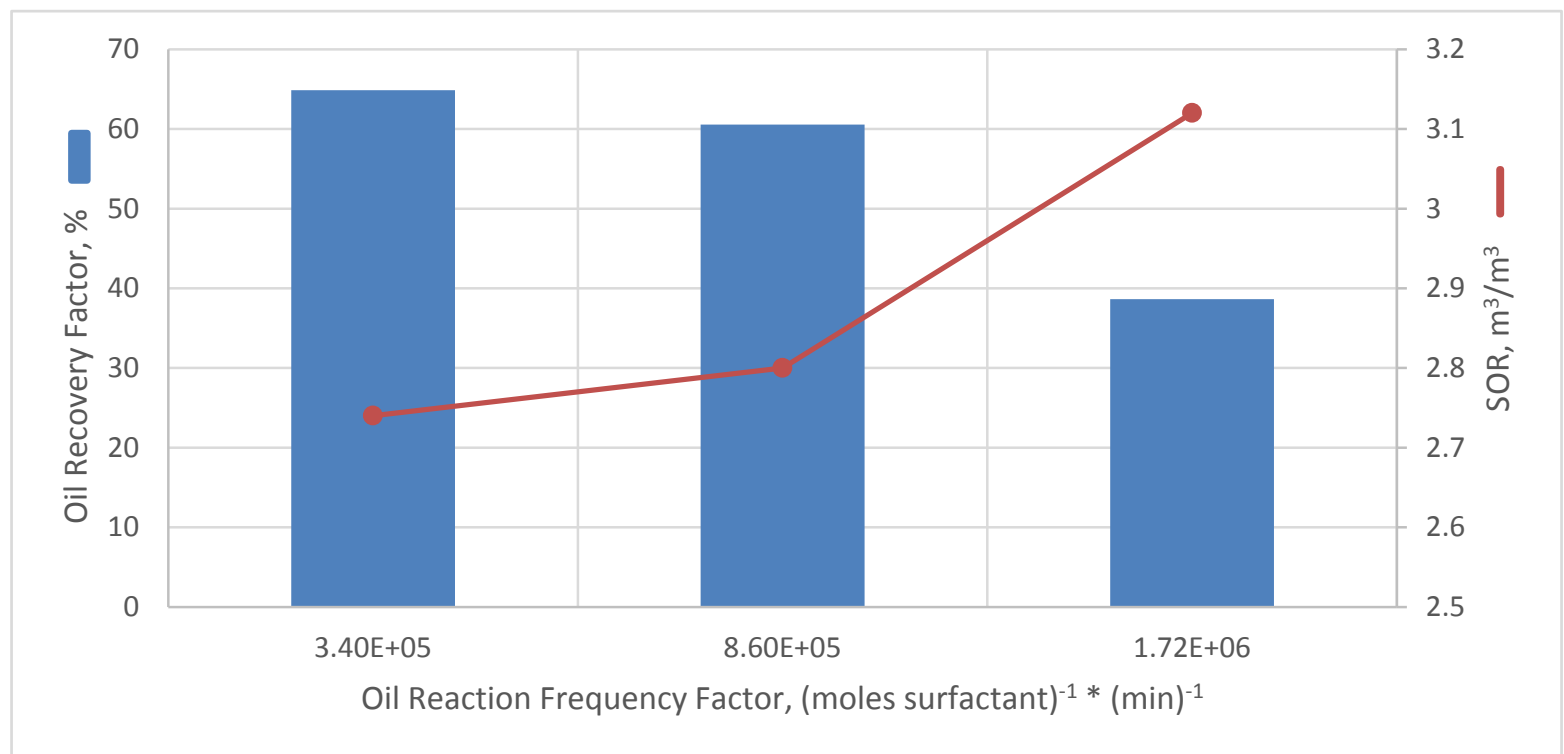

Figure 4-23 Sensitivity analysis for oil influence study of 2D heterogeneous model

Compared to Figure 4-18, Figure 4-21 shows the significant collapse of strong foam at the border as it lies close to the oil drainage path where oil influence is extremely severe. The weak bubbles inside the steam chamber are also impacted. In addition, the bubbles in the low-permeable area are still rather weak due to the relatively high oil saturation. Relatively strong bubbles accumulate where oil saturation approaches residual oil saturation and high water saturation area at the top. Consequently, it is also obvious that the steam chamber enlarges and protrudes in the highpermeable layers as the foam's restriction capacity for steam movement declines (Figure 4-22). The collapse of strong foam due to oil influence impacts the CAFA-SAGD operation dramatically, resulting in $10,000 \mathrm{~m}^{3}$ loss in oil production with a 10.93\% higher SOR (Table 4-3). A sensitivity analysis is conducted towards the oil influence extent. It is reflected that intensifying the oil 
influence by four times brings about a $40 \%$ drop in the oil recovery factor with a $14 \%$ increase in SOR (Figure 4-23).

\subsubsection{Chemical Additives Adsorption}

Surfactants are liable to be adsorbed at both liquid-liquid, liquid-gas and liquid-solid interfaces. As mentioned above, the adsorption at the liquid-liquid and liquid-gas interface does favor to lower the capillary pressure and intensify foam strength, claiming more oil and consuming less steam. But the adsorption at the liquid-solid interface may lead to a huge reduction in efficient surfactants concentration, and even a complete failure for surfactants assisted flooding. Combined with oil influence, we investigate the effects of surfactants adsorption.

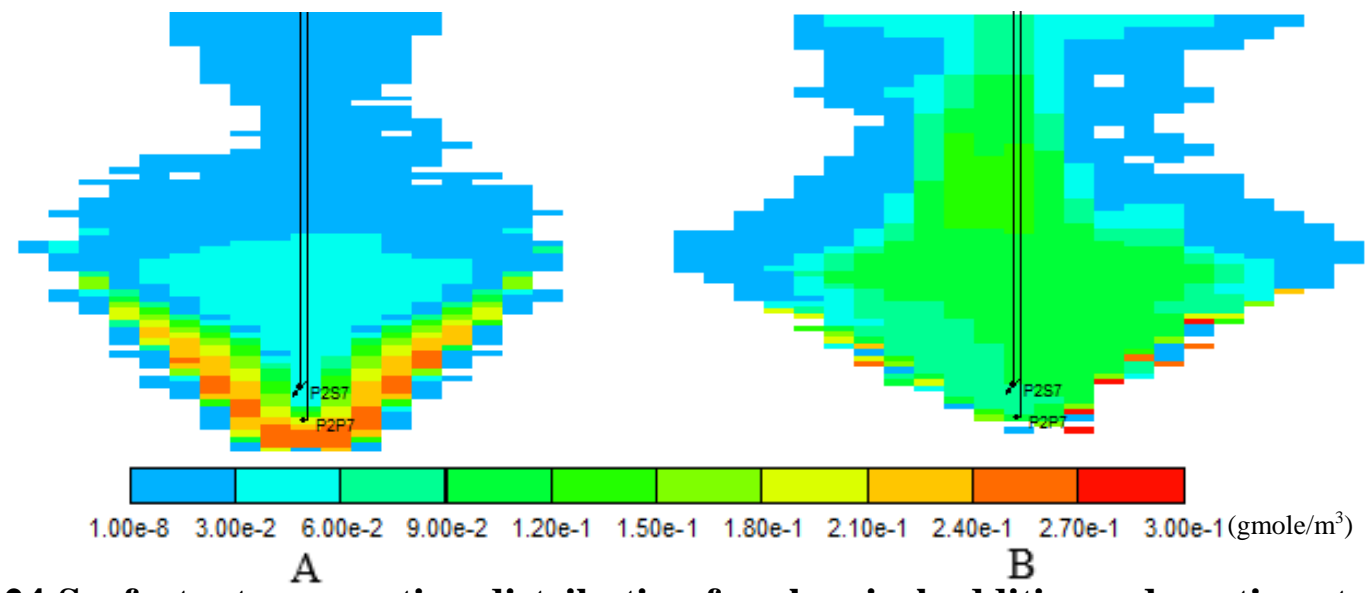

Figure 4-24 Surfactants adsorption distribution for chemical additives adsorption study of 2D heterogeneous model (gmole $\left./ \mathrm{m}^{3}\right)$ (A: May $1^{\text {st }}, 2007$; B: May $\left.1^{\text {st }}, 2009\right)$ 

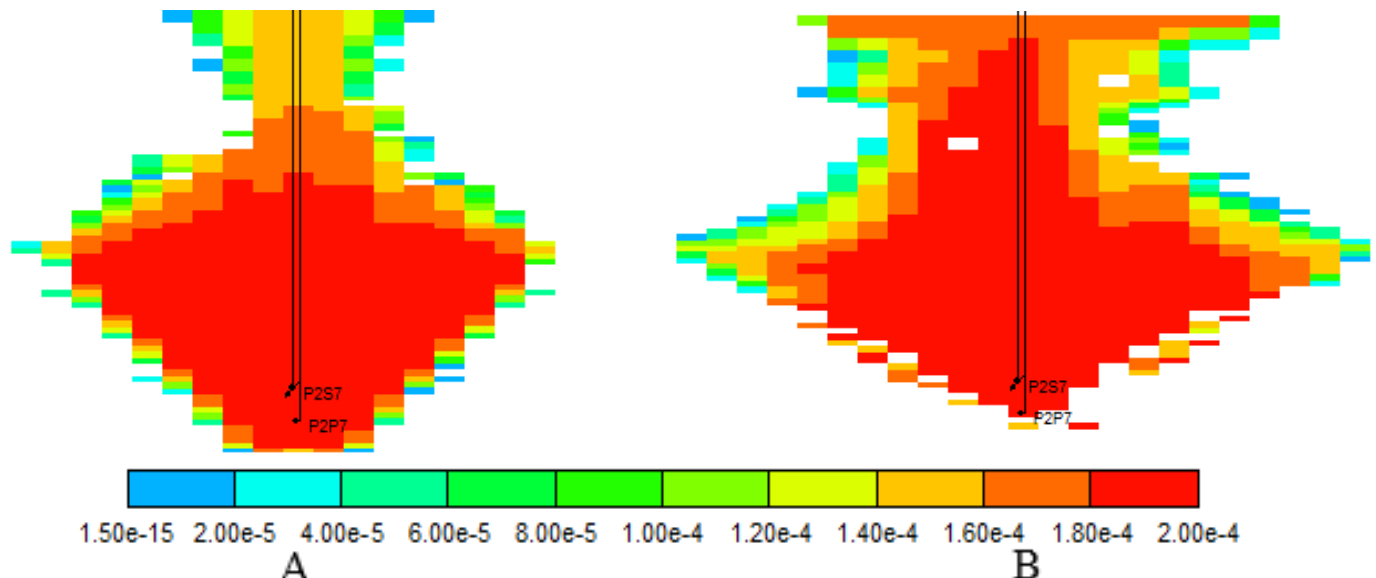

Figure 4-25 Surfactants mole fraction distribution for chemical additives adsorption study of 2D heterogeneous model (A: May $1^{\text {st }}, 2007$; B: May $\left.1^{\text {st }}, 2009\right)$

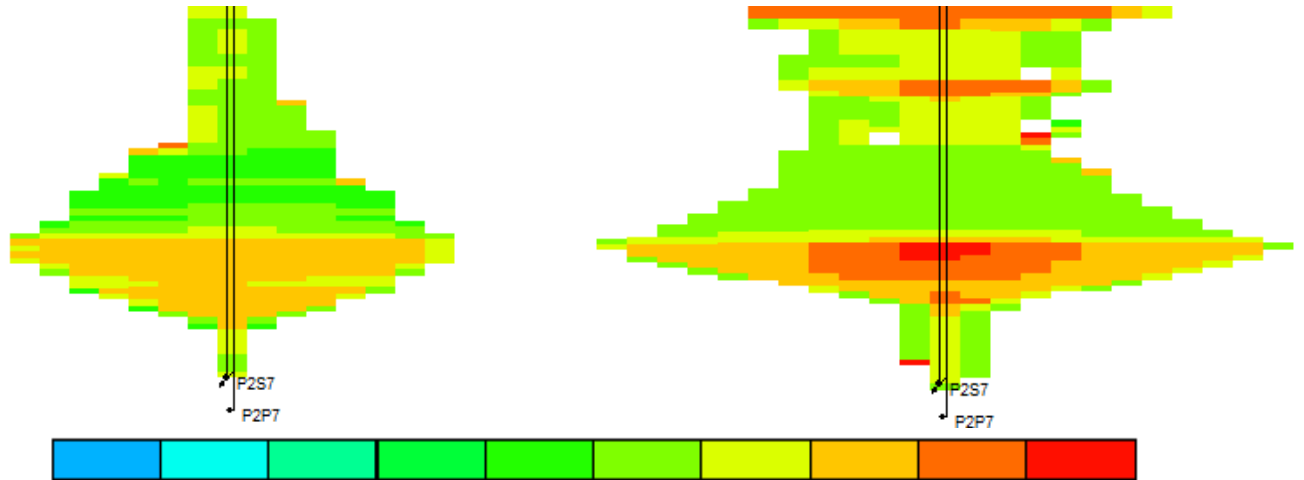

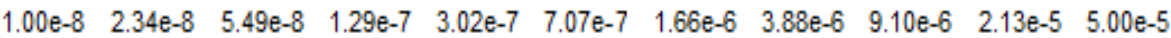

A

Figure 4-26 Lamella mole fraction distribution for chemical additives adsorption study of 2D heterogeneous model (A: May $1^{\text {st }}, 2007$; B: May $\left.1^{\text {st }}, 2009\right)$

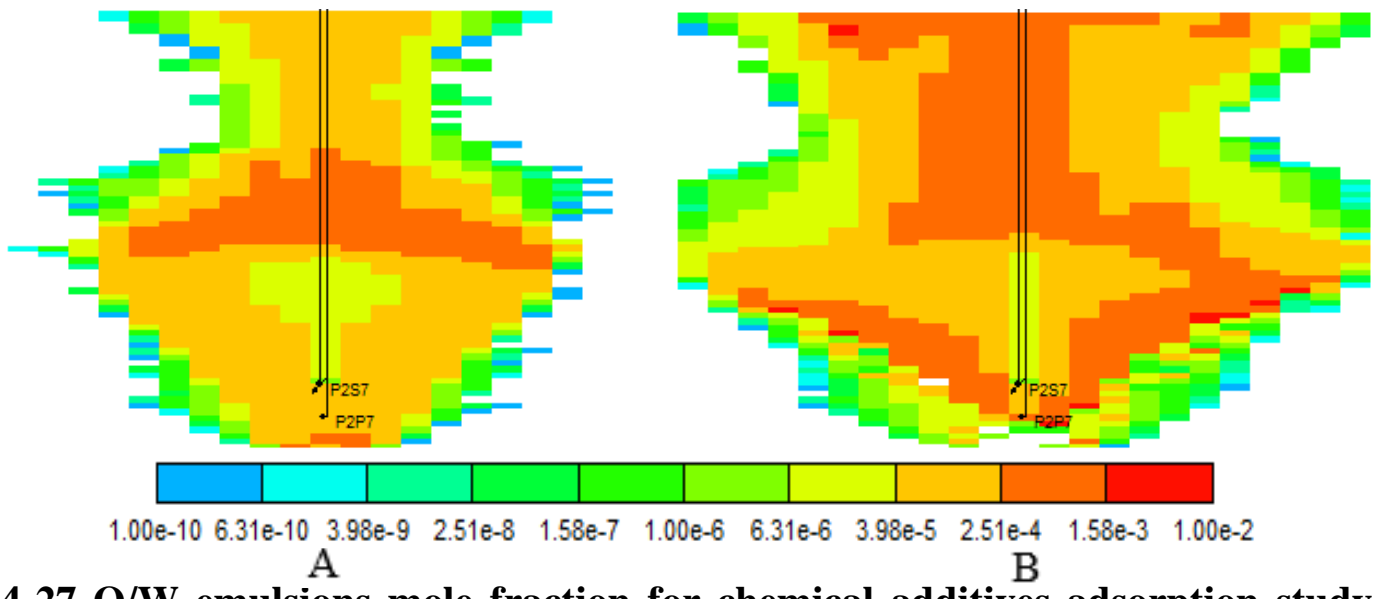

Figure 4-27 $\mathrm{O} / \mathrm{W}$ emulsions mole fraction for chemical additives adsorption study of $2 \mathrm{D}$ heterogeneous model (A: May $1^{\text {st }}, 2007$; B: May $\left.1^{\text {st }}, 2009\right)$ 


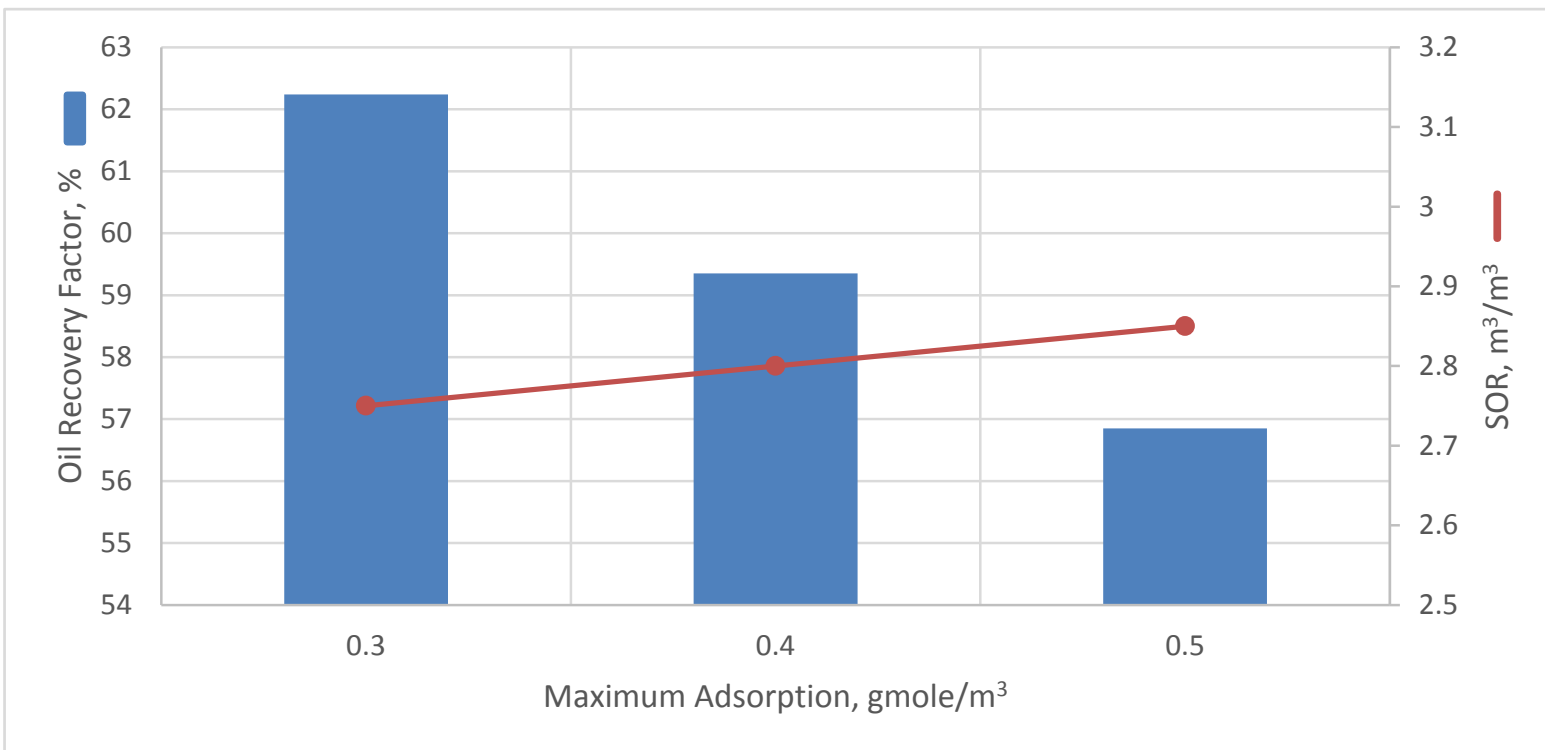

Figure 4-28 Sensitivity analysis for chemical additives adsorption study of 2D heterogeneous model

Figures 4-24 and 4-25 depict that the adsorption of surfactants mostly happens inside the steam chamber and along the drainage path. The surfactants concentration is higher close to the injector inside the steam chamber. Thus it is no wonder that the adsorption is much more severe as the base figure is larger. At the same time, even though fewer surfactants accommodate around the drainage path, the temperature is much lower. This lower temperature favors a larger adsorption coefficient. But the remaining surfactants content is still higher inside the chamber as the surfactants are continuously injected and remedied. According to Figure 4-26, the smaller efficient surfactants concentration leads to further collapse of some weak bubbles. The emulsions concentration also drops with a lower surfactants concentration (Figure 4-27). Table 4-3 shows that adsorption itself brings about 5\% further oil loss. According to the sensitivity analysis, enlarging the adsorption 
capacity by $2 / 3$ times leads to more than $5 \%$ reduction in oil recovery (Figure 4-28).

\subsubsection{Chemical Additives Degradation}

Besides adsorption, surfactants efficient concentration tends to be even lower. For one thing, after being injected, surfactants contact with fluids and rocks, initiating multiple physical and chemical phenomena, such as diffusion, dispersion and chemical reaction. Diffusion is the result of concentration difference. Molecular motion drives chemical additive molecules to diffuse from a high concentration area to a low concentration area, whittling down the amount of chemical additives working for oil recovery enhancement, while dispersion is caused by flow rate difference and complex pore structures by comparison. Surfactants molecules are also known to react with bivalent ions in the formation water and further precipitate. All those phenomena account for surfactants loss, which is a great technical barrier for the surfactants involved techniques. For another thing, phenomena caused by the complicated reservoir conditions such as thermal degradation aggravates the loss. High temperature is a big challenge to chemical additives stability.

It also affects the accumulation of their molecules at a lamella. We study the influence of surfactants degradation towards CAFA-SAGD performance based on the case above. 


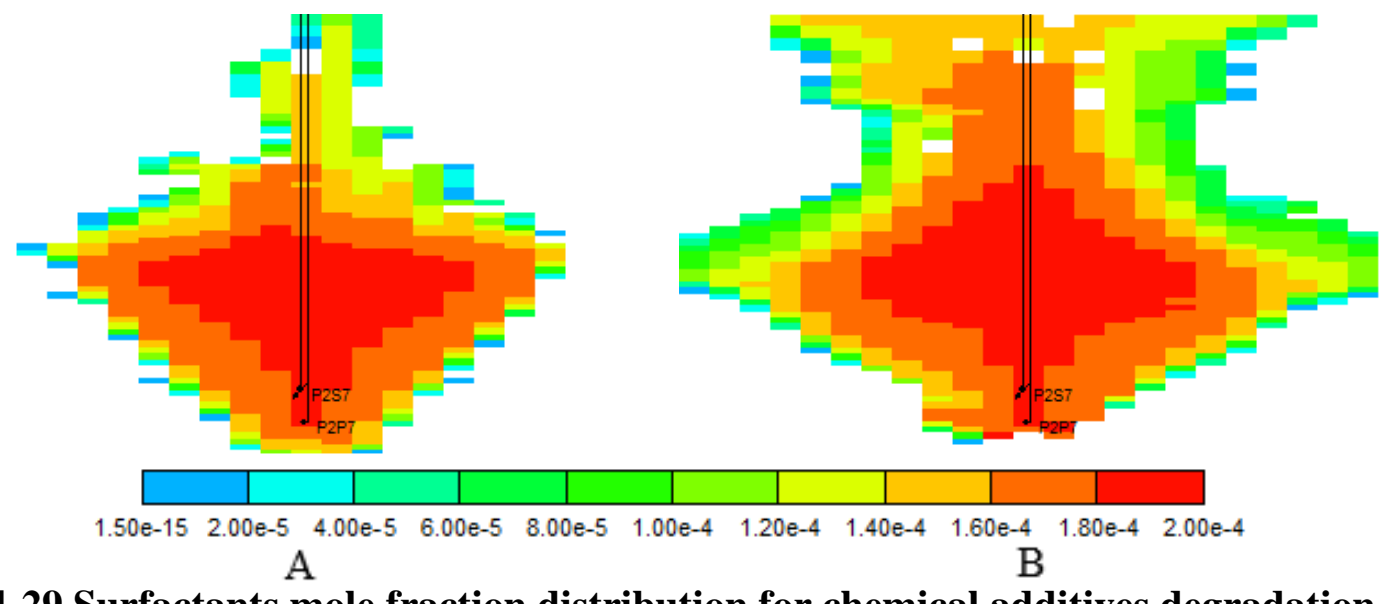

Figure 4-29 Surfactants mole fraction distribution for chemical additives degradation study of 2D heterogeneous model (A: May $1^{\text {st }}, 2007$; B: May $\left.1^{\text {st }}, 2009\right)$

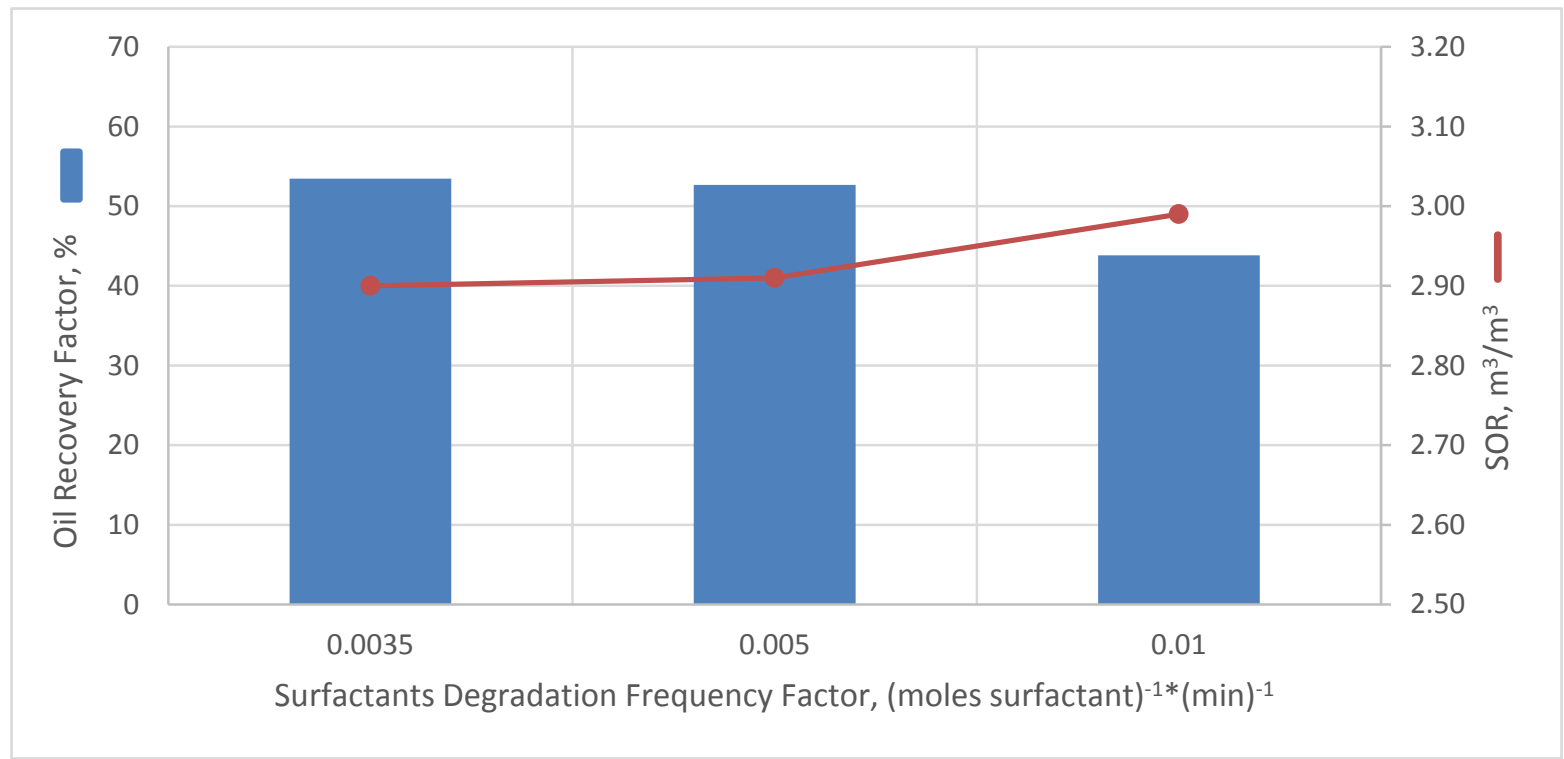

Figure 4-30 Sensitivity analysis for chemical additives degradation study of 2D heterogeneous model

Compared to Figure 4-25, it is shown that surfactants degradation leads to a certain loss of the surfactants (Figure 4-29). Similar to adsorption, degradation causes 3\% loss in oil output and a higher SOR due to lower surfactants concentration and fewer bubbles (Table 4-3). A sensitivity 
analysis shows that oil recovery is reduced by $19 \%$ along with the increase of surfactants degradation frequency by three times (Figure 4-30).

\subsubsection{Chemical Additives Partition}

Surfactants molecules also have the tendency to enter the oil phase if they have oil solubility. Those surfactants cannot participate the generation and preservation of bubbles as foam is hardly stabilized in the oil phase. More surfactants in the center of a steam chamber enters the oil phase as the surfactants concentration is higher there (Figures 4-31, 4-32). The higher the partition coefficient, the less foam is generated and protected. Consequently, oil production is reduced by 0.3\% slightly (Table 4-3). Figure 4-33 shows that the influence of K-values is relatively small compared to the elements mentioned above. Oil recovery only drops by less than $3 \%$ when oil solubility is increased by three times.

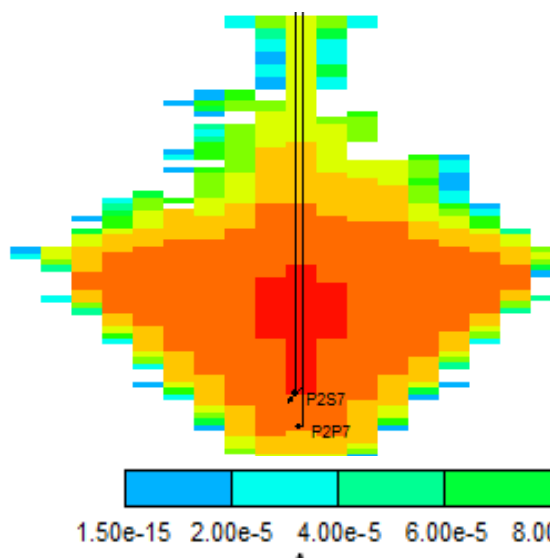

A

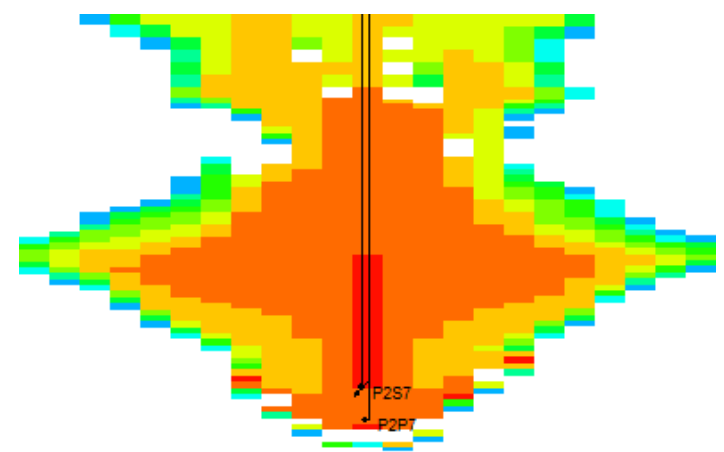

Figure 4-31 Surfactants mole fraction distribution in water phase for chemical additives partition study of 2D heterogeneous model (A: May $1^{\text {st }}, 2007$; B: May $1^{\text {st }}, 2009$ ) 


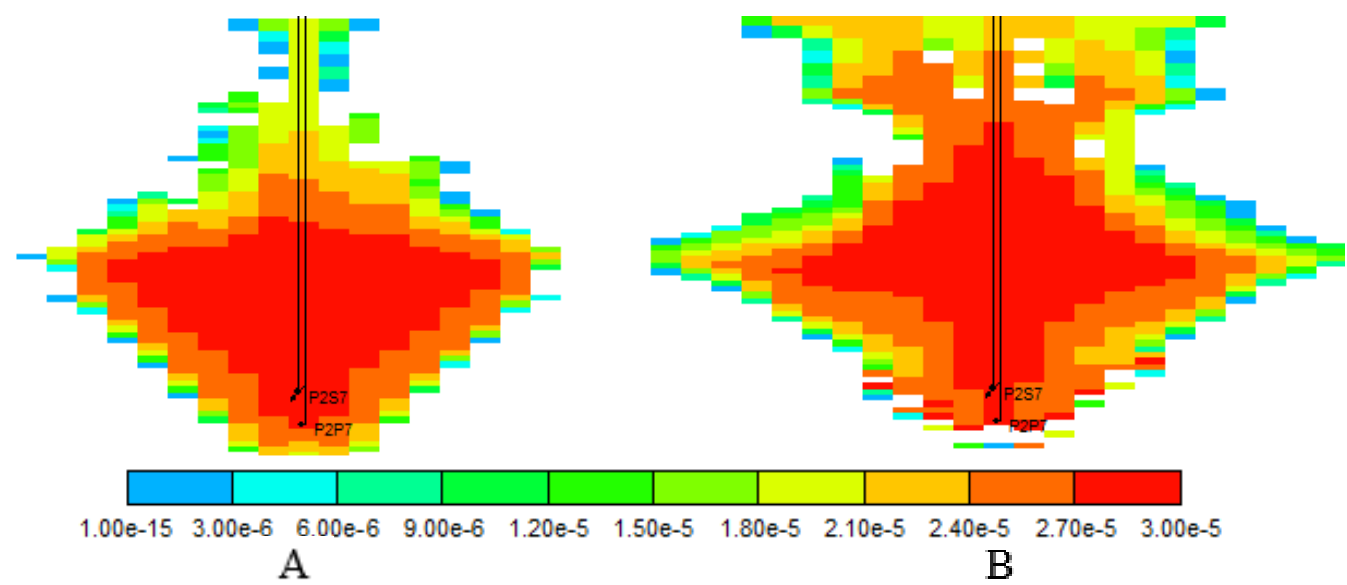

Figure 4-32 Surfactants mole fraction distribution in oil phase for chemical additives partition study of 2D heterogeneous model (A: May $1^{\text {st }}, 2007$; B: May $1^{\text {st }}, 2009$ )

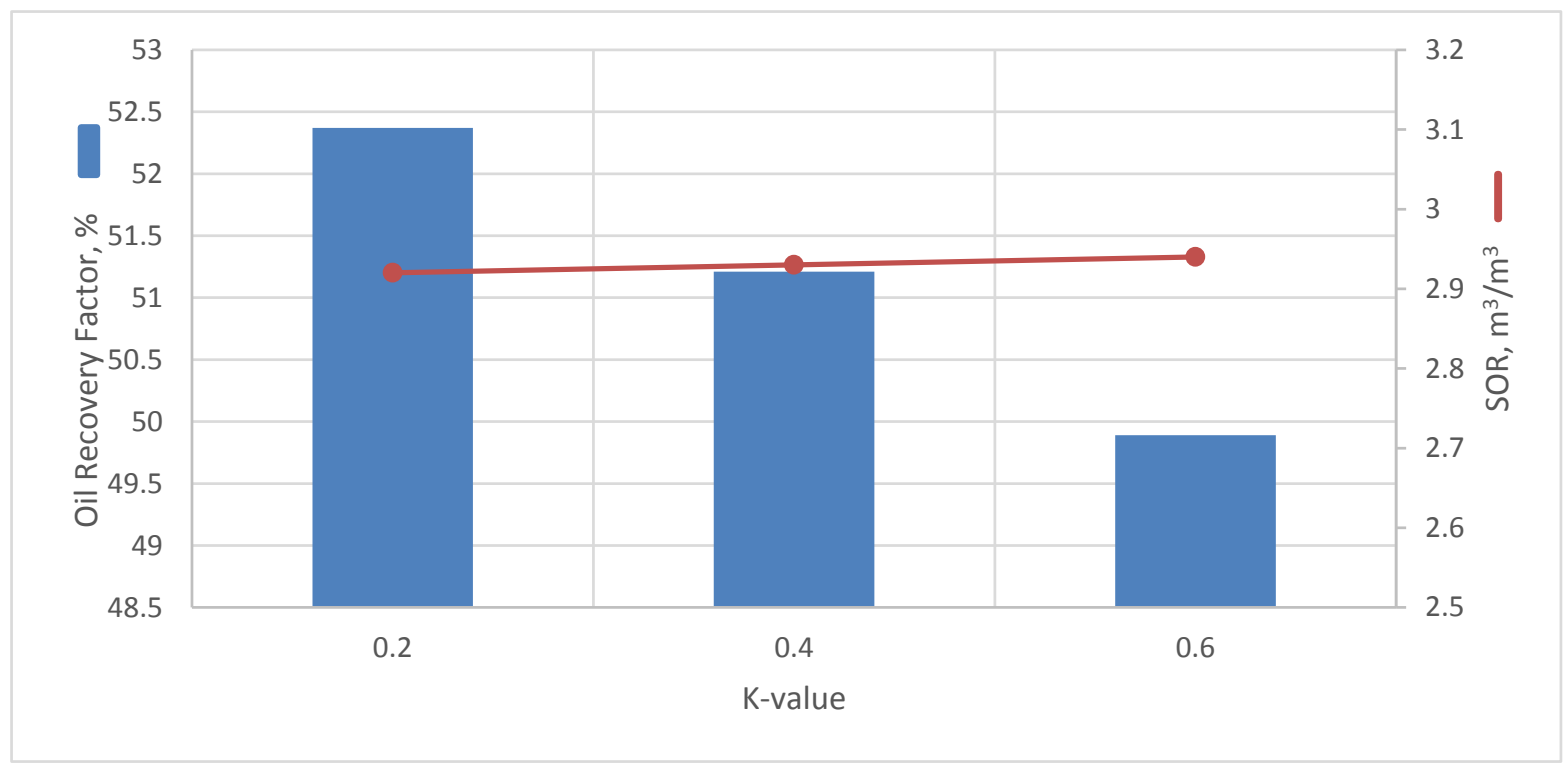

Figure 4-33 Sensitivity analysis for chemical additives partition study of 2D heterogeneous model

\subsection{Conclusions}

In this chapter, a heterogeneous model is built to study how foam behaves in the field. The results show that foam behaves well in reducing the heat loss towards the water zone and diverting the 
steam into low-permeable layers to maintain a uniform expansion of the steam front, which helps to obtain higher sweep efficiency. However, numerous influencing factors, for instance, oil influence, chemical additives adsorption, degradation and partition need to be considered as they pose great threats to CAFA-SAGD. According to Table 4-3, the oil recovery factor of CAFASAGD is around $21 \%$ higher than that of SAGD after all the above elements being included. Simultaneously, SOR is reduced by $16 \%$ approximately. It is suggested to find and synthesize surfactants and foam which are able to resist the above-mentioned influencing factors to achieve the highest stability. 


\section{CHAPTER 5: ANALYTICAL MODEL}

Experiments show that steam front advances in the form of numerous fingers rather than a flat front. SAGD relies on heat transfer through steam chamber fingers protruding into a cold reservoir to lower the oil viscosity and further drains oil downward to a production well. Under the assumptions that the fingers rise at a constant velocity and heat transfer is carried out merely by conduction, Butler developed an analytical model to predict the steam finger rising velocity and the corresponding oil production rate considering multiphase flow, which is shown in Appendix A. As illustrated above, with a lamella acting as division between the gas and aqueous phases, gas phase movement is blocked and steam breakthrough at the overburden is controlled. Therefore, the gas flow rate decreases and oil production process is disturbed. The addition of surfactants, which is required to generate foam, reduces the interfacial tension and intensifies the emulsification process. Multiphase flow is thus disrupted, and more trapped oil is mobilized in this process. Therefore, we derive the CAFA-SAGD model accounting for the above-mentioned phenomenon based on Butler's finger rising model. We also measure and analyze the effects of surfactants concentration, oil saturation and a capillary number.

\subsection{Modified CAFA-SAGD Model}

As previously discussed, the decreased interfacial tension at the water-gas interface facilitates lamellae and bubbles generation. With a lamella separating between the gas phase and the aqueous 
phase, the movement of the gas phase is hindered. Though both the apparent steam viscosity and gas relative permeability are changed. But to make it simple, only the alteration of gas relative permeability is adopted to account for the gas phase mobility alteration, while the gas viscosity is considered as constant. Here we use the empirical model used in CMG ${ }^{\circledR}$ STARS introduced in Chapter 2 to illustrate the foam performance. Also, as foam is a complicated mixture whose properties rely heavily on its texture and the texture keeps changing with a large amount of elements during the movement and production, we will analyze some influencing factors.

\subsubsection{CMG Empirical Foam Model}

The basic foam model in $\mathrm{CMG}^{\circledR}$ STARS relies on the dimensionless interpolation factor $F M$ to measure the mobility reduction mechanism. $F M$ is the calculation result after integrating several elements which are capable to alter foam strength. In the simulator, the gas permeability is reduced to $F M * k_{r g}$, in which $F M$ ranges from 0 to 1 . Therefore, mobility reduction is larger when $F M$ is closer to 0 (CMG Manual, 2015).

$$
F M=\frac{1}{1+F M M O B * F 1 * F 2 * F 3 * F 4 * F 5 * F 6}
$$

$F 1$ is a surfactants concentration dependent function.

$$
F 1=\left(\frac{\text { surfactant mole fraction }}{F M S U R F}\right) \text { EPSURF }
$$

where FMSURF is a critical surfactants mole fraction and EPSURF is the parameter that controls the mobility's dependence on surfactants concentration. $F 1$ increases with a smaller 
FMSURF while it decreases with a larger EPSURF. The reason is that the injected surfactant concentration is more easily to reach FMSURF and form strong bubbles when FMSURF is smaller, which is conducive to foam mobility control.

$F 2$ is an oil saturation dependent function.

$$
F 2=\left(\frac{\text { FMOIL-OIL SATURATION }}{\text { FMOIL-FLOIL }}\right)^{E P O I L}
$$

where FMOIL and FLOIL are a higher critical oil saturation and a lower critical oil saturation used in foam interpolation separately. EPOIL is the parameter determining the oil saturation contribution to the calculation. F2 is smaller if FMOIL and FLOIL decline, which implies a lower threshold for foam collapse and less foam stability when foam encounters oil droplets.

F3 is a capillary number dependent function.

$$
F 3=\left(\frac{F M C A P}{\text { CAPILLARY NUMBER }}\right)^{E P C A P}
$$

where FMCAP is reference rheology capillary number. EPCAP stands for the effect of the capillary number. It is obvious that a larger FMCAP guarantees bubbles with higher stability and mobility reduction ability.

F4 is a critical capillary number dependent function.

$$
\left.F 4=\left(\frac{F M G C P-C A P I L L A R Y N U M B E R}{F M G C P}\right)\right)^{E P G C P}
$$

where $F M G C P$ is a critical capillary number for foam generation. EPGCP reflects the effect of 
critical capillary number towards $F M$. A lower $F M G C P$ is more likely to generate weaker bubbles.

F5 is an oil mole fraction dependent function.

$$
F 5=\left(\frac{\text { FMOMF-OIL MOLE FRACTION (NUMX)) }}{\text { FMOMF }}\right)^{\text {EPOMF }}
$$

where $F M O M F$ is a critical oil mole fraction for component $N U M X$. EPOMF is the exponent for the oil mole fraction contribution to do the interpolation. Increasing FMOMF contributes to the foam mobility reduction efficiency.

$F 6$ is a salt mole fraction dependent function.

$$
F 6=\left(\frac{\text { MOLE FRACTION (NUMW)-FLSALT }}{\text { FMSALT-FLSALTY NUMBER }}\right) \text { EPSALT }
$$

where FMSALT and FLSALT are a critical higher and a critical lower salt mole fraction used in foam interpolation separately. EPSALT is the parameter that controls the salt mole fraction contribution to the calculation. Increasing both FMSALT and FLSALT tends to destroy foam stability.

\subsubsection{Modified CAFA-SAGD Model}

As the gas relative permeability needs to be altered due to foam generation, Equation (A-2) is changed to Equation (5-8). 


$$
Q_{g}=\left(\frac{K K_{r g} x F M}{\mu_{g}}\right)\left(\frac{\partial P}{\partial y}-\rho_{g} g\right)
$$

where $Q_{g}$ is the gas volumetric flow, $\mathrm{m}^{3} /(\mathrm{m} \cdot \mathrm{s}) ; K$ is the reservoir permeability, $\mathrm{m}^{2} ; K_{r g}$ is the gas relative permeability; $x$ is the distance away from the center on finger, $\mathrm{m} ; \mu_{g}$ is the gas viscosity, $\mathrm{Pa} \cdot \mathrm{s} ; \frac{\partial P}{\partial y}$ is pressure gradient, $\mathrm{Pa} / \mathrm{m} ; \rho_{g}$ is the gas density, $\mathrm{kg} / \mathrm{m}^{3} ; g$ is the gravity acceleration, $\mathrm{m}^{2} / \mathrm{s}$.

Here we discuss the W/O emulsions as the emulsification type can change along with surfactants and salinity. W/O emulsions have a larger viscosity compared to oil. The viscosity of W/O emulsions is shown below (Equation (5-9)). Then the viscosity of oil flow receives the influences from both steam heating and emulsification when the W/O emulsions drains together with oil at the interface.

$$
\mu_{\mathrm{em}}=\mu_{\mathrm{o}}\left[1+2.5\left(\frac{\varphi+0.4}{\varphi+1}\right) \mathrm{V}\right]
$$

where $\mu_{\mathrm{em}}$ is the emulsions viscosity, Pa.s; $\mu_{\mathrm{o}}$ is the oil viscosity, Pa.s; $\varphi$ is the water to oil viscosity ratio; $\mathrm{V}$ is the volume fraction of water in the emulsions.

Introducing the kinematic viscosity into Equation (5-9), we can get Equation (5-10).

$$
\frac{1}{\vartheta_{e m}}=\frac{\frac{\rho_{e m}}{\rho_{o}}+\frac{\rho_{e m} \mu_{\mathrm{W}}}{\rho_{o}^{2} \vartheta_{o}}}{(2.5 V+1) \frac{\mu_{\mathrm{W}}}{\rho_{o}}+(V+1) \vartheta_{o}}
$$

where $\vartheta_{\text {em }}$ is the emulsions kinematic viscosity, $\mathrm{Pa} \cdot \mathrm{s} ; \mu_{\mathrm{w}}$ is the water viscosity, $\mathrm{Pa} \cdot \mathrm{s} ; \rho_{\text {em }}$ is the emulsions density, $\mathrm{kg} / \mathrm{m}^{3} ; \rho_{o}$ is the oil density, $\mathrm{kg} / \mathrm{m}^{3} ; \vartheta_{o}$ is the oil kinematic viscosity, $\mathrm{m}^{2} / \mathrm{s}$. 
With the help of Equations (A-4) and (A-5), Equation (5-10) is further developed into Equation $(5-11)$.

$$
\frac{1}{\vartheta_{e m}}=\frac{\frac{\rho_{e m}}{\rho_{o}}+\frac{\rho_{e m} \mu_{\mathrm{w}}}{\rho_{0}^{2} \vartheta_{o S}}\left(1-\frac{\varepsilon}{\sqrt{\pi \alpha t}}\right)^{m}}{(2.5 V+1) \frac{\mu_{\mathrm{W}}}{\rho_{o}}+(V+1) \vartheta_{o s}\left(1-\frac{\varepsilon}{\sqrt{\pi \alpha t}}\right)^{-m}}
$$

$\vartheta_{O S}$ is the oil kinematic viscosity at $T_{S}, \mathrm{~m}^{2} / \mathrm{s} ; T_{S}$ is the steam temperature, ${ }^{\circ} \mathrm{C} ; \varepsilon$ is the distance away from the point $\mathrm{P}$, which is a point at the inner border of the oil drainage path, $\mathrm{m} ; \alpha$ is the thermal diffusivity, $\mathrm{m}^{2} / \mathrm{s} ; t$ is time, $\mathrm{s} ; m$ is a constant depending on oil properties.

As $\rho_{\mathrm{em}}$ is the density of water in oil emulsions, it can be given by Equation (5-12).

$$
\rho_{\mathrm{em}}=\rho_{\mathrm{w}} \mathrm{V}+\rho_{\mathrm{o}}(1-\mathrm{V})
$$

where $\rho_{w}$ is the water density, $\mathrm{kg} / \mathrm{m}^{3}$.

Then Equation (5-11) is transformed into Equation (5-13).

$$
\frac{1}{\vartheta_{e m}}=\frac{\frac{\rho_{\mathrm{W} V}+\rho_{o}(1-\mathrm{V})}{\rho_{O}}+\frac{\left[\rho_{\mathrm{W}} \mathrm{V}+\rho_{o}(1-\mathrm{V})\right] \mu_{\mathrm{W}}}{\rho_{0}^{2} \vartheta_{S}}\left(1-\frac{\varepsilon}{\sqrt{\pi \alpha t}}\right)^{m}}{(2.5 V+1) \frac{\mu_{\mathrm{W}}}{\rho_{O}}+(V+1) \vartheta_{o s}\left(1-\frac{\varepsilon}{\sqrt{\pi \alpha t}}\right)^{-m}}
$$

We define several parameters to simplify the equation.

$$
\begin{gathered}
A=\frac{\rho_{\mathrm{w}} \mathrm{V}+\rho_{\mathrm{o}}(1-\mathrm{V})}{\rho_{o}} \\
B=\frac{\left[\rho_{\mathrm{w}} \mathrm{V}+\rho_{\mathrm{o}}(1-\mathrm{V})\right] \mu_{\mathrm{w}}}{\rho_{o}^{2} \vartheta_{o s}} \\
C=(2.5 V+1) \frac{\mu_{\mathrm{w}}}{\rho_{o}} \\
D=(V+1) \vartheta_{o s}
\end{gathered}
$$




$$
\mathrm{z}=\left(1-\frac{\varepsilon}{\sqrt{\pi \alpha t}}\right)
$$

Then Equation (5-13) is represented by Equation (5-19).

$$
\frac{1}{\vartheta_{e m}}=\frac{A+B z^{m}}{C+D z^{-m}}
$$

We consider that all the heated oil is emulsified. The temperature of emulsions leaving a finger is $T_{e m}$. Similar to Equation (A-14), $T_{e m}$ can be calculated by Equation (5-20).

$$
T_{e m}=\int_{0}^{\varepsilon_{1}} \frac{T d \varepsilon}{\vartheta_{e m}} / \int_{0}^{\varepsilon_{1}} \frac{d \varepsilon}{\vartheta_{e m}}=\frac{\int_{0}^{1}\left[T_{R}+\left(T_{S-} T_{R}\right) z\right] \frac{A+B z^{m}}{C+D z^{-m}} d z}{\int_{0}^{1} \frac{A+B z^{m}}{C+D z^{-m}} d z}
$$

where $\varepsilon_{1}$ is the distance between point $\mathrm{P}$ and the symmetry plane, $\mathrm{m} ; T_{R}$ is the reservoir temperature, ${ }^{\circ} \mathrm{C}$.

After the derivation of mixture temperature, we can continue to calculate $H_{c}, H_{o}$ and $H_{R}$ with Equations (A-11) to (A-13), where $H_{c}$ is the heat inside the steam chamber, $\mathrm{kJ} / \mathrm{s} ; H_{o}$ is the heat in oil flow leaving between the steam chambers, $\mathrm{kJ} / \mathrm{s}$; and $H_{R}$ is the heat in the reservoir, $\mathrm{kJ} / \mathrm{s}$.

The steam oil ratio $R^{\prime}$ is further shown in Equation (5-21). $R^{\prime}=R \rho_{g} / \rho_{o}$, where $R$ is the ratio of the gas flow rate to the oil flow rate, through which the mass steam oil ratio is changed to the volumetric steam oil ratio. 


$$
\begin{aligned}
& R^{\prime}=\frac{1}{\rho_{e m} \emptyset \lambda \Delta S_{o^{\prime}} X_{i}}\left\{\rho_{c} C_{c}\left(T_{S}-T_{R}\right) X_{i}+\rho_{e m} C_{e m} \emptyset \Delta S_{o}{ }^{\prime}\left[\frac{\int_{0}^{1}\left[T_{R}+\left(T_{S-} T_{R}\right) z\right] \frac{A+B z}{C+D z^{-m}} d z}{\int_{0}^{1} \frac{A+B z^{m}}{C+D z^{-m}} d z}-T_{R}\right] X_{i}+\right. \\
& \left.\frac{1}{2} \rho_{R} C_{R}\left(T_{S}-T_{R}\right)\left(1-X_{i}\right)\right\}
\end{aligned}
$$

where $\emptyset$ is the porosity; $\lambda$ is latent heat, $\mathrm{kJ} / \mathrm{kg} ; \Delta S_{o}{ }^{\prime}$ is the change of oil saturation after the surfactants injection, which will be discussed later; $X_{i}=x_{i} / x_{1}$, which is the dimensionless finger width; $x_{1}$ is half distance between the two fingers, $\mathrm{m} ; x_{i}$ is the interface position, $\mathrm{m} ; \rho_{c} C_{c}$ is the volumetric heat capacity of the steam chamber together with the residual oil and connate water, $\mathrm{kJ} /\left(\mathrm{m}^{3} \cdot{ }^{\circ} \mathrm{C}\right) ; C_{e m}$ is the specific heat capacity of the emulsions flow leaving between the steam chambers, $\mathrm{kJ} /\left(\mathrm{kg} \cdot{ }^{\circ} \mathrm{C}\right) ; \rho_{R} C_{R}$ is the volumetric heat capacity of the reservoir, $\mathrm{kJ} /\left(\mathrm{m}^{3} \cdot{ }^{\circ} \mathrm{C}\right)$.

Similar to Equation (A-8), the emulsions flow rate $Q_{e m}$ is calculated similarly to the oil flow rate (Equation (5-22)).

$$
Q_{e m}=K K_{r o}{ }^{\prime}\left(g-\frac{1}{\rho_{e m}} \frac{Q_{e m} R \mu_{g}}{K K_{r g} x F M}\right) \sin \theta \int_{0}^{\varepsilon_{1}} \frac{d \varepsilon}{\vartheta_{e m}}
$$

where $K_{r o}{ }^{\prime}$ is the oil relative permeability after the surfactants injection, which will be discussed in the flowing section; $\theta$ is the angle between the boundary and the horizontal plane.

Eliminating $\frac{1}{\vartheta_{e m}}$ in Equation (5-22) with Equation (5-19),

$$
Q_{e m}=K K_{r o}{ }^{\prime}\left(g-\frac{1}{\rho_{e m}} \frac{Q_{e m} R \mu_{g}}{K K_{r g} x F M}\right) \sin \theta \sqrt{\pi \alpha t} \int_{0}^{1} \frac{A+B z^{m}}{C+D z^{-m}} d z
$$

At the particular point $\mathrm{P}$ on the boundary, 


$$
Q_{i e m}=K K_{r o}{ }^{\prime}\left(g-\frac{1}{\rho_{e m}} \frac{Q_{i e m} R \mu_{g}}{K K_{r g} x_{i} F M}\right)\left(x_{1}-x_{i}\right) \int_{0}^{1} \frac{A+B z^{m}}{C+D z^{-m}} d z
$$

Similar to Equation (A-9),

$$
Q_{i e m}=\emptyset \Delta S_{o}{ }^{\prime} x_{i} u
$$

where $u$ is the finger rising velocity, $\mathrm{m} / \mathrm{s}$.

Combining Equations (5-21), (5-24) and (5-25), we can finally get the equation illustrating the relationship between $u$ and $X_{i}$ for the CAFA-SAGD model. Actually, not all of the mobilized oil can be emulsified. Thus the real results lie between the values of Butler's model and the modified CAFA-SAGD model.

\subsubsection{Discussion of Oil Saturation and Relative Permeability}

Due to the injection of surfactants, oil relative permeability rises and residual oil saturation drops along with the decreasing interfacial tension and increasing oil mobility. The model provided by Jahanbakhsh et al. (2014) is adopted to account for these effects (Equations (5-26) to (5-29)). Therefore, we can estimate the oil saturation and relative permeability affected by the surfactants through the relationship between the surfactants concentration and the corresponding interfacial tension. It is supposed that foam is stabilized once it is generated and the connate water saturation is constant.

$$
K_{r o}=K_{r o}^{l} f(\sigma)+K_{r o}^{M}(1-f(\sigma))
$$




$$
\begin{gathered}
f(\sigma)=\left(\frac{\sigma}{\sigma_{o}}\right)^{\frac{1}{n_{l}}} \\
K_{r o}^{M}=\frac{S_{o}-S_{\text {ori }} f(\sigma)}{1-S_{w c i}-S_{\text {ori }} f(\sigma)} \\
S_{\text {or }}=S_{\text {ori }} f(\sigma)
\end{gathered}
$$

where $K_{r o}^{l}$ is the original oil relative permeability without surfactants; $K_{r o}^{M}$ is the oil relative permeability when oil and water are miscible; $\sigma$ and $\sigma_{o}$ are the interfacial tension after and before surfactants injection separately; $n_{l}$ is a constant parameter lying between 4 and 10; $S_{\text {or }}$ and $S_{\text {ori }}$ are the residual oil saturation after and before surfactants injection separately; $S_{w c i}$ is the original water saturation; $S_{o}$ is the oil saturation corresponding to $K_{\text {ro }}$.

\subsection{Numerical Example}

The data listed in Tables 5-1 to 5-3 is applied to compare Butler's model and our derived CAFASAGD model to observe the differences.

Table 5-1 Data used for comparison (Gotawala and Gates, 2008)

\begin{tabular}{|c|c|c|c|}
\hline Parameter & Value & Parameter & Value \\
\hline $\mathrm{T}_{\mathrm{R}}{ }^{\circ} \mathrm{C}$ & 4 & $\alpha, \mathrm{m}^{2} / \mathrm{s}$ & $7.06 \mathrm{e}-07$ \\
\hline $\mathrm{Ts},{ }^{\circ} \mathrm{C}$ & 200 & $\mathrm{~S}_{\mathrm{oi}}$ & 0.8 \\
\hline $\mathrm{P}, \mathrm{kPa}$ & 1,553 & $\mathrm{~S}_{\mathrm{or}}$ & 0.15 \\
\hline$\lambda, \mathrm{J} / \mathrm{kg}$ & $1,941,000$ & $\mathrm{k}_{\mathrm{ro}}$ & 0.5 \\
\hline$\varphi$ & 0.39 & $\mathrm{k}_{\mathrm{rg}}$ & 0.4 \\
\hline$\rho_{\mathrm{o}}, \mathrm{kg} / \mathrm{m}^{3}$ & 1,005 & $\mathrm{~m}$ & 4 \\
\hline$\rho_{\mathrm{c}} \mathrm{C}_{\mathrm{c}}, \mathrm{J} / \mathrm{m}^{3 \cdot{ }^{\circ} \mathrm{C}}$ & 373,000 & $\mathrm{~V}$ & 0.5 \\
\hline$\rho_{\mathrm{R}} \mathrm{C}_{\mathrm{R}}, \mathrm{J} / \mathrm{m}^{3} \cdot{ }^{\circ} \mathrm{C}$ & $2,184,000$ & $\rho_{\mathrm{w}}, \mathrm{kg} / \mathrm{m}^{3}$ & 1,000 \\
\hline$\rho_{\mathrm{o}} \mathrm{C}_{\mathrm{o}}, \mathrm{J} / \mathrm{m}^{3}{ }^{\circ} \mathrm{C}$ & $1,879,600$ & $\mathrm{FM}$ & 0.5 \\
\hline $\mathrm{k}, \mathrm{D}$ & 0.5 & & \\
\hline
\end{tabular}


Table 5-2 Fluid data used for comparison (Athabasca Oil, m=4) (Murtaza et al, 2014)

\begin{tabular}{|c|c|c|c|c|}
\hline$T_{\mathrm{s}}$ & $v_{\mathrm{os}}, \mathrm{m}^{2} / \mathrm{s}$ & $\nu_{\mathrm{gs}}, \mathrm{m}^{2} / \mathrm{s}$ & $\rho_{\mathrm{g}}, \mathrm{kg} / \mathrm{m}^{3}$ & $v_{\mathrm{w}}, \mathrm{m}^{2} / \mathrm{s}$ \\
\hline 100 & 0.0003 & $1.71 \mathrm{e}-05$ & 0.598 & $2.94 \mathrm{e}-07$ \\
\hline 200 & $1.84 \mathrm{e}-05$ & $2.04 \mathrm{e}-06$ & 7.86 & $2.94 \mathrm{e}-07$ \\
\hline 250 & $1.06 \mathrm{e}-05$ & $8.76 \mathrm{e}-07$ & 20 & $2.94 \mathrm{e}-07$ \\
\hline 300 & $2.86 \mathrm{e}-06$ & $4.26 \mathrm{e}-07$ & 42.6 & $2.94 \mathrm{e}-07$ \\
\hline
\end{tabular}

Table 5-3 Foam Parameters (Reme, 1999)

\begin{tabular}{|c|c|c|c|}
\hline Parameter & Value & Parameter & Value \\
\hline FMMOB & 57,958 & FLOIL & 0.2 \\
\hline FMSURF & $1.43725 \mathrm{e}-4$ & EPOIL & 0.15 \\
\hline EPSURF & 8 & EPCAP & 1.1215 \\
\hline FMOIL & 0.8 & & \\
\hline
\end{tabular}

The comparison results are shown below (Figures 5-1, 5-2). There is no doubt that fingers rise more quickly at a higher temperature for the two models due to the oil viscosity reduction. It is also obvious that the finger rising rate is significantly reduced due to the generation of foam at the same injection pressure. In addition, the difference is larger along with the increasing temperature. The finger rising velocity is reduced from $14.76 \mathrm{~cm} /$ day to less than $8.74 \mathrm{~cm} /$ day at the temperature of $300{ }^{\circ} \mathrm{C}$. Similarly, SOR drops after reaching a peak at around $250{ }^{\circ} \mathrm{C}$. It is estimated that the decrease of available latent heat accounts for the increase of SOR. But later on, the oil output increase overcomes the additional usage of steam, reducing SOR. In addition, SOR of the CAFASAGD model is reduced owing to less consumption of steam and more mobilization of oil compared to the SAGD model. SOR is significantly cut down from 5.56 to 4.12 , almost by $24.27 \%$, at $300{ }^{\circ} \mathrm{C}$. 


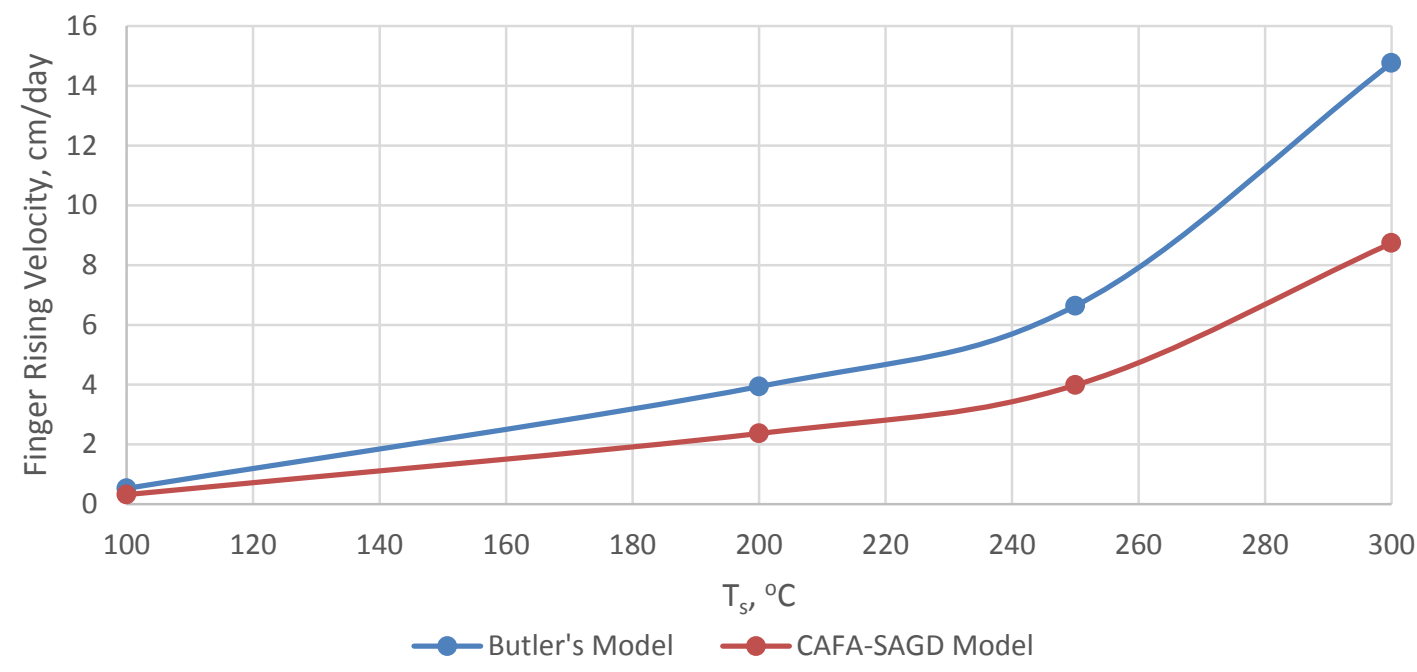

Figure 5-1 Steam finger rising velocity comparison between Butler's model and CAFASAGD model

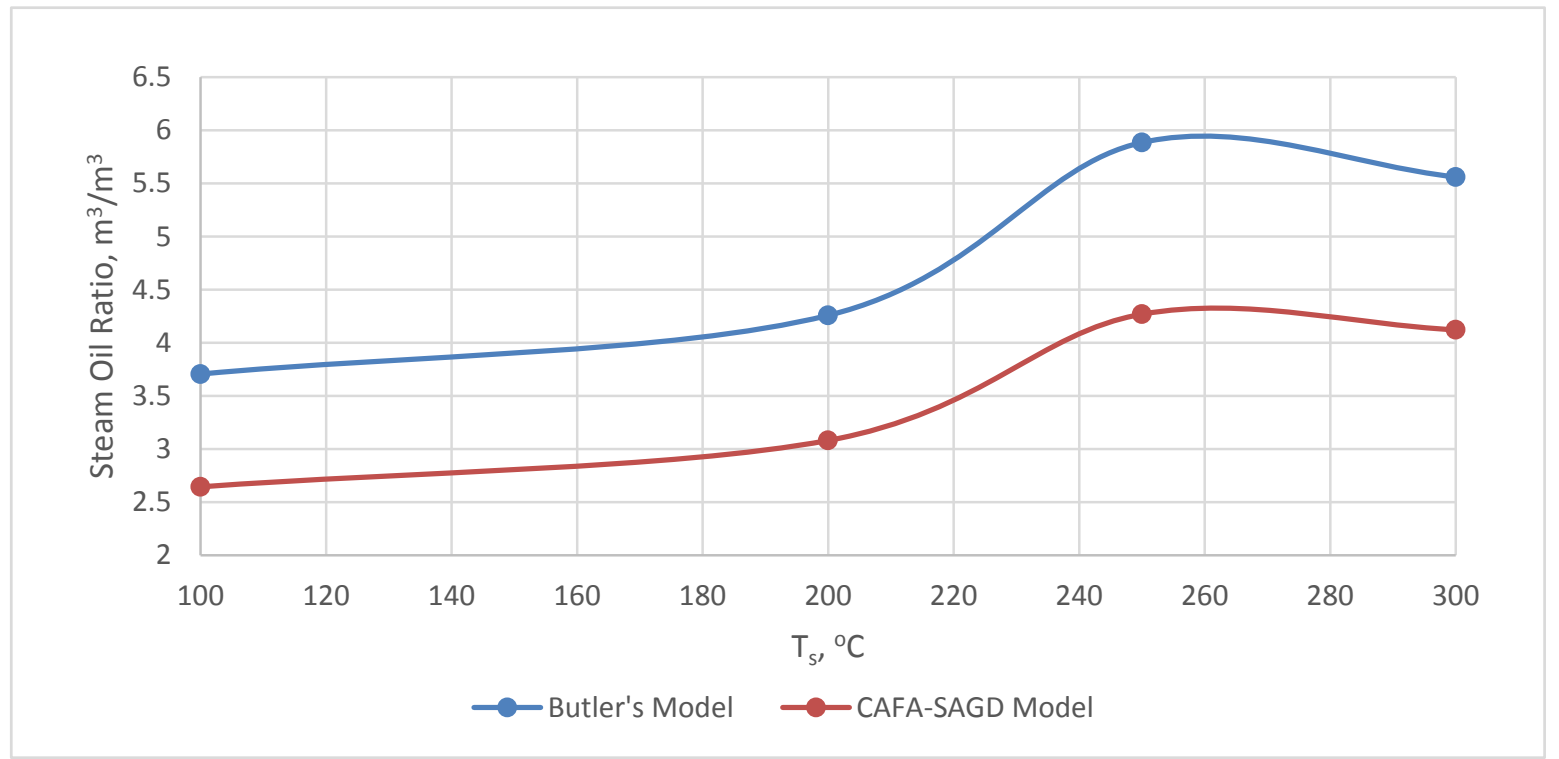

Figure 5-2 SOR comparison between Butler's model and CAFA-SAGD model 


\subsubsection{Effects of Oil Saturation}

A high initial oil saturation is a detrimental threat for bubbles' life as stated. Figure 5-3 illustrates that even though lower oil saturation helps to maintain the foam stability. It still owns a slightly higher finger rising velocity as lower oil saturation implies less oil available to be produced, which also leads to a high SOR. SOR is increased from 4.12 to 5.66 at $300{ }^{\circ} \mathrm{C}$ when the original oil saturation is set to be 0.5 (Figure 5-4).

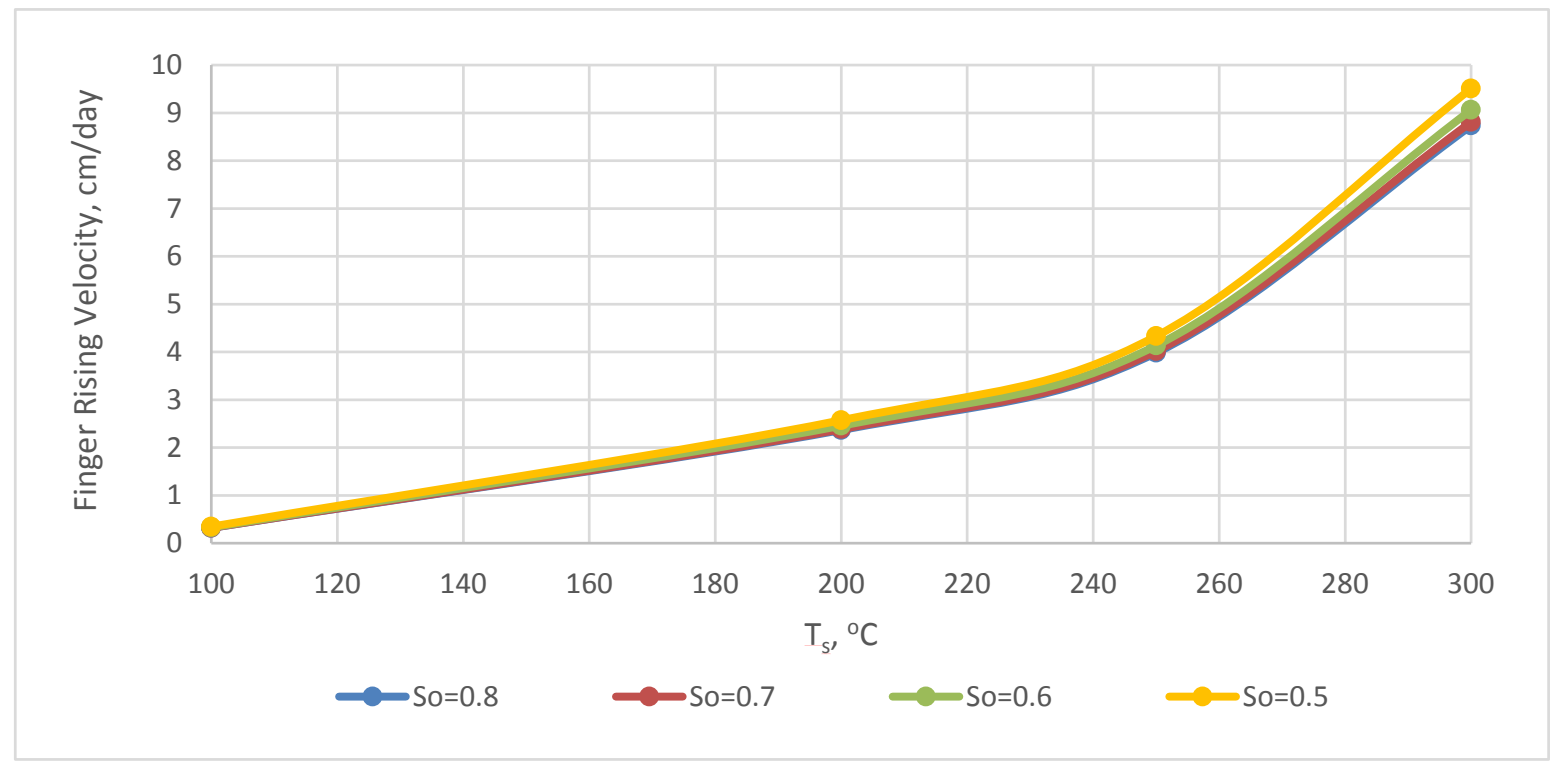

Figure 5-3 Steam finger rising velocity sensitivity analysis for oil saturation study 


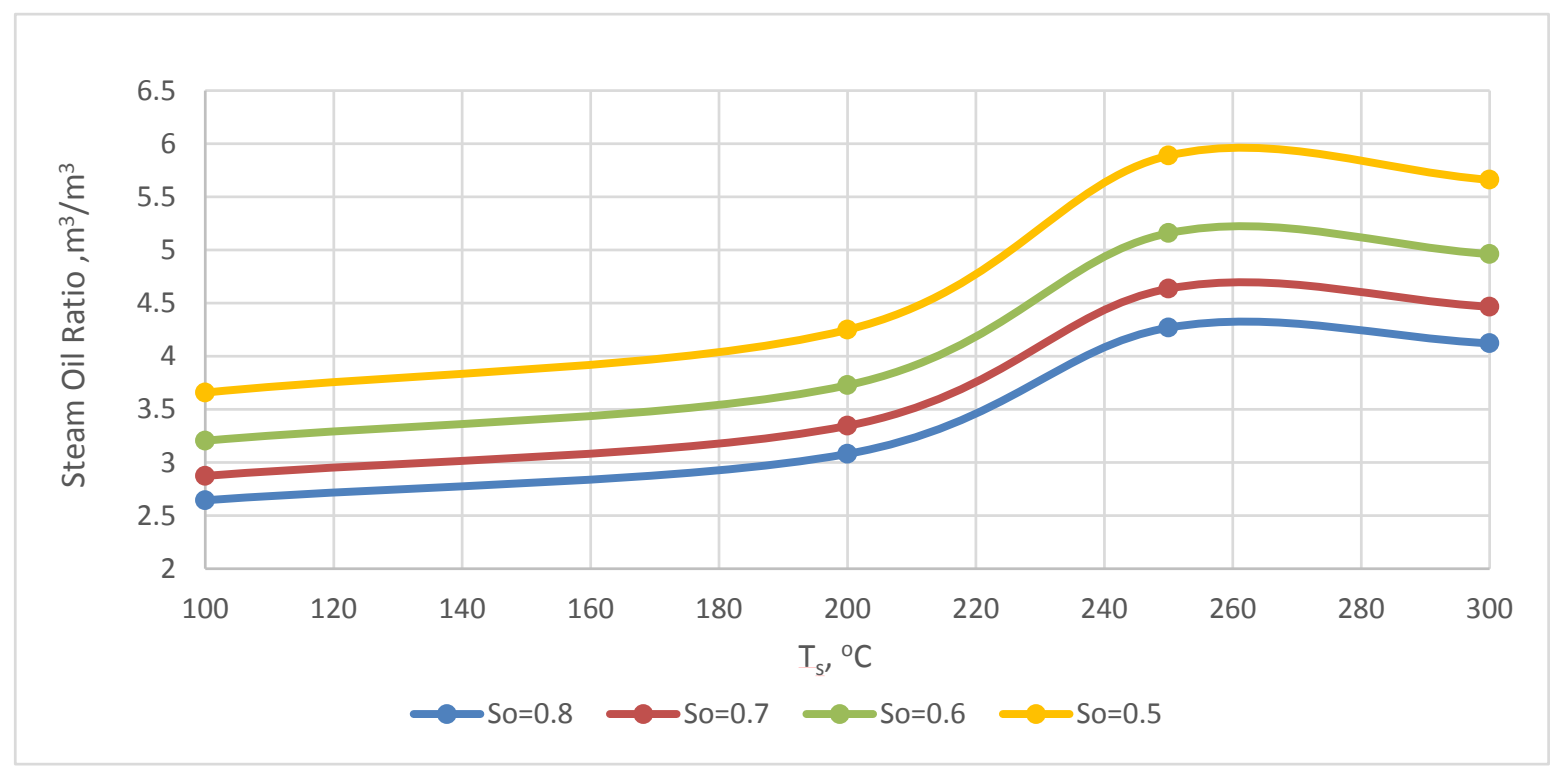

Figure 5-4 SOR sensitivity analysis for oil saturation study

\subsubsection{Effects of Surfactants Concentration}

Increasing surfactants concentration favors a lower IFT, a lower residual oil saturation and higher foam strength, which is shown by Figures 5-5 and 5-6 directly. Increasing surfactants concentration from $0.0025 \%$ to $0.015 \%$ at $300{ }^{\circ} \mathrm{C}$ slows down the finger rising velocity to as low as $2.41 \mathrm{~cm} /$ day approximately as the result of high-strength generated foam. Furthermore, its ability to lower IFT and intensify emulsification is further beneficial to the decrease of SOR through additional oil yields. 


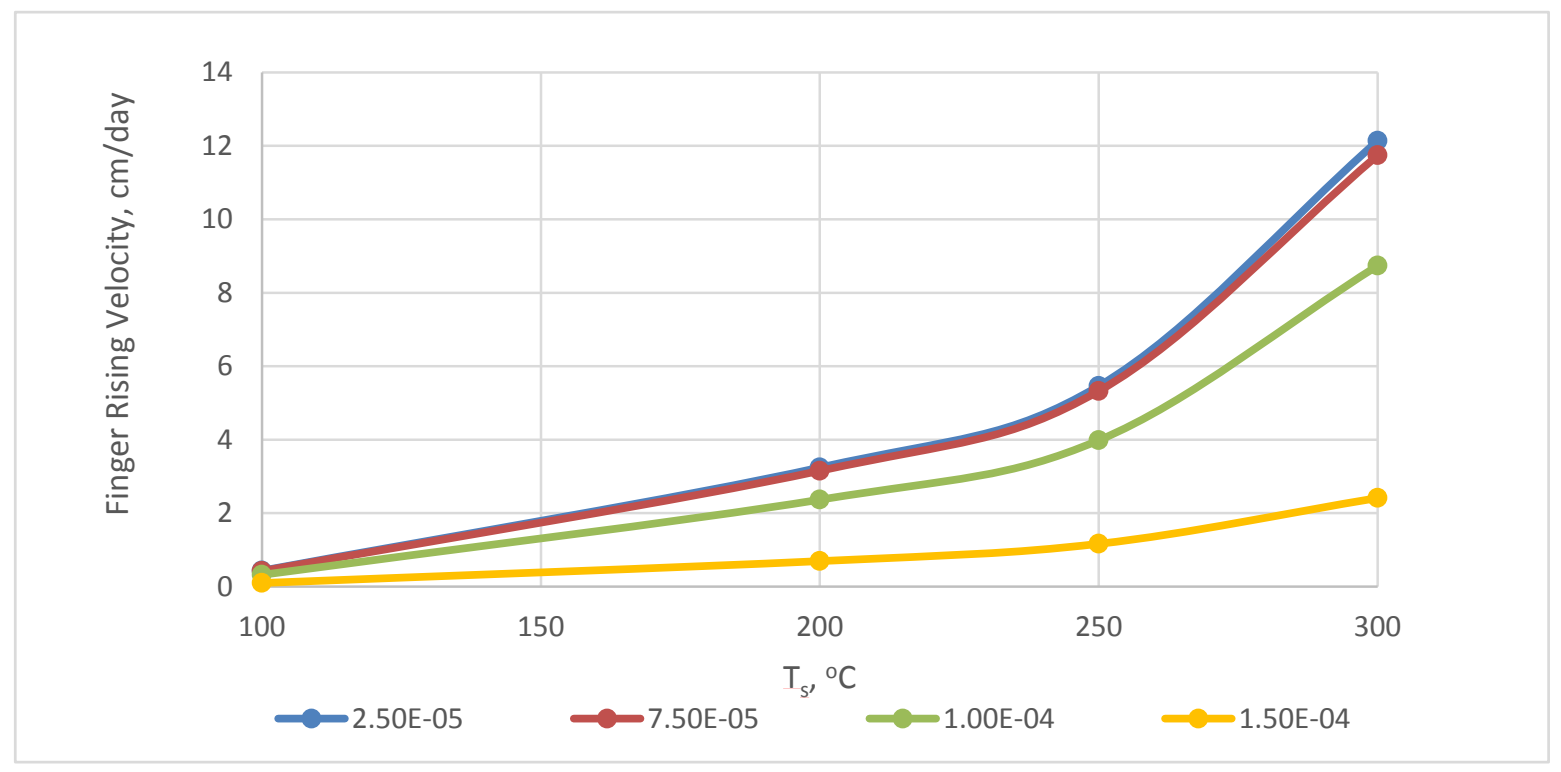

Figure 5-5 Steam finger rising velocity sensitivity analysis for surfactants concentration study

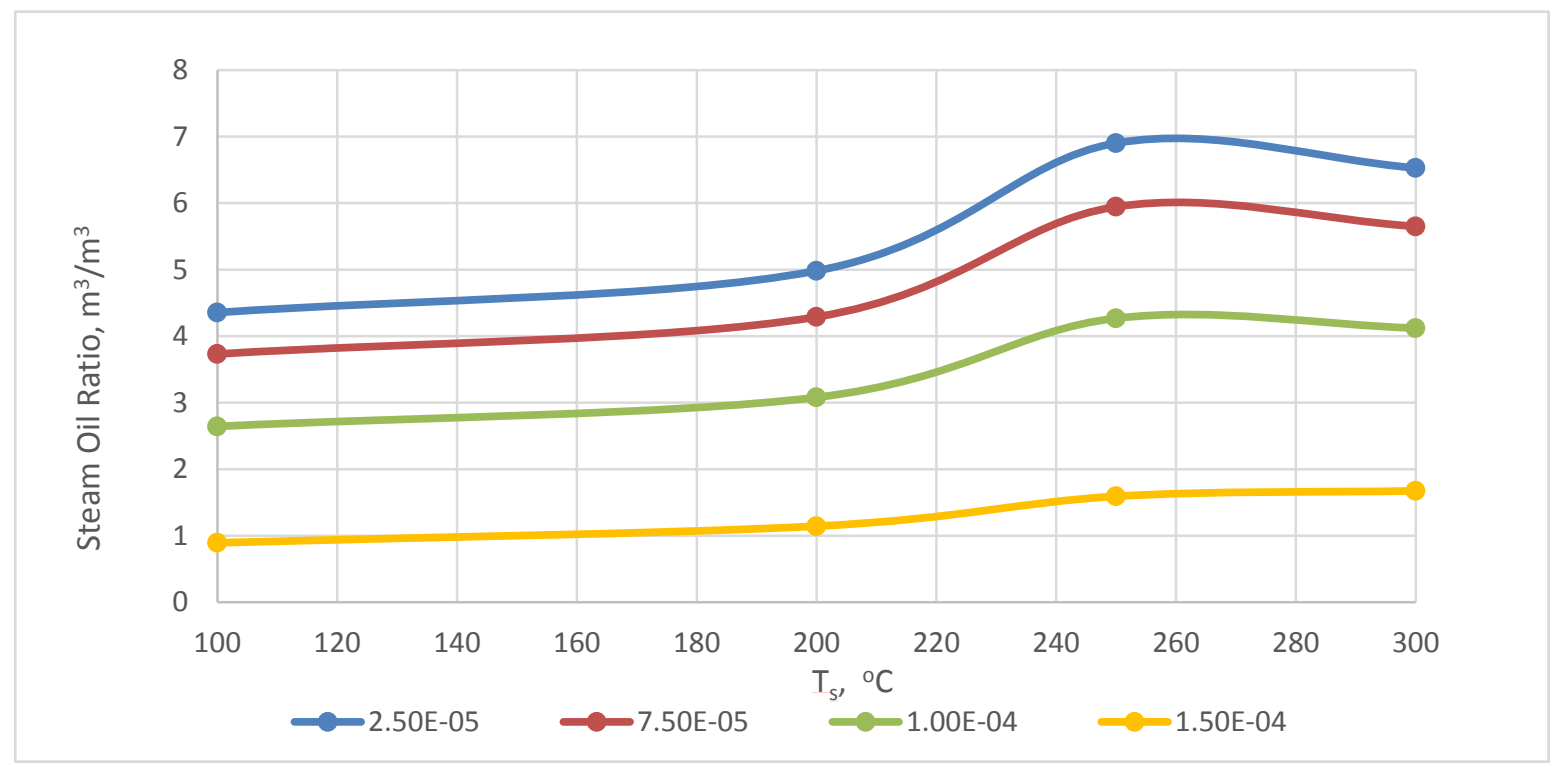

Figure 5-6 SOR sensitivity analysis for surfactants concentration study 


\subsubsection{Effects of Emulsions Volume Ratio}

The water-oil volume ratio of emulsions determines the emulsions properties. According to Figures 5-7 and 5-8, a lower water content helps to achieve a quickly-expanded steam chamber and lower SOR as more residual oil is carried away in form of emulsion droplets. Reducing the water content by $60 \%$ at $300{ }^{\circ} \mathrm{C}$ reduces SOR by approximately $8.60 \%$.

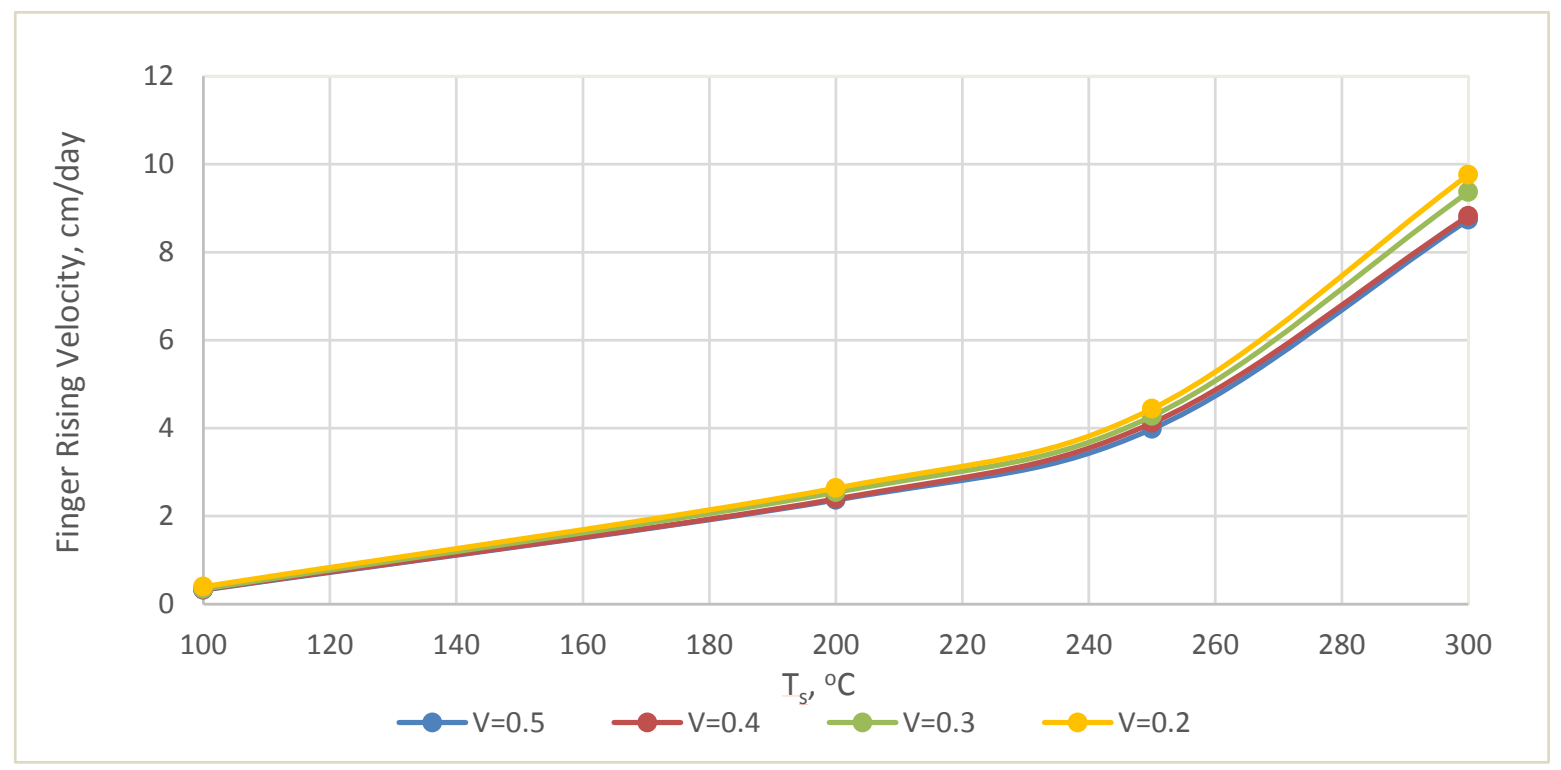

Figure 5-7 Steam finger rising velocity sensitivity analysis for volume ratio study 


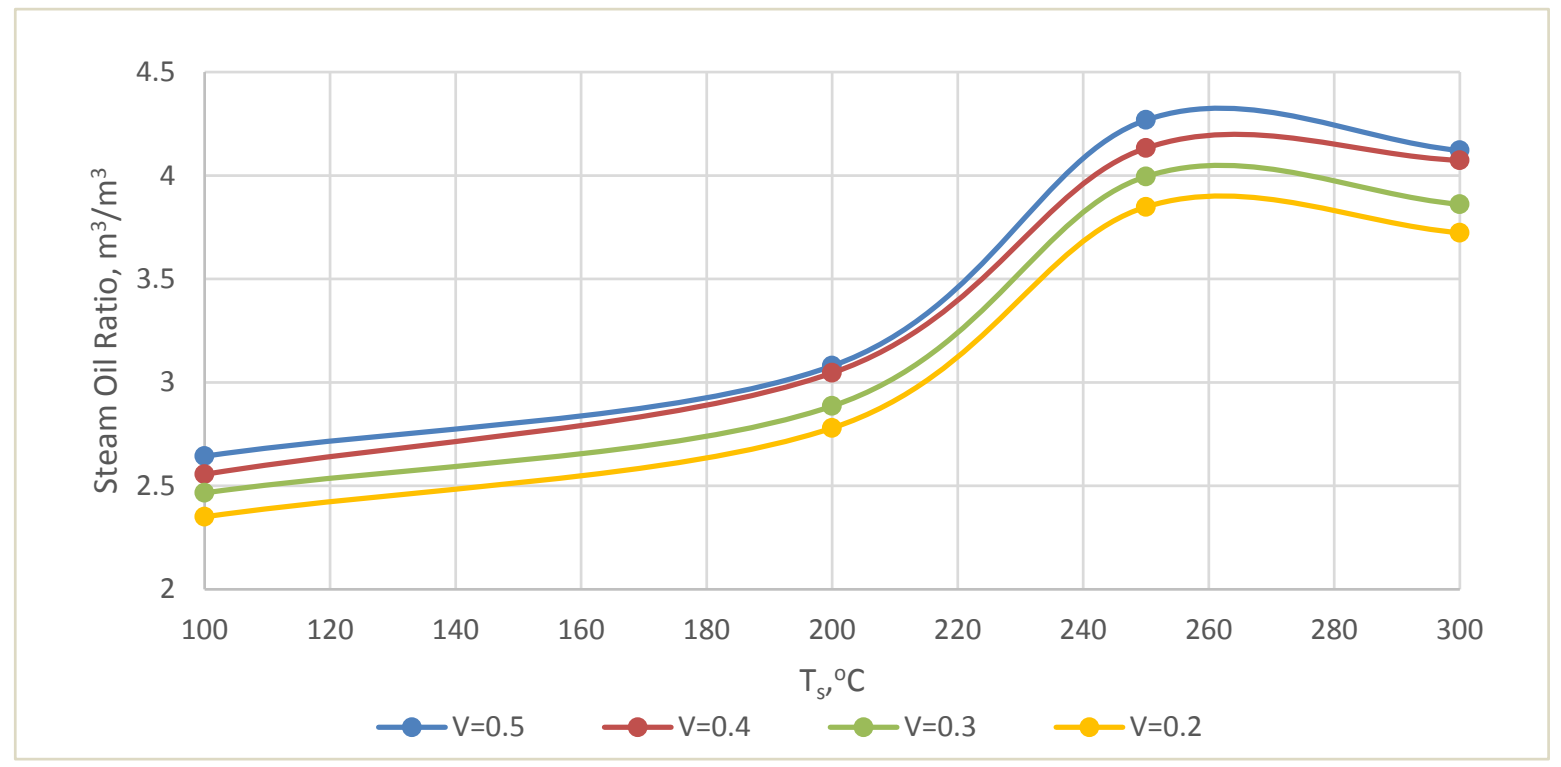

\section{Figure 5-8 SOR sensitivity analysis for volume ratio study}

\subsection{Conclusions}

Assuming that all the mobilized oil is emulsified, an analytical model is established based on the modification of Butler's finger rising model to account for the influences of surfactants injection. We use the representative Athabasca field data to draw the finger rising velocity and SOR plots for the two models. It shows that the finger rising velocity is restricted and SOR can be reduced by injecting surfactants if the injection pressure is maintained. We further investigate the influences of initial oil saturation, surfactants concentration and water content in the emulsions droplets. The alteration of surfactant concentration brings on changes in both the oil rate and SOR considerably. 


\section{CHAPTER 6: CARBONATE MODEL}

With the increasing demand of energy, complex carbonate formations with fractures, vugs, matrixes and karsts in Western Canada catch the industry attention due to their large reserve volume of heavy oil. Thermal methods such as SAGD are usually used to exploit immobile oil. However, on this account, steam tends to escape through naturally high permeability conduits like fractures and karsts while bypassing low-permeable matrixes, leading to partially developed steam chambers and loss of oil production. Based on the mechanisms and analyses illustrated above, CAFA-SAGD is put forward to carbonate reservoirs to enhance the thermal recovery efficiency.

\subsection{Carbonate Single Porosity Model}

Similar to Chapter 3, a homogeneous model is built to test the potential performance of CAFASAGD for carbonate reservoirs. First, we use a 2D single porosity carbonate model in CMG ${ }^{\circledR}$ STARS to observe the steam front movement properties in both matrix and fractures. Then chemical additives are added and foam is generated to observe the foam-steam front. Table 6-1 delivers the parameters of the model. A small fracture grid size $(0.1 \mathrm{~mm})$ is liable to generate nonconvergence. Thus we use a larger grid size $(1 \mathrm{~cm})$ with a smaller permeability to simulate the fractures. It can be seen that steam moves much faster inside the fractures. Thus a large sum of oil reserved in the matrix has no opportunity to contact steam, resembling the situation of the lowpermeable layers in heterogeneous reservoirs. But the situation is even worse as the property 
differences between fracture and matrix are extremely large. It is highly required to restrain steam breakthrough in the fracture. CAFA-SAGD is applied and a higher pressure is introduced in this case. The steam movement inside the fractures is greatly restricted and $11.02 \%$ higher oil output is achieved (Figures 6-1, 6-2).

Table 6-1 Basic reservoir parameters of single porosity carbonate model

\begin{tabular}{|c|c|c|c|}
\hline Parameter & Value & Parameter & Value \\
\hline Matrix Size, $\mathrm{m}$ & 1 & $\begin{array}{l}\text { Rock Thermal Conductivity, } \\
\mathrm{J} /\left(\mathrm{m}^{*} \text { day }^{* 0} \mathrm{C}\right)\end{array}$ & $1.5 \mathrm{e} 5$ \\
\hline Fracture Size, m & 0.01 & Rock Heat Capacity, $\mathrm{J} /\left(\mathrm{m}^{3 * 0} \mathrm{C}\right)$ & $2.35 \mathrm{e} 6$ \\
\hline Matrix Porosity & 0.1 & $\begin{array}{l}\text { Water Thermal Conductivity, } \\
\mathrm{J} /\left(\mathrm{m}^{*} \text { day*o } \mathrm{C}\right)\end{array}$ & $5.36 \mathrm{e} 4$ \\
\hline Fracture Porosity & 0.999 & $\begin{array}{l}\text { Oil Thermal Conductivity, } \\
\mathrm{J} /\left(\mathrm{m}^{*} \text { day }^{* 0} \mathrm{C}\right)\end{array}$ & $1.12 \mathrm{e} 4$ \\
\hline Matrix Permeability, mD & 200 & $\begin{array}{l}\text { Gas Thermal Conductivity, } \\
\mathrm{J} /\left(\mathrm{m}^{*} \text { day }^{* 0} \mathrm{C}\right)\end{array}$ & 4,984 \\
\hline Fracture Permeability, mD & 1,725 & & \\
\hline
\end{tabular}

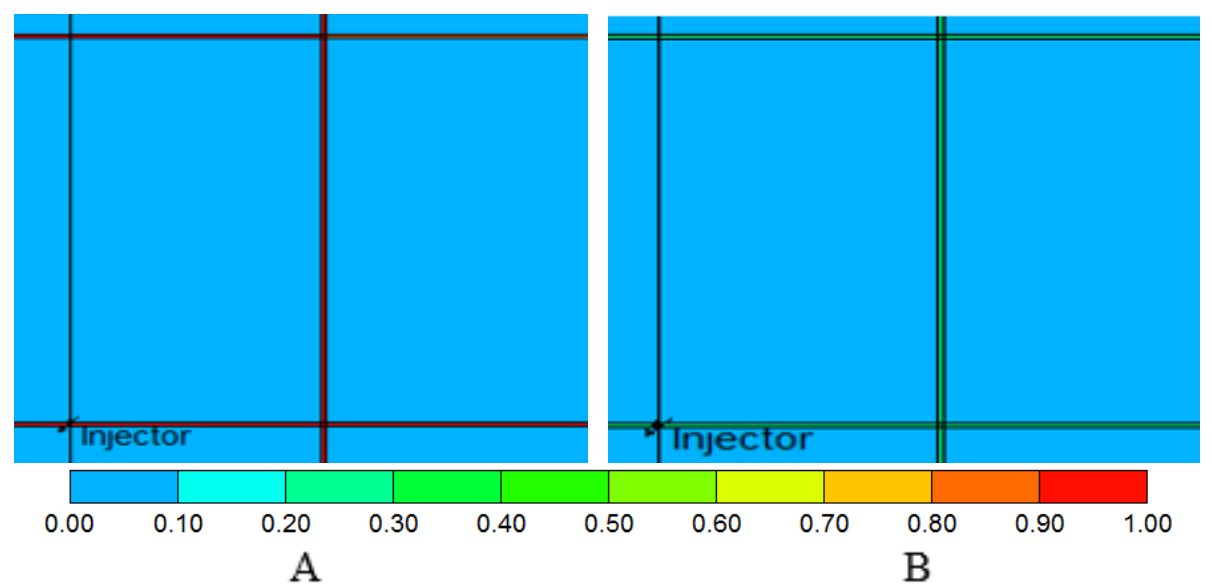

Figure 6-1 Gas relative permeability comparison (1 year after surfactants injection) (single porosity model) (A: SAGD; B: CAFA-SAGD) 


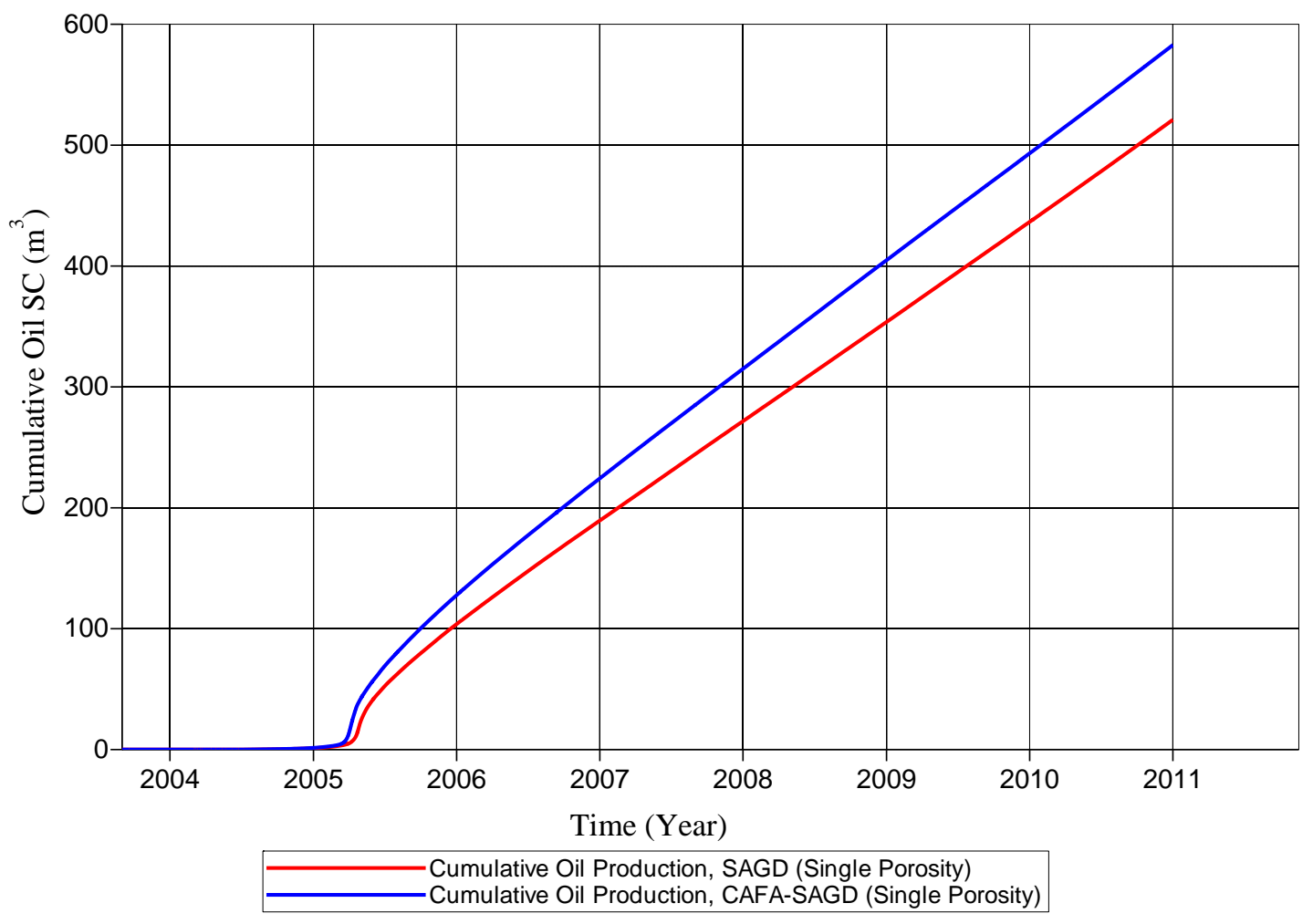

Figure 6-2 Cumulative oil production comparison (single porosity model)

\subsection{Carbonate Dual Porosity Model}

Then a dual porosity carbonate model is built to carry out a further comparison (Table 6-2). Figure

6-3 shows that the steam front of CAFA-SAGD is much more uniform due to the effective gas mobility control, while the steam chamber profile of SAGD has lots of temperature fingers (Figure 6-4). This help to generate $100 \mathrm{~m}^{3}$ more oil yields and lower SOR, which drops from $14 \mathrm{~m}^{3} / \mathrm{m}^{3}$ to $12 \mathrm{~m}^{3} / \mathrm{m}^{3}$, which is still not quite economical (Figure 6-5). 
Table 6-2 Basic reservoir parameters of dual porosity carbonate model

\begin{tabular}{|c|c|c|c|}
\hline Parameter & Value & Parameter & Value \\
\hline Matrix Porosity & 0.19 & Rock Thermal Conductivity, $\mathrm{J} /\left(\mathrm{m}^{*}\right.$ day $\left.{ }^{* 0} \mathrm{C}\right)$ & $1.5 \mathrm{e} 5$ \\
\hline Fracture Porosity & 0.01 & Rock Heat Capacity, $\mathrm{J} /\left(\mathrm{m}^{3 * \mathrm{o}} \mathrm{C}\right)$ & $2.35 \mathrm{e} 6$ \\
\hline Matrix Permeability, $\mathrm{mD}$ & 10 & Water Thermal Conductivity, $\mathrm{J} /\left(\mathrm{m}^{*}\right.$ day $\left.{ }^{* 0} \mathrm{C}\right)$ & $5.36 \mathrm{e} 4$ \\
\hline Fracture Permeability, $\mathrm{mD}$ & 1,000 & Oil Thermal Conductivity, $\mathrm{J} /\left(\mathrm{m}^{*}\right.$ day $\left.^{* 0} \mathrm{C}\right)$ & $1.12 \mathrm{e} 4$ \\
\hline & & Gas Thermal Conductivity, $\mathrm{J} /\left(\mathrm{m}^{*}\right.$ day $\left.^{* 0} \mathrm{C}\right)$ & 4,984 \\
\hline
\end{tabular}
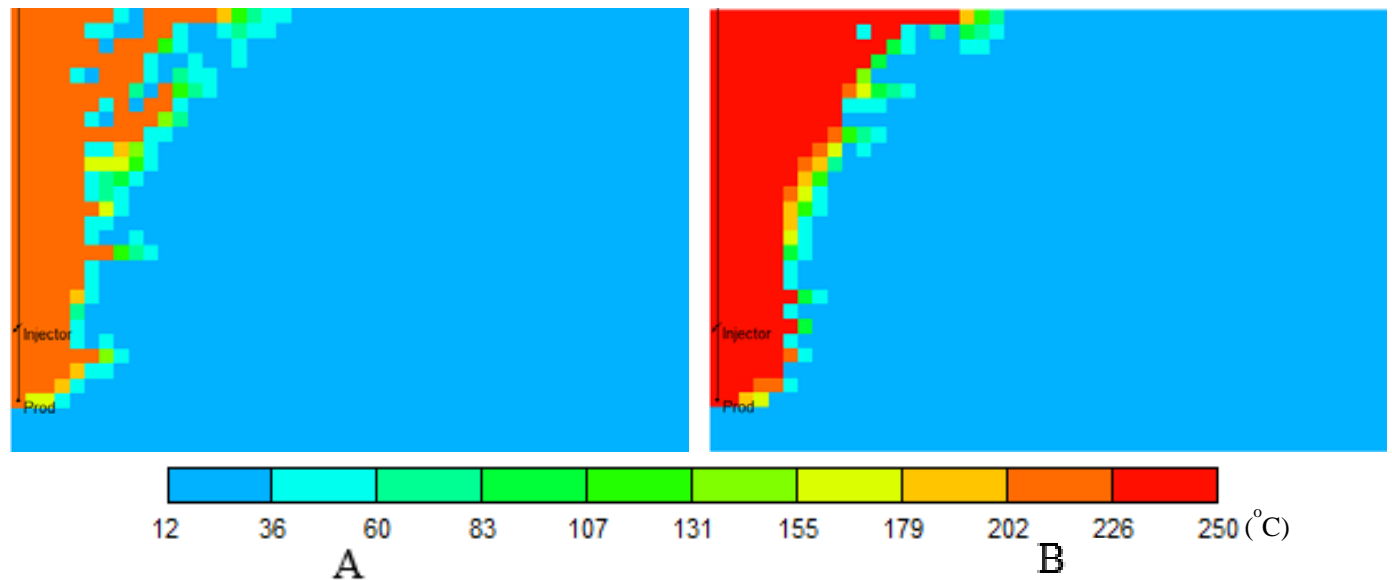

Figure 6-3 Temperature comparison of dual porosity model (1 year after surfactants injection) ( $\left.{ }^{\circ} \mathrm{C}\right)$ (A: SAGD; B: CAFA-SAGD)

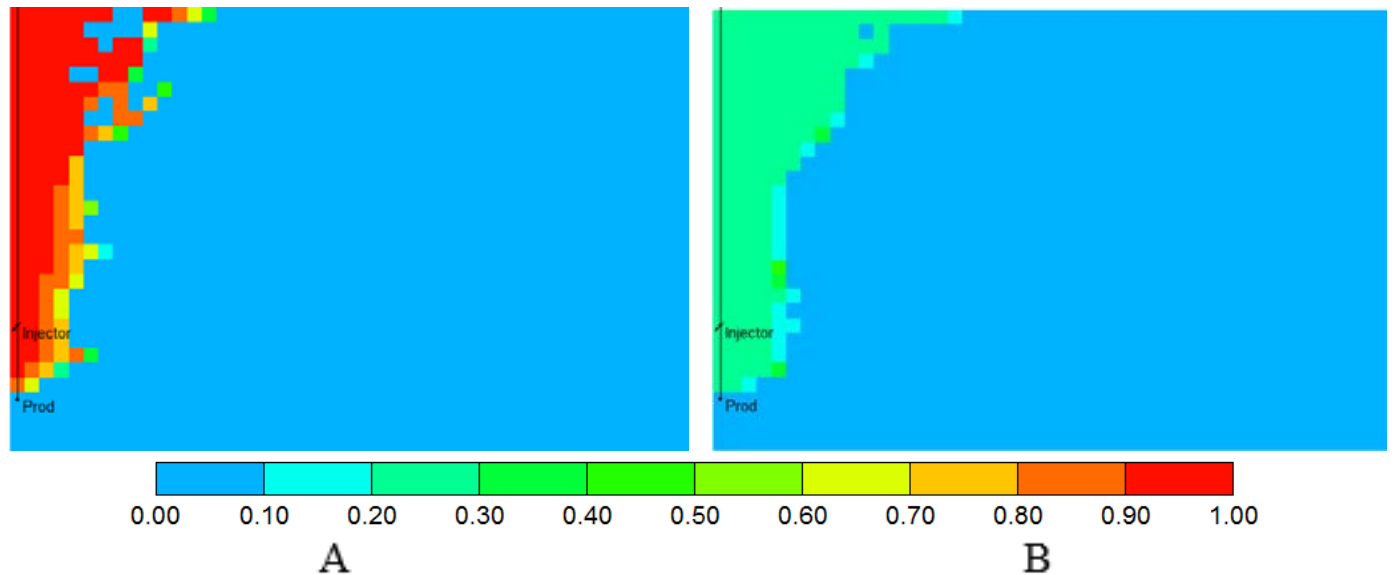

Figure 6-4 Gas relative permeability comparison of dual porosity model (1 year after surfactants injection) (A: SAGD; B: CAFA-SAGD) 


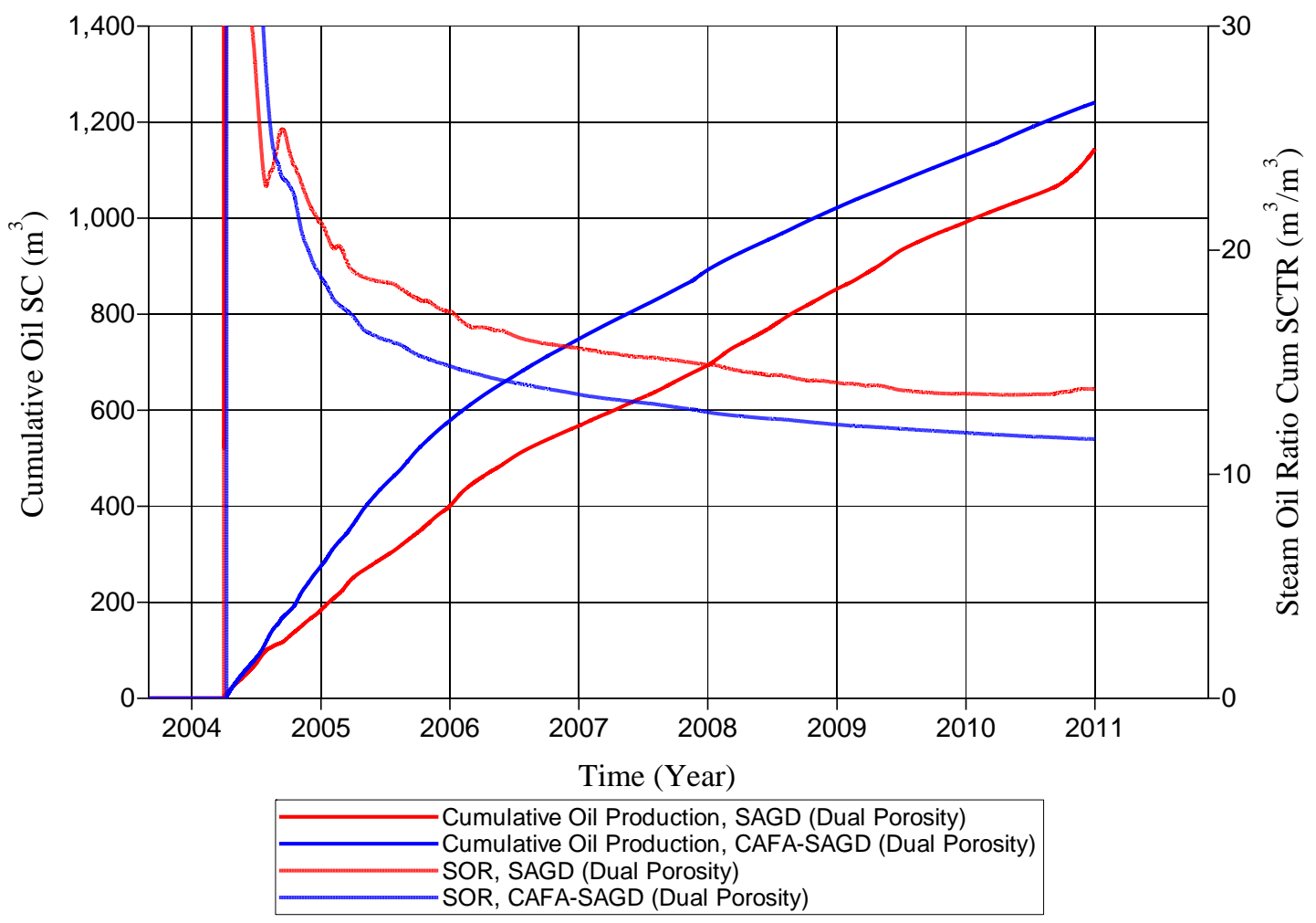

Figure 6-5 Cumulative oil production and SOR comparison of dual porosity model

\subsection{Conclusions}

It shows that there is a possibility that chemical additives and foam can be employed to further enhance SAGD performance to carbonate reservoirs as it helps to control the steam breakthrough in fractures and diverts more steam into matrix. However, more research should be conducted in terms of the heterogeneous model. 


\section{CHAPTER 7: CONCLUSIONS AND FUTURE WORK}

\subsection{Conclusions}

Through the comparisons between SAGD and CAFA-SAGD with a homogeneous model, it is shown that around 30\% more oil is produced due to gas mobility control, interfacial tension drop and emulsification, and SOR is further reduced by approximately 35\%. Gas mobility control mainly contributes to the less consumption of steam, while interfacial tension reduction and emulsification helps to drive more oil. In terms of the described homogeneous model, strong bubbles are mainly accumulated around a steam chamber border and weak foam are concentrated inside the chamber. In addition, injection scheme is also optimized. It is highly suggested that chemical additives should be injected after the steam chamber achieves an enough expansion area to guarantee a reasonable oil rate. Constant injection is beneficial due to its generation of stable foam, while an alternate injection has the advantages of both. The choice of an injection scheme should be based on the analysis of reservoir properties.

The heterogeneous model based on Suncor's Firebag project has a lot of low-permeable layers and a top water zone. The addition of chemical additives and foam does favor to divert the steam into the low-permeability areas and maintain a uniformly developed steam chamber as much as possible. Heat loss towards the top water zone is also able to be reduced by bubbles generation. However, foam collapse by oil interruption, surfactants adsorption, degradation and partition 
undermine CAFA-SAGD performance to some extent. It is advised to carry out experiments towards the properties of chemical additives to achieve the highest stability in a high temperature and high pressure environment.

The modified CAFA-SAGD finger rising model further shows that the CAFA-SAGD owns a lower steam front velocity and lower SOR with the typical Athabasca reservoir data. Higher initial oil saturation only brings about a significantly high SOR and it leads to severe bubbles rupture. More surfactants help to displace more oil with less steam.

Finally, a simple homogeneous carbonate model is used to test the feasibility of CAFA-SAGD. Both a single porosity model and a dual porosity model show a more uniformly developed steam chamber. The steam movement in fractures is greatly restricted and more steam is pushed into the matrix.

\subsection{Future Work}

1. The phase behavior during the CAFA-SAGD (especially during emulsification) needs to be performed by both simulation and programming, like how the emulsions are formed, where the emulsions droplets locate during SAGD, and how the emulsification behaves during the production process and influenced by the factors like temperature, salinity and pressure. Salinity is a very important factor which determines emulsification a lot. 
2. The influence of light components in oil towards the CAFA-SAGD process needs to be studied. The current research only considers dead oil but ignores gas. One needs to study how the existence of light hydrocarbons influences the CAFA-SAGD process and the formation and alteration of foam.

3. There are several analytical models to represent a foam process. One needs to combine those models with a SAGD analytical model to describe the foam phenomenon. When only gas relative permeability alteration is considered, the influences of critical water saturation will be further investigated. If gas viscosity is discussed, the effects of a gas phase volumetric flux and lamella density will be explored. One needs to validate the models with experimental data.

4. Also, the detailed employment of foam in the carbonate reservoirs is another promising research area. How foam is distributed and how the foam-steam fronts sweeping advances in matrix and fractures with a heterogeneous model is unclear yet. Also, one can focus on how chemical additives and foam influence the mechanisms of gravity drainage, capillary drainage and imbibition and solution gas drive. In the same time, the influences of a permeability ratio, fracture spacing and shape factor can be studied. 


\section{References}

Akin, Serhat. "Mathematical modeling of steam assisted gravity drainage."SPE Reservoir Evaluation \& Engineering 8.05 (2005): 372-376.

Al-Bahlani, Al-Muatasim, and Tayfun Babadagli. "SAGD laboratory experimental and numerical simulation studies: A review of current status and future issues." Journal of Petroleum Science and Engineering 68.3 (2009): 135-150.

Ali, S. M. "Is there life after SAGD?." Journal of Canadian Petroleum Technology 36.06 (1997).

Ali, Syed Mohammad Farouq. Practical heavy oil recovery. SM Farouq Ali, 2006.

Anderson, Mark T., and Kennedy David. "SAGD startup: Leaving the heat in the reservoir." SPE Heavy Oil Conference Canada. Society of Petroleum Engineers, 2012.

Azom, Prince Nnamdi, and Sanjay Srinivasan. "Mechanistic Modeling of emulsion formation and heat transfer during the steam-assisted gravity drainage (SAGD) process." SPE Annual Technical Conference and Exhibition. Society of Petroleum Engineers, 2009.

Baker, Richard Oren, et al. "Practical considerations of reservoir heterogeneities on SAGD projects." International Thermal Operations and Heavy Oil Symposium. Society of Petroleum Engineers, 2008.

Bancroft, Wilder D. "The theory of emulsification, V." The Journal of Physical Chemistry 17.6 (1913): 501-519.

Bernard, George G., and L. W. Holm. "Effect of foam on permeability of porous media to gas." Society of Petroleum Engineers Journal 4.03 (1964): 267-274.

Bitumen and heavy crudes: The energy security problem solved?". Oil and Energy Trends 31 (6): 3-5. 2006

Bryan, Jonathan Luke, and Apostolos Kantzas. "Enhanced heavy-oil recovery by alkali-surfactant flooding." SPE Annual Technical Conference and Exhibition. Society of Petroleum Engineers, 2007. 
Butler, R. M. "Rise of interfering steam chambers." Journal of Canadian Petroleum Technology 26.03 (1987).

Butler, Roger M. "Thermal recovery of oil and bitumen." (1991).

Butler, R. "The steam and gas push (SAGP)." Journal of Canadian Petroleum Technology 38.03 (1999).

Butler, Roger M., and Betty Dargie. Horizontal wells for the recovery of oil, gas, and bitumen. No. 2. Gulf Pub Co, 1994.

Butler, R. M., and C. T. Yee. "Progress in the in situ recovery of heavy oils and bitumen." Journal of Canadian Petroleum Technology 41.01 (2002).

Canbolat, Serhat, Akin Serhat, and Anthony R. Kovscek. "A study of steam-assisted gravity drainage performance in the presence of noncondensable gases." SPE/DOE Improved Oil Recovery Symposium. Society of Petroleum Engineers, 2002.

Chang, S. H., et al. "The Effect of Microscopic Heterogeneity on CO2-Foam Mobility: Part 2Mechanistic Foam Simulation." SPE/DOE Enhanced Oil Recovery Symposium. Society of Petroleum Engineers, 1990.

Chen, Qing, Margot G. Gerritsen, and Anthony R. Kovscek. "Effects of reservoir heterogeneities on the steam-assisted gravity-drainage process."SPE Reservoir Evaluation \& Engineering 11.05 (2008): 921-932.

Chung, K. H., and R. M. Butler. "Geometrical Effect Of Steam Injection On The Formation Of Emulsions Nn The Steam-Assisted Gravity Drainage Process." Journal of Canadian Petroleum Technology 27.01 (1988).

CMG Manual, "Computer Modeling Group." (2015).

Das, Swapan Kumar. "Application of thermal processes in heavy oil carbonate reservoirs." SPE Middle East Oil and Gas Show and Conference. Society of Petroleum Engineers, 2007.

Doan, L. T., et al. "An investigation of the steam-assisted gravity-drainage process in the presence of a water leg." SPE Annual Technical Conference and Exhibition. Society of Petroleum Engineers, 1999. 
Edmunds, Neil. "On the difficult birth of SAGD." Journal of Canadian Petroleum Technology 38.01 (1999).

Edmunds, Neil, and Harbir Chhina. "Economic optimum operating pressure for SAGD projects in Alberta." Journal of Canadian Petroleum Technology40.12 (2001).

Energy, I. H. S. "Accumap User’s Guide." IHS Energy, Calgary, Canada (2013).

Friedmann, Francois, W. H. Chen, and P. A. Gauglitz. "Experimental and simulation study of hightemperature foam displacement in porous media." SPE reservoir engineering 6.01 (1991): 37-45.

Gaviria, Fernando, et al. "Pushing the Boundaries of Artificial Lift Applications: SAGD ESP Installations at Suncor Energy, Canada." SPE Annual Technical Conference and Exhibition. Society of Petroleum Engineers, 2007.

Glass, D. J. "Lexicon of Canadian stratigraphy volume 4 Western Canada, including eastern British Columbia." Alberta, Saskatchewan and southern Manitoba (1990).

Gong, J., M. Polikar, and R. J. Chalaturnyk. "Fast SAGD and geomechanical mechanisms." Canadian International Petroleum Conference. Petroleum Society of Canada, 2002.

Good, William K., J. D. Scott, and R. W. Luhning. "[7] 4 Review and Assessment of Steam Assisted Gravity Drainage (SAGD) Applications in Canada." 14th World Petroleum Congress. World Petroleum Congress, 1994.

Gotawala, Dharmesh R., and Ian D. Gates. "Steam fingering at the edge of a steam chamber in a heavy oil reservoir." The Canadian Journal of Chemical Engineering 86.6 (2008): 1011-1022.

Govind, P. A., et al. "Expanding Solvent SAGD in Heavy Oil Reservoirs. Paper SPE 117571 presented at the International Thermal Operations and Heavy Oil Symposium, Calgary, 30-23 October." (2008).

Griffin, William C. "Classification of surface-active agents by" HLB"." J Soc Cosmetic Chemists 1 (1946): 311-326.

Hirasaki, G. J., and J. B. Lawson. "Mechanisms of foam flow in porous media: apparent viscosity in smooth capillaries." Society of Petroleum Engineers Journal 25.02 (1985): 176-190. 
Islam, M. R., and S. M. Ali. "New scaling criteria for chemical flooding experiments." Journal of Canadian Petroleum Technology 29.01 (1990).

Ito, Y. "On the difficult birth of SAGD-Discussion." Journal of Canadian Petroleum Technology 38.5 (1999): 22-24.

Ito, Y., and G. Ipek. "Steam fingering phenomenon during SAGD process."SPE International Thermal Operations and Heavy Oil Symposium. Society of Petroleum Engineers, 2005.

Jahanbakhsh, Amir, Hamidreza Shahverdi, and Mehran Sohrabi. "Relative Permeability Normalization-Effects of Permeability, Wettability and Interfacial Tension." SPE Annual Technical Conference and Exhibition. Society of Petroleum Engineers, 2014.

Kiasari, H. Hashemi, B. Sedaee Sola, and A. Naderifar. "Investigation on the effect of the reservoir variables and operational parameters on SAGD performance." Brazilian journal of petroleum and gas 4.2 (2010).

Kovscek, A. R., et al. "Foam flow through a transparent rough-walled rock fracture." Journal of Petroleum Science and Engineering 13.2 (1995): 75-86.

Kovscek, A. R., T. W. Patzek, and C. J. Radke. "Simulation of foam transport in porous media." SPE Annual Technical Conference and Exhibition. Society of Petroleum Engineers, 1993.

Kular, G. S., K. Lowe, and D. Coombe. "Foam application in an oil sands steamflood process." SPE Annual Technical Conference and Exhibition. Society of Petroleum Engineers, 1989.

Kumar, Dhananjay, Mayuri Murugesu, and Sanjay Srinivasan. "Modeling Effect of Permeability Heterogeneities on SAGD Performance Using Improved Upscaling Schemes." SPE Heavy Oil Conference-Canada. Society of Petroleum Engineers, 2014.

Llaguno, P. E., et al. "A reservoir screening methodology for SAGD applications." Canadian International Petroleum Conference. Petroleum Society of Canada, 2002.

Ma, Kun, et al. "Modeling techniques for foam flow in porous media." SPE Journal 20.03 (2015): 453-470.

Marfoe, C. H., H. Kazemi, and W. F. Ramirez. "Numerical simulation of foam flow in porous media." SPE Annual Technical Conference and Exhibition. Society of Petroleum Engineers, 1987. 
Martinez, Jose Manuel Alvarez. Foam-Flow Behavior in Porous Media: Effects of Flow Regime and Porous-Medium Heterogeneity. Diss. University of Texas, 1998.

McCormack, M. "Mapping of the McMurray Formation for SAGD." Journal of Canadian Petroleum Technology 40.08 (2001).

Meyer, Richard F., Emil D. Attanasi, and Philip A. Freeman. Heavy oil and natural bitumen resources in geological basins of the world. No. 2007-1084. 2007.

Mohammadzadeh, Omidreza, and Ioannis Chatzis. "Pore-level investigation of heavy oil recovery using steam assisted gravity drainage (SAGD)."International Petroleum Technology Conference. International Petroleum Technology Conference, 2009.

Mukherjee, N. J., N. R. Edmunds, and S. D. Gittins. "Impact and mitigation of certain geological and process factors in the application of SAGD at AOSTRA's UTF"." Canadian SPE/CIM/CANMET International Conference on Recent Advances in Horizontal Well Applications, 1994.

Munoz, Ricardo. "Simulation Sensitivity Study and Design Parameters Optimization of SAGD Process." SPE Heavy Oil Conference-Canada. Society of Petroleum Engineers, 2013.

Murtaza, Muhammad, Zhongxue He, and Hassan Dehghanpour. "An approach to model threephase flow coupling during steam chamber rise."The Canadian Journal of Chemical Engineering 92.6 (2014): 1100-1112.

Nasr, T. N., et al. "Steam assited gravity drainage (SAGD) in horizontal wells: a visualization model study: SPE 37521, SPE Int." Thermal Operations and Heavy Oil Sym., Bakersfield USA (1997).

Nasr, T. N., et al. "Novel Expanding Solvent-SAGD Process" ES-SAGD"."Journal of Canadian Petroleum Technology 42.01 (2003).

Nguyen, Huy Xuan, et al. "Effects of reservoir parameters and operational design on the prediction of SAGD performance in Athabasca Oilsands." SPE Europec/EAGE Annual Conference. Society of Petroleum Engineers, 2012.

Osterloh, W. T., and M. J. Jante Jr. "Effects of gas and liquid velocity on steady-state foam flow at high temperature." SPE/DOE Enhanced Oil Recovery Symposium. Society of Petroleum Engineers, 1992. 
Patzek, T. W. "Description of foam flow in porous media by the population balance method." (1985).

Prada, J., L. Cunha, and F. Alhanati. "Impact of Operational Parameters and Reservoir Variables During the Startup phase of a SAGD Process." SPE Paper 97918.

Ransohoff, T. C., and C. J. Radke. "Mechanisms of foam generation in glass-bead packs." SPE reservoir engineering 3.02 (1988): 573-585.

Reis, John C. "A steam-assisted gravity drainage model for tar sands: linear geometry." Journal of Canadian Petroleum Technology 31.10 (1992).

Reme, A. B. Parameter Fitting and Calibration Study with a Commercial Foam Simulator. Diss. Thesis, Norwegian university of Science and Technology, 1999.

Roof, J. G. "Snap-off of oil droplets in water-wet pores." Society of Petroleum Engineers Journal 10.01 (1970): 85-90.

Rossen, W. R., and Z. H. Zhou. "Modeling Foam Mobility at the Limiting Capillary Pressure. SPE Advanced Technology Series 3 (1): 146-152." (1995).

Sasaki, K., et al. "Gas production system from methane hydrate layers by hot water injection using dual horizontal wells." Journal of Canadian Petroleum Technology 48.10 (2009): 21-26.

Schlumberger. Petrel Software, Version 2014.1; 2014.

Schramm, Laurier L. "Emulsions(fundamentals and applications in the petroleum industry)." Advances in Chemistry Series (1992).

Schramm, Laurier Lincoln. Foams: fundamentals and applications in the petroleum industry. Vol. 242. An American Chemical Society Publication, 1994.

Schramm, Laurier L., and Jerry J. Novosad. "Micro-visualization of foam interactions with a crude oil." Colloids and Surfaces 46.1 (1990): 21-43.

Sepehrnoori, Kamy, and Russell T. Johns. "Theoretical and experimental study of foam for enhanced oil recovery and acid diversion." (2003). 
Sharma, Jyotsna, and Ian D. Gates. "Multiphase flow at the edge of a steam chamber." The Canadian Journal of Chemical Engineering 88.3 (2010): 312-321.

Sharma, Jyotsna, and Ian D. Gates. "Convection at the edge of a steam-assisted-gravity-drainage steam chamber." SPE Journal 16.03 (2011): 503-512.

Shin, H., and M. Polikar. "Review of reservoir parameters to optimize SAGD and Fast-SAGD operating conditions." Journal of Canadian Petroleum Technology 46.01 (2007).

Singhal, Ashok K., Yoshiaki Ito, and Mahnaz Kasraie. "Screening and design criteria for steam assisted gravity drainage (SAGD) projects." SPE International Conference on Horizontal Well Technology. Society of Petroleum Engineers, 1998.

Soo, H., and C. J. Radke. "A filtration model for the flow of dilute, stable emulsions in porous media-I. Theory." Chemical Engineering Science 41.2 (1986): 263-272.

Stalder, John L. "Cross-SAGD (XSAGD)-An Accelerated Bitumen Recovery Alternative." SPE International Thermal Operations and Heavy Oil Symposium. Society of Petroleum Engineers, 2005.

Suncor Firebag SAGD Report, 2006.

Walls, E., C. Palmgren, and K. Kisman. "Residual oil saturation inside the steam chamber during SAGD." Journal of Canadian Petroleum Technology42.01 (2003).

Wang, Jinxun, and Mingzhe Dong. "Simulation of O/W emulsion flow in alkaline/surfactant flood for heavy oil recovery." Journal of Canadian Petroleum Technology 49.06 (2010): 46-52.

Wang, Jing Yi Jacky, Cosmas Chigozie Ezeuko, and Ian Donald Gates. "Energy (Heat) Distribution and Transformation in the SAGP Process." SPE Heavy Oil Conference Canada. Society of Petroleum Engineers, 2012.

Yang, Guihua, and R. M. Butler. "Effects of reservoir heterogeneities on heavy oil recovery by steam-assisted gravity drainage." Journal of Canadian Petroleum Technology 31.08 (1992).

Yuan, Jian-Yang, and Daniel Nugent. "Subcool, Fluid Productivity, and Liquid Level Above a SAGD Producer." Journal of Canadian Petroleum Technology52.05 (2013): 360-367.

Zhang, ZF., Freedman, VL., and Zhong, L. “Foam transport in porous media: A review”. Pacific 
Northwest National Laboratory, 2009. 


\section{Appendix A}

\section{Derivation for Butler's Finger Rising Model}

Butler (1987) developed an analytical model to predict the steam chamber rising rate, oil production rate and SOR. Besides the suppositions that the fingers rose at a constant speed and heat transfer was proceed by conduction, he also hypothesized that oil was driven downward parallel to the steam chamber boundary by gravity while impeded by the pressure differential pressure of the gas phase. Also, both the ratio of the gravity force available to displace oil and oil kinematic viscosity varied with location (Figure A-1). At point P, where the boundary inclines to the horizontal at an angle of $\theta$, Darcy's law is deformed into Equation (A-1).

$$
Q_{o}=K K_{r o}\left(g-\frac{1}{\rho_{o}} \frac{\partial P}{\partial y}\right) \sin \theta \int_{0}^{\varepsilon_{1}} \frac{d \varepsilon}{\vartheta_{o}}
$$

where $Q_{o}$ is oil volumetric flow across the normal plane, $\mathrm{m}^{3} /(\mathrm{m} \cdot \mathrm{s}) ; K$ is the reservoir permeability, $\mathrm{m}^{2} ; K_{\text {ro }}$ is the oil relative permeability; $g$ is the gravity acceleration, $\mathrm{m}^{2} / \mathrm{s} ; \rho_{o}$ is

the oil density, $\mathrm{kg} / \mathrm{m}^{3} ; \frac{\partial P}{\partial y}$ is pressure gradient, $\mathrm{Pa} / \mathrm{m} ; \varepsilon$ is the distance away from the point $\mathrm{P} ; \varepsilon_{1}$ is the distance between point $\mathrm{P}$ and the symmetry plane, $\mathrm{m} ; \vartheta_{o}$ is the oil kinematic viscosity, $\mathrm{m}^{2} / \mathrm{s}$.

The pressure gradient blocks oil flow, but it is the driving force for the steam upward movement (Equation (A-2)).

$$
Q_{g}=\left(\frac{K K_{r g} x}{\mu_{g}}\right)\left(\frac{\partial P}{\partial y}-\rho_{g} g\right)
$$


where $Q_{g}$ is the gas volumetric flow, $\mathrm{m}^{3} /(\mathrm{m} \cdot \mathrm{s}) ; K_{r g}$ is the gas relative permeability; $x$ is the distance away from the center on finger; $\mu_{g}$ is the gas viscosity, Pa·s; $\rho_{g}$ is the gas density, $\mathrm{kg} / \mathrm{m}^{3}$.

Combining Equations (A-1) and (A-2) and ignoring the gas density, we can calculate the oil flow with Equation (A-3).

$$
Q_{o}=K K_{r o}\left(g-\frac{1}{\rho_{o}} \frac{Q_{o} R \mu_{g}}{K K_{r g} x}\right) \sin \theta \int_{0}^{\varepsilon_{1}} \frac{d \varepsilon}{\vartheta_{o}}
$$

where $R$ is the ratio of the gas flow rate to the oil flow rate.

The oil kinematic viscosity varies with location mainly due to the temperature difference at different locations (Equation (A-4)). And it is further assumed that temperature depends linearly on distance (Equation (A-5)). Equation (A-4) and Equation (A-5) are combined and simplified into Equation (A-6).

$$
\begin{gathered}
\frac{1}{\vartheta}=\frac{1}{\vartheta_{O S}}\left[\frac{T-T_{R}}{T_{S}-T_{R}}\right]^{m} \\
\frac{T-T_{R}}{T_{S}-T_{R}}=1-\frac{\varepsilon}{\sqrt{\pi \alpha t}} \text { for } \varepsilon_{1} \geq \sqrt{\pi \alpha t} \\
\int_{0}^{\varepsilon_{1}} \frac{d \varepsilon}{\vartheta_{o}}=\frac{\sqrt{\pi \alpha t}}{(m+1) \vartheta_{O S}} \text { for } \varepsilon_{1} \geq \sqrt{\pi \alpha t}
\end{gathered}
$$

where $T_{R}$ is the reservoir temperature, ${ }^{\circ} \mathrm{C} ; T_{S}$ is the steam temperature, ${ }^{\circ} \mathrm{C} ; \vartheta_{O S}$ is the oil kinematic viscosity at $T_{S}, \mathrm{~m}^{2} / \mathrm{s} ; m$ is a constant depending on oil properties; $\alpha$ is the thermal diffusivity, $\mathrm{m}^{2} / \mathrm{s} ; t$ is time, $\mathrm{s}$. 
With the help of Equation (A-6), Equation (A-3) can be further transformed into Equation (A-7).

$$
Q_{o}=K K_{r o}\left(g-\frac{1}{\rho_{o}} \frac{Q_{o} R \mu_{g}}{K K_{r g} x}\right) \sin \theta \frac{\sqrt{\pi \alpha t}}{(m+1) \vartheta_{o S}}
$$

At a particular point at the interface when two fingers just interferes (Figure A-2), oil flow can be expressed in Equation (A-8).

$$
Q_{i o}=K K_{r o}\left(g-\frac{1}{\rho_{o}} \frac{Q_{i o} R \mu_{g}}{K K_{r g} x_{i}}\right) \sin \theta \frac{\sqrt{\pi \alpha t}}{(m+1) \vartheta_{O S}}=K K_{r o}\left(g-\frac{1}{\rho_{o}} \frac{Q_{i o} R \mu_{g}}{K K_{r g} x_{i}}\right) \frac{\left(x_{1}-x_{i}\right)}{(m+1) \vartheta_{O S}}
$$

where $Q_{i o}$ is the oil flow from point $\mathrm{P}$ to the point of interference, $\mathrm{m}^{3} /(\mathrm{m} \cdot \mathrm{s}) ; x_{1}$ is half distance between the two fingers, $\mathrm{m} ; x_{i}$ is the interface position, $\mathrm{m}$.

Under the assumption that the fingers rise at a constant velocity $u$, the volumetric oil flow rate at the particular point is given by Equation (A-9).

$$
Q_{i o}=\emptyset \Delta S_{o} x_{i} u
$$

where $\emptyset$ is the porosity; $\Delta S_{o}$ is the alteration of oil saturation during production.

Then the oil flow rate can be eliminated to get the finger rising velocity by Equation (A-10).

$$
u=\frac{K K_{r o} g\left(1-X_{i}\right)}{(m+1) \vartheta_{O S} \emptyset \Delta S_{o}}\left(\frac{1}{X_{i}+\frac{K_{r o} \mu_{g} R^{\prime}\left(1-X_{i}\right)}{K_{r g} \rho^{(m+1)} O S}}\right)
$$

where $X_{i}=x_{i} / x_{1}$, which is the dimensionless finger width, and $R^{\prime}=R \rho_{g} / \rho_{o}$, through which the mass steam oil ratio is changed to the volumetric steam oil ratio. 
But the steam oil ratio should be solved through heat balance to calculate the velocity. Butler maintained that the heat released by the injected steam mainly went to a steam chamber, the residual oil and connate water, and the oil flow leaving the fingers and the oil saturated reservoir. They are expressed by Equations (A-11) to (A-13).

$$
\begin{gathered}
H_{c}=\rho_{c} C_{c} u\left(T_{S}-T_{R}\right) x_{i} \\
H_{o}=\rho_{o} C_{o} u \emptyset \Delta S_{o}\left(T_{m}-T_{R}\right) x_{i} \\
H_{R}=\frac{1}{2} \rho_{R} C_{R} u\left(T_{S}-T_{R}\right)\left(x_{1}-x_{i}\right)
\end{gathered}
$$

where $H_{c}$ is the heat inside the steam chamber, $\mathrm{kJ} / \mathrm{s} ; \rho_{c} C_{c}$ is the volumetric heat capacity of the

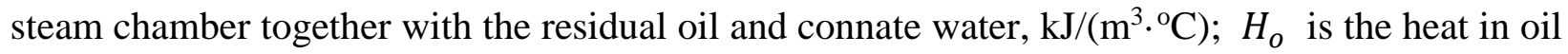
flow leaving between the steam chambers, $\mathrm{kJ} / \mathrm{s} ; \rho_{o} C_{o}$ is the heat capacity of oil, $\mathrm{kJ} /\left(\mathrm{m}^{3 \cdot{ }^{\circ}} \mathrm{C}\right) ; T_{m}$ is the mixing temperature of oil, ${ }^{\circ} \mathrm{C} ; H_{R}$ is the heat in the reservoir, $\mathrm{kJ} / \mathrm{s} ; \rho_{R} C_{R}$ is the heat capacity of the reservoir, $\mathrm{kJ} /\left(\mathrm{m}^{\left.3 \cdot{ }^{\circ} \mathrm{C}\right)}\right.$.

The mixing temperature of the oil flow $T_{m}$ is given by Equation (A-14).

$$
T_{m}=\frac{\int_{0}^{\varepsilon_{1}} \frac{T d \varepsilon}{\vartheta_{o}}}{\int_{0}^{\varepsilon_{1}} \frac{d \varepsilon}{\vartheta_{o}}}=T_{R}+\frac{m+1}{m+2}\left(T_{S}-T_{R}\right)
$$

Consequently, the total heat consumed $H_{T}$ is calculated by Equation (A-15).

$$
H_{T}=u\left(T_{S}-T_{R}\right)\left[\rho_{c} C_{c} x_{i}+\rho_{o} C_{o} \emptyset \Delta S_{o}\left(\frac{m+1}{m+2}\right) x_{i}+\frac{1}{2} \rho_{R} C_{R}\left(x_{1}-x_{i}\right)\right]
$$


Dividing the total heat by the latent heat of condensation $\lambda$, the amount of steam required to provide the heat above $m_{S}$ is calculated in Equation (A-16).

$$
m_{S}=\frac{u\left(T_{S}-T_{R}\right)\left[\rho_{c} C_{C} x_{i}+\rho_{o} C_{o} \varnothing \Delta S_{o}\left(\frac{m+1}{m+2}\right) x_{i}+\frac{1}{2} \rho_{R} C_{R}\left(x_{1}-x_{i}\right)\right]}{\lambda}
$$

With the amount of steam provided by Equation (A-16), the oil produced is $\rho_{o} \emptyset \Delta S_{o} x_{i} u$. Therefore, the steam oil ratio $R^{\prime}$ is finally expressed by Equation (A-17).

$$
R^{\prime}=\frac{\left(T_{S}-T_{R}\right)}{\rho_{o} \varnothing \lambda \Delta S_{o} x_{i}}\left[\rho_{c} C_{c} x_{i}+\rho_{o} C_{o} \emptyset \Delta S_{o}\left(\frac{m+1}{m+2}\right) x_{i}+\frac{1}{2} \rho_{R} C_{R}\left(x_{1}-x_{i}\right)\right]
$$

To make it simple, we arrange $R^{\prime}$ in the format of Equation (A-18).

$$
R^{\prime}=a+\frac{b}{x_{i}}
$$

where

$$
\begin{gathered}
a=\frac{\left(T_{S}-T_{R}\right)}{\rho_{o} \varnothing \lambda \Delta S_{o}}\left[\rho_{c} C_{c}+\rho_{o} C_{o} \varnothing \Delta S_{o}\left(\frac{m+1}{m+2}\right)-\frac{1}{2} \rho_{R} C_{R}\right] \\
b=\frac{\left(T_{S}-T_{R}\right)}{\rho_{o} \varnothing \lambda \Delta S_{o}}\left(\frac{1}{2} \rho_{R} C_{R}\right)
\end{gathered}
$$

Finally, the steam rising rate ends to be shown in Equation (A-21).

$$
u=\frac{K K_{r o} g\left(1-X_{i}\right) X_{i}}{\vartheta_{O S} \emptyset \Delta S_{O}}\left(\frac{1}{\left.\left(m+1-a \frac{K_{r o}{ }^{\vartheta} g}{K_{r g} \vartheta^{\prime} O S}\right) X_{i}^{2}+(a-b) \frac{K_{r o} \vartheta^{\vartheta}}{K_{r g} O S} X_{i}\right)}\right)
$$

It can be seen that the velocity changes with the dimensionless width of a finger. By differentiating $X_{i}$, the maximum finger rising velocity is obtained in the end. 


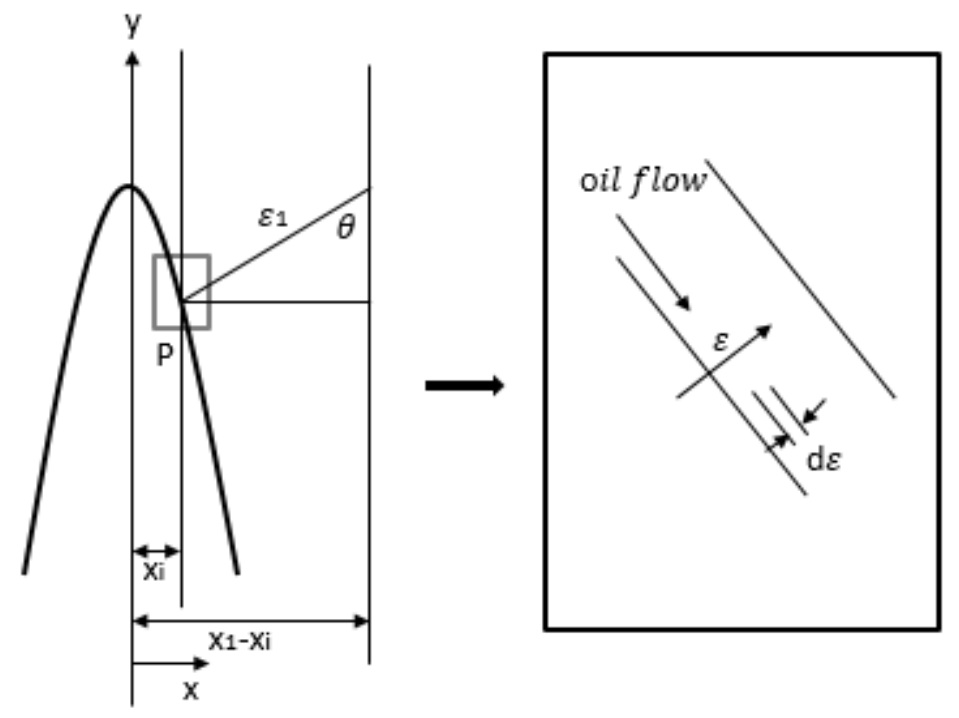

Figure A-1 Rising finger plot (Butler, 1987)

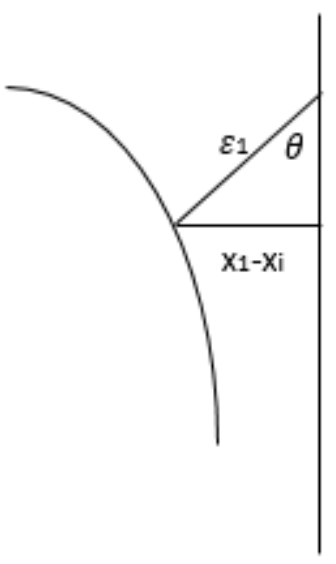

Figure A-2 Interfering steam chambers plot (Butler, 1987) 